received $5-\mathrm{HT}_{1}$ agonists for severe headaches that were subsequently shown to have been presenting with atypical symptoms, the diagrosis of migraine should be reconsidered if response is seen after the first dose of $70 \mathrm{mic}$

Seizures: Caution should be observed if ZOMIGa is to be used in patients with a history of epilepsy or structural brain lesions which lower the convilion threshold.

Hepatic impairment: ZOMFG should be administered with caution to patients with moderate Or severe hepatic imparment using a dose lower than 25 rog isee ACrIONS AND CUMCA OF severe hepatic imparment, using a dose lower than $2.5 \mathrm{mg}$ (see

Psychomotor Etfect: Athough ZOMIG did not interfere with psychomotor perfomance in heathy volunteers, some patients in clinical trials experienced sedation with $20 \mathrm{Mll} \mathrm{G}^{\text {क }}$. Patien should thus be advised to avoid driving a car or operating hazardous machinery until the are reasonably certain that ZOMIG ${ }^{\text {* }}$ does not affect them adversely.

Drug Interactions

Ergot-Containing Drugs: Ergot-containing drugs have been reported to cause prolonged vasospastic reactions. Because there is a theoretical basis tor these effects being additive ergot-conteining or ergot-ype medications (like dinydroergotarnine or methysergide) are contraindicated whin 24 hours of ZONIG" administration (see CONTRANDICATIONS). Other 5 -HT, Agonists: The administration of ZOMIG' with other $5-\mathrm{HT}_{1}$ agonists has not been evaluated in migraine patients. As an increased risk of coronary vasospasm is a theoretical possibiity with coadministration of $5-\mathrm{HT}_{1}$ agonists, use of these drugs within 24 hours each other is contraindicates.

All drug interaction studies with drugs listed below were performed in healthy wolunteers using a single $10 \mathrm{mg}$ dose of $20 \mathrm{Mll} \mathrm{G}^{3}$ and a single dose of the ofher drug, except where therwise noted.

MAO inhibitors: In a limited number of subjects, fol owing one week administration of $150 \mathrm{mg}$ bid moclobernice, a specific MA0-A inhibitor, there was an increase of approximately $26 \%$ both AUC and Crax for zomitriptan and a 3-tod increase in the AUC and Criax of the active -desmethy metacoite. Administration of selegline, a selective MAO-B inhibitor, at a dose of 10 miday tor one week, had ro effect on the pharmacokinetic parameters of zolmitriptan and the actue N-desmetnyl metabolite. The speciticity of seleg line dimininishes with higner doses and vares between patients. Therefore, coadministration of zolnt

Cimetidine and other $1 \mathrm{A2}$ inhibitors: Following administration of cimetidine, a general P450 nhibitor, the half life and AUC of zolmitriptan and its active metabolite were approximately doubed. Patients teking cimetidine should not exceed a dose of $5 \mathrm{mg} 2 \mathrm{OM} / \mathrm{G}$ in any 24 hour 10. 1A2 cannol be excluded. Fherefore, the same dose reduction is recommenticed with campon of this type, suth as fluwoxamine and the quin nlones (e.g, ciprintoxachin). Following the zoimitriptan or its active metabolite were observed.

Oral Contraceptives: Retrospective analysis of pharrnacokinetic data across studies indicater that mean plasma concentrations of zolmitriptan were gerereally greater in females taking o contraceptives compared to those not laking oral contracepitives. Mean $\mathrm{C}_{\text {max }}$ and ALC of

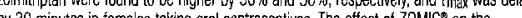
pharmacokinetics of oral contracentives has not beer studied.

Propranotot: Propranclol, at a dose of $160 \mathrm{mg} / \mathrm{day}$ for 1 week increased the $\mathcal{C}_{\max }$ and AUC of zolmitriptan by 1.5 -fold. Cmax and AUC of the N-desmethyl metabolite were reduced of $30 \%$ and $15 \%$, espectively. There were no interactive effects on blood pressure or pulse ate following administration of propranolol with zolmitripta

Selective serotonin reuptake inhibitors (SSRIS, e.g., fluoxetine, paroxetine, ithvoxamine, sertrathel: SSRIs have been reported, rarely, to cause weakness, hyper-reflexia, and incoordinallon when co-administered with 5-HT, aconists. If concom tant treatment w ZOMIG $G^{\circ}$ and an SSPI is cinically waranted, appropriate observation of the patient for acute and long-term adverse events is advised.

The pharmacokinetics and effects of $20 M 16^{\circ}$ on blood pressure were unaffected by 4-week pre-treatment with oral flicoxeting

Acetaminophen: Atter concurrent administration of single $10 \mathrm{mg}$ doses of $20 \mathrm{M} / \mathrm{G}^{\mathrm{B}}$ and $1 \mathrm{~g}$ acetanninophen, here was no signilcant elloc. on he pharmacokinelcs of ZOMilG' ZOM the tmax

Nettciopramide: Metsciopramide (single $10 \mathrm{mg}$ dose) had no effect on the pharmacokinetics of ZOMIG" or its metabolites

Ulse in Preanancy: The safety of $Z O M \mid G^{\sharp}$ for use during human pregnancy has not been
estabished. ZOMMIG should be used during pregnancy only if the potential benefit justifies the potentiai risk to the fetus

Use in Nursing Mothers: It is noot known whether zolmitriptan and/or its metabolites are excreted in human milk. Because many drugs are excreted in human milk, caltiton should be exercised when considering the adminisistation of ZOMIG G $^{\circ}$ to nursing women. Lactating rais dosed with zol mitriptan had milk levels equitim 4 times higher than plasma levels at 4 hours.

Use in Pedjatrics: Safety and efficacy of ZOMlGs have not been studied in children under 12 years of age. Use of the drug in this age group is, therefore, not recommended. Use in Adolescents (12-17 years of age): Systemic exposure to the parent compound does not difter significantly between adolescents and adults, however exposure to the active metabolite Is greater in adolescents (see ACThish A A Datients 12-17 years of age. The use a and em: $G^{G}$ in adolescents is, therefore, not recomimended.

Use in the Ederry: The safey and effectiveness of ZOMGG have not been studied in individua over 65 years of age. The risk of adverse reactions to this drug may be greater in elderly $\mathrm{CAD}$, and experience blood pressure increases that may be mose pronounced. Clinica studies did not include patients over 65 years of age. Its use in this age group is, therefore

Drug/Laboratory Test Interactions: Zolmitriptan is not known to interfere with commonly employed clinical labcratory tests

Dependence Liability: The abuse potential of ZOMIIG has not been assessed in cinical trial Binding to Melanin-Contzining Tissues: When pigmented rats were given a single oral dose of $10 \mathrm{mg} / \mathrm{kg}$ of radio abeled zomitriptan, the radioact vily in the eye atter 7 days, the lates zolnitriptan and/or its metabolites may bind to the melarin of the eye. Because there could

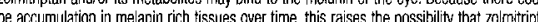
be auccumath cause toxicity in these tissues atter exterded use However could cause toxicity in hese lissues after exernded sse. However, no effects on the retin related to treatment with zolmituplan were noted in any of the toxicty studies. No systematc monitoring of ophthalmologic tunction was undertaken in clinical trials, and no specritc be awa'e of the possibility of long-term ophthalmologic effects.

\section{ADVERSE EVENTS}

Serious cardiac events, including some that have been fatal, have occurred following the use of $5-\mathrm{HT}_{1}$ agonists. These events are extremely rare and most have been reported in patients with risk tactors predictive of CAD. Events reported have includec coronary artery vasospasm, transient myocardial ischemiz, myocardial infarction,
ventricular tachycardia, and ventricular fibrillation (see CONTRANOICATIONS, WARNIIGS AND PRECAUTIONS).

\section{Experience in Controlled Clinical Trials with zoM(G) (zolmitriptan)}

Typical 5-HT, Agonist Adverse Reactions: As with other 5-HT, agonists, Z0MIG has been
These may occur in any part of the body including the chest, throat, reck, aw and upper limb. in very reere cases

Acute Safety: In placebo-controlled migraine trials, 1,673 patients received at least one dose of ZOMIG ${ }^{\circ}$. The following table (Table 3) lists adverse events that occurred in placebo-controlled clinical trials in migraine patients. Events that occurred at an incidence of $1 \%$ or more in any one of the ZOMIG $\sigma^{\pi}+\mathrm{mg}_{2}, 2.5 \mathrm{mg}$ or $5 \mathrm{mg}$ dose groups and that occurred at a high under in artal din

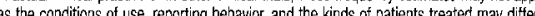
Several of the adverse events appear dose related, notably paresthesia, sensation of heaviness or tightness in chest, reck, jaw and throat, dizziness, somnolence, and possibly asthenia and nausea.

Table 3: Treatment Emergent Adverse Events in Five Single-Attack Placebo-Controlled Migraine Irials, Reported by $\geq 1 \%$ Patients Treated With zOMIG $6^{\circ}$

\begin{tabular}{|c|c|c|c|c|}
\hline Number of patients & $\frac{\text { Placeldo }}{401}$ & 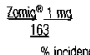 & $\frac{20 m i 8^{\circ} 25 \mathrm{mg}}{498}$ & $\begin{array}{c}20 \mathrm{~min}^{6} \mathrm{~m}^{\mathrm{m}} \mathrm{mg} \\
\underline{1012}\end{array}$ \\
\hline Symptoms of potential cardiac or & \multicolumn{4}{|c|}{- sincisence } \\
\hline 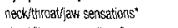 & 3.0 & 6.1 & 7.0 & 10.3 \\
\hline chesththorax sensations" & 1.2 & 1.8 & 3.4 & 3.8 \\
\hline upper limb sencaltions" & 0.5 & 2.4 & 4.2 & 4.1 \\
\hline palptiations & 0.7 & 0 & 0.2 & 2.2 \\
\hline \multicolumn{5}{|l|}{ Other Brody Systems: } \\
\hline dziness & 4.0 & 5.5 & 8.4 & 9.5 \\
\hline nervolsness & 0.2 & 0 & 1.4 & 0.7 \\
\hline sortringencice & 3.0 & 4.8 & 6.0 & 7.7 \\
\hline thinkirg abnormal & 0.5 & 0 & 1.2 & 0.3 \\
\hline tremer & 0.7 & 0.6 & 1.0 & 0.7 \\
\hline yertigo & 0 & 0 & 0 & 1.5 \\
\hline hyperesthesia & 0 & 0 & C.6 & 1.1 \\
\hline \multicolumn{5}{|l|}{ Diagestive: } \\
\hline diarthea & 0.5 & 0.6 & 1.0 & 0.6 \\
\hline diry mouth & 1.7 & 4.9 & 3.2 & 3.2 \\
\hline 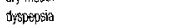 & 0.5 & 3.1 & 1.6 & 1.0 \\
\hline Dhenhagia & 0 & 0 & 0 & 1.8 \\
\hline nausea & 3.7 & 3.7 & 9.0 & 6.2 \\
\hline vomit & 2.5 & 0.6 & 1.4 & 1.5 \\
\hline \multicolumn{5}{|l|}{ Msceltanocus: } \\
\hline asthenia & 3.2 & 4.9 & 32 & 8.8 \\
\hline limb sencations (upper \& lowert" & 0.7 & 0.6 & 0.4 & 1.6 \\
\hline 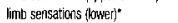 & 0.7 & 1.2 & 0.4 & 1.8 \\
\hline sensatioris - kcalion urspectile ou" & 5.2 & 4.9 & 5.8 & 9.2 \\
\hline abdominal pain & $\begin{array}{l}2.2 \\
1.7\end{array}$ & 1.2 & 0.6 & 1.3 \\
\hline reaction aggravated & 1.0 & 1.2 & 1.0 & 0.7 \\
\hline head 'taces sensstions' & 1.7 & 6.7 & 86 & 10.9 \\
\hline myaligia & 0.2 & 6 & 02 & 13 \\
\hline myesthenia & 0.2 & 0 & 0.6 & 1.9 \\
\hline oyspneas & 0.2 & 0.6 & 0.2 & 1.2 \\
\hline rininits & 0.2 & 1.2 & 1.2 & 0.9 \\
\hline swatitinn & 12 & 0 & 16 & 2.5 \\
\hline taste perversion & 0.5 & 2.5 & 0.6 & 0.7 \\
\hline
\end{tabular}
* The term sensation encompasses adverse events described as pain, disconfort ZOMiGs is generally well tolerated. Across all doses, most adverse events were mild to moderate in severity as well as transient and self-limiting. The incidence of adverse events in controled clinical trials was not afected by gender, weight, or age of pasens, use of prcphylactic medications; or presence of aura. There were insufficient data to assess the impact of race on the incidence of adverse events.

Long-Term Satety: In a long-term open label study in which patients were allowed to tra mutitiple migraine attacks for up to one year, $8 \%\{167$ of 2,058$)$ of patients withwirew from the study due to an adverse experience. In this study migraine headaches could be treated with either a single $5 \mathrm{mg}$ dose of $Z O M \mathrm{MG}^{\circ}$, or an intitial $5 \mathrm{mg}$ dose followed by a second $5 \mathrm{~m}$ dose if necessary $(5+5 \mathrm{mg})$. The most common adverse events (defined as occurring at an inciderce of at least $5 \%$ ) recorded for the $5 \mathrm{mg}$ and $5+5 \mathrm{mg}$ doses, respectively, wert little different and comprised, in descending order of frequency: neck'throat sensation $[16 \%, 15 \%)$, head/face sensations ${ }^{*}(15 \%, 14 \%)$, asthenia $(14 \%, 14 \%)$, sensations location unspecified (12\%, 11\%), limb sensations* $(11 \%, 11 \%)$, nausea $112 \%, 8 \%$, dizziness $\{11 \%, 9 \%$, somnolence $\{10 \%, 10 \%)$, chest fhrorax sensations $77 \%, 7 \%$, dry mouth $(4 \%, 5 \%)$, and hyseresthesia $(5 \%, 4 \%)$. Due to the lack of a placebo ar in this study, the role of $20 \mathrm{M} / \mathrm{G}^{*}$ in causation cannot be reliably determined. ("S footnote for Table 3) The long-term safety of a $2.5 \mathrm{mg}$ dose was not assessed in
this stucy Long-term satety information on the $25 \mathrm{mg}$ dose is nol yet availabie. Other Events: In the paragraphs that follow, the frequencies of less commonly reported adverse clinical events are presented. Because the reports include events observed in open and uncontrolled studes, the role of ZOMIG in their causation cannot be relizbly determ Furthermore, variability associated with adverse event reporting, the terminology used to describe adverse events, etc., limit the value of the quartitative frequency estimates provided. Event frequencies are calculated as the number of patients who used ZOMIG ${ }^{x}$ (n=4,027) and reconted an event divided by the total number of patients exposed to ZOMIG All reported events are inciuded except those already listed in the previous table, those to general to be informative, and those not reasonably associated with the use of the drug. Events are further classified within body system categories and enumerated in order of decreasing irequency using the followng definitions infrequent adverse events are those
occurring in $1 / 100$ to $1 / 1,000$ patients and rare adverse events are those occurring in fewer than $1 / 1,000$ perionts

Atypical sensation: Infrequent was hyperesthesia.

Generali: Infrequent were allergy reaction, chills, tacial ederna, fever, malaise and phatosensitivity.

Cardlovascular: Infrequent were arrhythmias, hypertension and syncope. Rare were bradycardia, extrasystoles, postural hypotension, QT prolongation, tachycardia and thrombochlebitis

Digestive: Infiequent were increased appetite, tongue edema, escophagitis, gastroenterits liver function abnormality and itirst. Rare were anorexia, constipation, gastritis, hematemes's pancretitis melena and uloer

Hemic: Intrequent was ecchymosis. Fare were cyanosis, thrombocytopenia, eosinophilia and leukopenia.

Metabolic: Irirequent was edema. Rare were hyperghycemia and alkaline phosphatase

Musculoskeletal: Infrequent were back pain, leg cramps and tenosynovitis. Rare were arthritis, telany and twitching.

Neurologicali: Irrequert were agitation, anxiety, depression, emotional lability and insomnia Rare were akathesia amnesia, apathy, ataxia, dystonia, evchoria, halucinations, cerebra ischemia, hyperkinesia, hypotonia, hypertonia and irritability

Respiratcon: Infrequent were bronchitis, bronchospassm, epistaxis, hiccup, larnngitis and yawn. Rare were apnea and voice alteration.

Skin: Infrequent were prututus, rash and urticaria Soecial Serses: Intrequent were dry eye, eye pain, hyperacusis, ear pain, parcssnia, and

Urogenita: Infrequent were hernaturia, cystitis, polyuria, urinary frequency, urinary A-29 urgency Rare were miscarriage and dysmenorrhag

SYMPTOMS AND TREATMENT OF OVERDOSAGE

There is no experience with clincal overdose. Volunteers receiving single $50 \mathrm{mg}$ oral doses

The elimination half-life of zoimitriptan is $2.5-3$ hours isee ACTIONS \& CLINICAL PHAMMACQLCGy, and theretore manitoring of patients atter overdose with 20MIG should continue for at least 15 hours or while symptoms or signs persist.

There is no specific antidote to zolmitriptan. In cases of severe intoxication, intensive care procedures are recommended, includirng establishing and meintaining a patent airway, ensuring adequate oxygenation and ventiation, and monitoring and support of the card ovascular system.

It is unknown what effect hemodialysis or peritoneal dialysis has on the serum concentrations of zolmitriptan.

\section{DOSAGE AND ADMINISTRATION}

ZOMG $G^{*}$ (zomitriptan) is recommended only for the acute treatment of migraine attacks.

Adults: The minimal effective single adult dose of ZOMIG is $1 \mathrm{mg}$. The recommended single dose is $2.5 \mathrm{mg}$. The $1 \mathrm{mg}$ dose can be approximated by manually breaking a $2.5 \mathrm{mg}$ table

In controlled clinical trials, single doses of $1 \mathrm{mg}, 2.5 \mathrm{mg}$ or $5 \mathrm{mg} Z \mathrm{ZOM} \mathrm{g}^{\mathrm{a}}$ were shown to be effective in the acute treatment of migraine headaches. In the only direct comparison of the

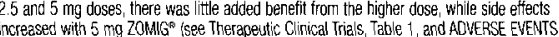
able 3 .

ff the headache returns, the dose may be repeated atter 2 hours. A total cumulative dose o the effectiveness of a second dose if the initial dose is ineffective.

The safety of treating more than 3 migraine headaches with $Z \mathrm{ZMIG}^{\mathrm{x}}$ in a one month period mains to be estabished

Hepatic impairment: Patients with moderate to severe hepatic impairment have decreased clearance of zolmitriptan and significant elevation in blood pressure was observed in some patents. Use of a low dose $(<2.5 \mathrm{mg})$ with blood pressure monitoring is recommended

Seo

Hypertension: ZOMIG $6^{6}$ should not be used in patients with uncontrolled or severe hypertension. in patients with mild to moderate controlled hypertension, patients should be treated cautious at the lowest effective dose.

Cimetidine and other $1 \mathrm{~A} 2$ inhibitors: Patients laking cimetidine and other $1 \mathrm{~A} 2$ inhibitor hould not exceed

\section{PHARMACEUTICAL INFORMATION}

\section{Prua Substance}

Prover name:

Zolmitriptan

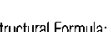

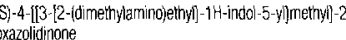

Structural Formula:

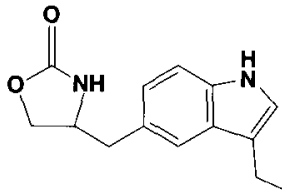

Molecular Formula: $\quad \mathrm{C}_{16} \mathrm{H}_{21} \mathrm{~N}_{3} \mathrm{O}_{2}$

28736

Physical Form: White to amost white powder

Solubility: $\quad$ slightly soluble in wate

(1.3 mgg/ml at $25^{\circ} \mathrm{C}$ ),

$0.1 \mathrm{M}$ rydrochloric acid

$9.64+0.01$

Ká:

Partition co-efficient: octanol-1-ol/water partition $\log K_{D}=-1.0$.

Melting point: $\quad 136^{\circ} \mathrm{C}$

Composition Inactive ingredients: anhydrous lactose, hydroxypropyl methylcelluose, magresium stearade, micocriystalline celulcse, polyethy

\section{AVAILABILITY OF DOSAGE FORMS}

ZOMIG' (zolmitriptan) $2.5 \mathrm{mg}$ tablets are yellow, round biconvex film-coated tablets intagliated ' $Z$ ' on one side. Available in blster packs of 3 and 6 tablets.

Product Monograph available on request.

Zomigs (zolmitriptan) is a registered trademark of the AstraZeneca group of companies

Reterences: 1. Rapoport AM et al. Optmizing the dose of zolfitriptan (Zomig, "311C90) for the acute treatment of migraine. A muticenter, double-blind, placebo-controlled, dose range-finding study. Neurotogy 1997:48(5):1210-1218. 2. Zomig (zolmitriptan) Product Monograph, AstraZeneca 3. Saper $\downarrow$ et al. Zomig is cons stently effective in the acute treatment of migraine Headache 1998; (38):400 4. Zagami AS 311C90: Long-term efficacy and tolerablilyy profile tor the acute treatnent of migraine. Neurnology 1997;48(Supp 3):S25-S28. 5. Edmeads JG, Millson DS Tolerability profie of zolmitriptan (Zomig TM: $311 \mathrm{c90}$ ), a novel dual central and peripheraly acting

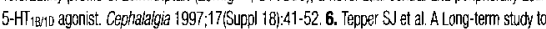

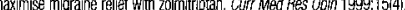

\section{AstraZeneca $\$$}

The AstraZeneca logo is a trademark of AstraZeneca PLC and

used under license by Astra Pharma Inc. and Zeneca Pharma Inc 


\section{$n \theta r g e$}

$1 \& 2.5 \mathrm{mg}$ Tablets

Therapeutic Classification: Migraine Therapy

Actions and Clinical Pharmacology. AMERGE (naratriptan hydrochloride) has been demonstrated to be a selective agonist for a vascular 5-hydroxytryptamine, receptor subtype (probably a member of the 5-HT 1810 family) with little or no binding affinity for 5-HT 23 receptor subtypes, alpha 1;, alpha 2; or beta-adrenergic; dopamine 1; dopaminez; muscarinic; or benzodiazepine receptors. Naratriptan did not exhibit agonist or antagonist activity in ex vivo assays of $5-\mathrm{HT}_{4}$ and 5 - $\mathrm{HT}$, receptor-mediated activities. The therapeutic activity of AMERGE in migraine is generally attributed to its agonist activity at $5-H_{1} / 85-\mathrm{HT}_{10}$ receptors. Two currert theories have been proposed to explain the efficacy of $5-\mathrm{HT}_{1}$ receptor agonists in migraine. One theory suggests that activation of $5-H T_{1}$ receptors located on intracranial blood vessels, including those on the arteriovenous anastomoses, leads to vasoconstriction which is believed to be correlated with the relief of migraine headache. The other hypothesis suggests that activation of $5-H_{1} T_{1}$ receptors on perivascular fibres of the trigeminal system results in the inhibition of pro-inflammatory neuropeptide release. These theories are not mutually exclusive.

Pharmacokinetics: Absorption: AMERGE tablets are well absorbed, with $74 \%$ oral bioavalability in females and $63 \%$ in males. After oral administration, the absorption is rapid and peak concentrations are obtained in 2 to 5 hours. A two-period crossover study was days later by another $2.5 \mathrm{mg}$ treatment during a non-migraine period. During a migraine attack, absorption is slower, although exposure (AUC) and elimination half-life are not significantly affected.

Table 1: Pharmacokinetic Parameters in Female Migraine Patients after receiving $2.5 \mathrm{mg}$ AMERGE Tablets'

\begin{tabular}{|c|c|c|}
\hline Parameter & Migraine Attack ( $N=15$ ) & Non-Migraine Period ( $\mathrm{N}=15$ ) \\
\hline $\begin{array}{l}C_{\max }(n g / m L) \\
t_{\max }(\mathrm{h}) \\
\text { AUC }(n g / m L h) \\
\text { CVF (mL/min) }\end{array}$ & $\begin{array}{lr}7.66 & (3.07) \\
3.8 & (2.1) \\
86.7 & (32.5) \\
467.5 & (126.4) \\
6.75 & (1.44)\end{array}$ & $\begin{array}{lr}9.50 & (3.63) \\
20 & (1.0) \\
92.0 & (33.7) \\
520.7 & (222.6) \\
7.02 & (2.39)\end{array}$ \\
\hline
\end{tabular}

values quoted are arithmetic mean (standard deviation)

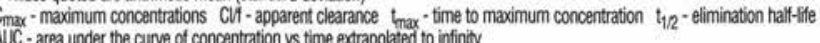
Cencolated to infinity

Plasma levels of naratriptan increase in a dose-proportional manner consistent with linear pharmacokinetics over a 1 to $10 \mathrm{mg}$ dose range. The absorption and elimination are independent of the dose. Administration with food does not appreciably influence the drug accumulation.

Metabolism and Distribution: In vitro, naratriptan is metabolized by a wide range of cytochrome P450 isoenzymes into a number of nactive metabolites. Naratriptan is a poor inhibitor of cytochrome P450 isoenzymes, and does not inhibit monoamine oxidtase MAO) enzymes; metabolic interactions between naratriptan and drugs metabolized by $\mathrm{P} 450$ or MA0 are, therefore, unfike According to a population pharmacokinetic estimate, naratriptan is distributed into a volume of approximately $261 \mathrm{~L}$

Protein Binding: Plasma protein binding is low (29\%)

Elimination: The elimination hall-life generally ranges from 5.8 hours. Oral clearance is $509 \mathrm{~mL} / \mathrm{min}$ in females and $770 \mathrm{~mL} / \mathrm{min}$ in males. The renal clearance ( $220 \mathrm{~mL} / \mathrm{min})$ exceeds the glomerular filtration rate, suggesting that the drug undergoes active tubular secretion Naratriptan is predominantly eliminated in urine, with $50 \%$ of the dose recovered unchanged and $30 \%$ as metabolites Special Populations:

Age Efflects: A study was performed to compare the pharmacokinetics of naratriptan in young ( 6 female 6 male, 24-44 years) and elderly ( 6 fermale 6 male, $65-77$ years) subjects. The subjects received two doses each of placebo, $1 \mathrm{mg}$ naratiptan, and $2.5 \mathrm{mg}$ maratriptan separated by 4 hour intervals. A minimum 96 hour period intervened between consecutive treatment days. Elderly subjects experienced a higher degree of exposure to naratriptan than did younger subjects. Mean $C_{\text {max }}$ and area under the plasma concentration time curve values were $28 \%$ and $38 \%$ higher, respectively, for the $1 \mathrm{mg}$ treatment group and $15 \%$ and $32 \%$ higher, respectively, for the $2.5 \mathrm{mg}$ group. Total and renal clearance were decreased by about $30 \%$, while the elimination half-life was creased by about 1 hour

Elevations in systolic blood pressure at the $2.5 \mathrm{mg}$ dose were more pronounced in the elderly subjects than in the young subjects mean peak increases $12 \mathrm{minh}$ in elderly versus 2 mming in young subjects).

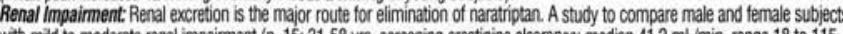
$\mathrm{mL} / \mathrm{min}$ ) to gender-matched healthy subjects ( $n=8,21-47$ yrs) showed a decrease in oral clearance (mean decreased by $50 \%$ ) mLmin) to gender-matched healthy subjects (n=8, 21-47 yrs) showed a decrease in oral clearance (mean decreased by $50 \%$ ) $40 \%$ ). In this study, blood pressure measurements suggested that increased exposure in renally-impaired subjects may be associated with increases in blood pressure which are larger than those seen in healthy subjects receiving the same dose (5 mg). SE DOSAGE AND ADMINISTRATION

Hepatic Impaiment: Liver metabolism plays a limited role in the clearance of naratriptan. The pharmacokinetics of a single $2.5 \mathrm{mg}$ dose of naratriptan were determined in subjects with moderate hepatic impairment (Child-Pugh grade A or B,n=8) and gender an age-matched healthy subjects ( $n=8$ ). Subjects with hepatc impairment showed a moderate decrease in clearance (approximately $30 \%$ ) resulting in increases of approximately $40 \%$ in the half-life (range 8 to 16 hours) and the area under the plasma concentration me curve (see Dosage and Administration.

Clinical Studies Therapeutic Clinical Trials: Four double-blind, placebo-controlled, dose-ranging clinical trials evaluated the safety and efficacy of AMERGE at oral doses ranging from 0.1 to $10 \mathrm{mg}$ in a total of 3160 adult patients with migraine attacks characterized by moderate or severe pain. The minimal effective dose was $1.0 \mathrm{mg}$. In three of the four clinical trials, a higher overall rate of headache relief was achieved with a $2.5 \mathrm{mg}$ dose. Single doses of $5 \mathrm{mg}$ and higher are not recommended due to an increased incidence of adverse events. Onset of significant headache relief (defined as no or mild pain) became apparent at $60-120$ minutes after these doses. AMERGE also relieved the nausea, phonophobia, and photophobia associated with migraine attacks.

The following table shows the 4 hour efficacy results obtained for the recommended doses of AMERGE in two of the four doseranging efficacy studies. In Study 1, patients were randomised to receive placebo or a particular dose of AMERGE for the treatment of a single migraine attack according to a parallel group design, whereas, in Study 2, patients were randomised to receive each of the 240 minutes post-dose, but experienced a worsening of severity between 4 and 24 hours post-dosing were permitted to take a second dose of double-blind medication identical to the first.

Table 2: Results at 240 Minutes Post First Dose

\begin{tabular}{|c|c|c|c|c|c|c|}
\hline Parameter & $\begin{array}{l}\text { Placebo } \\
(n=107)\end{array}$ & $\begin{array}{l}\text { Study } 1 \\
\text { AMERGE } 1 \mathrm{mg} \\
(\mathrm{n}=219)\end{array}$ & $\begin{array}{l}\text { AMERGE } 2.5 \mathrm{mg} \\
(n=209)\end{array}$ & $\begin{array}{l}\text { Placebo } \\
(n=602)\end{array}$ & $\begin{array}{l}\text { Study } 2 \\
\text { AMERGE } 1 \mathrm{mg} \\
(\mathrm{n}=595)\end{array}$ & $\begin{array}{l}\text { AMERGE } 2.5 \mathrm{mg} \\
(\mathrm{n}=586)\end{array}$ \\
\hline Pain relief $(0 / 1)^{1}$ & $27 \%$ & $52 \%^{\circ}$ & $66 \% " M$ & $33 \%$ & $57 \%^{\circ}$ & $68 \%{ }^{\circ} M$ \\
\hline Pain free $(0)^{2}$ & $10 \%$ & $26 \%^{\circ}$ & $43 \% \cdot M$ & $15 \%$ & $33 \%^{\circ}$ & $45 \%$ \\
\hline Nausea free & $56 \%$ & $71 \% !$ & $77 \% 1$ & $54 \%$ & $69 \%^{\circ}$ & $75 \%^{\circ}$ \\
\hline Photophobia free & $34 \%$ & $57 \%$ ! & $67 \% !$ & $33 \%$ & $53 \%^{\circ}$ & $61 \%^{\circ}$ \\
\hline Phonophobia free & $\wedge$ & $\wedge$ & A & $36 \%$ & $55 \%^{\circ}$ & $65 \%^{\circ}$ \\
\hline $\begin{array}{l}\text { Clinical disability }{ }^{3} \\
\text { (ON1) }\end{array}$ & $49 \%$ & $62 \% !$ & $72 \% !$ & $50 \%$ & $70 \% \%^{\circ}$ & $76 \%^{\circ}$ \\
\hline
\end{tabular}

Pain relief is defined as a reduction in headache severity from grade 3 or 2 (severe or moderate) to grade 1 or 0 (mild or no pain) 2 a ain tree is defined as a headache severity score of 0 (no pain)

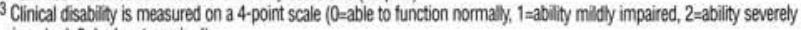
impaired, $3=$ bed rest required

photophobia and phonophobia collected as one measure

p<0.01 versus placebo

MDC0.01 versus AMERGE $1 \mathrm{mg}$. Note: comparisons were not performed for any parameter other than pain relief and pain free in study 1 and for pain relief in study 2 .

Significant headache relief was sustained over 24 hours. Data from four placebo controlled studies $(n=3160)$ showed that of the patients who achieved headache relief with AMERGE Tablets $2.5 \mathrm{mg}, 72 \%$ to $83 \%$ did not experience recurrence of headache between 4 and 24 hours post-dosing. Subgroup analyses of the overall population of patients participating in the placebo-controlled triaks, indicate that the efficacy of AMERGE was unaffected by migraine type (withwithout aura), gender, oral contraceptive use, or chias, indicate that the efficacy of AMierGe was unaffected by migraine type (With without aura), gender, oral contraceptive use, or In a long-term, repeat dose, open study of 417 patients (all were initiated on a $2.5 \mathrm{mg}$ dose of AMERGE but were given the option to titrate down to a $1 \mathrm{mg}$ dose if $2.5 \mathrm{mg}$ was not well tolerated) a total of 15.301 attacks were treated (mean number of treated

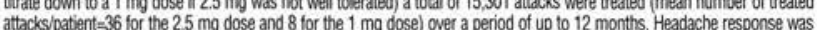

sustained (as judged by the proportion of attacks treated with AMERGE resulting in headache relief). The median percentage of attacks per patient requiring a second dose for headache recurrence was $8 \%$. Of the 417 patients treating attacks, 10 patients opted or a dosage reduction.

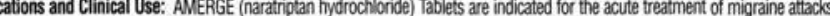
COr without aura. AMERGE Tablets are not for use in the management of hemiplegic, basilar, or ophthalmoplegic minraine (see CONIRAINDICATIONS). Safety and efficacy have not been established for cluster headache which is present in an older, predominanty male population.

Contraindications: AMERGE (naratriptan hydrochloride) Tablets is contraindicated in patients with history, symptoms, or signs of ischemic cardiac, cerebrovascular or peripheral vascular syndromes, valvular heart disease or cardiac antythmias (especially tachycardias). In addition, patients with other significant underlying cardiovascular disease (e.g., atherosclerotic disease, congenital heart disease) should not receive AMERGE. Ischemic cardiac syndromes include, but are not limitted to angina pectoris of any type (e.g., stable angina of effort and vasospastic forms of angina such as the Prinzmetals variant), a forms of myocardial intarction, and silent myocardial ischemia. Cerebrovascular syndromes include, but are not limited to,
strokes of any type as well as transient ischemic attacks (TIAs). Peripheral vascular disease includes, but is not limited to, strokes of any type as well as transient ischemic attacks (TIAs). Peringe
ischemic bowel disease, or Raynaud's syndrome (see WARNINGS).

ischemic bower disease, or Raynaud's syndrome (see WARNIINGS).

Because AMERGE can give rise to increases in blood pressure, it is contraindicated in patients with uncontrolled or severe Aypertension (see WARNIINGS). Ergot-containing drugs have been reported to cause prolonged vasospastic reactions. Because AMERGE may also cause coronary vasospasm and these effects may be additive, the use of AMERGE within 24

dilhydroergotamine, methysergide) is contraindicated. AMERGE is contraindicated in patients with hemiplegic, basilar, or ophthalmoplegic migraine. AMERGE Tablets are contraindicated in patients with severe renal impairment (creatinine clearnnee $15 \mathrm{~mL} / \mathrm{min}$ ) (see ACTIONS AND CUINICAL PHARMACOLOGY AND DOSAGE AND ADMINISTRATION) AMERGE Tablets are contraindicated in patients with severe hepatic impairment (Child-Pugh grade C) (see ACTIONS AND CLINICAL PHARMACOLOGY AND DOSAGE AND ADMINISTRATION

AMERGE Tablets are contraindicated in patients with hypersensitivity to naratriptan or any component of the formulation

Wamings:

indrochoride) should only be used where a clear diagnosis of migraine has been established. Risk of Mvocardial lschemia and/or Intarction and Other Adverse Cardiac Events: AMERGE has been associated with transient chest and/or neck pain and tightness which may resemble angina pectoris. In rare cases, the symptoms have been identified being the likely result of coronary vasospasm or myocandial ischemia. Rare cases of serious coronary events or anthythmia or vasospastic coronary artery disease (see CONTRAINDICATIONS). It is strongly recommended that AMERGE not be given to patients in whom unrecognized coronary artery disease (CAD) is predicted by the presence of risk tactors (e.g., hypertension, hypercholesterolemia, smoking, obesity, diabetes, strong tamily history of CAD, temale who is surgically or physiologically postmenopausal, or male who is over 40 years of age) unless a cardiovascular evaluation provides satisfactory clinical cardiovascular disease. The sensittivity of cardiac diagnostic procedures to detect cardiovascular disease of predisposition to coronary artery vasospasm is unknown. It, during the cardiovascular evaluation, the patient's medical history or electrocardiographic investigations reveal findings indicative of or consistent with coronary artery vasospasm or myocardial ischemia, AMERGE should not be administered (see CONTRAINDICATONS).

For patients with risk factors predictive of CAD who are considered to have a satistactory cardiovascular evaluation, the first dose of AMERGE should be administered in the setting of a physicians office or similar medically staffed and equipped facilith Because cardiac ischemia can occur in the absence of clinical symptoms, consideration should be given to obtaining electrocardiograms in patients with risk factors during the interval immediately following AMERGE administration on the first occasion of use. However, an absence of drug-induced cardiovascular effects on the occasion of the initial dose does not occasion of use. However, an absence of drug-induced cardiovascular effects on the
preclude the possibility of such effects occurring with subsequent administrations. preclude the possibility of such effects occurring with subsequent administrations.
Intermittent long-term users of AMERGE who have or acquire risk factors predictive of CAD, as described above, should receive
periodic interval cardiovascular evaluations over the course of treatment.

periodic interval cardiovascular evaluations over the course of treatment. changes.

The systematic approach described above is intended to reduce the likelihood that patients with unrecognized cardiovascular disease will be inadvertently exposed to AMERGE (naratriptan hydrochloride).

Cardiac Events and Fatalities Associated With 5-HIT Agonists: AMERGE can cause coronary artery vasospasm. Serious adverse cardiac events, including acute myocardial intartion, life threatening disturbances of cardiac rimythm, and death have been reported within a few hours following the administration of $5-\mathrm{HT}_{1}$ agonists. Considering the extent of use of $5-\mathrm{HT}$, agonists in patients with migraine, the incidence of these events is extremely low.

Premarketing Experience With AMERGE Tablets: Among approximately 3500 patients with migraine who participated in premarketing clinical trials of AMERGE Tablets, four patients treated with single oral doses of AMERGE ranging from 1 to $10 \mathrm{mg}$ experienced asymptomatic ischemic ECG changes with at least one, who took $7.5 \mathrm{mg}$, likely due to coronary vasospasm.
Cerebrovascular Events and Fatalities With $5-\mathrm{HT}_{1}$ Agonists: Cerebral hemorrtage, subarachnoid hemornhage, stroke, and other cerebrovascular events have been reported in patients treated with 5 -HT, agonists, and some have resulted in fatalities. In a number of cases, it appears possible that the cerebrovascular events were primary, the agonist having been administered in the incorrect belief that the symptoms experienced were a consequence of migraine, when they were not. It should be noted that patients with migraine may be at increased risk of certain cerebrovascular events (e.g., stroke, hemorrhage, TIA).

Special Cardiovascular Pharmacology Studies: In subjects $(n=10)$ with suspected coronary artery disease undergoing angiography. naratriptan at a subcutaneous dose of $1.5 \mathrm{mg}$ produced an $8 \%$ increase in aortic blood pressure, an $18 \%$ increase in pulmonary artery blood pressure, and an $8 \%$ increase in systemic vascular resistance. In addition, mild chest pain or tightness was reported by chest paindiscomtor

Migraine patients $(n=35$ ) free of cardiovascular disease were subjected to assessments of myocardial perfusion by positron emission tomography while receiving subcutaneous naratriptan $1.5 \mathrm{mg}$ in the absence of a migraine attack. Naratriptan was associated with a reduced coronary vasodilatory reserve $(-10 \%)$, increased coronary resistance $(-20 \%)$, and decreased hyperemic myocardial blood flow $(-10 \%)$. The relevance of these findings to the use of recommended oral doses of naratriptan is not known.

Hypersensitivity: Rare hypersensitivity (anaphylaxis/anaphylactoid) reactions may occur in patients receiving 5-HT 1 agonists such a AMERGE. Such reactions can be life threatening or fatal. In general, hypersensitivity reactions to drugs are more likely to occur in hypersensituity reactions, AMERGE should not be used in patients having a history of fypersensitivity to sumatriptan or chemicalty related 5-HT, receptor agonists. As AMERGE contains a sulphonamide component, there is a theoretical risk of hypersensitivity reactions in patients with known hypersensitvity to sulphonamides.

Other Vasospasm-Related Events: 5 -HT 1 agonists may cause vasospastic reactions other than coronary artery vasospasm. Extensive post-market experience has shown the use of another $5-\mathrm{HT}_{1}$ agonist to be associated with rare occurrences of peripheral vascular ischemia and colonic ischemia with abdominal pain and bloody diarmen

Increases in Blood Pressure: Elevations in blood pressure have been reported following use of AMERGE. At the recommended oral doses, the elevations are generally small (population average maximum increases of $<5 \mathrm{mmHh}$ systolic and $<3 \mathrm{mmHh}$ diastolic at the $25 \mathrm{mg}$ dose). The effects may be more pronounced in the elderly and hypertensive patients. In a pharmacodynamic study conducted in nomotensive patients ( $n=12$ ) and in hypertensive patients controlled by antilhypertensive treatment (n=12), the presser effects of AMERGE were greater in hypertensive patients (weighted mean increases in systolic and diastolic blood pressure of 6 and $4 \mathrm{mmHg}$ in hypertensive subjects versus 3 and $2 \mathrm{mmHHg}$ in normotensive patients receiving two $2.5 \mathrm{mg}$ doses separated by a 2 hour time intervant Two hypertensive patients experienced three events of chest discomfort why rese reving narastriptan. Signticant time interval). Two hypertensive patients experienced three events of chest discomfort whise receiving naratriptan. Signiticant with and without a history of hypertension. AMERGE is contraindicated in patients with uncontrolled or severe hypertension (see CONTRAINDICATIONS).

Precautions: Cardiovascular: Discomfort in the chest, neck, throat, and jaw (including pain, pressure, heaviness, tightness) has been reported after administration of AMERGE (naratriptan hydrochloride). Because $5-\mathrm{HT}_{1}$ agonists may cause coronary arter) vasospasm, patients who experience signs or symptoms suggestive of angina following AMERGE should be evaluated for the
presence of CAD or a predisposition to variant angina before receiving additional doses, and should be monitored electropresence of CAD or a predisposition to variant angina before receiving additional doses, and should be monitored electrosuggestive of decreased arterial flow, such as ischemic bowel syndrome or Raynaud's syndrome following naratriptan administration should be evaluated for atherosclerosis or predispostion to vasospasm (see CONTRAINDICATIONS and WARNINGS). Neurologic Conditions: Care should be taken to exclude other potentially serious neurologic conditions before treating headache in patients not previously diagnosed with migraine or who experience a headache that is atypical for them. There have been rare reports Where patients received 5-HT, agonists for severe headaches that were subsequently shown to have been secondary to an evolving neurologic lesion. For newiy diagnosed patients or patients presenting with atypical symptoms, the diagnosis of migraine should be reconsidered it no response is seen after the first dose of AMERGE.

Seizures: Caution should be observed if AMERGE is to be used in patients with a history of epilepsy or structural brain lesions which lower the convulsion threshold.

Renal or Hepatic Impairment: AMERGE Tablets should be administered with caution to patients with impaired renal or hepatic function (see ACTIONS AND CLINICAL PHARMACOLOGY, CONTRAINDICATIONS, and DOSAGE AND ADMINISTRATION). Psychomotor Impairment: in a study of psychomotor function in healthy volunteers, single oral 5 and $10 \mathrm{mg}$ doses of AMERGE were associated with sedation and decreased alertness. Although these doses are higher than those recommended for the treatment of migraine, patients should be cautioned that drowsiness may occur following trester.

Drug Interactions: The limited metabolism of AMERGE and the wide range of cytochrome P450 isoenzymes invowed, as determined by in vitro studies, suggest that significant drug interactions with AMERGE are unlikely. AMERGE did not inhibit monoamine oxidase enzymes (MAO-A or MAO-B) in vitro. The possibitity of pharmacodynamic in wo interactions between AMERGE and monoamine enzymes (MAO-A or MAO-B) in vitro. The poss

Ergot-Containing Orugs: Ergot-containing drugs have been reported to cause prolonged vasospastic reactions. Because there is a 

theoretical basis for these effects being additive, ergot-containing or ergot-type medications (like dihydroergotamine or methysergide)

Other 5-HT, Agonists: The administration of AMERGE with other 5-HT, agonists has not been evaluated in migraine patients. As an increased risk of coronary vasospasm is a theoretical possibility with co-administration of $5-\mathrm{HT}_{1}$ agonists, use of these drugs within 24 hours of each other is contrainticated.

Other Serotonergic Drigs: Rare postmarketing reports describe patients with weakness, hyperreflexia, and incoordination following the combined use of a selective serotonin reuptake inhibitor (SSRI) and 5-HT, agonists, If concomitant treatment with AMERGE and an SSRI (e. g. fluoxetine, fluvoxamine, paroxetine, sertraline), tricyclic antidepressant, monoamine oxidase inhibitor, or other drug with serotonergic activity is clinically warranted, appropriate observation of the patient for acute and long-term adverse events is advised. Hormonal contraceotives: In a population pharmacokinetic study in migraine patients, homonal contraceptive use was associated with a $32 \%$ decrease in naratiptan clearance.

Tobacco: In a population pharmacokinetic study in migraine patients, tobacco use was associated with a $29 \%$ increase in naratriptan

Alcohol and food: Clinical studies did not reveal any pharmacokinetic interaction when naratriptan was administered together with alcohol or food.

Use in Pregnancy: The safety of AMERGE for use during human pregnancy has not been established. AMERGE Tablets should be used during pregnancy only if the potential benefit justifies the potential risk to the fetus. To monitor fetal outcomes of pregnant women exposed to AMERGE, Glaxo Wellcome Inc. maintains a Naratriptan Pregnancy Registry. Health care providers are encouraged to register patients by calling (800) $722-9292$, ext. 39441

Use in Nursing mothers: AMERGE and/or its metabolites are distributed into the milk of lactating rats (at 2 hours post oral gavage dosing, levels in milk were 3.5 times higher than maternal plasma levels). Therefore, caution should be exercised when considering the administration of AMERGE Tablets to nursing women.

Use in Pediatrics: Safety and effectiveness of AMERGE Tablets have not been studied in children under 12 years of age. Use of the drug in this age group is, therefore, not recommended.

Adolescents: The efficacy of AMERGE Tablets at single doses of $0.25,1.0$ and $2.5 \mathrm{mg}$ was not demonstrated to be greater than placebo in adolescents (12-17 years). Therefore, the use of the drug in adolescents is not recomrnended.

use in the Elderty: The safety and effectiveness of AMERGE has not been adequately studied in individuals over 65 years of age. AMERGE Tablets are known to be substantially excreted by the kidney, and the risk of adverse reactions to this drug may be greate in elderly patients who have reduced renal function. In addition, elderly patients are more likely to have decreased hepatic tunction;
they are at hi;gher risk for CAD; and blood pressure increases may be more pronounced in the eiderly. Clinical studies of AMERGE Tablets did not include patients over 65 years of age. Its use in this age group is, therefore, not recommended.

Drug Laboratory Test Interactions: AMERGE Tablets are not known to interfere with commonly employed clinical laboratory tests. Dependence Liability: In one clinical study enrolling 12 subjects, all of whom had experience using oral opiates and other psychoactive drugs, subjective responses typically associated with many drugs of abuse were produced with less intensity during treatment with AMERGE (1-5 mg) than with codeine (30 to $90 \mathrm{mg}$ ). Long term studies (12 months) in migraine patients using AMERGE Tablets revealed no evidence of increased drug utilization

Melanin Binding: In pigmented rats treated with a single oral dose $(10 \mathrm{mg} / \mathrm{kg})$ of radiolabelled naratriptan, radioactivity was detected in the eyes at 3 months post-administration, a finding which suggests that the drug or its metabolites may bind to the melanin of the eye. The possible clinical significance of this finding is unknown. No systematic monitoring of ophthalmologic function was undertaken in clinical trials. Prescribers should consider the possibility of long-term ophthalmologic effects due to accumulation of naratripten in melanin-rich tissures

Adverse Reactions: Serious cardlac events, including some that have been tatal, have occurred following the use of $5-\mathrm{HT}$ agonists. These events are extremely rare and most have been reported in patients with risk tactors predictive of CAD. Events reported have included coronary artery vasospasm, transient myocardial ischemia, myocardial intarction, ventricula

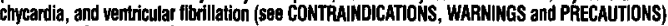

\section{Exerience in Controlled Cinical Trials with AMERG}

othet $5-H T_{1}$ agonists, AMERGE (naratriptan twd fochloride) has been associated with sensations of heaviness, pressure, tightness or pain which may be intense. These may occur in any part of the body including the chest, throat, neck, jaw and upper limb.

Acute Salety: The safety and efficacy of the 1 and $2.5 \mathrm{mg}$ doses of AMERGE were investigated in four placebo-controlled clinical trials in adult migraine patients. Two of these trials were of parallel group design and involved the treatment of a single migraine attack. A third study was of crossover design and involved the treatment of one migraine attack per dose group. The fourth study was a parallel group trial in which patients treated up to 3 migraine attacks. In all studies, patients who achieved headache relief a 240 minutes post-dose, but experienced a worsening of severity between 4 and 24 hours post-dosing, were permitted to take a second dose of double-bind medication identical to the first.

The overall incidence of adverse events following doses of $1 \mathrm{mg}$ or $2.5 \mathrm{mg}$ AMERGE (one or two doses) were similar to placebo $(28.5 \%$ and $30.2 \%$ versus $28.9 \%$ with placebo). AMERGE Tablets were generally well tolerated and most adverse reactions were mild, transient and self-limiting. The most common adverse events to occur at a higher rate than in the corresponding placebo group were malaisefatigue $(2.4 \%$ versus $0.8 \%$ with placebo) and neckthroatjaw sensations ( $2.1 \%$ versus $0.3 \%$ with placebo). Table 3 ists the most common adverse events that occurred in the four large placebo-controlled clinical trials. Only events that occurred at trequency of $1 \%$ or more in the AMERGE Tablets $2.5 \mathrm{mg}$ or $1 \mathrm{mg}$ group and were more frequent in that oroup than in the placebo group are included in Table 3 . From this table, it appears that many of these adverse events are dose related.

Table 3: Treatment-Emergent Adverse Events in Placebo-Controlled Clinical Trials Reported by at Least $1 \%$ of Patients With Migraine

\begin{tabular}{|c|c|c|c|}
\hline & Placebo & AMERGE $1 \mathrm{mg}$ & AMERGE $2.5 \mathrm{mg}$ \\
\hline Number of Patients & 922 & 1024 & 1016 \\
\hline $\begin{array}{l}\text { Number of Migraine Attacks Treated } \\
\text { Symptoms of Potentially Cardiac Origin }\end{array}$ & 1059 & 1387 & 1368 \\
\hline - neckthroatjjaw sensations" & $0.3 \%$ & $1.7 \%$ & $2.1 \%$ \\
\hline - chest sensations ${ }^{*}$ & $1.1 \%$ & $0.8 \%$ & $1.2 \%$ \\
\hline - upper limb sensations* & $0.3 \%$ & $0.5 \%$ & $1.4 \%$ \\
\hline \multicolumn{4}{|l|}{ Neurology } \\
\hline - dizziness & $1.5 \%$ & $1.0 \%$ & $2.2 \%$ \\
\hline - drowsiness/sleepiness & $0.8 \%$ & $0.9 \%$ & $1.7 \%$ \\
\hline - paresthesia & $0.8 \%$ & $1.6 \%$ & $1.5 \%$ \\
\hline - headface sensations* & $0.5 \%$ & $0.5 \%$ & $1.3 \%$ \\
\hline - headache & $0.2 \%$ & $0.4 \%$ & $1.0 \%$ \\
\hline \multicolumn{4}{|l|}{ Gastrointestinal } \\
\hline - nausea & $6.2 \%$ & $5.9 \%$ & $6.3 \%$ \\
\hline - hyposalvation & $0.3 \%$ & $0.5 \%$ & $1.0 \%$ \\
\hline \multicolumn{4}{|l|}{ Non-Site Specilic } \\
\hline
\end{tabular}

"The term "sensations" encompasses adverse events described as pain \& discomfort, pressure, heaviness,

constriction, tightness, heatburning sensation, paresthesia, numbness, tingling and strange sensations.

Long-Torm Safety: In a long-term open study, 417 patients treated 15,301 migraine attacks with AMERGE over a period of up to 1 year. The most common adverse events in descending order of trequency were as follows: nausea $(16 \%)$; malaise/fatigue $(11 \%)$ drowsiness $(10 \%)$; chest sensations ${ }^{*}(8 \%)$; neckthroatjaw sersations ${ }^{*}(8 \%)$; paresthesia $(7 \%)$; head/face sensations ${ }^{*}(6 \%)$; vomiting ( $6 \%$ ); and diziness ( $5 \%$ ). Due to the lack of a placebo arm in this study, the role of AMERGE in causation cannot be reliably determined. (*See footnote for Table 3 )

Other Adverse Events Observed in Association with AMERGE: In the paragraphs that follow, the trequencies of less commonly reported adverse clinical events are presented. Because some events were observed in open and uncontrolled studies, the role of AMERGE Tabiets in their causation cannot be reliably determined. All reported events are inciuded except those already listed in Table 3, those too general to be informative, and those not reasonably associated with the use of the drug. Event frequencies are calculated as the number of patients reporting an event divided by the total number of patients $(\mathbb{N}=2790)$ exposed to AMERGGE Tablets. Events are further classified within body system categories and enumerated in order of decreasing frequency using the following definitions: frequent adverse events are defined as those occurring in at least $1 / 100$ patients' infrequent adverse events are those occuring in $1 / 100$ to 1/1,000 patients: rare adverse events are those occurring in fewer than 1/1,000 patients.

Cardiovascular. Intrequent were palpitations, increased blood pressure, tachyarrituthmias and abnormal ECGs. Rare were bradycardia mypotension varicosities and heart murm

Ear, Nose \& Throat: Frequent were ear, nose \& throat infections. Infrequent were phonophobia, sinusitis, and upper respiratory inflammation. fare were allergic chinitis, labyrinthitis, tinnitus, ear, nose \& throat haemorhage and hearing difficulty. Endocrine \& Metabolic: Infrequent were thirst and polydipsia, dehydration and fluid retention. Rare were hyperlipidemia, hypercholesterolemia, hypothyroidism, hyperglycemia, glycosuria and ketonuria and parathyroid neoplasm.

Eve: Infrequent was photophobia. Rare were eye haemorrhage, dry eyes and dificulty focusing.

Gastrointestinal: Frequent was vomiting. Infrequent were dyspeptic symptoms, diarthea, hyposalivation, gastrointestinal discomfort Gastroinlestinal: Frequent was vomiting. Infrequent were dyspeptic symptoms, diarthea, hyposalivation, gastrointestinal discomfort
\& pain, gastroenteritis and constipation. Rare were abnormal liver function tests, abnormal bilirubin levels, salivary gland swelling,
hemorrhoids gastritis, esophagitis, oral itching \& irrtation, regurgitation \& reflux and gastic ulcers.

Musculoskelelal: Infrequent were musculoskeletall/muscle pain, muscle cramps \& spasms, arthralgia \& articular rheumatism. Rare Musculoskeletal: Infrequent were musculoskeletal/ming
were joint and muscle stiffness, tightness \& rigidity.

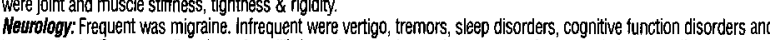

Neurology: Frequent was migraine. infrequent were vertigo, tremors, sleep disorders, cognitive function disorders and
hyperesthesia. Rare were disorders of equilibrium, decreased consciousness, confusion, sedation, coordination disorders, neuritis,

hyperesthesia. Rare were disorders of equilibrium, decreased consciousness, contus
dreams, altered sense of taste, motor retardation, muscle twitching \& fasciculations.
Non-Site Specific: Frequent were paresthesia and heat sensations. Infrequent were chills and/or tever, descriptions of odour or taste and feelings of pressure/tightnessiheaviness. Rare were allergies \& allergic reactions, mobility disorders and taintness. Psychiaty: Intrequent were anxiety and depressive disorders. Rare were agaression, agitation and detachment Reproduction: Rare were lumps of female reproductive tract and inflammation of the fallopian tube. Skin: infrequent were skin photosensitivity, skin rashes, pruritus, sweating and urticaria. Rare were skin enythema, dermakitis dermatosis and pruritic skin rash.

Urology. Infrequent were urinary infections. Rare were urinary tract haemornhage, urinary urgency and pyelitis.

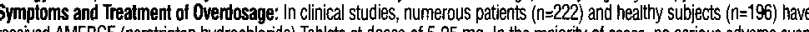
recich reported. One patient treated wh a 7.5-mg dose experienced ischemic ECG changes which were likely due to coronary vasospas This event was not associated with a serious clinical outcome. A patient who was mildly hypertensive experienced a significan administration of a $10 \mathrm{mg}$ dose (4 times the maximum recommended single dose). The event resalved with antihypertensive administration of a $10 \mathrm{mg}$ dose

$25 \mathrm{mg}$ (10 times the maximum recommended single dose) in one heathy male subject increased blood pressure from 120/67 $\mathrm{mmHlg}$ pretreatment up to $191 / 113 \mathrm{mmHg}$ at approximately 6 hours postdose and resulted in adverse events including lightheadedness, tension in the neck, tiredness, and loss of coordination. Blood pressure returned to near baseline by 8 hours after dosing without any pharmacological intervention.

The elimination half-life of naratriptan is about 5 to 8 hours (see ACTIONS AND CLINICAL PHARMACOLOGY), and therefore monitoring of patients after overdose with AMERGE Tablets should continue for at least 24 hours or longer if symptoms or sign persist. Standard supportive treatment should be applied as required. If the patient presents with chest pain or other symptoms consistent with angina pectoris, electrocardiogram monitoring should be performed for evidence of ischemia. Appropriate treatment

(e.g., nitroglycerin or other coronary artery vasodilators) should be admininistered as required.
It is unknown what effect hemodialysis or pertoneal dialysis has on the serum concentrations of AMERGE.

Dosage and Administration: AMERGE (naratriptan hydrochloride) Tablets are recommended only for the acute treatment of migrain attacks. AMERGE should not be used prophylactically.

Adults: The minimal effective single adult dose of AMERGE Tablets is $1 \mathrm{mg}$. The maximum recommended single dose is $2.5 \mathrm{mg}$ (see CLINICAL STUDIES).

Table 4: Percentage of Patients with Headache Relief at 4 Hours Post-Dosing?

\begin{tabular}{|c|c|c|c|}
\hline & Placebo & AMERGE $1 \mathrm{mg}$ & AMERGE $2.5 \mathrm{mg}$ \\
\hline Study 1 & $\begin{array}{ll}39 & \text { (91) }\end{array}$ & $\begin{array}{ll}64 & (85)\end{array}$ & $63^{n}$ \\
\hline Study 2 & $34 \quad(122)$ & $50^{*} \quad(117)$ & $60^{\circ} \wedge \quad(127)$ \\
\hline Study 3 & $27 \quad(107)$ & $52^{*}$ & $66 \times 14 \quad(209)$ \\
\hline Study 4 & $33(602)$ & $57^{*}$ & $68^{\circ} \cdot M \quad(586)$ \\
\hline
\end{tabular}

? Pain relief is defined as a reduction in headache severity from grade 3 or 2 (severe or moderate) to grade 1 or 0 (mild or no pain) "Comparison between $1 \mathrm{mg}$ and $2.5 \mathrm{mg}$ AMERGE doses was not performed " $\mathrm{D}<0.05$ versus placebo

$M$ P $<0.01$ versus AMERGE $1 \mathrm{mg}$

In three of the four studies, optimal rates of headache relief were achieved with a $2.5 \mathrm{mg}$ dose. As patients may vary in their doseresponsiveness, the choice of dose should be made on an individual basis, weighing the possible beneffit of the $2.5 \mathrm{mg}$ dose with the potential tor a greater risk of adverse events

If the migraine headache retums, or if a patient has a partial response, the initial dose may be repeated once after 4 hours, for a maximum dose of $5 \mathrm{mg}$ in a 24 hour period. The safety of treating, on average, more than four headaches in a 30 day period has not been established.

AMERGE Tablets should be swallowed whole with fluids. AMERGE tablets should be taken as early as possible atter the onset of a migraine headache, but are effectrve if taken at a later stage

if a patient does not respond to the first dose of AMERGE Tablets, a second dose should not be taken for the same attack, as it is unlikely to be of benefit.

Renal diseaseffunctional impairment causes prolongation of the half-life of orally administered AMERGE. Consequently, if treatment is deemed advisable in the presence of renal impairment, a maximum single dose of $1 \mathrm{mg}$ should be administered. No more than a total of $2 \mathrm{mg}$ should be taken in any 24 hour period. Repeated dosing in renally impaired patients has not been evaluated (see ACTIONS ANO CLINICAL PHARMACOLOGY). Administration of AMERGE tablets in patients with severe renal impairment (creatinine clearance 15 mL/min) is contraindicated (see CONTRAINDICATIONSGE

Hepatic disease/functional impairment causes prolongation of the hali-life of orally administered AMERGE. Consequently, if

treatment is deemed advisable in the presence of hepatic impairment, a maximum single dose of $1 \mathrm{mg}$ should be administered. No treatment is deemed advisable in the presence of hepatic impairment, a maximum single dose of $1 \mathrm{mg}$ should be administered. No more than a total of $2 \mathrm{mg}$ should be taken in any 24 hour period (See ACTIONS AND CLINICAL PHARMACOLOGY. Administration of AMERGE Tablets in patients with severe hepatic impaiment (Child-Pugh grade $C$ ) is contraindicated (see CONTRAINDICATIONS). Hypertension: AMERGE should not be used in patients with uncontrolled or severen
controlled hypertension should be treated cautiously at the lowest effective dose.

Pharmaceutical Information

Drug Substance

Proper Name:

Chemical Name:

Structural Formula:

naratriptan hydrochlorid acid methylamide hydrochloride

$\mathrm{CH}_{3}$

$\begin{array}{ll}\text { Molecular Formula: } & \mathrm{C}_{1} \mathrm{H}_{25} 5 \mathrm{~N}_{3} \mathrm{O}_{2} \mathrm{~S} . \mathrm{HCl} \\ \text { Molecular Weight: } & 371.9 \\ \text { Physical Characteristics: } & \text { white to pale yellow microcrystalline solid with a melting point } \\ \text { Solubilitic: } & \text { of } 246^{\circ} \mathrm{C} \\ \text { In and pKa: } & \text { In water }\left(25^{\circ} \mathrm{C}\right)=35 \mathrm{mg} / \mathrm{mL} \\ \text { pKa }=9.7 \text { (piperidinyl nitrogen) }\end{array}$

Composition: AMERGE $2.5 \mathrm{mg}$ Tablets contain $2.5 \mathrm{mg}$ of naratriptan (base) as the hydrochloride salt and the following nonmedicinal ingredients: croscarmellose sodium; hydroxypropyl methylcellulose; indigo carmine aluminium lake (FD\&C Blue No. 2) iron oxide yellow, lactose; magnesium stearate; microcrystalline cellulose; tianium dioxide; and triacelin.

AMERGE $1 \mathrm{mg}$ Tablets contain $1 \mathrm{mg}$ of naratriptan (base) as the hydrochloride salt and the following non-medicinal ingredients croscarmellose sodium; hydroxypropyl methylcellulose; lactose; magnesium stearate; microcrystalline cellulose; titanium dioxide; and triacetin

Stability and Storage Recommendalions: AMERGE Tablets should be stored below $30^{\circ} \mathrm{C}$

Availability of Dosage Forms: AMERGE Tablets $2.5 \mathrm{mg}$ are green film-coated, D-shaped tablets embossed GXCE5 on one side. available in blister packs of 2 or 6 tablets ( 4 blister packs inserted into a carton), or bottles of 60 tablets.

AMERGE Tablets $1 \mathrm{mg}$ are white film-coated, D-shaped tablets embossed GXCE3 on one side, available in blister packs of 2 tablets ( 4 blister packs inserted into a carton), or bottles of 60 tablets.

References:

1. Product Monograph of PrAMERGE ${ }^{\circledR}$ (naratriptan hydrochloride); Glaxo Wellcome Inc. April 1998.

2. Mathew NT, Asgharnejad M, Peykamian M et al. Naratriptan is effective and well tolerated in the acute treatment of migraine: results of a double-blind, placebo-controlled, crossover study. Neurology 1997:49:1485-1490.

3. Klassen A, Elkind A, Asgharnejad $M$ et al. Naratriptan is effective and well tolerated in the acute treatment of migraine: results of double-blind, placebo-controlled, parallel-group study. Headache 1997;37;640-645.

4. Bomhof MAM, Heywood J, Pradalier A et al. Tolerability and efficacy of naratriptan tablets with long-term treatment (6 months) Cephalalgia 1998; 18:33-37

Product Monograph available to health care professionals upon request.

\section{GlaxoWellcome}

Glaxo Wellcome Inc.

7333 Mississauga Road North, Mississauga, Ontario L5N 6L4

PTAMERGE ${ }^{\circledR}$ is a registered trademark of Glaxo Group Limited, Glaxo Wellcome Inc. licensed use 


\section{'BETASERON"}

\section{'BeTas}

THERAPEUTIC CLASSIFICATION

\section{ACTION AND CLINICAL PHARMACOLOG}

Description: BETASERON` (interferon beta-1b) is a purfied, sterile, lyophilized protein product produced by recombinant DNA techniques and formulated for use by Injection. Interferon beta- $1 \mathrm{~b}$ is manutactured by bacterial fermentation of a strain of Escherichis coli that bears a genetically engineered plasmid containing the gene for human interferon beta wntr. $^{2}$. The native gene was obtained from human fibroblasts and altered in a way that sub. stitutes serine for the cysteine residue found at position
17 . Interferon beta-10 is a highly purified protein that has 165 amino acids and an approximate molecular weight of 18,500 dallons. It does not include the cartohydrate side chains found in the natural material.

General: Interferons are a family of naturally occurring proteins, which have molecular weights ranging from 15,000 to 21,000 daltons. Three major classes of interterons have been identified: alpha, beta, and gamma. Interferon beta -10 , interferon alpha, and interteron gamma have overlapping yet distinct biologic activities. The activities of interferon beta- $1 \mathrm{~b}$ are species-restricted and therefore, the most pertinent pharmacological information On BETASERON (interferon beta- $1 \mathrm{~b}$ ) is
of human cells in culture and in vivo.

of human cells in culture and in vivo. Biologic Activities: Interferon beta- 16 has been shown to possess both antiviral and immunomodulatory activities. The mechanisms by which BETASERON exerts its actions in
multiple sclerosis (MS) are not clearly understood. However, multiple sclerosis (MS) are not clearly understood. Howeve,
it is known that the biologic response-modifying properties of interferon beta-1b are mediated through its interactions with specific cell receptors found on the surface of human cells. The binding of interferon beta- $1 \mathrm{~b}$ to these receptors
induces the expression of a number of interferon-induced induces the expression of a number of interferon-induced kinase, and indoleamine 2,3-dioxygenase) that are believed to be the mediators of the biological actions of interferc beta- $1 \mathrm{~b}$. A number of these interteron-induced products fractions of blood collected from patients treated with tractions of blocd collex

Clinical Trials: The efficacy of 8 MUU BETASERON. dministered subcutaneously every other day, has be studied in one placebo-controlled clinical trial in recontrolled trial in secondary-progressive MS patients $(\mathrm{n}=360)$.

1. Relapsing-Remitting MS: The effectiveness of BETASERON in relapsing-remitting MS was evalu in a double-blind, multiclinic (11 sites: 4 in Canada clinical investigation of 2 years duration. The study included MS pattents, aged 18 to 50 , who were ambulatory Kurtzke expanded disability status scale [EDSSI of 5 5.5), exhibited a relapsing-remitting clinical course, met Poser's criteria for clinically definite and/or laboratory supported definite MS and had experienced at least two exacerbations over 2 years preceding the trial without exacerbation in the preceding preceding the trial without exacerbation in the preceding
month. Patients who had received prior immunosuporessant therapy were excluded

An exacerbation was defined, per protocol, as the pearance of a new clinical sign/symptom or the clinical worsening of a previous sign'symptom ione that had been stable for at least 30 days) that persisted for a minimum of 24 hours.

Tabie 1: 2-Year Study Results

\section{Primary and Secondary Endpoints}

\begin{tabular}{|c|c|c|c|c|c|c|c|}
\hline \multicolumn{8}{|c|}{ Primary and Secondary Endpoints } \\
\hline \multirow{2}{*}{\multicolumn{2}{|c|}{$\begin{array}{l}\text { Primary and Secondary Endpoints } \\
\text { Efficacy Parameters } \\
\text { Primary Clinical Endpoints }\end{array}$}} & \multicolumn{3}{|c|}{ Treatment Groups } & \multicolumn{3}{|c|}{$\begin{array}{l}\text { Statistical Comparisons } \\
\text { p-value }\end{array}$} \\
\hline & & $\begin{array}{l}\text { Placebo } \\
\text { (n=123) }\end{array}$ & $\begin{array}{l}0.05 \mathrm{mg} \\
(1.6 \mathrm{MiV}) \\
(\mathrm{n}=125)\end{array}$ & $\begin{array}{l}0.25 \mathrm{mg} \\
\text { (8 MUV) } \\
\text { (n=124) }\end{array}$ & $\begin{array}{l}\text { Placebo } \\
\text { vs } \\
0.05 \mathrm{mg} \\
\text { (1.6 Miv) }\end{array}$ & $\begin{array}{l}0.05 \mathrm{mg} \\
(1.6 \mathrm{MIU}) \\
\mathrm{vs} \\
0.25 \mathrm{mg} \\
(8 \mathrm{MIU})\end{array}$ & $\begin{array}{l}\text { Placebo } \\
\text { vs } \\
0.25 \mathrm{mg} \\
\text { (8 MiV) }\end{array}$ \\
\hline Annual exacerbation rate & & 1.31 & 1.14 & 0.90 & 0.005 & 0.113 & 0.0001 \\
\hline Proportion of exacerbatic & & $16 \%$ & $16 \%$ & $25 \%$ & 0.609 & 0.288 & 0.094 \\
\hline $\begin{array}{l}\text { Exacertation frequency } \\
\text { per patient }\end{array}$ & $\begin{array}{r}0 \\
1 \\
2 \\
3 \\
4 \\
25\end{array}$ & $\begin{array}{l}20 \\
32 \\
20 \\
15 \\
15 \\
21\end{array}$ & $\begin{array}{r}22 \\
31 \\
28 \\
15 \\
7 \\
16\end{array}$ & $\begin{array}{r}29 \\
39 \\
17 \\
14 \\
9 \\
8\end{array}$ & 0.151 & 0.077 & 0.001 \\
\hline
\end{tabular}

Secondary Endpoints

\begin{tabular}{|c|c|c|c|c|c|c|}
\hline $\begin{array}{l}\text { Median number of months to first } \\
\text { on-study exacerbation }\end{array}$ & 5 & 6 & 9 & 0.299 & 0.097 & 0.010 \\
\hline $\begin{array}{l}\text { Rate of moderate or severe } \\
\text { exacerbations per year }\end{array}$ & 0.47 & 0.29 & 0.23 & 0.020 & 0.257 & 0.001 \\
\hline Mean number of moderate or severe & 44.1 & 33.2 & 195 & 0229 & 0.064 & 0.001 \\
\hline $\begin{array}{l}\text { Mean change in EDSS scoreł } \\
\text { at endpoint }\end{array}$ & 0.21 & 0.21 & 0.07 & 0.995 & 0.108 & 0.144 \\
\hline $\begin{array}{l}\text { Mean change in Scripps score\#\# } \\
\text { at endpoint }\end{array}$ & 0.53 & .0 .50 & 0.66 & 0.641 & 0.051 & 0.126 \\
\hline Median duration per exacerbation (days) & 36 & 3 & 35.5 & NO & ND & ND \\
\hline $\begin{array}{l}\text { Schange in mean MRi lesion area } \\
\text { at endpoint }\end{array}$ & $21.4 \%$ & $9.8 \%$ & $0.9 \%$ & 0.015 & 0.019 & 0.0001 \\
\hline
\end{tabular}

ND Not done

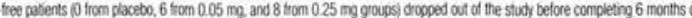
therapy These patients are exchuded tom this analos

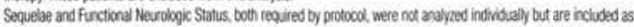
a tunction of the EDSS

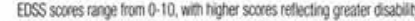

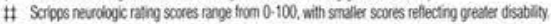
evaluated after 2 years.

Patients who required more than three 28 -day courses of corticosterrids were withdrawn from the study. Minor anagesics (e.g. acetaminophen), antidepressants, and or anti-inflammatory drug (NSAID) use was not allowed. The primary, protocol defined, outcome assessment measures were 1) frequency of exacerbations per A number of secondary outcome measures were also A moloued as described in Table 1 .

addition to clinical measures, annual magnetic resonance imaging (MRI) was performed and quantitated

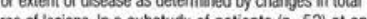
site, MRls were performed every 6 weeks and quantitated for disease activity as determined by changes in size and er of lesions.

Results at the protocol designated endpoint of 2 years eduction in annual exacerbation rate, from 1.31 in the lacebo group to 0.9 in the $0.25 \mathrm{mg}$ (8 MiL) group. The value for this difference was 0.0001 . The proportion patients free of exacerbations was $16 \%$ in the placebo Mily group

Of the first 372 patients randomized, 72 (19\%) failed to complete 2 full years on their assigned treatments. The Jeasons given for withdrawal varied with treatment assign-

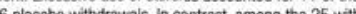
drawals from the $0.25 \mathrm{mg}(8 \mathrm{MM})$ assigned group, ex. Withdrawals for adverse events attributed to study article. hatients: 1 and 10 withdrew from the placebo and $25 \mathrm{mg}(8 \mathrm{MIU})$ groups, respectively.

Over the 2-year period, there were 25 MS-related mospitalizations in the $0.25 \mathrm{mg}$ (8 MIU) BETASERON-treated roup compared to 48 hospitalizations in the placebo distributed between the groups, with 16 in the $0.25 \mathrm{mg}$ MUU) BETASERON group and 15 in the placebo group. the average number of days of MS-related steroid use was 41 days in the $0.25 \mathrm{mg}$ (8 MU) BETASERON group and 55 days in the placebo group $(p=0.004)$.

MRI data were also analyzed for patients in this study. Ail area at the end of 2 years was obtained by grouping Figure 1 displays a histogram of the proportions of patients who fell into each of these intervalis. The median percent change in MFI area for the $0.25 \mathrm{mg}$ (8 MIU) group was oserved for the placebo group $(0=0.0001$ )

Fitty-two patients at one site had frequent MRI scans (every 6 weeks). The percentage of scans with new or expanding lesions was $29 \%$ in the placebo group and in the $0.25 \mathrm{mg}(8 \mathrm{MII})$ treatment group $(\mathrm{p}=0.006)$. changes in white matter that are believed to be a reflection of the pathologic changes that, appropriately located within he central nervous system (CNS), account for some of the

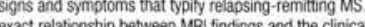
tatus of patients is unknow because many of the lesions affect so-called "silent"
Figure 1: Distribution of Change in MRI Area

Betaseron $0.25 \mathrm{mg}$ ( 8 million IU) BETASERON $(n=125)$ or $0.25 \mathrm{mg}$ (8 MUU) BETA $(n=124)$ self-administered subcutaneously every other day. A frequency distribution of the observed percent changes

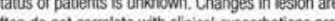

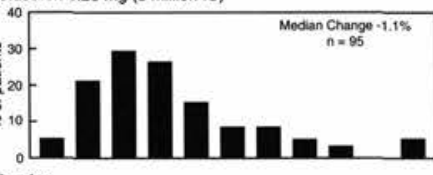

Placebo

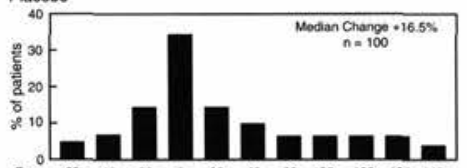

From $\begin{gathered}-60 \\ \text { To }<-40<20<0\end{gathered}$ Parcent Change in MPI Ares

regions of the CNS. Moreover, it is not clear what fraction of the lesions seen on MAI become foci of irreversible demyelinization (i.e., classic white matter plaques). The prognostic significance of the MRI findings in this study as not been evaluated

At the end of 2 years on assigned treatment, patients in the study had the cotion of continuing on treatment under blinded conditions. Approximately $80 \%$ of patients in each treatment group accepted. Athough there was a trend toward patient benefit in the BETASERON groups during
the third year, particularly in the $0.25 \mathrm{mg}$ (8 MiU) group, the third year, particularly in the $0.25 \mathrm{mg}$ ( 8 MiU) group.
there was no statistically significant difference between there was no statistically signilicant difference between exacerbation rate, ar in any of the secondary endpoints described in Table 1. As noted above, in the 2-year analys: there was a $31 \%$ reduction in exacerbation rate in the $0.25 \mathrm{mg}$ (8 MIU) group, compared to placebo. The p-value tor this difterence was 0.0001 . In the analysis of the third
year alone, the difference between treatment groups was year alone, the difference between treatment groups was
$28 \%$. The $p$-value was 0.065 . The lower number of patient may aocount for the loss of statistical significance, and lack of direct comparability among the patient groups in this extension study make the interpretation of these results difficult. The third year MRI data did not show a trend
toward additional benefit in the BETASERON arm.

toward additional benefit in the BETAC

Throughout the clinical trial, serum samples from patients
Tompared with the lacebo arm. were monitored for the development of antibodies to

interteron beta- $1 \mathrm{~b}$. In patients receiving $0.25 \mathrm{mg}(8 \mathrm{MU})$ BETASEAON ( $n=124)$ every other day, $45 \%$ were lound to have serum neutrallaing activity on at least one occasion. One third had neutraliang activity confimed by at least two consecutive posivive tires. This developinent or nedral ing activity may be associated with a reduction in clinical efficacy, athough the exact relationship between antibody

formation and therapeutic efficacy is not yet known. 2. Secondary-Progressive MS: The effectiveness of BETASERON administered subcutaneously at a dose of $0.25 \mathrm{mg}(\mathrm{B} \mathrm{MIU})$ every other day lor 3 years was studied in turopean mulicenter (32 sless), randomized, double-bind, placebo-controlled trial in patients with condary-progressive MS.

The study included patients between 18 and 55 years of age mo had clinically definte or laboratory-supponted detinte MS tor not less than one year. Disease had to be in the secondary-progressive phase and detenioration could not be exclusively related to incomplete recovery 3.0 and 6.5 and patients had to have a history of at least 3.0 and 6.5 and patients had to have a history or at least 1 EDSS point $($ or 0.5 points between EDSS scores of 6.0 to 7.0$)$ within the preceding 24 months.

The primary efficacy endpoint was time to confirmed
Touth progression in disability, as determined by an increase by one point on the EDSS from baseline if the entry score was 3.0 to 5.5 , or 0.5 points on the EDSS if the baseline score was 6.0 or 6.5 . The increased score had to be mant 6 . or 6.5 . The increased score ha te confirmed secon time to becoming wheelchair-bound (EDSS 7.0) and annual relanse rate.

Although the study was designed with a treatment duration of three years, a prospectively planned interim had completed 2 years in the study. This resulted in decision by an independent Advisory Board to terminate the study early. Approximately $85 \%$ of all EDSS data for the three year study duration were available for the interim analysis of the primary endpoint. The primary analysis of efficacy was based on all patients randomized to treatment (Intent to Treat). The primary statistical method for the primary endpoint was a non-parametric analysis of covariance with stratification for centre and adjustment for baseline EDSS. Results presented below are for the dataset at study termination. During the study, assessment of the EDSS was performed by a physician not otherwise involved in the treatment of the patient. All EDSS physicians were regularly trained to guarante a maximally standardized assessment of the EDSS. All efforts were undertaken to maintain the binding, e.g. standard clothing to cover injection sites was coligatory.

A total of 718 patients ( 358 on placebo and 360 cn BETASERON) were enrolled of temale patients exceeded that of males

(Placebo: $64.2 \%$ vs. $35.8 \%$; BETASERON: $58.1 \%$ vs. $41.9 \%$ ), but this difference was not statistically signicant hive mean tme cr treatment was 886 Cays for placebo and Eghy eng tudy irnespertive the 3-year study period, treatment was discontinued prenaturely by $117(32.7 \%)$ placebo patients and a adverse events and non-compliance were the most $6.4 \%$ and $7.5 \%$ of the placebo group and in $7.5 \%$ $14.2 \%$ and $3.3 \%$ of the BETASERON group, respectively. The treatment groups were well-balanoer for all relevant baseline values, including EDSS at baseline, and time since evidence of secondary. progressive disease.

There was a statistically significant difference in time to confirmed progression in disability in favour Or BETASERON ( $p=0.0046$ ), as shown in Table 2. The delay in progression in disability became apparen ignificant from month 12 onwards. The proportion of patients with confirmed progression in disability was reduced from $60.9 \%$ in the placebo group to $51.9 \%$ in the BETASERON group $(p=0.0245)$

The treatment effect was consistent across all baselin Eoss levels studied, however, the difterence in the proportion of patients having confirmed progression in diswas lower for patients with study entry EDSS values of 26.0 , compared to the other EDSS categories (EDSS $\leq 3.5$. $15.0 \%$; EDSS $4.0-5.5: 11.3 \%$ and EDSS $\geq 6.0: 3.5 \%$ ). Athough the proportion of male patients in the BETASERON group with confirmed progression in disability was slightly group with contirmed progression in disability was sigh regression analysis did not reveal any significant treatment by gender interaction $(p=0.4335)$.

Kaplan-Meier plots (post-hoc analysis) of the data are shown in Figure 2. The Kaplan-Meier estimate of the percentage of patients progressing by the end of 3 years was $53.9 \%$ for placebo and $45.3 \%$ for BETASERON-treated

the time to becoming wheelchair-bound (EDSS $=7.0$ as also significantly prolonged $(p=0.0047)$ and the reduced from $28.5 \%$ in the placebo group to $18.6 \%$ in

the BETASERON group $(p=0.0069)$.

BETASERON reduced the relapse rate by $26.3 \%$ over the entire study period ( $p=0.0034$ ). The prosortion of patients with moderate or severe relapses was reduced trom $54.2 \%$ in the placebo group to $47.2 \%$ in the BETASERON group $(p=0.0508)$. The mean annual rate of moderate or severe relanses was 0.44 and 0.31 in the placebo and the BETASERON group, respectively $(p=0.0037$ ).

The incidence of hospitalizations due to MS was reduced: $44.4 \%$ of placebo patients required hospitalization due to MS vs. $36.1 \%$ in the BETASERON group $(p=0.0003)$. The number of patients with steroid courses was $73.2 \%$ and $62.5 \%$ of patients in the placebo and BETASERON group espectively $(p=0.0010)$

in addition to clinical measures, annual magnetic esonance imaging (MRII) was performed. All patients of patients (Placebo, monts 16 and secondary and tertiary MRI endpoints showed significant differences between treatment groups in favor of 
Table 2

Secondary-Progressive MS Study Pesults

\begin{tabular}{|c|c|c|c|}
\hline \multicolumn{4}{|c|}{$\begin{array}{l}\text { Secondary-Progressive WS Study Hesults } \\
\text { Summary of Key Efficacy Endpoints }\end{array}$} \\
\hline & \multicolumn{2}{|c|}{ Treatment Groups } & \multirow[t]{2}{*}{ p-value } \\
\hline & $\begin{array}{l}\text { Placebo } \\
(n=358)\end{array}$ & $\begin{array}{c}\text { Betaseron } 0.25 \mathrm{mg} \\
(8 \mathrm{~N} \| \mathrm{U}) \\
(\mathrm{n}=360) \\
\end{array}$ & \\
\hline \multicolumn{4}{|l|}{ Primary Endpoints } \\
\hline Time to Contirmed Progression in Disabaility & & & 0.0046 \\
\hline Year 1 & 0.70 & 0.81 & 0.0032 \\
\hline Vear 2 & 0.53 & 0.64 & 0.0013 \\
\hline Month 33 & 0.44 & 0.53 & 0.0066 \\
\hline \multicolumn{4}{|l|}{ Secondary Cllnical Endpoints } \\
\hline Time to becoming wheelchair-bound ${ }^{2}$ & & & 0.0047 \\
\hline Year 1 & 0.90 & 0.96 & 0.0139 \\
\hline Year 2 & 0.81 & 0.86 & 0,0006 \\
\hline Month 36 & 0.69 & 0.80 & $0,004 ?$ \\
\hline Proportion of pectents becoming wheelchair-bound & $28.5 \%$ & $18.6 \%$ & 0.0069 \\
\hline Mean annual relacse rate & 0.57 & 0.42 & 0.0034 \\
\hline $\begin{array}{l}\text { MPli: mean percent change in T2 lesion yolume } \\
\text { (toaseline to last scari) }\end{array}$ & 15.4 & -2.1 & $<0.0001$ \\
\hline MAli: mean number of newly active lesions (months $1 \cdot 6$ ) & $\begin{array}{l}10.24 \\
\{\pi=61\}\end{array}$ & $\begin{array}{c}3.57 \\
{[n=64)}\end{array}$ & $<0.0001$ \\
\hline \multicolumn{4}{|l|}{ Tertiary Endpoints } \\
\hline Proportion of patients with confirmed progression & $60.9 \%$ & $51.9 \%$ & 0.0245 \\
\hline Mean endpoint EOSS & 5.93 & 5.58 & 0.0065 \\
\hline Mecian time to first relapse (dayss) & 385 & 644 & 0.0088 \\
\hline $\begin{array}{l}\text { Mift rean number of persistently enhancing lesions } \\
\text { simonths } 1-6 \mid\end{array}$ & $\begin{array}{l}3.10 \\
(\pi=61)\end{array}$ & $\begin{array}{l}1.02 \\
(n=64) \\
\end{array}$ & 0.0009 \\
\hline $\begin{array}{l}\text { MPl: mean number of persistently enhancing lesions } \\
\text { [months 19-24] }\end{array}$ & $\begin{array}{c}3.04 \\
{[n=53]}\end{array}$ & $\begin{array}{l}0.36 \\
{[n=56]}\end{array}$ & 0.0004 \\
\hline
\end{tabular}

Frobability of remaining progression-free during the interval.

\section{INDICATIONS AND CLINICAL USE}

BETASERON (inteferon beta-1b) is indicated fo:

- the reduction of the frequency of clinical exacerbations

in ambulatory patients with relapsing-remitting multip

sclerosis. Relapsing-remitting MS is characterized by

recurrent attacks of neurologic

- the slowing of progressien in disability and the reduction

of the frequency of clinical exacerbations in patients

of the frequency of clinical exacerbations in pa

The safety and efficacy of BETASERON in primary

progressive MS have not been evaluated

\section{CONTRAINDICATIONS}

BETASERON (interferon beta- 1 b) is contraindicated in patients with a history of hypersensitivity to natural or recombinant interferon beta, Albumin Human USP, or any other component of the formulation.

\section{WARNINGS}

The administration of cytokines to patients with a preexisting monoclonal gammcpathy has been associated with the development of systemic capillary leak syndrome with shock-like symptoms and fatal outcome.

In the RR-MS clinical trial, one suicide and four atten:pted sulicides were observed among 372 study patients during a 3-year period. All five patients received BETASERON (interferor beta-1b) (three in the $0.05 \mathrm{mg}$ [1.6 Milu] group
and two in the $0.25 \mathrm{mg}$
$[8.0 \mathrm{MlU}]$ group]. There were no attempted suicides in patients on study who did not receive BETASERON. In the SP-MS study there were 5 suicide attempts in the placebo group and 3 in the BETASERON group Including one patient in each group who committted occur in patients receiving interteron alpha, a related occur in patients receiving interteron alpha, a related
compound. Patients treated with BETASERON should be intormed that depression and suicidal ideation may be a side effect of the treatment and should report these symptoms immediately to the prescribing physician. Fatients exhibiting depression should be monitored

\section{PRECAUTIONS}

General: Rare cases of cardiomyopathy have been reported. If this cccurs, and a relationship to BETASERON (interferon beta-1b) is suspected, treatment should be discontinued.

Rare cases of thyroid dystunction inyper- as well as hypothyroidism) as

Symptoms of flu syndromie observed with BETASERON therapy may prove stresstul to patients with severe cardia conditions. Patients with cardiac disease such as angina, congestive heart failure or arrthythria should be monitored closely for worsening of their clinical conditions Information to be Provided to the Patient: Patients should be instructed in iniection techniques to assure the safe self-administration of EETASERON. See below and the BETASERONO WFORMATION FOR THE PATIENT Procedures: it is recommended that the first injection be administered by, or under the direct supervision of a physician. Appropriate instructions for reconstitution of BETASERON and self-injection, using asentic techniques should be given to the patient. A careful review of the section is also recommendo

Patients should be cautioned against the re-use of needles or syringes and instructed in safe disposa procedures intormation on how to acquire a punctureresistant container for disposal of used needles and syringes should be given to the patient aiong with instructions ior safe disposal of full contalners
Overall, $80 \%$ of patients in the two controlled clinical trials reported injection site reactions at one or more times during therapy. Post-marketing experlence has been consistent with this finding, with infrequent reports of injection site necrosis.

The onset of injection site recrosis usually appears early in therapy with most cases reported to have occurred in the where necrosis has been observed was number Where necrosis has been observed was variable.
Rarely, the area of necrosis has extended to subRarely, the area of necrosis has extended to sub-
cutanecus fat or fascia. Response to treatment of iniection cutanecus fat or fascia. Response to treatment of injection
site necrosis with antibiotics and/or steroids has been site necrosis with antibiotics and/or steroids has been
variable. In some of these patients elective debridement variable. In some of these patients elective debridement
and, less frequently, skin grafting took place to facil itate and, less frequently, skin gratting took place to facil
healing which could take from three to six months. healing which could take from three to six months.
Some patients experienced healing of necrotic skin
lesions while BETASERON therapy continued. In other lesions while BETASERON therapy continued. In other was discontinued. The nature and severity of all reported reactions should
be carefully assessed. Patent understanding and use of asertic self-iniection technique and procedures should be aseptic self -injection technil

Flu-like symotoms are not uncommon following initiation Hu-like symptoms are not uncommon to lowing initiation
of therapy with BETASERON. in the controlled MS clinica trials, acetaminophen was permitted for relief of fever or trials, ace

Patients should be cautioned not to change the dosage or the schedule of administration without medical

consultation.

Awareness of Adverse Reactions: Patients should be the use of BETASERON particularly injection site reactions REACTIONS).

Patients should be cautioned to report depression or suicidal ideation (see WARNINGS)

Patients should be advised about the abortifaclent potential of BETASERON (see PRECAUTIONS, Use in Pregnancy)

Laboratory Tests: The following laboratory tests are at periodic intervals thereafter: thyroid function test, counts, platelet counts and differential white blood cell liver tunction tests A pregnancy test chest roentiung and ECG should also be performed prior to initititing BETASERON therapy. In the controlied MS trials, patients were monitored every 3 months. The study protocol stipulated that BETASERON therapy be discontinued in the event the absolute neutrophil count fell below $750 / \mathrm{mm}^{3}$. When the absolute neutroohil count had returned to a value reduced dose. No patients were withdrawn or dose-reduced for neutropenia or lymphopenis.

Similarly, if AST/ALT (SGOT/SGPT) levels exceeded 10

times the upner limit of normal, or if the serum bili rubin

exceeded 5 times the upper limit of normal, therapy was discontinued. In each instance during the controlled MS trial, creased to below these levels, therapy could be restarted at a $50 \%$ dose reduction if clinically appropriate. Dose was reduced in two patients due to increased liver enzymes: one continued on treatment and one was ultimately

\section{withdrawn.}

Drug Interactions: Interactions between BETASERON and other drugs have not teen evaluated. Athough studies designed to examine drug interactions have not been do received corticosteroid or ACTH treatment of relapses for periods of up to 28 days. and the fu-like symptom complex isee ADVERSE recommended prior to initiating BETASERON therapy and greater than $750 / \mathrm{mm}^{3}$, therapy could be restarted at a $50 \%$ hepatic enzyme abnormailities returned to normal following
BETASERON audministered in three cancer patients over a dose range of $0.025 \mathrm{mg}(0.8 \mathrm{M}(\mathrm{U})$ to $2.2 \mathrm{mg}(71 \mathrm{MU})$ led to a dose-dependent inhibition of antipyrine elimination. The effect of alternate-day administration of $0.25 \mathrm{mg}(8 \mathrm{Mil})$ BETASERON an drug metabolism in MS patierts is unknown. Interferons have been reported to reduce the activity of hepatic chtochrome P450-dependent enzymes in humans and animals. Caution should be exercised when BETASERON is adrninistered in combination with agents BETASERON is adrninistered in conbination with age that have a narrow therapeutic index and are largely dependent on

Impairment of Fertility: Studies in female thesus monkeys wh normal mastral cycles, at doses up recolites recommended human dose based on body surface ar comparison, showed no acparent adverse effects on the menstrual cycle or on associated hormonal protlles
(progesterone and estradiol) when administered over 3 consecutive menstrual cycles. The extrapolability of anima doses to human doses is not known. Effects of BETASERON on women with normal menstrual cycles are not known. Use in Pregnancy: BETASEFON W was not teratog
doses up to $0.42 \mathrm{mg}$ (13.3 MUU/ $/ \mathrm{kg} /$ day in thesus monkeys, but demonstrated dose-related aborttacient activity monkeys, but demonstrated dose-related aborttacient
when administered at doses ranging from $0.028 \mathrm{mg}$ $(0.89 \mathrm{MIU}) / \mathrm{kg} /$ /day $(2.8$ times the recommended human dose based on tody surface area comparisony to $0.42 \mathrm{mg}$ based on body sufface area comparison). The extrapolability of animal doses to human doses is not known. Lower doses were not studied in monkeys. Spontaneous abortions while on treatment were reported in 4 patients who participated in the BETASERON RR-MS clinical trial, whereas there was one induced abortion in each of the placebo and BETASERON groups in the SP-MS trial. BETASERON given to rhesus monkeys on gestation days 20 to 70 dd not cause teratogenic effects; however, it is not known if teratogenic effects exist in hurnans. There are no adequate and wellcontrolled studies in pregnant women. Women of childbearing potential should take reliable contraceptive measures. If the patient becomes pregnant or plans to becorne pregnant while taking BETASERON, the patient should discontinue therapy. It is not known if interferon alter the efficacy of oral contraceptives.

Nursing Mothers: it is not known whether BETASERON is excreted in human milk. Given that many drugs are excreted in human milk, there is a potential for serious adverse reactions in nursing infants, therefore a decision should be made whether to discontinue nursing or discontinue BETASERON treatment.

Pediatric Use: Safety and efficacy in children under 8 years of age have not been established.

Dependence Liability: No evidence or experience suggests that abuse or dependence occurs with BETASERON therapy; however, the risk of dependence has not been systematical y evaluated.

\section{ADVERSE REACTIONS}

erse events were observed in placebo. controlied clinical studies of BETASERON (interferon beta-1b), at the recommended dose of $0.25 \mathrm{mg}$ ( 8 MIU secondary-progressive MS in $=360$ )

1. Relapsing-remitting MS: Injection site reaction (85\%) and injerticn site necrosis (5\%) occurred after administration of BETASERON. Inflammation, pa hypersensitivity, necrosis, and non-specific reactions were sicrificicanty associated $(0<0.05)$ with the $0.25 \mathrm{mg}$ (8) Mill BETASERON-treated group, cornpared to placebo. Only inflammation, pain, and necrosis were reported as severe events. The incidence rate for injection site reactions was calculated over the course of 3 years. This incidence rate decreased over time, with $79 \%$ of patients experiencing the event during the first 3 months of treatment compared to $47 \%$ during the last 6 months. The median time to the first cccurrence of an injection site reaction was 7 days. Patients with injection site reactions reported these even 183.7 days per year. Three patients withdrew from the
$0.25 \mathrm{mg}$ ( $8 \mathrm{ML})$ BETASERON-treated group for injection site pain

Flu-like symptom complex was reported in $76 \%$ of the patients treated with $0.25 \mathrm{mg}(8$ MUL) BETA.SERON.

A patient was defined as having a flu-like symptom complex if flu-like syndrome or at least two of the following symptoms were concurrently reported. tever, chils, myalgia, mataise or sweating. Only myalgia, fever, and chills were reported as severe in more than $5 \%$ of the patients. The incidence rate for flu-fike symptom complex was also calculated over the course of 3 years. The incidence rate of these events decreased over time, with $60 \%$ of patien experiencing the event during the first 3 months of teatment compared to $10 \%$ during the last 6 months. The median time to the first occurrence of flu-like symptom was 7.5 days per year

ilies include

- lymphocyte count < $1500 / \mathrm{mm}^{3}(82 \%)$

- absolute neutrophil count $<1500 / \mathrm{mm}^{3} 318 \%$

(no patients had absolute neutrophil counts $<500 / \mathrm{mm}^{3}$ ) - $W B C<3000 / \mathrm{mm}^{3}(16 \%)$, and

- total tilirubin $>2.5$ times baseline value $(6 \%)$

Three patients were withdrawn from treatment with 0.25 mg 18 MIII) BETASERON for abnormal liver enzymes including one following dose reduction
PRECAUTIONS, Laboratory Tests).

Twenty- 0 ne $(28 \%)$ of the 76 females of child dbearing age the 76 temales reported menstrual disorders All repots were of mild to reported menstrual disorders. Aill reports were of mild to rioderate severity and included: intermenstrual beedring
and spotting, early or delayed menses, decreased days of menstrual flow, and clotting and spotting during menstruation. Mental disorders such as depression, anxiety, emotional
lability, depersonalization, suicice attempts and confusion were observed in this study. Two patients withdrew for confusion. One suicide and four attempted suicides were also reported. It is not known whether these symptoms ma be related to the underlying neurological basis of MS, to BETASERON treatment, or to a combination of both. Some similar symptoms have been noted in patients receiving interteron alpha and both interterons are thought to act through the same receptor. Patients who experience these therapy should be considered.

Additional common clinical and laboratcry adverse events associated with the use of BETASERON arg listed in the following paragraphs. These events occurred at an incidence of $5 \%$ or more in the 124 MS patients treated with $0.25 \mathrm{mg}$ (8 MUU) BETASERON every other day for periods of up to 3 years in the controlled trial, and at an incidence that was at least twice that observed in the 123 placebo patients. Common adverse clinical and laboratory events associated with the use of BETASERON were

- injection site reaction (85\%),

- lymphocyte count < $1500 / \mathrm{mm}^{3}$ (82\%)

- ALT (SGPT) > 5 times baseline value $(19 \%)$

- menstrual disorder (17\%),

- palpitation (8\%).

- dyspnea $(8 \%)$

- cystitis $(8 \%)$

- hypertension $(7 \%)$

- breast pain (7\%)

- gastrointestinal disorders $16 \%$

- total bilirubin $>2.5$ times baseline value $(6 \%)$

- somolence $6 \%$

- pelvic pain $(6 \%$

- menorrhagia (6\%

- injection site necrosis $(5 \%)$, and

A total of 277 MS patients have been treated with BETASERON in doses ranging from $0.025 \mathrm{mg}(0.8 \mathrm{MIU}$ to $0.5 \mathrm{mg}$ ( $16 \mathrm{Mll}$ ). During the first 3 years of treatment withdrawals due to clinical adverse events or

- tatigue (2\%,6 patients)

- cardiac arrhythmia (< 1\%, 1 patient). 


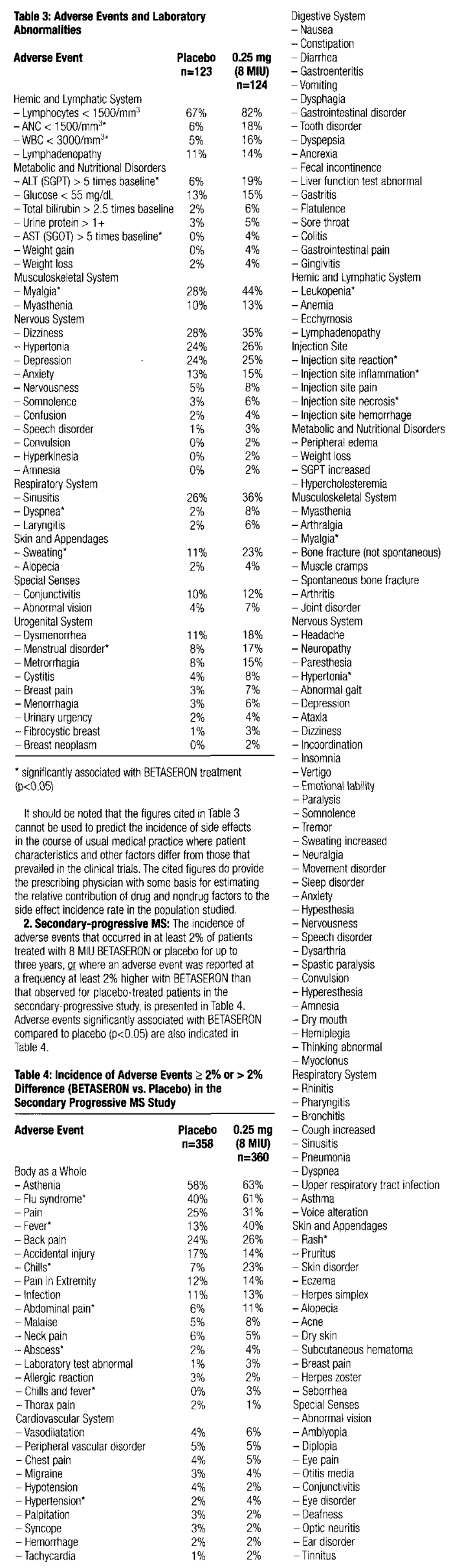

\begin{tabular}{|c|c|c|c|c|}
\hline & & Urogenital System & & \\
\hline $13 \%$ & $13 \%$ & - Urinary tract infection & $25 \%$ & $22 \%$ \\
\hline $12 \%$ & $12 \%$ & - Urinary Incontinence & $15 \%$ & $8 \%$ \\
\hline $10 \%$ & $7 \%$ & - Urinary tract disorder & $10 \%$ & $7 \%$ \\
\hline $5 \%$ & $6 \%$ & - Cystitis & $9 \%$ & $7 \%$ \\
\hline $6 \%$ & $4 \%$ & - Urinary urgency & $7 \%$ & $8 \%$ \\
\hline $5 \%$ & $4 \%$ & - Menstrual disorder & $13 \%$ & $9 \%$ \\
\hline $5 \%$ & $4 \%$ & - Increased urinary trequency & $5 \%$ & $6 \%$ \\
\hline $4 \%$ & $4 \%$ & - Metrorrhagia & $6 \%$ & $12 \%$ \\
\hline $4 \%$ & $4 \%$ & - Urinary retention & $6 \%$ & $4 \%$ \\
\hline $2 \%$ & $4 \%$ & -Vaginitis & $4 \%$ & $3 \%$ \\
\hline $3 \%$ & $2 \%$ & - Amenornea & $4 \%$ & $3 \%$ \\
\hline $1 \%$ & $3 \%$ & - Dysurla & $2 \%$ & $2 \%$ \\
\hline $2 \%$ & $2 \%$ & - Impotence & $4 \%$ & $7 \%$ \\
\hline $1 \%$ & $3 \%$ & - Menopause & $4 \%$ & $2 \%$ \\
\hline $1 \%$ & $2 \%$ & - Menorrhagia & $4 \%$ & $2 \%$ \\
\hline $2 \%$ & $0 \%$ & - Nocturia & $1 \%$ & $2 \%$ \\
\hline $0 \%$ & $2 \%$ & - Vaginal moniliasis & $2 \%$ & $2 \%$ \\
\hline \multirow[t]{2}{*}{$0 \%$} & $2 \%$ & - Kidney pain & $2 \%$ & $0 \%$ \\
\hline & & - Pyelonephritis & $0 \%$ & $2 \%$ \\
\hline $5 \%$ & $10 \%$ & - Prostatic disorder & $1 \%$ & $2 \%$ \\
\hline $5 \%$ & $2 \%$ & & & \\
\hline & $1 \%$ & & & \\
\hline
\end{tabular}

$4 \% \quad 48 \% \quad$ Seventy-four (74) patients discontinued treatment due $5 \% \quad 9 \%$ to adverse events (23 on placebo and 51 on BETASERON) $\begin{array}{lll} & 5 \% & \text { Injection site reactions were significantly aSsociated with } \\ 2 \% & 2 \% & \text { early termination of treatment in the BETASEFON group }\end{array}$ $7 \% \quad$ compared to placebo $(0<0,05)$. The highest frequency of

nervous system, of which depression $(70$ on placebo and 11 on BETASERON) was the most common

Significantly more patients on active therapy $(14,4 \%$ vs. $4.7 \%$ on placebo) had elevated ALT (SGPT) values (>

times baseline value). Elevations were also observed in AST ( $\mathrm{SGOT}$ ) and gamma-GT values in the BETASERON group throughout the study. In the BETASERON group, most ALT (SGPT) abnormalities resolved spontaneously with continued treatrment whereas some resolved upon dose reduction or temporany discontinuat on of treatment. Lymphopenia $\left(<1500 / \mathrm{mm}^{3}\right.$ ) was observed in $90.9 \%$ of BETASERON patients compared to $74.3 \%$ of placebo patients and neutropenia $\left(<1400 /\left(\pi \mathrm{m}^{3}\right)\right.$ was noted in $18.0 \%$ BETASERON and $5.1 \%$ placebo patients.
Other events observed during pre-marketing evaluation Other events observed during pre-marketing evaluation
of various doses of BETASERON in 1440 patients are listed of various doses of BETASEFON in 1440 patients are listed in the paragraphs that follow. Given that most of the events were observed in open and uncontrolled studies, the
BETASERON in their causation cannot be reliably

\section{determined.}

Body as a Whole: abscess, adenoma, anaphylactoid reaction, ascites, cellulitis, hernia, hydrocephalus, hypothermia, infecton, peritonitis, photcsensitvity, sarcoma. sepsis, and shock;

Cardiovascular System: angina pectoris, arrhythmia atrial fibrillation, cardiomegaly, cardiac arrest, cereoral hemorhage, cerebral ischemia, endocarditis, heart fallure, hypotension, myocardial infarct, pericardial effusion, postural hypotension, pulmonary embolus, spider angioma, subarachnoid hemorrhage, syncope, thrombophlebitis thrombosis, varicose ven, vasospasm, venous pressur increased, ventricular extrasystoles, and ventricular fibrillation:

Digestive System: aphthous stomatitis, cardiospasm, cheil:tis, cholecystitis, cholelithiasis, duodenal ulcer, dry mouth, enteritis, esophagitis, fecal impaction, fecal incontinence, flatulence, gastritis, gastrointestinal hemorrhage, gingivitis, glossitis, hematemesis, hepatic necplasia, hepatitis, hepatomegaly, ileus, increased salivation, intestinal obstruction, melena, nausea, ora leukoplakia, oral mon liasis, pancreatitis, periodontal abscess, proctitis, rectal hemorrhage, salivary gland enlargement, stomach ulcer, and tenesmus Endocrine System: Cushing's Syndrome, diabetes insipidus, dabetes mellitus, hypothyroidlsm, and inappropriate $\mathrm{ADH}$

Hemic and Lymphatic System: chronic lymphocytic leukemia, hemoglobin less than $9.4 \mathrm{~g} / 100 \mathrm{~mL}$, petechia piatelets less than $75,000 / \mathrm{mm}^{3}$, and splenomegaly; Metabolic and Mutritional Disorders: alcoho intolerance, alkaline phosphatase greater than 5 time baseline value, BUN greater than $40 \mathrm{mg} / \mathrm{dL}$, calcium greater than $11.5 \mathrm{mg} / \mathrm{dL}$, cyanosis, edema, glucose greater than $160 \mathrm{mg} / \mathrm{dL}$, glycosuria, hypoglycemic reaction, hypoxia, ketosis, and thirst

Musculoskeletal System: arthritis, arthrosis, bursitis leg cramps, muscle atrophy, myopathy, myositis, ptosis. and tenosynovitis;

Nervous System: abnormal gait, acute brain syndrome agitation, apathy, aphasia, ataxia, brain edema, chronic brain syndrome, coma, delirium, delusions, dementia, depersonalization, diplopia, dystonia, encephalopathy, euphoria, 'acial paralysis, foot drop, hal'ucinations, hemiplegia, hypalgesia, hyperesthesia, incoordination,
intracranial hypertension, ibido decreased, manic reaction intracraniai hypertersion, libido decreased, manic reaction meningitis, neuralgia, neuropathy, neurosis, nystagmus, oculogyric crisis, ophthalmoplegia, papilledema, paralysis, paranoid reaction, psychosis, reflexes decreased, stupor,
subdural hematoma, torticoll is, tremor and urinary subdural hat

retention;

Respiratory System: apnea, asthma, atelectasis, carcinoma of the lung, hemoptysis, hiccup, hyperventilation, hypoventilation, interstitial pneumonia, lung edema, pleura effusion, pneumonia, and pneumothorax Skin and Appendages: contact dermatitis, erythem nocosum, exfol ative dermatitis, furunculosis, hirsutism, leukoderma, lichenoid dermatitis, maculopapular ras psoriasis, seborrhea, skin benign neoplassn, skin urticaria, and vesiculobullouss rash;
Special Senses: blepharitis, blindness, deatness, dry eyes, ear pain, iritis, keratoconjunctivitis, mydriasis, otitis externa, otitis media, parosmia, photophobia, retinitis taste loss, taste perversion, and visual field cefect; Urogenital System: anuria, balanitis, breast engorgement, cervicitis, epididymitis, gynecomastia, hematuria, impotence, kidney calculus, kidney failure, kidney tubular disorder, ,eukorrhea, nephritts, nocturia, oliguria, polyuria, enlarged, uterine neoplasm, and vaginal hemorrhage.

\section{DOSAGE AND ADMINISTRATION}

FOR SUBCUTANEOUS USE ONLY

BETASERON (interferon beta- 1 b) should only be prescribed by (or following consultation with) clinicians who are experienced in the diagnosis and management of Multiple Sclerosis

The recommended cose of BETASERON for both relapsing-remitting and secondary-progressive MS patients is $0.25 \mathrm{mg}(8 \mathrm{MU})$ injected subcutaneously every other (see ACTION AND CLNICAL PHARMACOLOGY, Clinical Trials In the secondary-progressive MS study, patients initiated treatment with half the dose (4 MIU s.c. every other day) for a period of 2 weeks prior to escalating to the recom-

mended dose of $8 \mathrm{MUU}$ (s.c. every other day).

Efficacy of treatment for longer than 2 years has not been substantially demonstrated in relapsing-yemitting multiple sclerosis. For secondary-progressive multiple sclerosis,

safety and efficacy data beyond 3 years are not available.

lo reconstitute lyophil zed BETASERON for injection, use a sterile syringe and needle to inject $1.2 \mathrm{~mL}$ of the diluent supplien, Socium Chlorice, 0.54\% Solution, into the BETASERON vial. Gently swirl the vial of BETASERON to dissolve the drug completely; do not shake. Inspect the reconsituted product visualy and discard the product before use if it contains particulate matter or is discolored. After reconstitution with accompanying diluent, each $\mathrm{mL}$ of solution contains $0.25 \mathrm{mg}$ ( $8 \mathrm{MIU}$ ) interferon beta-1b. $13 \mathrm{mg}$ Alloumin Human USP and $13 \mathrm{mg}$ Dextrose USP. Withdraw $1 \mathrm{~mL}$ of reconstituted solution from the vial into a sterile syringe fitted with a 27 -gauge needle and inject the solution subcutaneously. Sites for sett-injection include abdomen, buttocks and thighs. A vial is suitable for single use only; unused portions should be discarded

3 hours after reconstitution. (SEe BETASERONФ [interferon beta-1b] INFORMATION FOR THE
PATIENT section for SELF-IMJECTION PROCEDURE.)

\section{AVAILABILITY OF DOSAGE FORMS}

BETASERON (interferon beta- $1 \mathrm{~b}$ ) is presented as a $3 \mathrm{~mL}$ single-use vial of lyophilized powder containing $0.3 \mathrm{mg}$
(9.6 MUU) interferon beta-1b, $15 \mathrm{mg}$ Aiburnin Human USP. and $15 \mathrm{mg}$ Dextrose, USP. BETASERON is supplied in cartons containing 15 valis of medication and 15 vials of diluent ( $2 \mathrm{~mL}$ of Sodium Chloride $0.54 \%$ solution, per vial).
Store under refrigeration at $2^{\circ}$ to $8^{\circ} \mathrm{C}\left(36^{\circ}\right.$ to $46^{\circ} \mathrm{F}$ ).

\section{Reterences:}

1. Product Monograph of "BETASERON" interferen beta-10),

2. The IFNB Multipla Sclerosis Study Group and the Lniversily of British Columbia MSiMPI Analysis Group. Interteron beta. $1 \mathrm{~b}$ in the treatment of multiple sclerosis: Final outcome of the randomised controled

tria. Neuroiogy 1995:45:1227-1285.

Product Monograph avaliable upon request.

PAAB RED 


\section{NEURONTIN \&}

(Gabapentin) $100 \mathrm{mg} .300 \mathrm{mg} .400 \mathrm{mg}$ Capsules

Antrepileptic Agent)

INDICATIONS AND CLINICAL USE

Neurontin (gatapentin) is indicated as adjunctive therapy for the management of patients with epdiepsy who are not gatistactorily controlled by conventional fherat

\section{CONTRAINDICATIONS}

Neurontin (gabapentin) is contraindicated in patients who have demonstrated hypersensitivity to the drug of to any of the components of the formulation

\section{PRECAUTIONS}

General

tive in the treatment of absence seirutes and should therefore be used

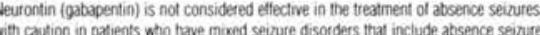

Tumorigenic Polential

Gatapentin produod an increased incibence of acinar cell adenomas and carcinomas in the pancreas of male rats, but not temale pats or in mice, in oncogenic studies wth doses of $2000 \mathrm{mg} / \mathrm{kg}$ which resulted in plasma concentrations 14 times highet than those ccourting in humans at the maximum recommended dose of 2400 mo/dyy The releans at these pan natic acinas cell tumours in male cats to humans is unknown particulaty since tumours of ductal tather than acinar ceff origin are the predominant form of tuman pancreatic cancer

Drue Discontinuation

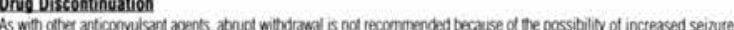
trequency when in the udgement of the clinician these is a need for dose reduction. discontinuation or substivion

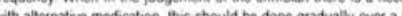
Occupational Hazards Paccuents with uncontrolled epilepsy should not drive or handle potentially dangerous machinery. During clinical trals.

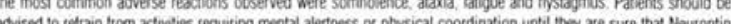
coes not attect them advesely does not aftect then adversety

Drug Interactions

Antiepileptic Agents: There is no interaction between Neurontin and pher phenobarbital. Consequently, Neurontin may bo used in combion antiepileptic drugs without co

Gatapentin steady-state pharmacokinetics are similar for heartiy subjects and patients with epilepsy receiving intiepileptic agents

Oral Contraceptives:
Coadministration of Neurontin with the oral contraceptive Norlestrin does not infuence the steady-state pharmacokinetics of norethindrone or ethingl estradiol

Antacids:

Antacids:

Coadministration of Neurontin with an aluminum and magnesium-based antacid reduces gabapentin bioavailability by up $1024 \%$. Athough the clinical significance of this dectease is not known, coadministration of similat antacids and gabapentin is not recommende-

Probenecid:

Renal excretion of gatapentin is unaleed by probenecif

Cimetidine:

A slight deccease in renal excretion of pabasentin observed when it is coadministered with cimetidine is not expected to be of clinical importance

Use in Pregnanc

No evidence of impaired fertility or harm to the fetus due to gabapentin administration was revealed in reproduction studies in mice at doses up to 62 times, and in rass and rabbits at doses up to 31 times the human dose of $2400 \mathrm{mg} / \mathrm{day}$. There are. however, no adequate and well-controlled studies in pregnant women. Becsuse animal reproduction studies are not always predictive of human response. this drug should only be used during pregnancy if the potential benetil to the mother justifies the potential risk to the letus.

Use in Lactation

It is not known if gabapentin is excreted in human milk, and the etfect on the nursing intant is unknown. Howevet. because many drugs are excreted in human milk, and because of the potential tor serious acverse readions in nursing intants from gabapentin, beess-leoding is only recominended if the potential benetit outweighs the potential risks Use in Children

Systematic studies to establish sately and etficacy in children trave not been pertormed Data in 39 patients between the ages of 12 and 18 years included in the double-blind, placebo-conttolled trials showed that gatapentin was superior to placebo in reducing seizure trequency Saldety data showed that the incidence of adverse events in this group of patients were similar to those observed in older individuals

Use in the Elderly

Use in the Elderily over the age of 65 years treated with Neurontin did not ditter trom those reponted for younges indwidials. The small number of individuals evaluated and the limited duration of exposure limits the strength of any conclusions reached about the influence of age. il any, on the kind and incidence of adverse everts associded with the use of Neurontin. As Neuroctin is eliminated ptimarily by tenal excretion, dosage adjustment may be requited in elderty patients because of declining renal function (See Dosage and Administration)

Use in Renal Impairment

Gatapertin clearance is makkedly reduced in this patient population and dosage reduction is neossary (See table 3 in Dosage and Administration:

Laboratory Tests

Clinicai trials data do not incicate thas routine monitoxing of clinical laboralory parameters is necessary for the sale use of Neutontin Neurontin may be used in combination with other commonly used antiepileptic drugs without concern lor alteration of the blood concentrations of gabagentin or other antiepileptc drugs. For urinary protein determination the sultosalicylic acid precipitation procedure is recommended. as talse positive readings were reported with the Ames N-Multistix SG* dipstick test, when gabapentin or piacebo was added to other anticonvulsant drugs

\section{Adverse Events in Controlled Trials}

$$
\text { ADVERSE REACTIONS }
$$

the most commonly observed advetse events associated with the use of Neurontin in combination with other antiepleptic druos, not seen at an equvalent frequency in placebo-treated patients, were somnolenos, dizziness, atax.

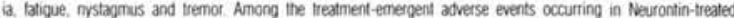
patients, somnolence and ataxia appeared to ection a positve dose-response relationshic. Patients treated with 1800 mogitay (n-54 from one controlled study) experiencad approvimately a two-told increase. as compared to patients on lower doses of 600 to $1200 \mathrm{mg} / \mathrm{dar}$ (n-489, from several controlled studies). in the incidence of nystagnus $(204 \%$ ).

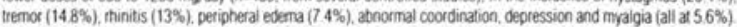
Adverse events were usually mild to moderate in intensity with a median time to resolution of 2 wosks. Since Neurontin was administered most often in combiration with other antiepleptic agents, it was not possible to determine which agent(s) was assaciated with adverse events. Data from long-term, open, uncontrolled studies shows that Neurontin treatment does not tesult in any new or unusual adverse events

Withdrawal From Treatment Due to Adverse Events

Approximately $64 \%$ of the 543 patients who received Neutontin in the placebo-controlled studies withdiew due tie adverse events in comparison, approximately $45 \%$ of the 378 placebo-controlled particinants withdrew due to advers: events during these studies. The adverse events most commonly associated with withdiawal were somnolence (1.2\%) alaxia $(0.8 \%)$. taigue, nausea and/or vomiting and diziness (all at $0.6 \%$ )

Other Adverse Events Observed in All Clinical Trials

Adverse events that occured in at least $1 \%$ of the 2074 individuals who participated in all cli nical trials are described aren isted the previous section

Body As a Whole

Cardiovascular Systern

Digestive Systern

resthena, malaise, facial eders

Mentatologicl yritghatic System

Musculoskeletal System

Nervous System

typentensicion

ancrexia Hlatulance gingivits

purpura. most otten descibed as bruises resulting tron

physical trauma

artralag

Respirztory System

Special Senses

vertigo, hyperkinesia, parasthesia, anxiety, hostility

decreased or absent reflexes

pneumonia

\section{SYMPTOMS AND TREATMENT OF OVERDOSAGE}

Acire, itie-threatening toxicity has not been observed with Neurontin (gabapentin) overdoses of up to 49 grams ingested at one time. in these cases, double vision, slutred speech, drowsiness, lethargy and diarthea were observed All patients recovered with supportive care.

Gabapentin can be removed by hemodialysis. Ailthough hemodialysis has not been performed in the few overdose cases reported, it may be indicated by the patient's clinical state or in patients with significant renal impaiment

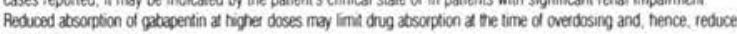
toxicity from overdoses

An oral lethal dose of gabapentin was not identified in mice and rats given doses as high as $8000 \mathrm{mg} / \mathrm{kg}$ Signs of acute toxicty in animals included ataxia laboured breathing ptosis, hypoactivily, of excitation

\section{Adults}

he usual effective maintenance dose is 900 to $1200 \mathrm{mg} / \mathrm{day}$ Treatment should be initiated with 300 to $400 \mathrm{mg} / \mathrm{dag}$ Titration to an effective dose. in increments of $300 \mathrm{mg}$ or $400 \mathrm{mg} / \mathrm{day}$. can progress rapidly and can be accomplished over three days (see Table 1). Neutontin is given orally with or without tood

\begin{tabular}{|c|c|c|c|}
\hline DOSE & Day 1 & Day 2 & Day 3 \\
\hline $\begin{array}{l}900 \mathrm{mg} / \mathrm{day} \\
1200 \mathrm{mp} / \mathrm{day}\end{array}$ & $\begin{array}{l}300 \mathrm{mg} 00 \\
400 \mathrm{mg} O D\end{array}$ & $\begin{array}{l}300 \mathrm{mg} \text { BID } \\
400 \mathrm{mg} \text { BID }\end{array}$ & $\begin{array}{l}300 \mathrm{mg} \text { TiD } \\
400 \mathrm{mg} \text { TID }\end{array}$ \\
\hline
\end{tabular}

Data from clinical trials suggest that doses higher than 1200 modday may have increased efticacy in some patients however, higher doses may also increase the incidence or adverse events (See Adverse Readions)

Daily maintenance doses should be given in three equally divided doses (See lable 2). and the maximum time between doses in a three times daily schedule should not exceed 12 hours it is not necessary to monitor gabagentin plassia concentrations in order lo optimize Neurontin therasy. Further, as there are no drug interactions with commonly used antiepileptic drugs. Neurontin may be used in combination with these drugs without concern for alleration of plasma concentrations of eifher gatapentin or other antiepileotic drugs

Table 2. Maintenance Dosage Schedule

\begin{tabular}{cl}
\hline Total Daily Dose (mg/day) & Schedule \\
\hline 900 & $300 \mathrm{mg}$ TiD \\
1200 & $400 \mathrm{mg} \mathrm{TID}$ \\
1800 & $2 \times 300 \mathrm{mg}$ Ti \\
2400 & $2 \times 400 \mathrm{mg} \mathrm{Tl}$ \\
\hline
\end{tabular}

Dosage adjustment in elderly parients due to declining renal function and in parients with renal moarment of undergoing hemodialysis is recommended as follows

Table 3. Maintenance Dosage of Neurontin in Adults With Reduced Renal Function

\begin{tabular}{|c|c|c|}
\hline Renal Function & Total Daily Dose & Dose Regimen \\
\hline $\begin{array}{l}\text { Creatinine Clearance } \\
(\mathrm{mL} / \mathrm{min})\end{array}$ & $(\mathrm{mg} / \mathrm{day})$ & (mg) \\
\hline$\frac{160}{60}$ & 1200 & 400 three 1 mes a 0ay \\
\hline $30-60$ & 600 & 300 Twioe a day \\
\hline $15-30$ & 300 & 300 Once a Day \\
\hline$<15$ & 150 & 300 Onoe Daily Every Oter Day \\
\hline Hemodiaysis & - & $200-300$ \\
\hline
\end{tabular}

Loading dose of 300 to $400 \mathrm{mg}$

Te $300 \mathrm{mg}$ Neurontin following each 4 hours of hemodialysis

Children Over 12 Years of Age

The dosage used in a limited number of patients in this age group was $900-1200$ mo/day. Doses above 1200 modday have not been investigated

AVAILABILTTY OF DOSAGE FORMS

(genapentin) apsules are supolied as follows

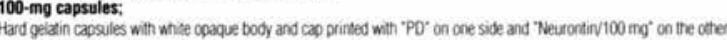
thothes of 100 capsules

300-mp capsules:

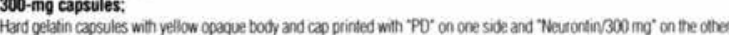

Hard gelatin capsules

400-mg capsules:

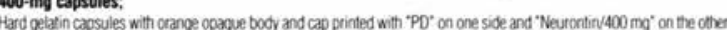
bolltes of 100 capsules

Full Prescribing Information Available On Reques

Parke-Davis Division

Warner-Lambert Canada inc

Scarborough, Ontario MiL 2N

Reterences

1. The Neurontin STEPS Study Team Study of Neurontin. Titraion to Elled. Profile of Sately in Program and

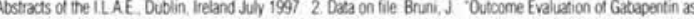
Adod-on Therapy for Patial Seizures". Canadian Jounal of Neurological Science 1998 vol $25134-1403$ Neurontin Product Monograph

(10) PARKE-DAVS

- TM Warner-Lambert Company Warner-Lambert Canada inc, lic use Scarborough, ON MIL 2N3 


\section{Topamax}

topiramate

25, 100 and $200 \mathrm{mg}$ Tablets and

15 and $25 \mathrm{mg}$ Sprinkle Capsules

Antiepileptic

\section{INDICATIONS AND CLINICAL USE}

TOPAMAX (topiramate) is indicated as odjunctive theropy for the management of patients (adults and children two years and older) with epilepsy who are not satistoctorily contolled with conventional theropy. There is limited infornction on the use of topitomate in monothenpy at this time. CONTRAINDICATIONS

TOPAMaX (topiramote) is controindicoted in potients with a history of hypersensitivity to any components of this product.

WARNINGS

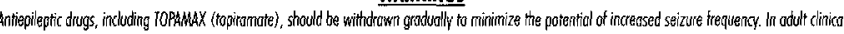
triols, dosaces were deccleosed by $100 \mathrm{mg} /$ day at weekly intervals.

Centrol Mervous System Etfests

Adverse event's most often associnted with the use of TOPMAXX were centrol nervous system-related, In adults, the most signiticont of these con be dassified

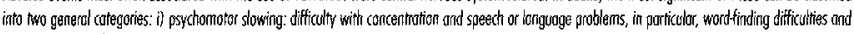
ii) somnolence of fatigue.

Additional nonspectific CNS effects occassionally observed with topiramate os odd on therapy include dizziness or imbolance, coniusion, memony problems, and exocerbation of mood disturbonces (e.g. irititability ond depression).

These events were generally mild to moderate, and generally occurred early in therapy. While the incidence of psychomotor stowing does not appens to be

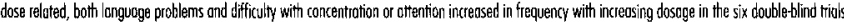
suggesting that these events are dose related. (See ADVERSE REACTIONS )

\section{PRECAUTIONS}

\section{Effects Relosed to Corbonic Anhydrase Inhibition}

Kidney Stones A totol of 32/1,715 (1.5\%) of potients exposed to TOPAMAX (topiramoted during its development leported the occurrence of kidney stones

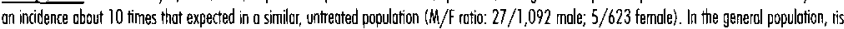
tactors for kidnay stone formation include gender (mole), ages between 20.50 yeors, prior stone formution, family history of nephroittiosiss, ond

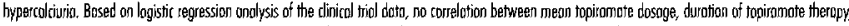
at age and the occurrence of kidney stones was established; of the risk foctors evoluated, only gender (male) showed o correlction with the occurrence of kidney stones. In the pediatic patients studied, there were no kidney stones observec.

Carbonic onhydrase inhibiters, e.g. ocetnzolornide, promote stone formation by reducing uinary citrote exccetion and by increasing urinary ph. Concomitont

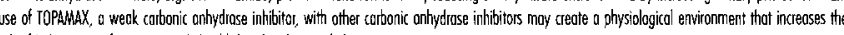
visk of kidney stone formation, and should therefore be owided.

Patients, especiolly those with o predisposition to nephroilthiosis, may have on incleased risk of renal stone formotion. Incceassed fluid intoke increases the urinary outpui, lowering the concentration of substances involved in stone formation. Therefore, adequate hycration is recommended to reduce this risk. None of the risk factors for nephrolitiosis con reliably predict stone formotion diving TOPAMAX treutment.

Paresthesin Paresthesia, on effect associcted with the use at other corbonic antydrase inhibitors, appears to be a common effect of TOPAMAX theropy. These events were ussully intermittent ond mild, and not necessorily related to the dosage of topiranote

Nutriliongl Supplementation

A diatrony suoplement or increased food intake may be considered if the patient is losing weight whille on this medication

\section{Weinht Loss in Pediotrics}

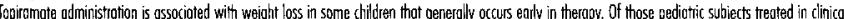
trials for at leost o yeer who experienced weight loss, $96 \%$ showed a resumption of weight gain within the period tested. In 2-4 year olds, the mecn thange in weight from baseline of 12 months ( $n=25)$ wos $+0.7 \mathrm{~kg}$ (range -1.1 to 3.2$)$; at 24 months $(n=14)$, the meon change was +2.2 (range -1.1 to 6.1$)$ ) In 5-10 year olds, the mean chonge in weight from boseline of 12 month (n $=88$ ) was $+0.7 \mathrm{~kg}$ (lange -6.7 to 11.8); of 24 months (n=67), the mean chonge wos +3.3 (ronge -8.6 to 20.0). Weight decreases, usually ossodinted with onoroxio or appetite changes, were repartad as adverse events for $9 \%$ of topiromctetereated padiatric patients. The lang term effects of redved weight goin in pediatic potients is not known.

\section{Adjustment of Dose in Renal Foilure}

The major route of elimination of unchenged topiromate and its mertbolites is vio the kidney. Renal elimination is dependent on renal function and is

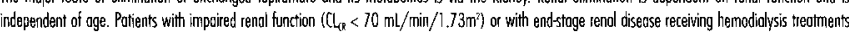
moy toke 10 to 15 days to rench steady-sote plasma concentrations os compored to 4 to 8 days in patients with narmol rencl function. As with all patients, the fitrefion schedule shiould be guided by dinical outcone (i.e. seizure control, avoidanke of side effects) vith the knowledge that pedients with known renol

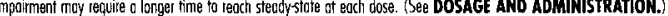

Decreased Hepatic Function

In henotically impoired patients, topiramote should be adrinisistered with coution os the clearnonce of tooiramcte was decreased compored with noumal subjects.

\section{Information for Patients}

Adeaunte Hydrotion Potients, especiolly those with predispasing factors, should be instructed to mointoin en adequote fleid intoke in order to minimize the risk of rendal stone formution.

\section{Effects on Ability to Drive and Use Machines}

Potients should be werned about the potentiol for somnolence, dzziness, contusion and difficulty concentrating ond advised not to drive or ooerote machinery until they hove gained sufficient experience on topiromate to gouge whether it adversely offlects their mental ond/or motor performance.

\section{Drun Interoctions}

Antiapileptic Drug

Effects of TOPAMAX on Other Antiepileptic Divas Potennial interoctions between topiramate ond stondard kEDS were meassied in controlled clinica

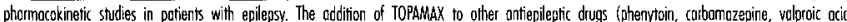

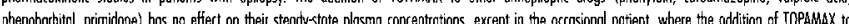
phenobartitital, primidone) hos no effect on their steodystate plosma conting

phenytoin may result in an increase of plasmo concentrations of phenytoin.

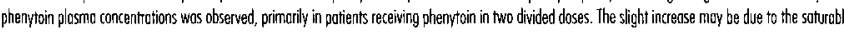
noture of phenytoin phomacokinetics and inhibition of phenytoin metetobolism iCYP2 $\mathrm{C}_{\text {nup }}$.

The addition of TOPAMAX thercoy to phenytoin should be guided by clinikal outcome. In general, os evidenced in clinical trials, patients do not require dese

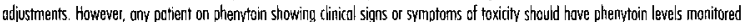

Effects of Other Antiepileatic Diugs on TOPAMAX Phenytoin ond carbomazepine deciease the plasma concentrotion of TOPAMAX. The andition or withdrowol of phenytoin and/ or carbomozepine during adjunctive thercoy with TOPAMAX may requile adjustment of the dose of TDPAMAX. This should be done by fitrating to dinicol effect. The acdition of withdrowol of valproic ocid does not produce dinically significant changes in plosma concentrotions a

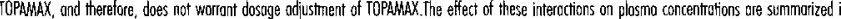
Table :

Table 1

Brug Interactions with TOPAMAX Theropy

\begin{tabular}{|c|c|c|}
\hline $\begin{array}{l}\text { AED } \\
\text { Coodministeresed }\end{array}$ & $\begin{array}{c}\text { AED } \\
\text { Concentration }\end{array}$ & $\begin{array}{l}\text { TOPAMAXX } \\
\text { Concentrotion }\end{array}$ \\
\hline Phenytoin & $\leftrightarrow^{\star \star}$ & $\downarrow 59 \%$ \\
\hline Carbomarepine (CBC) & $\leftrightarrow$ & $\downarrow 40^{\%} \%$ \\
\hline (B) epoxide ${ }^{*}$ & $\leftrightarrow$ & NS \\
\hline Valpoic acid & $\downarrow_{i 1} \%$ & $\$ 14 \%$ \\
\hline Phenobatibitol & $\leftrightarrow$ & NS \\
\hline Piimidone & $\leftrightarrow$ & NS \\
\hline
\end{tabular}

Is not administered but is an active metabolite of carbomazepine

$\leftrightarrow \quad$ No effect on plasma concentrotion $(<15 \%$ change)

** Plosmo concentrations increased $25 \%$ in some patients, generdly those on o bi.d. dosing regimen of phenytoin

Plosma concentrations decrease in individual patients

NS Not studied

AED Antiepileptic drug
Oher Drug Interactions

igoxin: In a single-dose study, serum dizoxin AUC decreased 12\% due to concomitcnt TOPAMAX administrotion. Multiple-dose strdies hove not been performed. When TOPAMAX is odded or withdrown in potients on digoxin therapy, caseful attention should be given to the routine monitoing of serum digoxin. CWS Depressont5: Cenconitant odministration of TOPAHAX topirmate and alcohol or other CNS depressont drugs hos not been evaluated in clinical studies.

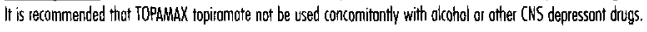

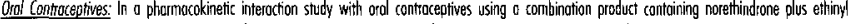
estradiol, TOPAMAX topizarnate did net significantly affect the ored dearonee of noiethindrone. The serum levels of the esstrogenic component decteossed by

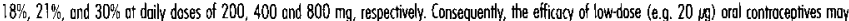
be reduced in this situation. Patients toking arol contraceptives should receive a preparation contraining not less thon $50 \mathrm{~kg}$ of esstrogenn. Potients toking orol controceptives stould be osked to report any chonge in their bieeding potterns.

Others: Conconitont use of TOPAMAX topiromote, o weok carbonic anhydrase inhibitor, with other corbonic anhydrose inhibitors, e.g. ocetazolomide, may create a physiological environment that incieases the isk of renol stone forrination, ond should therefotere be cvoided if possible.

Laboratory Tests

There ore no known initeroctions of TOPAMAX topiramate with commonly used laborotory tests.

Use in Preguancy and Lactation

Like other antieapleptic drugs, tooiramate was terotogenic in mice, rots, and robbits. In rots, ropiromote closses the plocental barriel.

There are no studies using IOPAMAX topironncte in pregnant worn:en, However, IOPAMAX thercpy should be used during pregnoncy only if the potentiol benefit outweighs the potenntial risk to the fatus.

Topiramote is excreted in the milk of lectoting rats. It is not known if topiramote is excreted in human milk. Since mony drugs are excreted in human milk, and beccuse the potentiol far serious adverse ranctions in nursing intants to TOPAMAX topiramote exists, the prescriber should decide whether to discontinue nursing or discontinue the drug, toking into occount the risk / benefit ratio of the importance of the drug to the motther ond the risks to the infont.

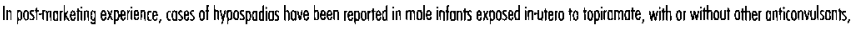
however, o cousul relationship with topiramote hos not been estoblished.

The effect of TOPAMXX rapiramate on labour and delivery in humons is unk rown.

\section{Pediatric Use}

Sofety ond effectiveness in children under 2 years of oge have not been estoblished.

Geriatric Use

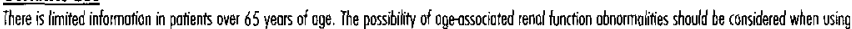
TOPAMAX topiramate.

\section{Race and Gender Effects}

Allhough diect comparison studies of pharmarokinetics howe nat been conducted, ondulysis of plesma concentrotion dato from dinical efficacy trials have

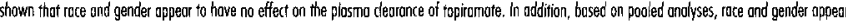
to have no effect on the efficocy of topiromote.

Adults

\section{ADVERSE REACTIONS}

The most commonlly observed adverse events associoted with the adiunctive use of TOPAMAX topiramote of dossags of 200 to $400 \mathrm{mg} /$ day in controlled trials in aduls that were seen at greoter frequency in topiramote-treated patients and did not oppear to be dose elated wittin this dosoge ronge were somnolence, dizziness, otoxia, speech disorders ond related speech problems, psychomotor slowing, nystogmus, and poresthesia (see Toble 2).

The most common dose-elated adverse events of dosages of $200 \mathrm{t} 01,000 \mathrm{mg} / \mathrm{day}$ were: nevvousness, difficulty with concentration or attention, contusion depressior, cnorexio, languoge problems, and mood problems (see Table 3\}.

Toble 2

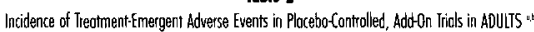

(Events that occurred in $\geq 2 \%$ of topiramote-treated potients and occurred more frequently in topiramate-trected than plocebo-treated patients)

\begin{tabular}{|c|c|c|c|}
\hline \multirow[b]{2}{*}{$\begin{array}{l}\text { Body System/ } \\
\text { Adverse Event }\end{array}$} & \multicolumn{3}{|c|}{ TOPAMAX Dosoge (mg/doy) } \\
\hline & $\begin{array}{l}\text { Plocebo } \\
(n=216)\end{array}$ & $\begin{array}{l}200-400 \\
(n=113)\end{array}$ & $\begin{array}{l}600 \cdot 1,000 \\
(n=414)\end{array}$ \\
\hline \multicolumn{4}{|l|}{ Body as a Whole } \\
\hline Asthenia & 1.4 & 8.0 & 3.1 \\
\hline Back Pain & 4.2 & 6.2 & 2.9 \\
\hline Chest Poiri & 2.8 & 4.4 & 24 \\
\hline Influenzo-like Symptoms & 3.2 & 3.5 & 3.6 \\
\hline Leg Pain & 2.3 & 3.5 & 3.6 \\
\hline Hot Fushes & 1.9 & 2.7 & 0.7 \\
\hline \multicolumn{4}{|l|}{ Nervous System } \\
\hline Dizziness & 15.3 & 28.3 & 32.1 \\
\hline Ataxio & 6.9 & 21.2 & 14.5 \\
\hline Speech Disorders/Reloted Speesch Problems & 2.3 & 16.8 & 11.4 \\
\hline Nystragmus & 9.3 & 15.0 & 11.1 \\
\hline Poresthesio & 4.6 & 150 & 19.1 \\
\hline Tremor & 6.0 & 10.6 & 8.9 \\
\hline Longuoge Problems & 0.5 & 6.2 & 10.4 \\
\hline Coordinotion Abnornal & 1.9 & 5.3 & 3.6 \\
\hline Hyooesshesio & 0.9 & 2.7 & 1.2 \\
\hline Abnounol Gait & 1.4 & 1.8 & 2.2 \\
\hline \multicolumn{4}{|l|}{ Gastrointestinol System } \\
\hline Nausea & 7.4 & 11.5 & 12.1 \\
\hline Dispepsia & 6.5 & 8.0 & 6.3 \\
\hline Alodominal Pain & 3.7 & 5.3 & 7.0 \\
\hline Constipotion & 2.3 & 5.3 & 3.4 \\
\hline Dry Mouth & 0.9 & 2.7 & 3.9 \\
\hline \multicolumn{4}{|l|}{ Metubolic and Mutritionol } \\
\hline Weightt Decreasse & 2.8 & 3.1 & 12.8 \\
\hline \multicolumn{4}{|l|}{ Neuropsychiotric } \\
\hline Somnolence & 9.7 & 30.1 & 27.8 \\
\hline Psychomotor Slowing & 2.3 & 16.8 & 20.8 \\
\hline Nervousness & 7.4 & 15.9 & 19.3 \\
\hline Difficulty with Memory & 3.2 & 12.4 & 14.5 \\
\hline Contusion & 4.2 & 9.7 & 13.8 \\
\hline Depression & 5.6 & 8.0 & 13.0 \\
\hline Difficully with Concentration/Attention & 1.4 & 8.0 & 14.5 \\
\hline Anotexio & 3.7 & 5.3 & 12.3 \\
\hline Agitotion & 1.4 & 4.4 & 3.4 \\
\hline Mood Probilems & 1.9 & 3.5 & 9.2 \\
\hline Aggressive Reaction & 0.5 & 2.7 & 2.9 \\
\hline Apathy & 0 & 1.8 & 3.1 \\
\hline Depersonolization & 0.9 & 1.8 & 2.2 \\
\hline Emotionol Lobility & 0.9 & 1.8 & 2.7 \\
\hline Reproductive, Female & $(n=59)$ & $(n=24)$ & $(n=128)$ \\
\hline Breost Pain, Femole & 1.7 & 8.3 & 0 \\
\hline Dysmeriontiba & 6.8 & 8.3 & 3.1 \\
\hline Menstruol Disorder & 0 & 4.2 & 0.8 \\
\hline Reproductive, Male & $(n=157)$ & $(n=89)$ & $(n=286)$ \\
\hline Prostatic Disorder & 0.6 & 2.2 & 0 \\
\hline \multicolumn{4}{|l|}{ Respiratory System } \\
\hline Phraryngitis & 2.3 & 7.1 & 3.1 \\
\hline Rhinitis & 6.9 & 7.1 & 6.3 \\
\hline Sinusiits & 4.2 & 4.4 & 5.6 \\
\hline Dysprea & 0.9 & 1.8 & 2.4 \\
\hline \multicolumn{4}{|l|}{ Skin and Appendages } \\
\hline Prunitus & 1.4 & 1.8 & 3.1 \\
\hline \multicolumn{4}{|l|}{ Vision } \\
\hline Ciplopin & 5.6 & 14.2 & 10.4 \\
\hline Wision Abnormal & 2.8 & 14,2 & 10.7 \\
\hline \multicolumn{4}{|l|}{ White Cell and RES } \\
\hline Leukopenic & 0.5 & 2.7 & 1.2 \\
\hline
\end{tabular}

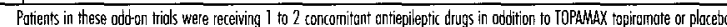

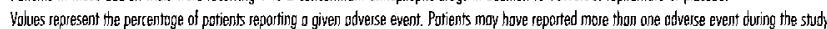
and con be included in more than one adverse event cotegory. 
Table 3

Dose-Related Adverse Events From Piocebo-Controlled, Add-On Triois in ADutTS

\begin{tabular}{|c|c|c|c|c|}
\hline \multirow[b]{2}{*}{ Adverse Event } & \multirow[b]{2}{*}{$\begin{array}{l}\text { Plucebo } \\
(n=216)\end{array}$} & \multirow[b]{2}{*}{$\begin{array}{c}200 \\
(n=45)\end{array}$} & \multicolumn{2}{|c|}{ TOPAMAX Dosoge (mg/day) } \\
\hline & & & $\begin{array}{c}400 \\
(n=68)\end{array}$ & $\begin{array}{c}600-1,000 \\
\langle(n=414)\end{array}$ \\
\hline Fatigue & 13.4 & 11.1 & 11.8 & 29.7 \\
\hline Nervousness & 7.4 & 13.3 & 17.6 & 19.3 \\
\hline $\begin{array}{l}\text { Diffically with } \\
\text { Concentrntion/Attention }\end{array}$ & 1.4 & 6.7 & 8.8 & 145 \\
\hline Confusion & 4.2 & 8.9 & 10.3 & 13.8 \\
\hline Depression & 5.6 & 8.9 & 7.4 & 13.0 \\
\hline Anorexic & 3.7 & 4.4 & 5.9 & 12.3 \\
\hline Longuoge probiems & 0.5 & 2.2 & 8.8 & 10.1 \\
\hline Anxiety & 6.0 & 2.2 & 2.9 & 10.4 \\
\hline Mood problems & 1.9 & 0.0 & 5.9 & 9.2 \\
\hline
\end{tabular}

In six doubleblind dinical triols, $10.6 \%$ of subjects (n=113) assigned to a topiramate dosoge of 200 to $400 \mathrm{mg} /$ day in addition to their standard AED theripy discortinued due to odverse events, compored to $5.8 \%$ of subeets $(n=69)$ receiving placebo. The percentrage of subiects discontinuing due to adverse

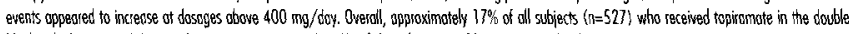
blind trials discontinued due to odverse events, compared to $4 \%$ of the subjects in=216) receiving plocebo.

\section{Pediatries}

Adverse events associoted witt: the use of topiremate of dosages of $5109 \mathrm{mg} / \mathrm{kg} / \mathrm{day}$ in worldwide pediatic clinical trials that were seen ot grenter

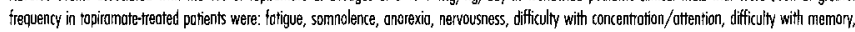
coggressive renction, ond weight decrease.

Toble 4 lists readmenternergent adverse events that occurred in at least $2 \%$ of children treated with 5 to $9 \mathrm{mg} / \mathrm{kg} /$ doy topiramate in controlled trials that were numerically more common than in potients treated with plocebo.

\section{Toble 4}

Incidence (\%) of Treatment Emergent Adverse Events in Worldwide Pedianic Clinical Trials Experience (2.16 years of Ages) (Events that Occurred in $22 \%$ of Topiramate-Freated Patients and Decurred More Frequently in Topiramote-Freated Than Placebo-Treated Patients)

\begin{tabular}{|c|c|c|}
\hline $\begin{array}{l}\text { Body System/ } \\
\text { Adverse Event }\end{array}$ & $\begin{array}{l}\text { Placebo } \\
(N=101)\end{array}$ & $\begin{array}{l}\text { Topiramute } \\
(\mathrm{N}=98)\end{array}$ \\
\hline \multicolumn{3}{|l|}{ Body as o Whole - General Disorders } \\
\hline Fotigue & 5 & 16.3 \\
\hline Iniviy & 12.9 & 14.3 \\
\hline Allergic Reaction & 1 & 2 \\
\hline \multicolumn{3}{|c|}{ Central \& Peripheral Morvous System Disorders } \\
\hline Gait Abnomol & 5 & 8.2 \\
\hline Atcxio & 2 & 6.1 \\
\hline Hyperkinessio & 4 & 5.1 \\
\hline Dizziness & 2 & 4.1 \\
\hline Speech Disorders/Related Speech Problems & 2 & 4.1 \\
\hline Convulsions Aggrovoted & 3 & 3.1 \\
\hline Hyporeflexio & 0 & 2 \\
\hline \multicolumn{3}{|l|}{ Gastrointestinal Sysiem Disorders } \\
\hline Housen & 5 & 6.1 \\
\hline Saliva Inciensed & 4 & 6.1 \\
\hline Constipation & 4 & 5.1 \\
\hline Gustroenterits & 2 & 3.1 \\
\hline \multicolumn{3}{|l|}{ Melobolik and Nutritional Disorders } \\
\hline Weight Decresse & 1 & 9.2 \\
\hline Thist & 1 & 2 \\
\hline \multicolumn{3}{|l|}{ Platelet, \&leading, \& Clotting Disorders } \\
\hline Purpure & 4 & 8.2 \\
\hline Epistoxis & 1 & 4.1 \\
\hline \multicolumn{3}{|l|}{ Nervous Oisorders } \\
\hline Somnolence & 15.8 & 25.5 \\
\hline Anorexio & 14.9 & 24.5 \\
\hline Nervousness & 6.9 & 14.3 \\
\hline Personolity Disorder (Behavior Problems) & 8.9 & 11.2 \\
\hline Difficulty with Concentration/Attention & 2 & 10.2 \\
\hline Aggressive Recction & 4 & 9.2 \\
\hline Insomnio & 6.9 & 8.2 \\
\hline Mood Problems & 6.9 & 7.1 \\
\hline Difficully with Memory NOS: & 0 & 5.1 \\
\hline Enotional Lablity & 5 & 5.1 \\
\hline Confusion & 3 & 4.1 \\
\hline Psychomotor Slowing & 2 & 3.1 \\
\hline \multicolumn{3}{|l|}{ Reproductive Disorders, female } \\
\hline Leukorheo & 0.0 & 2.3 \\
\hline \multicolumn{3}{|l|}{ Resistance Mechanism Disorders } \\
\hline Infection Viral & 3.0 & 7.1 \\
\hline Infection & 3.0 & 3.1 \\
\hline \multicolumn{3}{|l|}{ Respiratory System Disorders } \\
\hline Upper Respiratory Tract Infection & 36.6 & 36.7 \\
\hline Pneurrionia & 1.0 & 5.1 \\
\hline \multicolumn{3}{|l|}{ Skin and Appendages Disorders } \\
\hline Skin Disorder & 2.0 & 3.1 \\
\hline Alppeciı & 1.0 & 20 \\
\hline Derrnutitis & 0.0 & 2.0 \\
\hline Hypertrichosis & 1.0 & 2.0 \\
\hline Rash Erythemotous & 0.0 & 2.0 \\
\hline \multicolumn{3}{|l|}{ Urinary Systam Disorders } \\
\hline Uviniory Incontinence & 2.0 & 4.1 \\
\hline \multicolumn{3}{|l|}{ Vision Disorders } \\
\hline Eye Abnormality & 1.0 & 2.0 \\
\hline Vision Abnormol & 1.0 & 2.0 \\
\hline \multicolumn{3}{|l|}{ While Cell and RES Disordors } \\
\hline Leukopenic & 0.0 & 2.0 \\
\hline
\end{tabular}

Patients in these odd-en tricls were receiving 1 io 2 concomitont ontiepileptic drugs in addition to TOPAMAX tepiromate or plocebo.

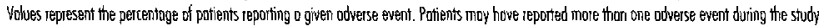
and can be included in more than one adverse event category.

Not Otherwise Specified

None of the pediotric patients who received topiramare adjunctive therapy at 5 to $9 \mathrm{mg} / \mathrm{kg} / \mathrm{dcy}$ in controlled clinical trials discontinued dus to odverse events. In open extensions of the controlled dirical trials, approxinately $9 \%$ of the 303 peciattic potients who received topiranate at dosages us to

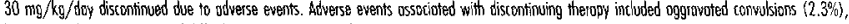
longyage problems (1.3\%), and diffially with concentrotion/ottention (1.3\%)

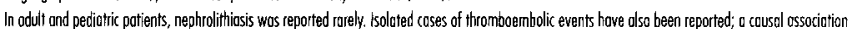
with the drug hics not been established.

When the safery expesience of patients receiving TOPAMAX ropiromote as adiunctive theropy in both double-blind and open-label tricls (1,446 codults

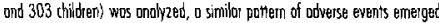

Post-Marketing Adverse Reactions

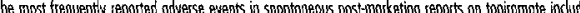

Psychioutrice somnolence or sedation, hallucination(s), depression, anorexic, oggressive reoction, psychosis, thinking obnormol, porancid reoction, insomnia, emotional iability, suicide ottempt, delusion

Central ond Peripheral Mervaus System: confusion, convulsions oggravated, poressthesio, agitotion, speech disorder, atoxia, dizziness,

convulsions, amnesia, headoche, hyperkinesia

Metabolis and Nutritional: weight decceose

Autonomic Nervous System: vomiting

Vision: vision abnomol

Gostrointestinal: nousea, dierritea, abdominal poin, constipation

Body as a Whole - General Disorders: fatigue

Urinery System: renal calculus

Skin ond Appendages: rosh

\section{SYMPTOMS AND TREATMENT OF OVERDOSAG}

In acute TCPAMAX topiramate overdose, it tha ingestion is recent, the stomach should be empried immediotely by lowage or by induction of amesis. Activoted charcoul has not been shown to adsorb topiromate in vitre. Thereffore, its use in overdosage is not recommended. Treotment should be appropiotely surportive.

Hemodialysis is an effective means of removing topiramate from the body. However, in the few cases of acute overdosoge reported, inducting doses of over $20 \mathrm{~g}$ in one individual, hemodidilysis has not been necessory.

\section{DOSAGE AND ADMINISTRATION}

General TOPAMAX Ioblets or Sprinkla Copsules con be token without regord to mieals. Toblets should not be broken. TOPAwAX Sprinkla Capsules moy ba

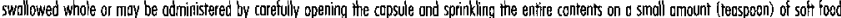
This drug/food mixture should be swallowed immediately ond not chewed. It should not be stored for future use. The sprinkle formulation is provided for those patients who connot swallow tablets, e.g. pediotic and the eiderly

Adults (Aqe 17 veors and older) It is recommended that TOPAMAXX topiomate as odjunctive theropy be initioted ot $50 \mathrm{mo} /$ day, followed by titration as needed and toleroted to an effective dose. At weekly intervals, the dose may be increosed by $50 \mathrm{mg} /$ doy ond raken in wo divided dases. $50 \mathrm{me}$ potients

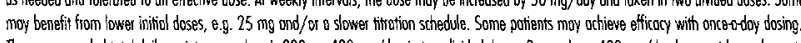
The recommended total daly maintenance dose is $200 \mathrm{mg}-400 \mathrm{mg} / \mathrm{day}$ in two divided doses. Doses above $400 \mathrm{mg} / \mathrm{day}$ have not been shown to improver responses and have been associated with o grecter incidence of adverse events. The meximum recommended dose is $800 \mathrm{mg} / \mathrm{day}$. Doily doses above 1,600 ing have not been studied.

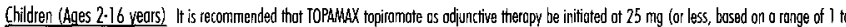

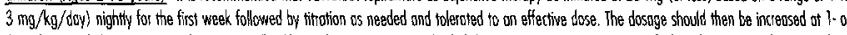
2-week intervals by increments of 1 to $3 \mathrm{mg} / \mathrm{kg} /$ day (odministered in two divided dosesi. Some patients mroy benefit from lower initial doses ond $/ \mathrm{or}$ slower fitation schedule.

The recommended total daily maintenance dase is approximately 5 to $9 \mathrm{mg} / \mathrm{kg} /$ day in wo divided doses. Daly doses up to $30 \mathrm{mg} / \mathrm{kg} /$ doy have been studied and were generally well tolemter.

Geriatrics

See PRECAUTIONS section

Patients with Renol Impairment

In renaly imparied subjects (creactinine dearcance less than $70 \mathrm{~mL} / \mathrm{min} / 1.73 \mathrm{~m}^{2}$ ), one-half of the usual odul dose is recommended. Such potients will require a longer time to reach steadystate of each dose.

\section{Patients Undergoing Hemedialysis}

Topiramote is cleared by hemodichysis at a rote that is 4 to 6 times greater thon a normol individual. Accordingly a prolonged period of dialysis nay couse topiromate concentration to fall below that requied to mointain on ontiseizure effect. To avoid repid drops in ropiramote plasmo concentrotion during hemodialysis a supplementel dose of topircmate may be required. The cctual ad ussment should toke into account 1) the durotion of cialysis, 2) tha clearance rate of the dialysis system being used, and 3) the effective renol deorence of topiranticte in the patient being dialyzed.

Patients with Hepatic Disease

In hepatically impaired potients, topiromate plasmo concentrations ore increased approximately 30\%. This moderate increase is not considered to wartant adiustrment of the topiramote dosing regimen Initite topirsmate theropy with the some dose ond raginen os for patients with normol hepatic function. The dose fitrution in these patients should be guided by cinicad outcome, i.e. seizure control, and ovoidance of adverse effects. Such patients will require o longer rime to reach steadystote ot each dose.

\section{AVAILABILITY OF DOSAGE FORMS}

TOPAMAX topiramote is available os embossed toblets in the following strengths os described below:

$25 \mathrm{mg}$ : white, round, coated toblets containing $25 \mathrm{mg}$ topirirmote.

100 mg: yellow, round, cooted tablets containing $100 \mathrm{mg}$ topiramate.

$200 \mathrm{mg}$ : saiman-coloured, round, cooted toblets containing $200 \mathrm{mg}$ topiromate.

TOPAinAX topiramate Sprinkle Copsules contain small white to off-white spheres. The gelatin cansules are white and dlear. They are morked as follows:

$15 \mathrm{mg}:$ "TिP" ond " $15 \mathrm{mg}$ " on the sice.

$25 \mathrm{mg}$ "TOP" and " $25 \mathrm{mg}$ " on the side

Supplied: Bottles of 60 toblets with desiccont.

Bottles of 60 capsules withour desictant.

TOPAMAX is o Schedule F Drug.

Product Monograph availcbie to physiciens and phormocists upon reques

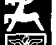

JANSSEN-ORTHO Inc.

Dole of lssunnce: April 2000

TXPI001013A

C 2000 JANSSEN-ORTHO IRC

* all trodemakrk rights used under license

Member

R\&D

$\widehat{P A B}^{*}$ 

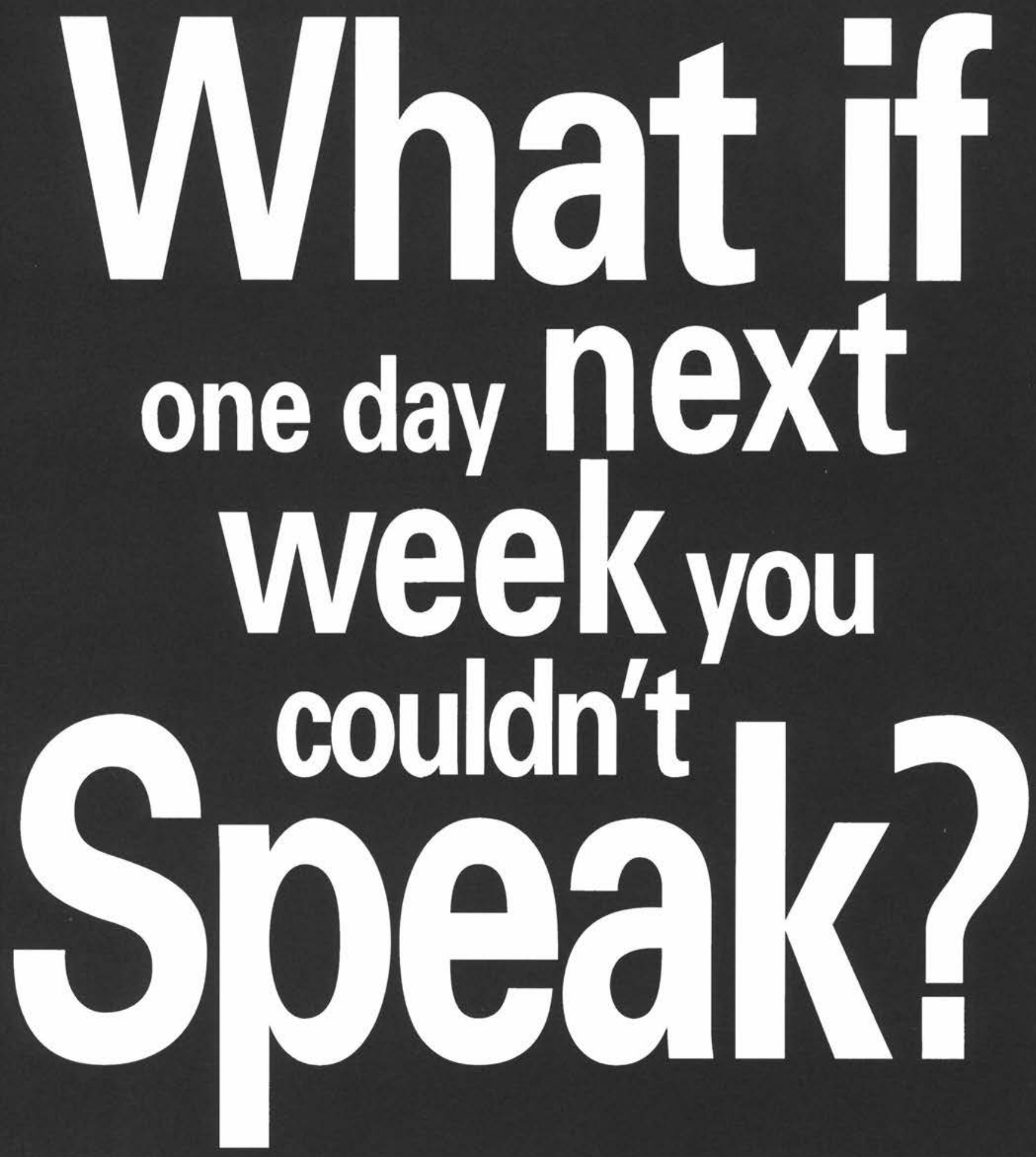

Or maybe you couldn't walk. Or your vision was blurred. That's what it's like to live with multiple sclerosis, an unpredictable disease of the central nervous system. Things you take for granted can become impossible and you don't know when or where or if it will strike again. But the research and services programs of the Multiple Sclerosis Society of Canada are providing some answers. With your help, we can connect with a cure. 1-800-288-7582 https://doi.org/10.1017/S0317167100050095 Published online by Cambridge University Press A-38

Multiple Sclerosis Society of Canada 
"DID IT MAKE A DIFFERENCE TO THE PEOPLE THAT

\section{'DOCTORS WITHOUT BORDERS' WAS THERE?}

FOR ME, THE ANSWER IS YES."

SIDNÉ MADDISON, NURSE FROM BRANTFORD, ONT BOSNIA \& CROATIA

D

octors Without Borders Canada volunteers run hospitals, set-up feeding stations for starving children, perform emergency surgery, train local health care personnel, manage massive vaccination campaigns and much more. They work in areas of the world where the health care system has broken down or is non-existent, in areas of immense poverty, in the midst of war and violence.

Your support will keep these volunteers where they are so desperately needed. Please donate to Doctors Without Borders Canada today.

Through a special arrangement with our international partners,

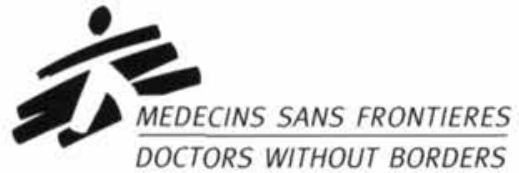

C A N A D A every dollar donated to Doctors Without Borders Canada is used to buy supplies and materials for emergency field missions.

Doctors Without Borders Canada is the Canadian partner of Médecins Sans Frontières / Doctors Without Borders, the world's largest independent charitable emergency medical aid organization. It is a registered Canadian charity, \# 0800516-11.

\section{INOS $2000^{\text {International Neuro-ophthalmology }}$ Society Meeting}

\section{SEPTEMBER 10-14, 2000 TORONTO, ONTARIO, CANADA}

Deadline for early registration: May 31, 2000 • Abstract submission deadline: April 21, 2000

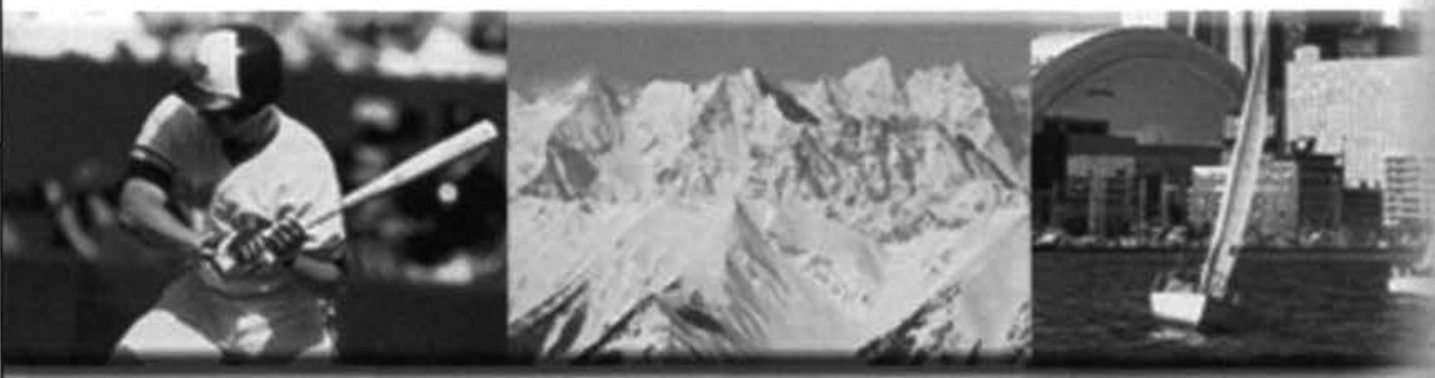

For further information, please contact

Venue West Conference Services Ltd.

\#645 - 375 Water Street, Vancouver, BC, V6B 5 C6 Canada

Tel: (604) 681-5226 Fax: (604) 681-2503

Email: congress@venuewest.com

Website: uww.venuewest.com/inos 2000

Regsitration and abstracts forms may be dowloaded from our website

Feel free to visit our website:
The Rocky Mountain Satellite Meeting will take place from September 15-17, 2000 in Banff. Alberta, Canada. This Meeting is available to registrants of INOS 2000. Space is limited and on a first come-first serve basis. 


\section{Zanaflex (tizanidine hydrochloride)}

Zanaflex $x^{\circ}$

(tizanidine $\mathrm{HCl}$ )

equivalent to $4 \mathrm{mg}$ tizanidine

Antispastic Agent

PRODUCT MONOGRAPH

CLINICAL PHARMACOLOGY

\section{MECHANISM OF ACTION ${ }^{1,2,3}$}

Tizanidine is an agonist at $\alpha_{2}$-adrenergic receptor sites and presumably reduces spasticity by increasing presynaptic inhibition of motor neurons. In animal models, tizanidine has no direct effect on skeletal muscle fibers or the neuromuscular junction, and no major effect on monosynaptic spinal reflexes. The effects of tizanidine are greatest on polysynaptic pathways The imidazoline chemical structure of tizanidine is related to that of the anti-hypertensive drug clonidine and other $\alpha_{2}$-adrenergic agonists. Pharmacological studies in animals show drug clonidine and other $\alpha_{2}$-adrenergic agonists. Pharmacological studies in animals show
similarities between the two compounds, but tizanidine was found to have one-tenth to similarities between the two compounds, but tizanidine was found to
one-fiftieth $(1 / 50)$ of the potency of clonidine in lowering blood pressure.

One-fiftieth $(1 / 50)$ of the
PHARMACOKINETICS

Following oral administration, tizanidine is essentially completely absorbed and has a half-life of approximately 2.5 hours (coefficient of variation $\mathrm{CV}=33 \%$ ). Following administration of tizanidine peak plasma concentrations occurred at 1.5 hours ( $\mathrm{CV}=40 \%)$ after dosing. Food increases $C_{\max }$ approximately 40 minutes, but the extent of tizanidine absorption is not affected. Tizanidin has linear pharmacokinetics over a dose of 1 to $20 \mathrm{mg}$. The absolute oral bioavailability of tizanidine is approximately $40 \%(\mathrm{CV}=24 \%)$, due to extensive first-pass metabolism in the liver; approximately $95 \%$ of an administered dose is metabolized. Tizanidine metabolites are not known to be active; their half-lives range from 20 to 40 hours. Tizanidine is widely
distributed throughout the body; mean steady state volume of distribution is $2.4 \mathrm{~L} / \mathrm{kg}$ $(\mathrm{CV}=21 \%)$ following intravenous administration in healthy adult volunteers.

Following single and multiple oral dosing of ${ }^{14} \mathrm{C}$-tizanidine, an average of $60 \%$ and $20 \%$ of total radioactivity was recovered in the urine and feces, respectively.

Tizanidine is approximately $30 \%$ bound to plasma proteins, independent of concentration over the therapeutic range.

\section{SPECIAL POPULATION}

Age Effects: No specific pharmacokinetic study was conducted to investigate age effects. Cross study comparison of pharmacokinetic data, following single dose administration of $6 \mathrm{mg}$ the elderly subjects. Zanaflex has not been evaluated in children (see PRECAUTIONS).

Hepatic Impairment: Pharmacokinetic differences due to hepatic impairment have not been studied (see WARNINGS).

Renal Impairment: Zanaflex clearance is reduced by more than $50 \%$ in elderly patients with renal insufficiency (creatinine clearance $<25 \mathrm{~mL} / \mathrm{min}$ ) compared to healthy elderly subjects; th would be expected to lead to a longer duration of clinical effect. Zanaflex should be used with caution in renally impaired patients (see PRECAUTIONS).

Gender Effects: No specific pharmacokinetic study was conducted to investigate gende effects. Retrospective analysis of pharmacokinetic data, however, following single and multiple dose administration of $4 \mathrm{mg}$ Zanaflex showed that gender had no effect on the pharmacokinetics of Zanaflex.

Race Effects: Pharmacokinetic differences due to race have not been studied.

Drug interactions -Oral Contraceptives: No specific pharmacokinetic study was conducted to investigate interaction between oral contraceptives and Zanaflex. Retrospective analysis of panaflex, however, showed that women concurrently taking oral contraceptives had $50 \%$ lower clearance of Zanaflex compared to women not on oral contraceptives (see

The capacity of Zanaflex (tizanidine $\mathrm{HCl}$ ) to reduce increased muscle tone associated with spasticity was demonstrated in two adequate and well controlled studies in patients with multiple sclerosis or spinal injury.

In one study, patients with multiple sclerosis were randomized to receive single oral doses of drug or placebo. ${ }^{4}$ Patients and assessors were blind to treatment assignment and efforts were made to reduce the likelihood that assessors would become aware indirectly of treatment assignment (e.g., they did not provide direct care to patients and were prohibited from asking questions

Response was assessed by physical examination; muscle tone was rated on a 5 point scale (Ashworth score), with a score of 0 used to describe normal muscle tone. A score 1 indicated a slight spastic catch while a score of 2 indicated more marked muscle resistance. A score of 3 was used to describe considerable increase in tone, making passive movement
difficult. A muscle immobilized by spasticity was given a score of 4 . Spasm counts were also difficult. A

Assessments were made at 1, 2, 3 and 6 hours after treatment. A statistically significan reduction of the Ashworth score for Zanaflex compared to placebo was detected at 1,2 and 3 hours after treatment. Figure 1 below shows a comparison of the mean change in muscle tone from baseline as measured by the Ashworth scale. The greatest reduction in muscle tone was 1 to 2 hours after treatment. By 6 hours after treatment, muscle tone in the 8 and $16 \mathrm{mg}$ tizanidine groups was indistinguishable from muscle tone in placebo treated patients. Within a given patient, improvement in muscle tone was correlated with plasma concentration. Plasma concentrations were variable from patient to patient at a given dose. Although $16 \mathrm{mg}$ produced a larger effect, adverse events including hypotension were more common an more severe than in the $8 \mathrm{mg}$ group. There were no differences in the number of spasms occurring in each group.

In a multiple dose study, 118 patients with spasticity secondary to spinal cord injury were randomized to either placebo or Zanaflex..$^{5}$ Steps similar to those taken in the first study were employed to ensure the integrity of blinding.

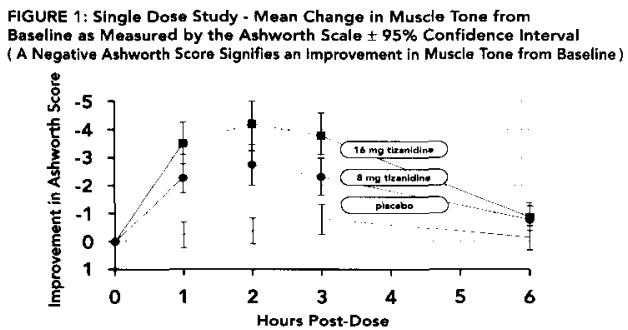

Patients were titrated over 3 weeks up to a maximum tolerated dose or $36 \mathrm{mg}$ daily given in three unequal doses (e.g., $10 \mathrm{mg}$ given in the morning and afternoon and $16 \mathrm{mg}$ given at night). Patients were then maintained on their maximally tolerated dose for 4 additiona weeks (i.e., maintenance phase). Throughout the maintenance phase, muscle tone was assessed on the Ashworth scale within a period of 2.5 hours following either the morning or
afternoon dose and counts of spasms were collected by patient diary.

At endpoint (the protocol-specified time of outcome assessment), there were statistically significant reductions in muscle tone and spasms in the Zanaflex treated group compared to placebo. The reduction in muscle tone was not associated with a red (a desirable outcome) but also did not lead to any consistent advantage of Zanaflex treated patients on measures of activities of daily living. Figures 2 and 3 below show a comparison of the mean change in muscle tone from baseline as measured by the Ashworth scale and a comparison of the mean change in daytime spasms as recorded in patient diaries, respectively.
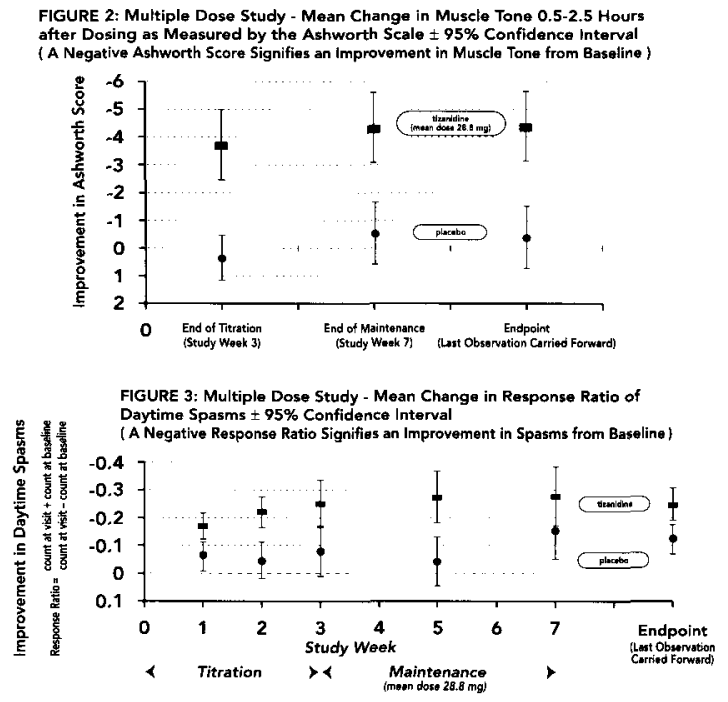

In a second multiple dose study, 187 patients with spasticity secondary to multiple sclerosis were randomized to either placebo or Zanaflex. Patients were titrated over 3 weeks up to maximum tolerated dose or $36 \mathrm{mg}$ dally given in three equal doses. Patients were then maintained on their maximally tolerated dose for $q$ additional weeks (i.e., maintenance phase). Throughout the maintenance phase, muscle tone was assessed on the Ashworth scale and global efficacy was assessed by both patient and investigator.

There was a statistically significant reduction in muscle tone in the Zanaflex treated group as compared to placebo at the last maintenance phase measurement of muscle tone (the protocol-specified time of outcome assessment) and throughout the maintenance phase. The reduction in muscle tone was not associated with a reduction in muscle strength.

INDICATIONS AND CLINICAL USE

Zanaflex (tizanidine $\mathrm{HCl}$ ) is a short-acting drug for the management of spasticity CONTRAINDICATIONS

Zanaflex (tizanidine $\mathrm{HCl}$ ) is contraindicated in patients with known hypersensitivity to Zanaflex or its ingredients.

WARNINGS

\section{HYPOTENSION}

Tizanidine $\mathrm{HCl}$ is an $\alpha_{2}$-adrenergic agonist (like clonidine) and can produce hypotension. In a single cose study where blood pressure was monitored closely after dosing, two-thirds of patients treated with $8 \mathrm{mg}$ of Zanaflex had a $20 \%$ reduction in either the diastolic or systolic was associated, at times, with bradycardia, orthostatic hypotension, lightheadedness/dizziness and rarely syncope. The hypotensive effect is dose related and has been measured following single doses of $\geq 2 \mathrm{mg}$.

The chance of significant hypotension may possibly be minimized by titration of the dose and by focusing attention on signs and symptoms of hypotension prior to dose advancement in addition, patients moving from a supine to a fixed upright position may be at increased risk for hypotensive and orthostatic effects.

Caution is advised when Zanaflex is to be used in patients who have a history of orthostatic hypotension or labile blood pressufe or who are receiving concurrent antihypertensive therapy. Zanaflex should not be used with other $\alpha_{2}$-adrenergic agonists.

RISK OF LIVER INJURY

Zanaflex use occasionally causes drug induced liver injury, most often hepatocellutar in type In controlled clinical studies, approximately $5 \%$ of patients treated with Zanaflex had elevations of siver function tests (ALT/SGPT, AST/SGOT) to greater than 3 times the upper limit of normal (or 2 times if baseline levels were elevated). The patients usually remain asymptomatic despite increased aminotransferases. In occasional symptomatic cases, asymptomatic despite increased aminotransferases. In occasional symptomatic cases, enzymes typically occurred within the first 6 months of treatment with Zanaflex and most enzymes typically occurred within the first 6 months of treatment with Zanaflex and most experience, three deaths associated with liver failure have been reported in patients treated with tizanidine, including one case of fatal fulminant hepatitis.

Monitoring of aminotransferase levels is recommended during the first 6 months of treatmen (e.g., baseline, 1, 3 and 6 months) and periodically thereafter, based on clinical status. Because of the potential toxic hepatic effect of tizanidine, the drug should be used only with extreme caution in patients with impaired hepatic function.

SEDATION

In the multiple dose, controlled clinical studies, $48 \%$ of patients receiving any dose of Zanaflex reported sedation as an adverse event. In $10 \%$ of these cases, the sedation was rated as severe compared to $<1 \%$ in the placebo treated patients. Sedation may interfere with every day activity.

The effect appears to be dose related. In a single dose study, $92 \%$ of the patients receiving $16 \mathrm{mg}$, when asked, reported that they were drowsy during the 6 hour study. This compares to $76 \%$ of the patients on $8 \mathrm{mg}$ and $35 \%$ of the patients on placebo. Patients began noting this effect 30 minutes following dosing. The effect peaked 1.5 hours following dosing. Of the patients who received a single dose of $16 \mathrm{mg}, 51 \%$ continued to report drowsiness 6 hours
following dosing compared to $13 \%$ in the patients receiving placebo or $8 \mathrm{mg}$ of Zanaflex. In the multiple dose studies, the prevalence of patients with sedation peaked following the first week of titration and then remained stable for the duration of the maintenance phase of the study. 


\section{HALLUCINATIONS}

Zanaflex use has been associated with hallucinations. Formed, visual hallucinations or delusions have been reported in 5 of 170 patients $(3 \%$ in two North American controlled clinical studies. Most of the patients were aware that the events were unreal. One patient developed psychoses in association with the hallucinations. One patient continued to have problems for at least 2 weeks following discontinuation of Zanaflex. Dosage reduction or discontinuation should be considered for patients who experience hallucinations while receiving Zanaflex. Particular caution should be observed if Zanaflex is administered to patients with a prior history of psychotic illness. UIMITED DATABASE FOR CHRONIC USE OF SINGLE DOSES ABOVE 8 MG AND
MULTIPLE DOSES ABOVE 24 MG PER DAY

Clinical experience with long-term use of Zanaflex at single doses of 8 to $16 \mathrm{mg}$ or total daily doses of 24 to $36 \mathrm{mg}$ is limited. Approximately 75 patients have been exposed to individual doses of $12 \mathrm{mg}$ or more for at least one year and approximately 80 patients have been exposed to total daily doses of 30 to $36 \mathrm{mg} /$ day for at least one year. There is essentially no long-term experigh da experience at high doses is limited, only those adverse events with a relatively high incidence are likely to have been identified.

\section{PRECAUTIONS}

GENERAL

Zanaflex (tizanidine $\mathrm{HCl}$ ) should be used with caution in patients for whom spasticity is used to obtain increased function, such as maintenance of upright posture and balance in locomotion.

\section{CARDIOVASCULAR}

Prolongation of the QT interval and bradycardia were noted in chronic toxicity studies in dogs at doses equal to the maximum human dose on a $\mathrm{mg} / \mathrm{m}^{2}$ basis. ECG evaluation was not performed in the controlled clinical studies. Reduction in pulse rate has been noted in association with decreases in blood pressure in the single dose controlled study (see
WARNINGS). OPHTHALMIC

Dose-related retinal degeneration and corneal opacities have been found in animal studies at doses equivalent to approximately the maximum recommended dose on a $\mathrm{mg} / \mathrm{m}^{2}$ basis. There have been $n 0$ reports of comeal opacities or retinal degeneration in the clinical studies.

USE IN ELDERLY

Zanaflex should be used with caution in elderly patients because clearance is decreased four-fold.

\section{USE IN CHILDREN}

There are no adequate and well-controlled studies to document the safety and efficacy of Zanaflex in children under 18 years in age.

USE IN OBSTETRICS

The effect of Zanaflex on labor and delivery in humans is unknown.

Reproduction studies performed in rats at a dose of $3 \mathrm{mg} / \mathrm{kg}$, equal to the maximum recommended human dose on a mg/m $/ \mathrm{m}^{2}$ basis and in rabbits at $30 \mathrm{mg} / \mathrm{kg}, 16$ times the maximum recommended human dose on a $\mathrm{mg} / \mathrm{m}^{2}$ basis did not show evidence of teratogenicity. Tizanidine at doses that are equal to and up to 8 times the maximum recommended human dose on a $\mathrm{mg} / \mathrm{m}^{2}$ basis increased gestation duration in rats. Prenatal and postnatal pup loss was increased and developmental retardation occurred. mplantation loss was increased in rabbits at doses of $1 \mathrm{mg} / \mathrm{kg}$ or greater, equal to or Zanaflex has not been studied in pregnant women. Zanaflex should be given to pregnant women only if clearly needed.

\section{NURSING MOTHERS}

It is not known whether Zanaflex is excreted in human milk, although as a lipid soluble drug. it might be expected to pass into breast milk.

\section{PATIENTS WITH SPECIAL DISEASES AND CONDITIONS}

USE IN RENALLY IMPAIRED PATIENTS

Zanaflex should be used with caution in patients with renal insufficiency ( $\mathrm{Clcr}<25 \mathrm{~mL} / \mathrm{min}$ ), as clearance is reduced by more than $50 \%$. In these patients, during titration, the individual doses
should be reduced. If higher doses are required, individual doses rather than dosing frequency should be reduced. If higher doses are required, individual doses rather than dosing frequency
should be increased. These patients should be monitored closely for onset or increase in severity of the common adverse events (dry mouth, somnolence, asthenia and dizziness) as indicators of potential overdose.

\section{USE IN WOMEN TAKING ORAL CONTRACEPTIVES}

Zanaflex should be used with caution in women taking oral contraceptives; as clearance of tizanidine is reduced by approximately $50 \%$ in such patients. In these patients, during DEPENDENCE LIABILITY

Monkeys were shown to self-administer tizanidine in a dose-dependent manner, and abrupt cessation of tizanidine produced transient signs of withdrawal at doses $>35$ times the maximum recommended human dose on a $\mathrm{mg} / \mathrm{m}^{2}$ basis. These transient withdrawal signs (increased locomotion, body twitching, and aversive behavior toward the observer) were not reversed by naloxone administration.

DRUG INTERACTIONS

In vitro studies of cytochrome $P 450$ isoenzymes using human liver microsomes indicate that neither tizanidine nor its major metabolites are likely to affect the metabolism of other drugs metabolized by cytochrome P450 isoenzymes.

Acetaminophen: Zanaflex delayed the $T_{\text {max }}$ of acetaminophen by 16 minutes. Acetaminophen did not affect the pharmacokinetics of Zanaflex.

Alcohol: Alcohol increased the AUC of Zanaflex by approximately $20 \%$ while also increasing its $C_{\max }$ by approximately $15 \%$. This was associated with an increase in side effects of Zanaflex. The CNS depressant effects of Zanaflex and alcohol are additive.

Oral Contraceptives: No specific pharmacokinetic study was conducted to investigate interaction between oral contraceptives and Zanaflex, but retrospective analysis of population
pharmacokinetic data following single and multiple dose administration of $4 \mathrm{mg}$ Zanaflex showed that women concurrently taking oral contraceptives had $50 \%$ lower clearance of showed that women concurrently taking oral con

Antihypertensives: In placebo-controlled clinical trials, Zanaflex has been administered concomitantly with antihypertensive medications in 30 patients. The addition of Zanaflex to antihypertensive therapy was associated with a $20-30 \%$ increase in the incioence of clinically significant decreases in systolic or diastolic blood pressure compared with both placebo plus antihypertensive

Concurrent use of antihypertensive and Zanaflex therapy also resulted in an increase in reports of orthostatic hypotension. Lower initial doses and cautious dose titration should be considered when Zanaflex is to be administered to patients receiving antihypertensive therapy or if antihypertensive therapy is to be initiated in a patient receiving Zanaflex.

\section{INFORMATION TO BE PROVIDED TO THE PATIENTS} Patients should be advised of the limited clinical experience with Zanaflex both in regard to
duration of use and the higher doses required to reduce muscle tone (see WARNINGS). Because of the possibility of Zanaflex lowering blood pressure, patients should be warned about the risk of clinically significant orthostatic hypotension (see WARNINGS).

Because of the possibility of sedation, patients should be warned about performing activities requiring alertness, such as driving a vehicle or operating machinery (see WARNINGS). Patients should also be instructed that the sedation may be additive when Zanaflex is taken in conjunction with drugs (baclofen, benzodiazepines) or substances (e.g., aicohol) that act as
CNS depressants.

\section{ADVERSE REACTIONS}

In multiple dose, placebo-controlled clinical studies, 264 patients were treated with Zanaflex (tizanidine $\mathrm{HCl}$ ) and 261 with placebo. Adverse events, including severe adverse events, were more frequently reported with Zanaflex than with placebo.

\section{COMON ADVERSE EVENTS LEADING TO DISCONTINUATION}

Forty-five of $264(17 \%)$ patients receiving Zanaflex and 13 of $261(5 \%)$ patients receiving placebo in three multiple dose, placebo-controlled clinical studies discontinued treatment for adverse events. When patients withdrew from the study, they frequently had more than one ranflex treated pating. The adverse and $/$ or tiredness) $(3 \%)$, somnolence $(3 \%)$, dry mouth $(3 \%)$, increased spasm or tone $(2 \%)$ and and/or tiredness)
dizziness (2\%).

\section{MOST FREQUENT
OF TIZANIDINE}

In multiple dose, placebo-controlled clinical studies involving 264 patients with spasticity, the most frequent adverse events were dry mouth, somnolence/sedation, asthenia (weakness fatigue and/or tiredness) and dizziness. Three quarters of the patients rated the events as mild to moderate and one quarter of the patients rated the events as being severe. These events appeared to be dose related.

ADVERSE EVENTS REPORTED IN CONTROLLED STUDIES

The events cited reflect experience gained under closely monitored conditions of clinica studies in a highly selected patient population. In actual clinical practice or in other clinica studies, these frequency estimates may not apply, as the conditions of use, reporting behavior, and the kinds of patients treated may differ. Table 1 lists treatment emergent signs and symptoms that were reported in greater than $2 \%$ of patients in three multiple dose, placebo-controlled studies who received Zanaflex where the frequency in the Zanaflex group was at least as common as in the placebo group. These events are not necessarily related to Zanaflex treatment. For comparison purposes, the corresponding
frequency of the event (per 100 patients) among placebo treated patients is also provided. TABLE 1: Multiple Dose, Placebo-Controlled Studies - Frequent $(>2 \%)$

Adverse Events Reported for Which Zanaflex Incidence is Greater Than Placebo

\begin{tabular}{lcc} 
Event & $\begin{array}{c}\text { Placebo } \\
\mathbf{N = 2 6 1} \\
\%\end{array}$ & $\begin{array}{c}\text { Zanaflex } \\
\mathbf{N = 2 6 4} \\
\%\end{array}$ \\
Dry mouth & 10 & 49 \\
Somnolence & 10 & 48 \\
Asthenia* & 16 & 41 \\
Dizziness & 4 & 16 \\
UTI & 7 & 10 \\
Infection & 5 & 6 \\
Constipation & 1 & 4 \\
Liver function tests abnormal & $<1$ & 3 \\
Vomiting & 0 & 3 \\
Speech disorder & 0 & 3 \\
Amblyopia (blurred vision) & $<1$ & 3 \\
Urinary frequency & 2 & 3 \\
Flu syndrome & 2 & 3 \\
SGPT/ALT increased & $<1$ & 3 \\
Dyskinesia & 0 & 3 \\
Nervousness & $<1$ & 3 \\
Pharyngitis & 1 & 3 \\
Rhinitis & 2 & 3 \\
\hline
\end{tabular}

* weakness, fatigue and/or tiredness

in the single dose, placebo-controlled study involving 142 patients with spasticity, the patients were specifically asked if they had experienced any of the four most common adverse events dry mouth, somnolence (drowsiness), asthenia (weakness, fatigue and/or tiredness), and dizziness. In addition, hypotension and bradycardia were observed. The occurrence of these adverse events are summarized in Table 2 . Other events were, in general reported at a rate of $2 \%$ or less.

TABLE 2: Single Dose, Placebo-Controlled Study - Common Adverse Events Reported

$\begin{array}{lccc}\text { Event } & \begin{array}{c}\text { Placebo } \\ \mathbf{N = 4 8} \\ \%\end{array} & \begin{array}{c}\text { Zanaflex } \mathbf{8} \mathbf{~ m g} \\ \mathbf{N}=\mathbf{4 5} \\ \%\end{array} & \begin{array}{c}\text { Zanaflex } 16 \mathbf{~ m g} \\ \mathbf{N}=\mathbf{4 9} \\ \text { \% }\end{array} \\ \text { Somnolence } & 31 & 78 & 92 \\ \text { Dry mouth } & 35 & 76 & 88 \\ \text { Asthenia } & 40 & 67 & 78 \\ \text { Dizziness } & 4 & 22 & 45 \\ \text { Hypotension } & 0 & 16 & 33 \\ \text { Bradycardia } & 0 & 2 & 10\end{array}$

* weakness, fatigue and/or tiredness

OTHER ADVERSE EVENTS OBSERVED DURING THE EVALUATION OF TIZANIDINE

Zanaflex was administered to 1187 patients in additional clinical studies where adverse event information was available. The conditions and duration of exposure varied greatly, and included (in overlapping categories) double-blind and open-label studies, uncontrolled and controlled studies, Inpatient and outpatient stucies, and titration studies. Untoward events associated with this exposure were recorded by clinical investigators using terminology of
their own choosing. Consequently, it is not possible to provide a meaningful estimate of the proportion of individuals experiencing adverse events without first grouping similar types of proportion of individuals experiencing adverse events without first group

In the tabulations that follow, reported adverse events were classified using a standard COSTART-based dictionary terminology. The frequencies presented, therefore, represent the proportion of the 1187 patients exposed to Zanaflex who experienced an event of the type cited on at least one occasion while receiving tizanidine All reported events are included except those already listed in Table 1 . If the COSTART term for an event was so general as to be uninformative, it was replaced with a more informative term. It is important to emphasize that, although the events reported occurred during treatment with Zanaflex, they were not necessarily caused by it.

Events are further categorized by body system and listed in order of decreasing frequency according to the following definitions: frequent adverse events are those occurring on one more occasions in at least 1/100 patients (only those not already listed in the tabulated results from placebo-controlled studies appear in this listing); infrequent adverse events are those occurring in $1 / 100$ to $1 / 1000$ patients.

BODY AS A WHOLE: Frequent: fever; Infrequent: allergic reaction, moniliasis, malaise, abscess, neck pain, sepsis, cellulitis, death, overdose; Rare: carcinoma, congenital anomaly, suicide attempt. CARDOOVASCULAR SYSTEM: Infrequent: vasodilatation, postural hypotension, syncope, migraine, arrhythmia; Rare: angina pectoris, coronary artery disorder, heart failure, myocardial infarct, phlebitis, pulmonary embolus, ventricular extrasystoles, ventricular tachycardia.

DIGESTME SYSTEM: Frequent; abdomen pain, diarrhea, dyspepsia; Infrequent: dysphagia cholelithiasis, fecal impaction, flatulence, gastrointestinal hemorrhage, hepatitis, melen Rare: gastroenteritis, hematemesis, hepatoma, intestinal obstruction, liver damage.

HEMIC AND LYMPHATIC SYSTEM: Infrequent: ecchymosis, hypercholesteremia, anemia, hyperlipemia, leukopenia, leukocytosis, sepsis; Rare: petechia, purpura, thrombocythemia, thrombocytopenia.

METABOLIC AND NUTRITIONAL SYSTEM: Infrequent: edema, hypothyroidism, weight loss; Rare: adrenal cortex insufficiency, hyperglycemia, hypokalemia, hyponatremia, hypoproteinemia respiratory acidosis.

MUSCULOSKELETAL SYSTEM: Frequent: myasthenia, back pain; Infrequent: pathological fracture, arthralgia, arthritis, bursitis. 


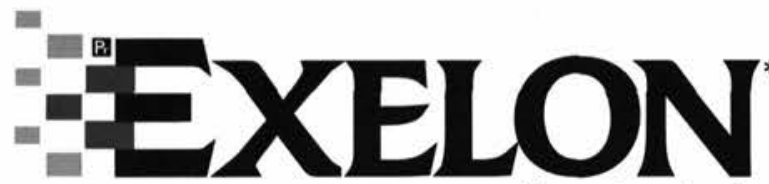

(rivastigmine)

(Rivastigmine as the Hydrogen Tartrate Salt)

Capsules $-1.5 \mathrm{mg}, 3 \mathrm{mg}, 4.5 \mathrm{mg}, 6 \mathrm{mg}$

PHARMACOLOGICAL CLASSI

\section{ACTIONS AND CLINICAL PHARMACOLOGY}

Pathological changes in Dementia of the Alzheimer type involve cholinergic neuronal pathways that project from the basal forebrain to the cerebral cortex and hippocampus. A decrease in the function of these cholinergic pathways has been proposed to account for some of the clinical manifestations of dementia. Rivastigmine, a reversible cholinesterase inhibitor of the carbamate-type, is thought to enhance cholinergic neurotransmission by slowing the degradation of acetylcholine released by cholinergic neurons through the neurotransmission by slowing the degradation of acetylcholine released by cholinergic neurons through the
inhibition of acetylcholinesterase. If this proposed mechanism of action is correct, rivastigmine's effect may inhibition of acetylcholinesterase. If this proposed mechanism of action is correct, rivastigmine's effect may
lessen as the disease process advances and fewer cholinergic neurons remain functionally intact.There is no evidence that rivastigmine alters the course of the underlying dementing process.

\section{Clinical Pharmacokinetics}

Absorption: Rivastigmine is well absorbed and peak plasma concentrations $\left(\mathrm{C}_{\operatorname{man}}\right)$ are reached in approximately 1 hour. A doubling of the dose within the recommended dose range yields an increase in bioavailability by approximately 3 times the expected increase indicating non-linear pharmacokinetics. The estimated absolute bioavailability for a $3 \mathrm{mg}$ dose in healthy young patients is low $(<35 \%)$. The elimination half-life $\left(t_{1 / 2}\right)$ of rivastigmine is about 1 to 2 hours in both the young and elderly. Plasma clearance is dose dependent and is approximately $1 \mathrm{l} / \mathrm{h} / \mathrm{kg}$ at $3 \mathrm{mg}$ in healthy young subjects. In healthy elderly male patients, plasma rivastigmine levels are approximately $30 \%$ higher than that noted in young subjects (see CLINICAL PHARMACOKINETICS: Age). When administered with food to healthy young subjects the absorption ( $\mathrm{T}_{\text {mux }}$ ) of rivastigmine was delayed by $90 \mathrm{~min}$, and $\mathrm{C}_{\max }$ was lowered while the AUC $\mathrm{C}_{0-\infty}$ was increased by approximately $25 \%$

Distribution: Rivastigmine is approximately $40 \%$ bound to plasma proteins over a concentration range of $1-400 \mathrm{ng} / \mathrm{mL}$. Rivastigmine distributes equally between blood and plasma with a blood-to-plasma partition ratio of 0.9 at concentrations which cover the therapeutic range $(1-400 \mathrm{ng} / \mathrm{mL}$ ) The apparent volume of distribution is $5 \pm 3 \mathrm{~L} / \mathrm{kg}$. Rivastigmine can be detected in the CSF, reaching peak concentrations in 1-4 hours. Mean AUC 0 -1azr ratio of CSF/plasma averaged $40 \pm 0.5 \%$ following $1-6 \mathrm{mg}$ bid doses. Metabolism: Rivastigmine is subject to first pass clearance and is rapidly and extensively metabolised, primarily via esterase-, including acetylcholinesterase--, mediated hydrolysis to a decarbamylated phenolic metabolite. In vitro preclinical studies suggest that the decarbamylated phenolic metabolite has approximately $10 \%$ the activity of the parent compound. The plasma half-life of the decarbamylated phenolic metabolite ranges from 2.5 to 4 hours. Additional metabolites include a sulphate conjugate, a demethylated sulfate coniugate and several unidentified minor metabolites. The pharmacokinetics of rivastigmine in patients with butyrylcholinesterase enzyme deficiency are unknown (see PRECAUTIONS: Genetic Polymorphism). Evidence from in vitro studies suggest that the major cytochrome P450 isozymes Genetic Polymorphism). Evidence from in vitro studies suggest that the major cytochrome P450
are minimally involved in rivastigmine metabolism (see PRECAUTIONS: Drug-Drug Interactions). Rivastigmine inhibits acetylcholinesterase (AChE) and butyrylcholinesterase (BChE) activity. In patients with Alzheimer Disease significant dose-dependent inhibition of AChE and BChE activity were noted in cerebrospinal fluid, with comparable maximum mean inhibition (62\%). In plasma, significant inhibition of BChE activity is generally observed from 1.5 hours post-dose up to 8 hours post-dose, with a maximum observed inhibition of $51 \%$ at $5 \mathrm{mg}$ b.i.d. Rivastigmine may therefore inhibit the butyrylcholinesterase mediated metabolism of other drugs (see PRECAUTIONS: Drug-Drug Interactions).

Excretion: Unchanged rivastigmine is not found in the urine; renal excretion is the major route of elimination of the metabolites. Following administration of a single $1 \mathrm{mg}$ or $2.5 \mathrm{mg}$ dose of ${ }^{14} \mathrm{C}$-labelled rivastigmine excretion of radioactivity in the urine (expressed as a percent of the administered dose) is over $90 \%$ within 24 hours. Approximately $7 \%$ of the decarbamylated phenolic metabolite is found in the urine. The sulfate conjugates account for about $40 \%$ of the dose. Less than $1 \%$ of the administered dose is excreted in the faeces. The accumulation potential of rivastigmine and its decarbamylated phenolic metabolite in patients with Alzheimer Disease has not been systematically studied however, population pharmacokinetic analyses suggest that no accumulation is expected.

Renal: In a single-dose study of 8 subjects with moderate renal impairment (GFR $=10-50 \mathrm{~mL} / \mathrm{min}$ ) mean peak plasma concentrations of rivastigmine were increased by almost 2.5 fold and overall plasma levels (AUC) of the decarbamylated phenolic metabolite were increased by approximately $50 \%$ compared to levels in age, weight, and gender matched control subjects. In this same study, patients with severe renal impairment (GFR $<10 \mathrm{~mL} / \mathrm{min}, \mathrm{n}=8$ ) showed no difference in rivastigmine blood levels compared to controls. The reason for this discrepancy is unclear. The safety and efficacy of rivastigmine in Alzheimer Disease patients with renal impairment have not been studied (see PRECAUTIONS: Renal Impairment) Hepatic: In a single dose study of 10 subjects with biopsy proven liver impairment (Child-Pugh score of 5-12), plasma concentrations of rivastigmine were increased, while that of the decarbamylated phenolic metabolite were decreased by about $60 \%$ compared to an age, weight and gender matched control group. The safety and efficacy of rivastigmine in Alzheimer Disease patients with hepatic impairment have not been studied (see PRECAUTIONS: Hepatic Impairment).

Age: In a study in which the effect of age on the pharmacokinetics of rivastigmine was assessed, 24 health male elderly (age range: $61-71$ years) and 24 healthy young patients (age range: 19-40 years) received $1.0 \mathrm{mg}$ or $2.5 \mathrm{mg}$ single oral doses of rivastigmine under fasted conditions. Plasma concentrations of rivastigmine exhibited a wider range of values and tended to be higher in the elderly as compared to young subjects after the $1 \mathrm{mg}$ dose. This difference was more pronounced with the higher dose $(2.5 \mathrm{mg})$ at which rivastigmine plasma concentrations were $30 \%$ greater in the elderly than in young subjects. Plasma levels of the decarbamylated phenolic metabolite were not substantially affected by age.

Gender and Race: No specific pharmacokinetic study was conducted to investigate the effect of gender and race on the disposition of rivastigmine. However, retrospective pharmacokinetic analyses suggest that gender and race (Blacks, Oriental, and Caucasians) will not affect the clearance of rivastigmine.

Nicotine Use: Population PK analysis showed that nicotine use increases the oral clearance of rivastigmine by $23 \%$ (Smokers: $n=75$; Nonsmokers: $n=549$ )

Clinical Trial Data: Efficacy data for rivastigmine in the symptomatic treatment of patients with mild to moderate dementia of the Alzheimer type (diagnosed by DSM-IV and NINCDS criteria, Mini-Mental State Examination $\geq 10$ and $\leq 26$ ) were derived from four clinical trials. These studies were randomized, doubleblind, and placebo controlled. The mean age of patients was 73 years (range: 41 to 95 ). Approximately $59 \%$ of the patients were women and $41 \%$ were men, while the racial distribution was: $87 \%$ Caucasian, $4 \%$ Black and $9 \%$ Other. In these clinical studies, the effectiveness of rivastigmine was evaluated using the following criteria: for primary efficacy two measures were used, (1) the cognitive subscale of the Alzheimer Disease Assessment Scale (ADAS-Cog), a widely used and well validated multi-item instrument which samples cognitive domains affected by the disease and (2) the CIBIC-Plus (Clinician Interview Based Impression of Change that required caregiver information). The CIBIC-Plus evaluates four major areas of functioning: general, cognition, behaviour and activities of daily living. As a secondary efficacy measure, the Progressive Deterioration Scale (PDS) was used. The PDS is a caregiver-rated evaluation which yields a compound score derived from a visual analogue scale of 29 items concerning participation in activities of daily living. Results for two of these studies, in which a flexible maintenance-dose regimen was used, are presented here. The data shown below were obtained from the Intent-to-Treat population (IIT analysis, i.e., All patients who were randomized to treatment, regardless of whether or not they were able to complete the study. For patients unable to complete the study, their last observation while on treatment was carried forward and used at endpoint).
Study I (B352, USA, 26 week trial)

This trial was of 26 weeks duration and was conducted in the USA. The study was subdivided into two phases, a forced titration phase, which could last up to 12 weeks, followed by a 14 week maintenance flexible-dose phase. A total of 699 patients were randomized to a $1-4 \mathrm{mg}$ daily dose $(n=233)$ or a $6-12 \mathrm{mg}$ daily dose $(n=231)$ of rivastigmine or placebo $(n=235)$ to be taken with food in two divided doses. Patients in the active treatment groups must have been able to tolerate the minimum dose in their assigned group (i.e. $0.5 \mathrm{mg}$ bid or $3 \mathrm{mg}$ bid) by titration Week 7 or they were discontinued. The dose escalation rate for the $1.4 \mathrm{mg} /$ day group was: Starting dose $0.5 \mathrm{mg}$ bid with $0.5 \mathrm{mg}$ bid increases every one or two weeks according to tolerability. The dose escalation rate for the 6-12 mg/day group was: Starting dose $1 \mathrm{mg}$ bid increased to $1.5 \mathrm{mg}$ bid after 3 days. Subsequent dose increases were at $0.5 \mathrm{mg}$ bid or $0.75 \mathrm{mg}$ bid every one or two weeks according to patient tolerability. The baseline mean Mini Mental State Exam (MMSE) score of patients was 19.7 and the mean score on the Global Deterioration Scale (GDS) was 4.0. Effects on ADAS-cog: At baseline, mean ADAS-cog scores (mean \pm SE) were for the placebo group: $21.74 \pm 0.74$ units; for the $1-4 \mathrm{mg} /$ day group: $22.38 \pm 0.75$ units and for the $6-12 \mathrm{mg} /$ day group: $22.31 \pm 0.75$ units. At the first measurement of efficacy (Week 12) mean ADAS-cog change scores from placebo (mean \pm standard error) were: $0.82 \pm 0.52$ units for the $1.4 \mathrm{mg} /$ day group and $3.24 \pm 0.54$ units for the $6-12 \mathrm{mg} /$ day dose groups. Differences from placebo were statistically significantly different only for the 6-12 mg/day group. At Week 18 , mean change scores from placebo were significant for both rivastigmine dose groups ( $1-4 \mathrm{mg} /$ day: $1.67 \pm 0.54$ units; $6-12 \mathrm{mg} /$ day: $3.83 \pm 0.57$ units). Both rivastigmine treated groups also showed significant differences from placebo in ADAS- $\operatorname{cog}$ mean change scores at Week 26 : (1-4 mg/day: $1.66 \pm 0.57$ units; 6-12 mg/day: $4.32 \pm 0.60$ units). A greater treatment effect size is noted for the $6-12 \mathrm{mg} /$ day treatment. At the end of the 26-week treatment period, either no evidence of deterioration or an improvement was observed in $27 \%$ of the placebo group, $35 \%$ ( $1-4 \mathrm{mg} / \mathrm{day}$ ) and $51 \%(6-12 \mathrm{mg} / \mathrm{day})$ in the rivastigmine groups. The difference between the $6-12 \mathrm{mg} /$ day group and the placebo group was statistically significant. A 4-point improvement in ADAS-cog score from baseline was observed in $6 \%$ of placebo patients, $12 \%$ (1-4 mg/day) and $23 \%(6-12 \mathrm{mg} /$ day) of rivastigmine treated patients at the end of the 26 week period. Statistical significance from placebo for this categorical measure was noted for both the $1-4 \mathrm{mg} /$ day and 6-12 $\mathrm{mg} /$ day group.

Effects on CIBIC-Plus: At Week 26 the mean drug-placebo differences were $0.22 \pm 0.11$ units for the $1-4 \mathrm{mg} /$ day group and $0.36 \pm 0.12$ units for the $6-12 \mathrm{mg} /$ day group. Differences from placebo were statistically significant, however, there was no statistically significant difference between the two active treatments. A histogram of the frequency distribution of CIBIC-Plus scores achieved at Week 26 by patients assigned to each of the three treatment groups is shown in Figure 1.

Figure 1: Frequency distribution of CIBIC-Plus scores at week 26

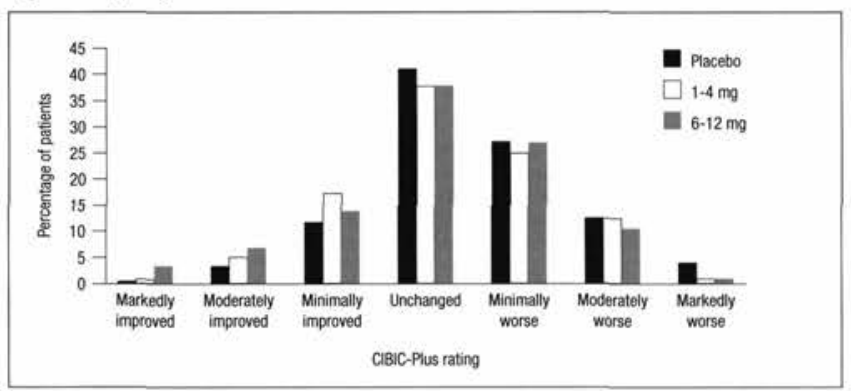

Effects on PDS: The progressive deterioration scale was used as a secondary efficacy measure. At baseline mean PDS scores (mean \pm SE) were for the placebo group: $53.7 \pm 1.2$ units; for the $1.4 \mathrm{mg} /$ day group: $54.7 \pm 1.2$ units; for the $6-12 \mathrm{mg} /$ day group: $52.0 \pm 1.2$ units. At Week 26 , the placebo group declined an $54.7 \pm 1.2$ units; for the $6-12 \mathrm{mg} /$ day group: $52.0 \pm 1.2$ units. At Week 26 , the placebo group declined
average of $5.2 \pm 0.7$ units, the $1-4 \mathrm{mg} /$ day group declined $5.3 \pm 0.7$ units and the $6-12 \mathrm{mg} /$ day group deteriorated minimally $(1.0 \pm 0.8$ units). The difference between the $6-12 \mathrm{mg} /$ day group and the placebo group was statistically significant.

Study II (B303, Multinational, 26 week tria)

This trial of 26 weeks duration was a multinational study (Austria, Canada, France, Germany, Switzerland and USA). A total of 725 patients were randomized into three different treatment arms: Placebo: $n=239$; $1-4 \mathrm{mg} /$ day rivastigmine: $n=243 ; 6-12 \mathrm{mg} /$ day rivastigmine: $n=243$. As in Study 1 , this trial was comprised of two phases, a forced titration phase, which could last up to 12 weeks, followed by a maintenance flexible-dose phase. Patients in the active treatment groups must have been able to tolerate the minimum dose in their assigned group (i.e. $0.5 \mathrm{mg}$ bid or $3 \mathrm{mg}$ bid) by titration Week 7 or they were discontinued. The baseline mean Mini Mental State Exam (MMSE) score was 20 and the mean score on the Global Deterioration Scale (GDS) was 4.0.

Effects on ADAS-cog: At baseline, mean ADAS-cog scores (mean \pm SE) were for the placebo group: $23.29 \pm 0.75$ units; for the $1-4 \mathrm{mg} /$ day group: $23.87 \pm 0.76$ units and for the $6-12 \mathrm{mg} /$ day group: $23.57 \pm 0.77$ units. At the first measurement of efficacy (Week 12) the difference in mean ADAS-cog change scores ( mean \pm standard error) for rivastigmine treated patients compared to placebo treated patients for the intent-to-treat (ITT) population were for the $1.4 \mathrm{mg} /$ day group: $0.19 \pm 0.55$ units and for the $6-12 \mathrm{mg} /$ day group: $1.71 \pm 0.57$ units. Only the difference between the $6-12 \mathrm{mg} /$ day group and placebo was significant at this time point. At Weeks 18 and 26 mean ADAS-cog change scores from placebo were for the $1.4 \mathrm{mg} /$ day group: $0.57 \pm 0.59$ (Week 18); $0.22 \pm 0.67$ units (Week 26) and for the $6-12 \mathrm{mg} /$ day group: $1.77 \pm 0.60$ units (Week 18); $2.29 \pm 0.69$ units (Week 26). As for Week 12, only the difference between the 6-12 mg/day group and placebo was statistically significant. At the end of the 26 -week treatment period, either no evidence of deterioration or an improvement was observed in $40 \%$ of the placebo group, $45 \%$ (1-4 mg/day) and $52 \%(6-12 \mathrm{mg} /$ day) in the rivastigmine groups. A 4-point improvement in ADAS-cog score from baseline was observed in $18 \%$ of patients who received placebo, $16 \%(1-4 \mathrm{mg} /$ day) and $27 \%(6-12 \mathrm{mg} /$ day) of rivastigmine treated patients at Week 26 . Differences between rivastigmine (6-12 mg/day) and placebo treated groups were significant for both categorical measures. Effects on CIBIC-Plus: At Week 26 the mean drug-placebo differences were $0.15+0.14$ units for the $1-4 \mathrm{mg} /$ day group and $0.44 \pm 0.15$ units for the $6-12 \mathrm{mg} /$ day group. Differences from placebo were statistically significant only for the $6-12 \mathrm{mg} /$ day dose group. A histogram of the frequency distribution of CIBIC-Plus scores achieved at Week 26 by patients assigned to each of the three treatment groups is shown in Figure 2 .

Figure 2: Frequency distribution of CIBIC-Plus scores at week 26

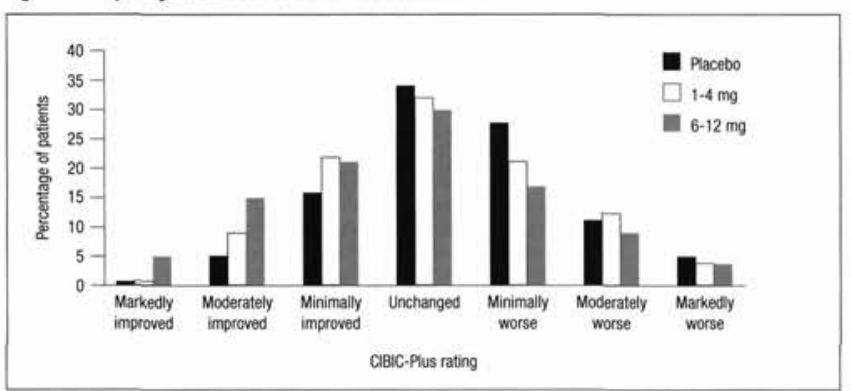


Effects on PDS: The progressive detericration scale was used as a secondary efficacy measure. At baseline mean PDS scores (mean \pm SE) were for the placebo group: $54.8 \pm 1.3$ units; for the $1-4 \mathrm{mg} /$ day group: $53.8 \pm 1.3$ units; for the $6-12 \mathrm{mg} /$ day group: $55.2 \pm 1.2$ units. At Week 26 , while the placebo group declined an average of $2.2 \pm 0.9$ units and the $1-4 \mathrm{mg} /$ day group deteriorated by $3.3 \pm 0.9$ units, the $6-12 \mathrm{mg} / \mathrm{day}$ group improved by $0.5 \pm 1.0$ units, which was a statistically significant difference. The $6-12 \mathrm{mg} /$ day group was statistically significantly superior to placebo as well as the lower dose range.

Data from these controlled clinical trials suggest that rivastigmine doses between 6-12 mg/day are more likely to result in beneficial symptomatic effects.

INDIGATIONS AND CLINIGAL USE

EXELON (rivastigmine as the hydrogen tartrate salt) is indicated for the symptomatic treatment of patients with mild to moderate dementia of the Alzheimer type. EXELON has not been studied in controlled clinical trials for longer than 6 months. EXELON capsules should only be prescribed by for following consultation with) clinicians who are experienced in the diagnosis and management of Alzheimer Disease. CONTRAINDICATIONS

EXELON (rivastigmine as the hydrogen tartrate salt) is contraindicated in patients with known hypersensitivity to rivastigmine, other carbamate derivatives or other components of the formulation. WARNINGS

Anesthesia: EXELON (rivastigmine as the hydrogen tartrate salt) as a cholinesterase inhibitor, is likely to exaggerate succinylcholine-type muscle relaxation during anesthesia.

Neurological Conditions: Seizures: In placebo controlled clinical trials with EXELON cases of seizures were reported. Cholinomimetics are believed to have some potential to cause generalized convulsions. Howeve seizure activity also may be a manifestation of Alzheimer Disease. The risk/benefit of EXELON treatment for patients with a history of seizure disorder must therefore be carefully evaluated. EXELON has not been studied in patients with moderately severe or severe Alzheimer Disease, non-Alzheimer dementias or individuals with Parkinsonian features. The efficacy and safety of EXELON in these patient populations is unknown.

Pulmonary Conditions: Like other cholinomimetic drugs, EXELON should be used with care in patients with a history of asthma or obstructive pulmonary disease. No experience is available in treating patients with these conditions.

Cardiovascular Gonditions: Because of their pharmacological action, cholinomimetics may have vagotonic effects on heart rate (e.g., bradycardia). The potential for this action may be particularly important to patien with "sick sinus syndrome" or other supraventricular cardiac conduction conditions. In clinical trials patients with serious cardiovascular disease were excluded. Caution should therefore be exercised in treating patients with active coronary artery disease or congestive heart failure. Syncopal episodes have been reported in association with the use of EXELON. It is recommended that EXELON not be used in patients with cardiac conduction abnormalities (except for right bundie branch block) including "sick sinus syndrome" and those with unexplained syncopal episodes.

Gastrointestinal Conditions: Through their primary action, cholinesterase inhibitors may be expected to increase gastric acid secretion due to increased cholinergic activity. Therefore, patients should be monitore for symptoms of active or occult gastrointestinal bleeding, especially those at increased risk for developing ulcers, e.g., those with a history of ulcer disease or those receiving concurrent nonsteroidal anti-inflammatory drugs (NSAIDS). In controlled clinical studies with EXELON, patients with a past history (last 2 years) of peptic ulceration and chronic diseases of the gastrointestinal tract were excluded. In the trial population who received EXELON there was no significant increase, relative to placebo, in the incidence of peptic ulcer disease. The incidence of Gl hemorrhage, in controlled clinical trials was $<1 \%(n=6 / 1923)$ for EXELON and $0 \%(n=0 / 868)$ for placebo. EXELON, as a predictable consequence of its pharmacological properties, has been shown to produce nausea, vomiting and diarrhea. These effects appear more frequently at higher doses (see ADVERSE REACTIONS section), with nausea and vomiting being more prevalent in women. Females are more sensitive to the cholinergic adverse effects associated with cholinesterase inhibitors and in general are more likely to experience nausea and vomiting than are males. In most cases these effects were of mild to moderate intensity and transient, and they resolved during continued EXELON treatment or upon treatment discontinuation.

Weight Loss: Cholinesterase inhibitors as well as Alzheimer Disease can be associated with significan weight loss. In controlled clinical trials the use of EXELON was associated with weight loss. Women exposed to doses of EXELON at the higher end of the therapeutic range ( $6-12 \mathrm{mg} / \mathrm{day})$ were at greater risk for weight loss. Approximately $24 \%$ of women on 6-12 mg/day doses of EXELON had weight loss of equal to or greater than $7 \%$ of their baseline weight compared to $6 \%$ on placebo. For males, $16 \%$ (6-12 mg/day) experienced a similar degree of weight loss compared to $4 \%$ on placebo. Where weight loss may be of clinical concern, body weight should be monitored.

Genitourinary: Although not reported in clinical trials of EXELON, cholinomimetics may cause bladder spasm.

PRECAUTIONS

\section{Concomitant use with other drugs:}

Use with Anticholinergics: Because of their mechanism of action, cholinesterase inhibitors have the potential to interfere with the activity of anticholinergic medications. Use with Cholinomimetics and Othe Cholinesterase Inhibitors: A synergistic effect may be expected when cholinesterase inhibitors are given concurrently with succinylcholine, similar neuromuscular blocking agents or cholinergic agonists such as bethanechol. Use with other Psychoactive Drugs: In controlled clinical trials with EXELON few patients received neuroleptics, antidepressants or anticonvulsants, there is thus limited information concerning the interaction of EXELON with these drugs.

Use in patients > 85 years old: In controlled clinical studies, the number of patients over 85 years old who received EXELON in the therapeutic dose range of $6-12 \mathrm{mg} /$ day was 68 . Of these patients, 12 received high doses of EXELON ( $>9$ or $\leq 12 \mathrm{mg} /$ day). The safety of EXELON in this patient population has not been adequately doses of EXELON ( $>9$ or $\leq 12 \mathrm{mg} /$ day). The safety of EXELON in this patient population has not been adequa characterized. In Alzheimer Disease patients in controlled clinical trials, nausea, diarrhea, vomiting, dizzi-
ness, anorexia, fatigue, dyspepsia and weakness increased with dose. Dose escalation in patients $>85$ yea ness, anorexia, fatigue, dyspepsia and weakness increased with dose. Dose escalation in patients $>85$ old should thus proceed with caution (see DOSAGE AND ADMINISTRATION: Special Populations).
Use in elderly patients with serious comorbid disease: There is limited information on the safety of EXELON treatment in patients with mild to moderate Alzheimer Disease and serious comorbidity. The use of EXEL ON in Alzheimer Disease patients with chronic illnesses common among the geriatric population, should be considered only after careful risk/benefit assessment and include close monitoring for adverse events. Dose escalation in this patient population should proceed with caution (see DOSAGE AND events. Dose escalation in this patient pop
ADMINISTRATION: Special Populations).

Renally and Hepatically Impaired Patients: There is limited information on the pharmacokinetics of EXELON in renally and hepatically impaired patients (see Clinical Pharmacokinetics and Metabolism section) It is therefore recommended that dose escalation with rivastigmine in renally or hepatically impaired patients with Alzheimer Disease be undertaken with caution and under conditions of close monitoring for adverse effects (see DOSAGE AND ADMINISTRATION: Special Populations)

Genetic Polymorphism: The effect of genetic polymorphism of butyrylcholinesterase enzyme on rivastigmine metabolism is unknown.

Drug-Drug Interactions

Studies to assess the potential of EXELON for interaction with digoxin, warfarin, diazepam or fluoxetine were limited to short term, single-dose studies in young healthy volunteers. No significant effects on the pharmacokinetics of these drugs or on the metabolism of rivastigmine were observed. Similar studies in elderly patients were not done.

Effect of EXELON on the Metabolism of Other Drugs: Rivastigmine is mainly metabolised through hydrolysis by esterases. No in vivo studies have investigated the effects of EXELON on the clearance of drugs metabolised by CYP450. Based on in vitro studies, no pharmacokinetic drug interactions with drugs metabolised by the following isoenzyme systems are expected: CYP1A2, CYP2D6, CYP3A4/5, CYP2E1, CYP2C9, CYP2C8, or CYP2C19. Rlvastigmine may inhibit the butyrylcholinesterase mediated metabolism of other drugs (see ACTIONS AND CLINICAL PHARMACOLOGY: Clinical Pharmacokinetics: Metabolism). of other drugs (see ACTIONS AND CLINICAL PHARMACOLOGY: Clinical Pharmacokinetics: Metabolism) are not expected to alter the metabolism of rivastigmine. Formal pharmacokinetic studies to assess the potential for drug interaction with other medications commonly taken by the elderly were not done
Population-pharmacokinetic analyses of a subset $(n=359 ; 6-12 \mathrm{mg} /$ day $)$ of patients with Alzheime Disease in controlled clinical trials do not suggest that the administration of EXELON with some commonly prescribed medications is associated with an alteration in the kinetics of rivastigmine, or an increased risk of clinically relevant untoward effects. However, the number of patients who received concomitant medications chronically was as follows: anilides (e.g. acetominophen) $(10 \%)$, antacids $(12 \%)$, antianginals $(6 \%)$, antihistamines $(2 \%)$, antihypertensives ( $12 \%)$, benzodiazepines ( $<1 \%)$, B-blockers $(7 \%)$, calcium channel blockers $(12 \%)$, digitalis glycosides ( $5 \%)$, non-steroidal anti-inflammatory drugs $(13 \%)$, oral hypoglycemics (3\%), and salicylic acid and derivatives (28\%).

Pregnancy

The safety of EXELON in pregnant women has not been established. EXELON should not be used in women of childbearing potential unless, in the opinion of the physician, the potential benefit to the patient justifies the potential risk to the fetus.

Nursing Mothers

It is not known whether EXELON is excreted into human milk, and therefore EXELON should not be used in nursing mothers.

Pediatric Use

The safety and effectiveness of EXELON in any illness occurring in pediatric patients have not been established.

ADVERSE REACTIONS

A total of 1923 patients with mild to moderate Alzheimer Disease were treated in controlled clinical studies with EXELON. Of these patients, $1417(74 \%)$ completed the studies. The mean duration of treatment for all EXELON groups was 154 days (range $1-255$ days).

Adverse Events Leading to Discontinuation

Overall, 18\% (340/1923) of patients treated with EXELON discontinued from Phase III controlled clinical trials due to adverse events compared to $9 \%(75 / 868)$ in the placebo group. During the titration phases of controlled clinical trials the incidence of discontinuations due to adverse events was $5 \%$ for placebo, $5 \%$ for EXELON 1-4 mg/day and $21 \%$ for EXELON 6-12 mg/day. During the maintenance phases, $3 \%$ of patients who received placebo, $3 \%$ of patients who received $1-4 \mathrm{mg} /$ day EXELON and $6 \%$ of patients who received EXELON 6-12 mg/day withdrew from studies due to adverse events. Female patients treated with EXELON were approximately twice as likely to discontinue study participation due to adverse events than were male patients (Females: $21 \%$; Males: 12\%). The most common adverse events leading to discontinuation, defined as those occurring in at least $2 \%$ of patients and at twice the incidence seen in placebo patients, are shown in Table 1.

Table 1. Most frequent adverse events ( $\geq 2 \%$ and twice the rate in the placebo group) leading to withdrawal from randomized placebo controlled clinical trials $\mathrm{B} 351, \mathrm{~B} 352$, and $\mathrm{B} 303$ during titration and maintenance phases"

\begin{tabular}{|c|c|c|c|c|c|c|}
\hline & \multicolumn{3}{|c|}{ Titration phase (weeks 1-12) } & \multicolumn{3}{|c|}{ Maintenance phase (weeks 13-26) } \\
\hline & $\begin{array}{l}\text { Placebo } \\
n=646\end{array}$ & $\begin{array}{l}1-4 \mathrm{mg} / \text { day } \\
\mathrm{n}=644\end{array}$ & $\begin{array}{l}6-12 \mathrm{mg} / \mathrm{day} \\
\mathrm{n}=824\end{array}$ & $\begin{array}{l}\text { Placebo } \\
n=588\end{array}$ & $\begin{array}{l}1-4 \mathrm{mg} / \text { day } \\
n=587\end{array}$ & $\begin{array}{l}6-12 \mathrm{mg} / \text { day } \\
\mathrm{n}=601\end{array}$ \\
\hline All events & $5 \%$ & $5 \%$ & $21 \%$ & $3 \%$ & $3 \%$ & $6 \%$ \\
\hline Nausea & $1 \%$ & $1 \%$ & $10 \%$ & $0 \%$ & $<1 \%$ & $1 \%$ \\
\hline Vomiting & $0 \%$ & $<1 \%$ & $5 \%$ & $0 \%$ & $<1 \%$ & $2 \%$ \\
\hline Anorexia & $0 \%$ & $<1 \%$ & $3 \%$ & $<1 \%$ & $<1 \%$ & $<1 \%$ \\
\hline Dizziness & $<1 \%$ & $<1 \%$ & $3 \%$ & $<1 \%$ & $0 \%$ & $1 \%$ \\
\hline $\begin{array}{l}\text { Abdominal } \\
\text { pain }\end{array}$ & $<1 \%$ & $<1 \%$ & $2 \%$ & $<1 \%$ & $<1 \%$ & $<1 \%$ \\
\hline Asthenia & $0 \%$ & $0 \%$ & $2 \%$ & $0 \%$ & $0 \%$ & $<1 \%$ \\
\hline Fatigue & $<1 \%$ & $<1 \%$ & $2 \%$ & $0 \%$ & $0 \%$ & $<1 \%$ \\
\hline
\end{tabular}

*All patients who received at least one dose of study medication were included in the results for the titration phase. All patients who entered the maintenance phase were represented in the results for the maintenance phase

Titration and maintenance dosing should remain flexible and be adjusted according to individual needs. Most Frequent Adverse Clinical Events Seen in Association with the Use of EXELON The most common adverse events, defined as those occurring at a frequency of at least $5 \%$ and twice the placebo rate, are largely predicted by EXELON's cholinomimetic effects. These include nausea, vomiting, dizziness, diarrhea, anorexia and abdominal pain. Table 2 presents a comparison of common adverse events ( $\geq 5 \%$ incidence and twice the placebo rate) by treatment group during titration (Weeks $1-12$ ) and maintenance (Weeks 13-26). The adverse events were generally mild in intensity, more frequent at higher doses, of short duration, and attenuated with continued dosing or discontinuation of drug.

Table 2. Common adverse events ( $\geq 5 \%$ and twice the rate in the placebo group) in randomized placebo controlled clinical trials B351, B352, and B303 during titration and maintenance phases

\begin{tabular}{lcclccc}
\hline & \multicolumn{3}{c}{ Titration phase (weeks 1-12) } & \multicolumn{3}{c}{ Maintenance phase (weeks 13-26) } \\
\hline $\begin{array}{l}\text { Adverse } \\
\text { event }\end{array}$ & $\begin{array}{l}\text { Placebo } \\
\mathrm{n}=646\end{array}$ & $\begin{array}{c}1-4 \mathrm{mg} / \text { day } \\
\mathrm{n}=644\end{array}$ & $\begin{array}{l}6-12 \mathrm{mg} / \text { day } \\
\mathrm{n}=824\end{array}$ & $\begin{array}{l}\text { Placebo } \\
\mathrm{n}=588\end{array}$ & $\begin{array}{l}1-4 \mathrm{mg} / \text { day } \\
\mathrm{n}=587\end{array}$ & $\begin{array}{l}6-12 \mathrm{mg} / \mathrm{day} \\
\mathrm{n}=601\end{array}$ \\
\hline Nausea & $9 \%$ & $15 \%$ & $40 \%$ & $4 \%$ & $8 \%$ & $15 \%$ \\
\hline Vomiting & $3 \%$ & $5 \%$ & $23 \%$ & $3 \%$ & $5 \%$ & $14 \%$ \\
\hline Dizziness & $10 \%$ & $10 \%$ & $19 \%$ & $4 \%$ & $6 \%$ & $10 \%$ \\
\hline Diarrhea & $9 \%$ & $8 \%$ & $16 \%$ & $4 \%$ & $5 \%$ & $9 \%$ \\
\hline Anorexia & $2 \%$ & $5 \%$ & $13 \%$ & $1 \%$ & $2 \%$ & $4 \%$ \\
\hline Abdominal & $4 \%$ & $5 \%$ & $10 \%$ & $3 \%$ & $3 \%$ & $4 \%$ \\
pain & & & & & & \\
\hline Fatigue & $4 \%$ & $4 \%$ & $8 \%$ & $1 \%$ & $2 \%$ & $3 \%$ \\
\hline Asthenia & $2 \%$ & $1 \%$ & $6 \%$ & $1 \%$ & $2 \%$ & $3 \%$ \\
\hline Somnolence & $2 \%$ & $4 \%$ & $5 \%$ & $1 \%$ & $1 \%$ & $1 \%$ \\
\hline
\end{tabular}

*All patients who received at least one dose of study medication were included in the results for the titration phase. All patients who entered the maintenance phase were represented in the results for the maintenance phase.

Titration and maintenance dosing should remain flexible and be adjusted according to individual needs. In an open label study involving 305 patients with Alzheimer Disease the tolerability of a $1.5 \mathrm{mg}$ bid ( $3 \mathrm{mg} /$ day) starting dose and dose escalation of $1.5 \mathrm{mg}$ bid ( $3 \mathrm{mg} /$ day) at a minimum interval of every two weeks were assessed. $A$ total of 40 of these patients (13\%) discontinued the study due to adverse events. The type and incidence of common adverse events reported did not appear to differ substantially from those noted in placebo-controlled studies.

Adverse Events Reported in Controlled Trials

The events cited reflect experience gained under closely monitored condition of clinical trials in a highly selected patient population. in actual clinical practice or in other clinical trials, these frequency estimates may not apply, as the conditions of use, reporting behavior, and the kinds of patients treated may differ. Table 3 lists treatment emergent signs and symptoms that were reported in at least $2 \%$ of patients in Phase 3 placebo-controlled trials for which the rate of occurrence was greater for EXELON assigned than placebo assigned patients. There were too few non Caucasian patients enrolled to assess the effect of race on the incidence of adverse events in the Phase III controlled studies. Similarly, there were too few patients aged more than 85 years to systematically assess the effect of advanced age. Female patients were more susceptible to nausea, vomiting, loss of appetite and weight loss. 
Table 3. Adverse events reported in controlled clinical trials in at least $2 \%$ of patients receiving EXELON and at a higher frequency than placebo-treated patients

\begin{tabular}{|c|c|c|}
\hline Body system/Adverse event & Placebo $(\mathrm{n}=868)$ & EXELON $(n=1923)$ \\
\hline Percent of patients with any adverse event & 79 & 87 \\
\hline $\begin{array}{l}\text { Autonomic Nervous System } \\
\text { Sweating increased }\end{array}$ & 1 & 3 \\
\hline $\begin{array}{l}\text { Body as a Whole } \\
\text { Fatigue } \\
\text { Asthenia } \\
\text { Malaise } \\
\text { Weight decrease }\end{array}$ & $\begin{array}{r}5 \\
2 \\
2 \\
<1\end{array}$ & $\begin{array}{l}7 \\
5 \\
4 \\
2\end{array}$ \\
\hline $\begin{array}{l}\text { Cardievascular Disorders, General } \\
\text { Hypertension }\end{array}$ & 2 & 3 \\
\hline $\begin{array}{l}\text { Central and Peripheral Nervous System } \\
\text { Dizziness } \\
\text { Headache } \\
\text { Somriolence } \\
\text { Tremor }\end{array}$ & $\begin{array}{r}11 \\
12 \\
3 \\
1\end{array}$ & $\begin{array}{r}19 \\
15 \\
5 \\
3\end{array}$ \\
\hline $\begin{array}{l}\text { Gastrointestinal System } \\
\text { Nausea } \\
\text { Vomiting } \\
\text { Diarrhea } \\
\text { Anorexia } \\
\text { Abdominal Pain } \\
\text { Dyspepsia } \\
\text { Constipation } \\
\text { Flatulence } \\
\text { Eructation }\end{array}$ & $\begin{array}{r}12 \\
6 \\
11 \\
3 \\
6 \\
4 \\
4 \\
2 \\
1\end{array}$ & $\begin{array}{r}37 \\
23 \\
16 \\
13 \\
11 \\
8 \\
5 \\
4 \\
2\end{array}$ \\
\hline $\begin{array}{l}\text { Psychiatric Disorders } \\
\text { Insomnia } \\
\text { Depression } \\
\text { Anxiety } \\
\text { Hallucination } \\
\text { Nervousness } \\
\text { Aggressive Reaction }\end{array}$ & $\begin{array}{l}7 \\
4 \\
3 \\
3 \\
3 \\
2\end{array}$ & $\begin{array}{l}8 \\
5 \\
4 \\
4 \\
4 \\
3\end{array}$ \\
\hline $\begin{array}{l}\text { Respiratory System } \\
\text { Rhinitis } \\
\text { Dyspnea }\end{array}$ & $\begin{array}{l}3 \\
1\end{array}$ & $\begin{array}{l}4 \\
2\end{array}$ \\
\hline $\begin{array}{l}\text { Skin and Appendages } \\
\text { Pruritus }\end{array}$ & 1 & 2 \\
\hline $\begin{array}{l}\text { Urinary System } \\
\text { Urinary Incontinence } \\
\text { Micturition Frequency }\end{array}$ & $\begin{array}{l}2 \\
1\end{array}$ & $\begin{array}{l}3 \\
2\end{array}$ \\
\hline $\begin{array}{l}\text { Vision Disorders } \\
\text { Vision Abnormal }\end{array}$ & 1 & 2 \\
\hline
\end{tabular}

Other Adverse Events Observed During Clinical Trials

EXELON has been administered to over 5297 individuals during clinical trials worldwide. Of these, 4326 patients have been treated for at least 3 months, 3407 patients have been treated for at least 6 months, 2150 patients have been treated for 1 year, 1250 have been treated for 2 years, and 168 have been treated for over 3 years. With regard to exposure to the highest dose, 1679 patients were exposed to mean daily doses of $10-12 \mathrm{mg}, 1659$ patients treated for 3 months, 1504 patients treated for 6 months, 885 patients treated for 1 year, 629 patients treated for 2 years, and 86 treated for over 3 years. Treatment emergent signs and symptoms that occurred during 8 controlled clinical trials and 9 open-label trials in North America, Western Europe, Australia, South Africa and Japan were recorded as adverse events by the clinical investigators using terminology of their own choosing. To provide an overall estimate of the proportion of individuals having similar types of events, the events were grouped into a smaller number of standardized categories using a modified WHO dictionary, and event frequencies were calculated across all studies. These categories are used in the listing below. The frequencies represent the proportion of all studies. These categories are used in the listing below. The frequencies represent the proportion of
5297 patients from these trials who experienced that event while receiving EXELON. All adverse events 5297 patients from these trials who experionced that event while receiving EXELON. All adverse events
occurring at least 6 times are included, except for those already listed in Table 3, WHO terms too general to occurring at least 6 times are included, except for those already listed in Table 3, WHO terms too general to
be informative, or events less likely to be drug caused. Events are classified by body system and listed using the following definitions: frequent adverse events - those occurring in at least $1 / 100$ patients; infrequent adverse events - those occurring in $1 / 100$ to $1 / 1000$ patients. These adverse events are not necessarily related to EXELON treatment and in most cases were observed at a similar frequency in placebo-treated patients in the controlled studies.

\section{Autonemic Nervous System:}

Frequent: Syncope.

Infrequent: Cold clammy skin, dry mouth, flushing, increased saliva.

Body as a Whole:

Frequent: Accidental trauma, allergy, chest pain, edema, fever, hot flushes, influenza-like symptoms, overdose, rigors.

Infrequent: Allergic reaction, chest pain substernal, edema periorbital, facial edema, feeling cold, halitosis, hypothermia, inflammatory reaction unspecified, pain, pallor, tumor unspecified, unspecified eyelid disorder, weight increase.

\section{Cardiovascular System:}

Frequent: Cardiac failure, hypotension, peripheral edema, postural hypotension.

infrequent: Chest pain, ECG abnormal, edema, generalized edema.

Central and Peripheral Nervous System:

Frequent: Abnormal gait, ataxia, convulsions, extrapyramidal disorder, paresthesia, vertigo.

Infrequent: Abnormal coordination, aphasia, apraxia, coma, dysphonia, hyperkinesia, hyperreflexia

hypertonia, hypoesthesia, hypokinesia, hyporeflexia, involuntary muscle contractions, migraine, neuralgia,

neuropathy, nystagmus, paresis, peripheral neuropathy, speech disorder.

Collagen Disorders:

Frequent: None.

Infrequent: Rheumatoid arthritis

Endocrine System:

Frequent: None.

Infrequent: Goitre, hypothyroidism.

Gastrointestinal Systom

Frequent: Fecal incontinence, gastritis, tooth disorder

Infrequent: Colitis, colorectal polyp, diverticulitis, duodenal ulcer, dysphagia, esophagitis, gastric ulcer,

gastroenteritis, gastroesophageal reflux, Gl hemorrhage, gingivitis, glossitis, hematemesis, hernia, hiccup,

increased appetite, intestinal obstruction, melena, pancreatitis, peptic ulcer, rectal disorder, rectal

hemorrhage, tenesmus, tooth caries, ulcerative stomatitis.

Hearing and Vestlbular Disorders:

Frequent: Tinnitus.

Infrequent: Deafness, earache, ear disorder unspecified, vestibular disorder.
Heart Rate and Rhythm Disorders:

Frequent: Bradycardia, fibrillation atrial, palpitation.

Infrequent: Arrhythmia, AV block, bundie branch block, cardiac arrest, extrasystoles, sick sinus syndrome, supraventricular tachycardia, tachycardia.

Liver and Biliary System Disorders:

Frequent: None.

Infrequent: Abnormal hepatic function, cholecystitis, cholelithiasis, increased gamma-glutamyl transferase, increased hepatic enzymes.

Metabolic and Nutritional Disorders:

Frequent: Dehydration, hypokalemia.

infrequent: Cachexia, diabetes mellitus, gout, hypercholesterolemia, hyperglycemia, hyperlipemia,

hypoglycemia, hyponatremia, thirst.

Musculoskeletal Disorders:

Frequent: Arthralgia, arthritis, back pain, bone fracture, leg cramps, leg pain, myalgia, pain.

infrequent: Arthropathy, arthrosis, bone disorder, bone pain, bursitis, cramps, hernia, joint malformation,

muscle weakness, osteoporosis, spine malformation, stiffness, tendinitis, tendon disorder, vertebral disc

disorder.

Myo-, Endo-, Pericardial and Valve Disorders:

Frequent: Angina pectoris, myocardial infarction.

Infrequent: Coronary artery disorder, heart sounds abnormal, myocardial ischemia

Neoplasms:

Frequent: Basal cell carcinoma.

Infrequent: Bladder carcinoma, carcinoma, colon carcinoma, malignant breast neoplasm (female), malignan skin neoplasm, unspecified adenocarcinoma, unspecified neoplasm.

Platelet, Bleeding, and Clotting Disorders:

Frequent: Epistaxis.

Infrequent: Hematoma, purpura, thrombocytopenia, unspecified hemorrhage.

Psychiatric Disorders:

Frequent: Agitation, behavioral disturbance, confusion, delusion, paranoid reaction, paroniria.

Infrequent: Abnormal dreaming, amnesia, apathy, decreased libido, delirium, dementia, depersonalization,

emotional lability, impaired concentration, increased libido, neurosis, psychosis, sleep disorder, stress

reaction, suicidal ideation.

Red Blood Cell Disorders:

Frequent: Anemia.

Infrequent: Anemia $\mathrm{B}_{12}$ deficiency, hypochromic anemia

Reproductive Disorders (Female \& Male):

Frequent: Prostatic disorder.

Infrequent: Atrophic vaginitis, breast pain (female), impotence, intermenstrual bleeding, unspecified uterine disorder, vaginal hemorrhage, vaginitis.

Resistance Mechanism Disorders:

Frequent: Infection, pneumonia, upper respiratory tract infection, urinary tract infection, viral infection.

Infrequent: Bacterial infection, cellulitis, cystitis, fungal infection, herpes simplex, herpes zoster, moniliasis,

onychomycosis, otitis media, parasitic infection, sepsis.

Respiratory System:

Frequent: Bronchitis, coughing, pharyngitis, sinusitis.

Infrequent: Abnormal chest sounds, apnea, bronchospasm, emphysema, hyperventilation, increased

sputum, laryngitis, pleural effusion, pulmonary disorder, pulmonary edema, respiratory disorder, respiratory

insufficiency.

Skin and Appendages:

Frequent: Rash, skin disorder, skin ulceration.

Infrequent:Abscess, acne, alopecia, bullous eruption, contact dermatitis, dermatitis, dry skin, eczema,

erythematous rash, furunculosis, genital pruritus, hyperkeratosis, maculo-papular rash, nail disorder, otitis

externa, psoriaform rash, seborrhea, skin cyst, skin discoloration, skin exfoliation, skin hypertrophy, sunburn,

urticaria, verruce.

Special Senses:

Frequent: None.

Infrequent: Loss of taste, perversion of taste.

Urinary System Disorders:

Frequent: Hematuria.

Infrequent: Acute renal failure, albuminuria, dysuria, micturition disorder, micturition urgency, nocturia polyuria, pyuria, renal calculus, renal cyst, renal function abnormal, unspecified bladder disorder, urethra polyuria, pyuna, renal calculve

Vascular (extracardiac) Disorders

Vascular (extracardiac) Disorders:
Frequent: Cerebrovascular disorder.

Infrequent: Aneurysm, circulatory disorder, hemorrhoids, intracranial hemorrhage, peripheral ischemla

phlebitis, pulmonary embolism, thrombophlebitis deep, thrombosis, varicose vein, vascular disorde

Vision Disorders:

Frequent: Cataract, conjunctivitis.

Infrequent: Abnormal lacrimation, blepharitis, conjunctival hemorrhage, diplopia, eye abnormality, eye pain,

glaucoma

White Cell and Resistance Disorders:

Frequent: None.

Infrequent: Leukocytosis, lymphadenopathy.

\section{SYMPTOMS AND TREATMENT OF OVERDOSAGE}

Symptoms: Overdosage with cholinesterase inhibitors can result in cholinergic crisis characterised by severe nausea, vomiting, salivation, sweating, bradycardia, hypotension, respiratory depression, collapse and convulsions. Increasing muscle weakness is a possibility and may result in death if respiratory muscles are involved.

Treatment: EXELON (rivastigmine as the hydrogen tartrate salt) has a short plasma half-life (about 1-

2 hours) and a moderate duration of cholinesterase inhibition of B-12 hours. It is recommended that in cases of asymptomatic overdoses, no further dose of EXELON should be administered for the next 24 hours and that patients be monitored. As in any case of overdose, general supportive measures should be utilised. Tertiary anticholinergics such as atropine may be used as an antidote for EXELON overdosage. Intravenous atropine sulfate titrated to effect is recommended: an initial dose of 1.0 to $2.0 \mathrm{mg}$ IV with subsequent doses based upon clinical response. Atypical responses in blood pressure and heart rate have been reported with other cholinomimetics when co-administered with quaternary anticholinergics such as glycopyrolate. Due to the short half-life of EXELON, dialysis (hemodialysis, peritoneal dialysis or hemotiltration) would not be with EXELON, a 69 year old female patient experienced vomiting, incontinence, hypertension, psychomotor retardation and loss of consciousness. The patient was managed conservatively with only supportive measures and fully recovered within 24 hours. Dose-related signs of toxicity in animals included lacrimation, excessive salivation, vomiting, decreased locomotor activity, ataxia, twitches/flutters, tremors and clonic convulsions. DOSAGE AND ADMINISTRATION

EXELON (rivastigmine as the hydrogen tartrate salt) capsules should only be prescribed by (or following consuttation with) clinicians who are experienced in the diagnosis and management of Aizheimer Disease. Adults: The usual maintenance dose range for EXELON is 6-12 mg/day. The following dosage escalation recommendations, derived from clinical trial data, are provided as a guide only, as individual tolerance to dose increases will vary. The incidence of cholinergic adverse events associated with EXELON increase with dose and are more prevalent in females (see ADVERSE REAGTIONS section). The usual starting dose of EXELON is $1.5 \mathrm{mg}$ bid ( $3 \mathrm{mg} /$ day). If this initial dose is well tolerated, after a minimum of 2 weeks the dose may be increased to $3 \mathrm{mg}$ bid ( $6 \mathrm{mg} /$ day). Dose increases above $6 \mathrm{mg} /$ day should proceed cautiously. 
Increases to $4.5 \mathrm{mg}$ bid ( $9 \mathrm{mg} /$ day) and then $6 \mathrm{mg}$ bid ( $12 \mathrm{mg} /$ day) should also be based on good tolerability of the current dose and should only be considered after a minimum of two weeks treatment at that dose level. The maximum dose should not exceed $6 \mathrm{mg}$ bid $(12 \mathrm{mg} /$ day). Following initiation of therapy or any dosage increase, patients should be closely monitored for adverse effects. If adverse effects (e.g. nausea, vomiting, abdominal pain, loss of appetite) are observed during treatment, the patient should be instructed to stop treatment for a few days and then restart at the same dose level, or lower, as clinically indicated. If side effects persist, the drug should be discontinued.

Special Populations: For elderly patients ( $>85$ years old) with low body weight (especially females) or Special Populations: For elderly patients (>85 years old) with low body weight (especially females) or
serious comorbid diseases (see WARNINGS and PAECAUTIONS), it is recommended to start treatment with serious comorbid diseases (see WARNINGS and PRECAUTIONS), it is recommended to start treatm
less frequent dosing (1.5 mg once a day) and to escalate dosage at a slower rate than for adults. less frequent dosing ( $1.5 \mathrm{mg}$ once a day) and to escalate dosage at a slower rate than for adults.
Renally or hepatically impaired: For patients with renal or hepatic impairment (see PRECAUTIONS) it is recommended that treatment be started with less frequent dosing ( $1.5 \mathrm{mg}$ once a day) and that dose escalation be slower than that recommended for adults. EXELON should be taken with food in divided doses in the morning and evening. In a population of cognitively-impaired individuals, safe use of this and all other medications may require supervision.

require supervision.

PHARMACEUTICAL INFOF

Trade Name: EXELON tartrate, also referred to as $(+)(\mathrm{S})-\mathrm{N}$-Ethyl-3[(1-dimethyl-amino)ethyl] - N-methyl-phenylcarbamate hydrogen tartrate. The optical rotation of the base is (-); the optical rotation of the (+) hydrogen tartrate salt is (+). Structural Formula:

$\mathrm{CH}_{3}$

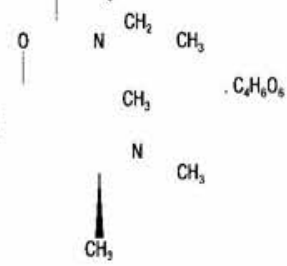

Molecular Formula: $\mathrm{C}_{1} \mathrm{H}_{2} \mathrm{~N}_{2} \mathrm{O}_{2}$ hydrogen tartrate

Molecular Weight: 400.43

Description: White to off-white, fine crystalline powder

Melting Point: $123.0-127.0^{\circ} \mathrm{C}$

Solubilities: Very soluble in water, soluble in ethanol and acetonitrile, slightly soluble in $n$-octanol and ven slightly soluble in ethyl acetate.

pK, in n-octanol/phosphate buffer solution at pH 7: 8.85

Composition of EXELON: Each hard gelatin capsule contains $1.5,3.0,4.5$, or $6.0 \mathrm{mg}$ of rivastigmine base. Inactive ingredients are: hydroxypropyl methylcellulose; magnesium stearate; microcrystalline cellulose

silicon dioxide; hard gelatin capsules contain: gelatin, titanium dioxide and red and/or yellow iron oxides.

Storage Requirements: Store at room temperature (below $30^{\circ} \mathrm{C}$ ).

\section{AVAILABILITY OF DOSAGE FORM}

EXELON (rivastigmine as the hydrogen tartrate salt) is supplied as hard-gelatin capsules containing either $1.5 \mathrm{mg}, 3.0 \mathrm{mg}, 4.5 \mathrm{mg}$, or $6.0 \mathrm{mg}$ of rivastigmine base.

The $1.5 \mathrm{mg}$ capsules are yellow. The strength $(1.5 \mathrm{mg})$ and "EXELON" are printed in red on the body of the capsule. Available in bottles of 60 .

The $3.0 \mathrm{mg}$ capsules are orange. The strength $(3 \mathrm{mg})$ and "EXELON" are printed in red on the body of the capsule. Available in bottles of 60 .

The $4.5 \mathrm{mg}$ capsules are red. The strength $(4.5 \mathrm{mg})$ and "EXELON" are printed in white on the body of the capsule. Available in bottles of 60 .

The $6.0 \mathrm{mg}$ capsules are orange and red. The strength $(6 \mathrm{mg})$ and "EXELON" are printed in red on the body of the capsule. Available in bottles of 60 .

Product Monograph available on request.

*Registered trademark

EXE-00-06-4980E

\section{(1) NOVARTIS}

\section{Continued from page A-41}

NerVous SYSTEM: Frequent: depression, anxiety, paresthesia; Infrequent: tremor, emotional lability, convulsion, paralysis, thinking abnormal, vertigo, abnormal dreams, agitation, depersonalization, euphoria, migraine, stupor, dysautonomia, neuralgia; Rare: dementia, hemiplegia, neuropathy.

RESPRIRATORY SYSTEM: Infrequent: sinusitis, pneumonia, bronchitis; Rare: asthma.

SKIN AND APPENDAGES: Frequent: rash, sweating, skin ulcer; Infrequent: pruritus, dry skin, acne, alopecia, urticaria: Rare: exfoliative dermatitis, herpes simplex, herpes zoster, skin carcinoma. SPECIAL SENSES: Infrequent: ear pain, tinnitus, deafness, glaucoma, conjunctivitis, eye pain, optic neuritis, otitis media, retinal hemorrhage, visual field defect; Rare: initis, keratitis, optic atrophy. UROGENITAL SYSTEM: Infrequent: urinary urgency, cystitis, menorrhagia, pyelonephritis, urinary retention, kidney calculus, uterine fibroids enlarged, vaginal moniliasis, vaginitis; Rare: albuminuria, glycosuria, hematuria, metrorrhagia.

\section{SYMPTOMS AND TREATMENT OF OVERDOSAGE}

One significant overdosage of Zanaflex (tizanidine $\mathrm{HCl}$ ) has been reported. Attempted suicide a 46 yar-old ingestion of 46 year-old male with multiple sclerosis ingestion of one hundred $4 \mathrm{mg}$ Zanaflex tablets. Pupils were not dilated and nystagmus was not present. The patient had marked respiratory depression with Cheyne-Stokes respiration. rastric lavage and forced diuresis with furosemide and mannitol were instituted. The patient
recovered several hours later without sequelae. Laboratory findings were normal. Should overdosage occur, basic steps to ensure the adequacy of an airway and the monitoring of cardiovascular and respiratory systems should be undertaken. For the most recent information concerning the management of overdose, contact a poison control centre.

\section{DOSAGE AND ADMINISTRATION}

A single oral dose of $8 \mathrm{mg}$ of Zanaflex (tizanidine $\mathrm{HCl}$ ) reduces muscle tone in patients with spasticity for a period of several hours. The effect peaks at approximately 1 to 2 hours and cissipates between 3 to 6 hours. Zanaflex dosing should be scheduled such that the peak effect Although single doses of less than $8 \mathrm{mg}$ have not been demonstrated to be effective in controlled clinical studies, the dose-related nature of Zanaflex's common adverse events, particularly blood pressure reduction, make it prudent to begin treatment with single ora doses of $4 \mathrm{mg}$. Increase the dose gradually $\langle 2$ to $4 \mathrm{mg}$ steps) to optimum effect (satisfactory

The dose can be repeated at 6 to 8 hour intervals, as needed, to a maximum of three doses in 24 hours. The total daily dose should not exceed $36 \mathrm{mg}$.

Experience with single doses exceeding $8 \mathrm{mg}$ and daily doses exceeding $24 \mathrm{mg}$ is limited. There is essentially no experience with repeated, single, daytime doses greater than $12 \mathrm{mg}$ or total daily doses greater than $36 \mathrm{mg}$ (see WARNINGS).

PHARMACEUTICAL INFORMATION

DRUG SUBSTANCE

Proper name: tizanidine $\mathrm{HCl}$ (USAN)

Chemical name: 5-chloro-4-(2-imidazolin-2-ylamino)-2,1,3-benzothiodiazole hydrochloride Molecular formula: $\mathrm{C}_{9} \mathrm{H}_{9} \mathrm{Cl}_{2} \mathrm{~N}_{5} \mathrm{~S}$

Structural formula:<smiles>Clc1ccc2nscc2c1NC1=NCCN1</smiles>

Molecular weight: 290.2

Appearance: white to off-white, fine crystalline powder, odorless or faint characteristic odor Solubility: approximately $5 \%$ soluble in water and methanol; solubility in water decreases as the $\mathrm{pH}$ increases

$\mathrm{pK}_{\mathrm{a}}$ value: 7.35 determined potentiometrically

$\mathrm{pH}: 4.3-5.3$

Partition coefficient: $3.6: 1$

Melting point: $288-290^{\circ} \mathrm{C}$

COMPOSITION

Zanaflex (tizanidine $\mathrm{HCl}$ ) tablets are composed of the active ingredient, tizanidine hydrochloride ( $4.576 \mathrm{mg}$ equivalent to $4 \mathrm{mg}$ tizanidine base), and the inactive ingredients, silicon dioxide colloidal, stearic acid, microcrystalline cellulose and anhydrous lactose. STABILITY AND STORAGE RECOMMENDATIONS

The product should be stored at $15-30^{\circ} \mathrm{C}\left(58-86^{\circ} \mathrm{F}\right)$. Dispense in containers with child resistant closure.

\section{AVAILABILTYY OF DOSAGE FORMS}

Zanaflex is supplied as $4 \mathrm{mg}$ white tablets for oral administration, embossed with the Athena logo and "594" on one side and cross-scored on the other. Zanaflex is available in $75 \mathrm{cc}$ white, square, wide mouth high density polyethylene (HDPE) bottles of 150 tablets.

REFERENCES: 1. Nance PW, Bugaresti J, Shellenberger K, et al. Efficacy and safety of tizanidine in the treatment of spasticity in patients with spinal cord injury. Neurology. 1994:44(Suppl 9):S44-S52. 2. Wagstaff AJ. And Bryson HM. Tizanidine A Review of its Pharmacology, Clinical Efficacy and Tolerability in the Management of Spasticity Associated with Cerebral and Spinal Disorders. Drugs 1997; 53(3):435-452. 3. Lataste X, Emre M, Davis C, Groves L. Comparative profile of tizanidine in the management of spasticity. Neurology 1994:44(Suppl 9):S53-S59. 4. Coward DM. Tizanidine: Neuropharmacology and Mechanism of Action. Neurology 1994;44(Suppl 9):S6-S11. 5. Zanaflex Product Monograph.

Full Product Monograph available upon request.
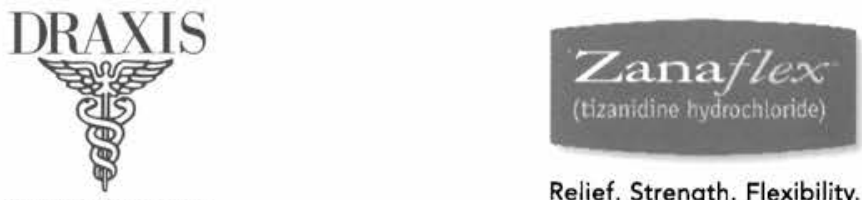

DRAXIS HEALTH INC.

Relief. Strength. Flexibility.

6870 Goreway Drive,

Mississauga, Ontario L4V 1P1

@Zanaflex is a registered trademark of Elan Pharmaceuticals Inc.

DRAXIS HEALTH INC. is the Canadian distributor of Zanaflex. 


\section{Lamictal}

Do not exceed the recommended initial dose and subsequent dose escalations of LAMICTAL. More rapid initial titration has been associated with an increased incidence of serious dermatological reactions (see WARNINGS).

Lamotrigine Tablets (25, 100, and $150 \mathrm{mg}$ Tablets; $5 \mathrm{mg}$ Chewable/Dispersble Tablets)

ACTION AND CLINICAL PHARMACOLOGY

LAMICTAL (lamotrigine) is a drug of the phenyltriazine class, chemically unrelated to existing antiepileptic drugs (AEDs). Lamotrigine is thought to act at voltage-sensitive sodium channels to stabilize neuronal membranes and inhibit the release of excitatory amino acid neurotransmitters (e.g., glutamate, aspartate) that are thought to play a role in the generation and spread of epileptic seizures.

Clinical trials

In adult placebo-controlled clinical studies, LAMICTAL has been shown to be effective in reducing seizure frequency and the number of days with seizures when added to existing antepileptic drug therapy in adult patients with partia seizures, with or without generalized tonic-clonic seizures, that are not satisfactorily controlled.

The effectiveness of lamotrigine adiunctive therapy has also been shown in pediatric and adult patients with LennoxGastaut syndrome. A significant reduction in major motor seizures, drop attacks, and tonic-clonic seizures was seen following lamotrigine treatment compared with placebo treated patients. Improvements in cognitive skills (speech, nonverbal communication, alertness, attention, intellectual capacity), behaviour, and fine coordination have been seen with lamotrigine treatment in these patients.

Studies have also been conducted using lamotrigine monotherapy in adult patients $(n=443)$ newly diagnosed with epilepsy (partial seizures, with or without secondary generalization or primary generalized tonic-clonic). Results have shown comparable efficacy (time to first seizure, seizure frequency, percentage of patients seizure-free) with fewer side effects than currently approved therapies.

Clinical trials have also demonstrated that adult patients (any seizure type) can be converted to lamotrigine monotherapy from polytherapy with significant numbers of pabents maintaining or improving seizure control. Efficacy was maintained during long-term treatment (up to 152 weeks).

Pharmacokinetics

Adults: LAMICTAL is rapidly and completely absorbed following oral administration, reaching peak plasma concentrations 1.4 to 4.8 hours $\left(T_{\text {max }}\right.$ ) post-dosing. When administered with food, the rate of absorption is slighttr reduced, but the extent remains unchanged. Following single LAMICTAL doses of $50-400 \mathrm{mg}$, peak plasm concentration $\left(C_{\max }=0.6-4.6 \mu \mathrm{g} / \mathrm{mL}\right.$ ) and the area under the plasma concentration-versus-time curve (AUC=29.9$211 \mathrm{~h} \mu \mathrm{g} / \mathrm{mL}$ ) increase linearly with dose. The time-to-peak concentration, elimination hall-life (t $\mathrm{k})$, and volume distribution (Vd/F) are independent of dose. The tip averages 33 hours after single doses and $\mathrm{Vd} / \mathrm{F}$ ranges from 0.9 to $1.4 \mathrm{Lkg}$. Following repeated dosing in healthy volunteers for 14 days, the tiv decreased by an average of $26 \%$ (mean 1.4 Lik Following healthy volunteers were administered both oral and intravenous doses of lamotrigine, the absolute bioavailabillty of oral lamotrigine was $98 \%$.

Lamotrigine is approximately $55 \%$ bound to human plasma proteins. This binding is unaffected by therapeutic concentrations of phenytoin, phenobarbital or valproic acid. Lamotrigine does not displace other antiepileptic drugs carbamazepine, phenytoin, phenobarbital) from protein binding sites.

Lamotrigine is metabolized predominantly in the liver by glucuronic acid conjugation. The major metabolite is an inactive $2-\mathrm{N}$-glucuronide conjugate that can be hydrolyzed by $\mathrm{B}$-glucuronidase. Approximately $70 \%$ of an oral LAMICTAL dose is recovered in urine as this metabolite.

Table 1 Mean pharmacokinetic parameters in adult patients with epilepsy or healthy volunteers

\begin{tabular}{|c|c|c|c|c|c|c|}
\hline & \multirow[b]{2}{*}{$\begin{array}{l}\text { LAMICTAL } \\
\text { administered }\end{array}$} & \multicolumn{2}{|c|}{ Healthy young volunteers } & \multicolumn{3}{|c|}{ Patients with epilepsy } \\
\hline & & LAMICTAL & $\begin{array}{l}\text { LAMICTAL } \\
\text { +Valproic } \\
\text { acid }^{*}\end{array}$ & $\begin{array}{c}\text { LAMICTAL } \\
\text { +Enzyme- } \\
\text { inducing } \\
\text { AEDs }\end{array}$ & $\begin{array}{l}\text { LAMICTAL } \\
\text { +Valproic } \\
\text { acid }\end{array}$ & $\begin{array}{l}\text { LAMICTAL } \\
\text { +Valproic acid } \\
\text { +Enzyme- } \\
\text { inducing } \\
\text { AEDs }\end{array}$ \\
\hline $\begin{array}{l}T_{\max } \\
\text { (hrs) }\end{array}$ & $\begin{array}{l}\text { Single dose } \\
\text { Multiple dose }\end{array}$ & $\begin{array}{c}22 \\
(0.25-12.0)^{\dagger} \\
1.7 \\
(0.5-4.0)\end{array}$ & $\begin{array}{c}1.8 \\
(1.0-4.0) \\
1.9 \\
(0.5-3.5) \\
\end{array}$ & $\begin{array}{c}2.3 \\
(0.5-5.0) \\
2.0 \\
(0.75-5.93) \\
\end{array}$ & $\begin{array}{c}4.8 \\
(1.8-8.4) \\
\text { ND }\end{array}$ & $\begin{array}{c}3.8 \\
(1.0-10.0) \\
\text { ND }\end{array}$ \\
\hline$t_{1 / 2}$ & $\begin{array}{l}\text { Single dose } \\
\text { Multiple dose }\end{array}$ & $\begin{array}{c}32.8 \\
(14.0-103.0) \\
25.4 \\
(11.6-61.6)\end{array}$ & $\begin{array}{c}48.3 \\
(31.5-88.6) \\
70.3 \\
(41.9-113.5)\end{array}$ & $\begin{array}{c}14.4 \\
(6.4-30.4) \\
12.6 \\
(7.5-23.1)\end{array}$ & $\begin{array}{c}58.8 \\
(30.5-88.8) \\
\text { ND }\end{array}$ & $\begin{array}{c}27.2 \\
(11.2-51.6) \\
\text { ND }\end{array}$ \\
\hline $\begin{array}{l}\text { Plasma } \\
\text { clearance } \\
\text { (mLminkg) }\end{array}$ & $\begin{array}{l}\text { Single dose } \\
\text { Multiple dose }\end{array}$ & $\begin{array}{c}0.44 \\
(0.12-1.10) \\
0.58 \\
(0.24-1.15)\end{array}$ & $\begin{array}{c}0.30 \\
(0.14-0.42) \\
0.18 \\
(0.12-0.33)\end{array}$ & $\begin{array}{c}1.10 \\
(0.51-2.22) \\
1.21 \\
(0.66-1.82)\end{array}$ & $\begin{array}{c}0.28 \\
(0.16-0.40) \\
\text { ND }\end{array}$ & $\begin{array}{c}0.53 \\
(0.27-1.04) \\
\text { ND }\end{array}$ \\
\hline
\end{tabular}

Valproic acid administered chronically (Multiple-dose study) or for 2 days (Single-dose study).

$\mathrm{ND}=$ Not done

Pediatrics: Lamotrigine was rapidly absorbed in children, with a $T_{\max }$ ranging from 1 to 6 hours. The mean $\mathrm{VdV} F$ of lamotrigine in children aged 5 to 11 years $(1.3$ to $1.4 \mathrm{Lkg})$ was similar to that seen in adults $(0.9 \mathrm{gt} 1.4 \mathrm{Lkg})$ but was larger in younger children $(1.8$ to $2.3 \mathrm{Lkg})$. As with adults, the elimination of lamotrigine in pediatric patients was similarly affected by concomitant AEDs. While the CLF was higher and t $\mathrm{k}$ was shorter in younger children than in older children, the mean CLF was higher and mean $t_{1}$ was shorter in both pediatric groups than in adults. Population analysis results showed that the estimated apparent plasma clearances in patients aged 13 to 18 years were similar to those found in adult patients.

Table 2 Mean pharmacokinetic parameters in pediatric patients with epilepsy

\begin{tabular}{|c|c|c|c|c|}
\hline $\begin{array}{l}\text { Pediatric study } \\
\text { population }\end{array}$ & $\begin{array}{l}\text { Number } \\
\text { of subjects }\end{array}$ & $\begin{array}{c}T_{\max } \\
\text { (h) }\end{array}$ & $\begin{array}{l}t_{1 / 2} \\
\text { (h) }\end{array}$ & $\begin{array}{c}\text { CL/F } \\
(\mathrm{mL} / \min / \mathrm{kg})\end{array}$ \\
\hline \multicolumn{5}{|l|}{10 months to 5.3 years of age } \\
\hline $\begin{array}{l}\text { Patients taking } \\
\text { EIAEDs }\end{array}$ & 10 & $\begin{array}{c}3.0 \\
(1.0-5.9)\end{array}$ & $\begin{array}{c}7.7 \\
(5.7-11.4)\end{array}$ & $\begin{array}{c}3.62 \\
(2.44-5.28)\end{array}$ \\
\hline $\begin{array}{l}\text { Patients taking AEDs } \\
\text { with no known effect on } \\
\text { drug-metabolizing enzymes }\end{array}$ & 7 & $\begin{array}{c}5.2 \\
(2.9-6.1)\end{array}$ & $\begin{array}{c}19.0 \\
(12.9-27.1)\end{array}$ & $\begin{array}{c}1.2 \\
(0.75-2.42)\end{array}$ \\
\hline Patients taking VPA only & 8 & $\begin{array}{c}2.9 \\
(1.0-6.0)\end{array}$ & $\begin{array}{c}44.9 \\
(29.5-52.5)\end{array}$ & $\begin{array}{c}0.47 \\
(0.23-0.77)\end{array}$ \\
\hline \multicolumn{5}{|l|}{5 to 11 years of age } \\
\hline Patients taking EIAEDs & 7 & $\begin{array}{c}1.6 \\
(1.0-3.0)\end{array}$ & $\begin{array}{c}7.0 \\
(3.8-9.8)\end{array}$ & $\begin{array}{c}2.54 \\
(1.35-5.58)\end{array}$ \\
\hline $\begin{array}{l}\text { Patients taking EIAEDs } \\
\text { plus VPA }\end{array}$ & 8 & $\begin{array}{c}3.3 \\
(1.0-6.4)\end{array}$ & $\begin{array}{c}19.1 \\
(7.0-31.2)\end{array}$ & $\begin{array}{c}0.89 \\
(0.39-1.93)\end{array}$ \\
\hline Patients taking VPA only & 3 & $\begin{array}{c}4.5 \\
(3.0-6.0)\end{array}$ & $\begin{array}{c}55.4 \\
(24.3-73.7)\end{array}$ & $\begin{array}{c}0.31 \\
(0.20-0.54)\end{array}$ \\
\hline \multicolumn{5}{|l|}{13 to 18 years of age } \\
\hline Patients taking ElAEDs & 11 & $t$ & $t$ & 1.3 \\
\hline Patients taking EIAEDs plus VPA & 8 & $t$ & $t$ & 0.5 \\
\hline Patients taking VPA only & 4 & $t$ & $t$ & 0.3 \\
\hline
\end{tabular}
oral dose of LAMICTAL (150 mg) was not different from the one in healthy young volunteers. (However, see PRECAUTIONS, Use in the elderly and DOSAGE AND ADMINISTRATION.

Renal impairment: The pharmacokinetics of a single oral dose of LAMICTAL $(100 \mathrm{mg})$ was evaluated in 12 individuals with chronic renal failure (with mean creatinine clearance of $13 \mathrm{~mL} / \mathrm{min}$ ) who were not receiving other antiepileptic drugs, In this study, the elimination half-fife of unchanged lamotrigine was prolonged (by an average of $63 \%$ ) relative to individuals with normal renal function (see PRECAUTIONS, Renal failure and DOSAGE AND ADMINISTRATION

Hemodialysis: In six hemodialysis patients, the elimination half-life of unchanged lamotrigine was doubled off cialysis, and reduced by $50 \%$ on dialysis, relative to individuals with normal renal function.

Hepatic impairment: The pharmacokinetics of lamotrigine in patients with impaired liver function has not been evaluated.

Gilbert's syndrome: Gilbert's syndrome (idiopathic unconjugated hyperbilinubinemia) does not appear to affect the phamacokinetic profile of lamotrigine.

Concomitant antiepileptic drugs: In patients with epilepsy, concomitant administration of LAMICTAL with enzymeinducing AEDs (phenytoin, carbamazepine, primidone, or phenobarbital) decreases the mean lamotrigine $t_{1 / 2}$ to 13 hours. Concomitant administration of LAMICTAL with valproic acid significantly increases $t_{1}$ and decreases the clearance of lamotrigine, whereas concomitant administration of LAMICTAL with valproic acid plus enzyme-inducing AEDs can prolong tis up to approximately 27 hours. Chronic administration of acetaminophen was shown to slighty decrease the to and increase the clearance of a single dose of lamotrigine. The key lamotrigine parameters for adull patients and healthy volunteers are summarized in Table 1, and for pediatric patients in Table 2

INDICATIONS AND CLINICAL USE

LAMICTAL (lamotrigine) is indicated: as adjunctive therapy for the management of adult patients with epilepsy who are not satisfactorily controlled by conventional therapy; for use as monotherapy in adults following withdrawal o concomitant antiepileptic drugs; as adjunctive therapy for the management of the seizures associated with LennoxGastaut syndrome in pediatric and adult patients.

CONTRAINDICATIONS

LAMICTAL. (lamotrigine) is contraindicated in patients with known hypersensitvity to lamotrigine or to any components of the formulation.

\section{WARNINGS}

SERIOUS RASHES ASSOCIATED WITH HOSPITALIZATION HAVE OCCURRED WITH THE USE OF LAMICTA (lamotrigine). THE INCIDENCE OF THESE RASHES IN CLINICAL TRIALS WAS $1 \%(1 / 100)$ IN PEDIATRIC PATIENTS (AGE < 16 YEARS) AND $0.3 \%(3 / 1000)$ IN ADULTS. THE INCIDENCE OF SERIOUS RASH REPORTED AS STEVENS-JOHNSON SYNDROME (SIS) IN CLINICAL TRIALS WAS $0.5 \%(1 / 200)$ IN PEDIATRIC PATIENTS AND $0.1 \%(1 / 1000)$ IN ADULTS. IN WORLDWIDE POSTMARKETING EXPERIENCE, RARE CASES OF TOXIC EPIDERMAL NECROLYSIS AND/OR DEATH ASSOCIATED WITH RASH HAVE BEEN REPORTED, BUT THEIR NUMBERS ARE TOO FEW TO PERMIT A PRECISE ESTIMATE OF THE RATE

A HIGHER INCIDENCE OF SERIOUS DERMATOLOGIC EVENTS (see PRECAUTIONS, Skin-related events, Tables 3 and 4; see also DOSAGE AND ADMINISTRATION) HAS BEEN ASSOCIATED WITH MORE RAPID INITLAL TITRATION (EXCEEDING THE RECOMMENDED INITIAL DOSE OR EXCEEDING THE RECOMMENDED DOSE ESCALATION) AND USE OF CONCOMITANT VALPROIC ACID. NEARLY ALL CASES OF RASH ASSOCIATED WITH LAMICTAL HAVE OCCURRED WITHIN 2 TO 8 WEEKS OF TREATMENT INITIATION. HOWEVER, ISOLATED CASES HAVE BEEN REPORTED AFTER PROLONGED TREATMENT (e.g., 6 MONTHS). ACCORDINGLY, DURATION OF THERAPY CANNOT BE RELIED UPON AS A MEANS TO PREDICT THE POTENTIAL RISK SIGNALLED BY THE FIRST APPEARANCE OF A RASH.

ALTHOUGH BENIGN RASHES ALSO OCCUR WITH LAMICTAL, IT IS NOT POSSIBLE TO PREDICT RELIABLY WHICH RASHES WIL PROVE TO BE LIFE-THREATENING. ACCORDINGLY, ALL PATIENTS WHO DEVELOP RASH SHOULD BE PROMPTLY EVALUATED AND LAMICTAL WITHDRAWN IMMEDIATELY, UNLESS THE RASH IS CLEARLY NOT DRUG RELATED.

Table 3 Effect of concomitant AEDs on rash associated with LAMICTAL in all adult controlled and uncontrolled clinical trials regardless of dosing escalation scheme

\begin{tabular}{|l|c|c|c|c|}
\hline AED group & $\begin{array}{c}\text { Total } \\
\text { patient } \\
\text { number }\end{array}$ & All rashes & $\begin{array}{c}\text { Withdrawal } \\
\text { due to rash }\end{array}$ & $\begin{array}{c}\text { Hospitalization } \\
\text { in association } \\
\text { with rash }\end{array}$ \\
\hline Enzyme-inducing AEDs* & 1788 & $9.2 \%$ & $1.8 \%$ & $0.1 \%$ \\
Enzyme-inducing AEDs + VPA & 318 & $8.8 \%$ & $3.5 \%$ & $0.9 \%$ \\
VPA \pm Non-enzyme-inducing AEDs ${ }^{\dagger}$ & 159 & $20.8 \%$ & $11.9 \%$ & $2.5 \%$ \\
Non-enzyme-inducing AEDs & 27 & $18.5 \%$ & $0.0 \%$ & $0.0 \%$ \\
\hline
\end{tabular}

"Enzyme-inducing AEDs indude carbamazepine, phenobarbital, phenyoin, and primidone.

†Nan-enzyme-inducing AEDs include donazepam, dobazam, ethoswómide, methsuximide, vigabatrin, and gabapentin

Table 4 Effect of the initial daily dose of LAMICTAL, in the presence of concomitant AEDs, on the incidence of rash leading to withdrawal of treatment in adult add-on clinical trials

\begin{tabular}{|c|c|c|c|c|c|c|}
\hline AED group & \multicolumn{2}{|c|}{ Enzyme-inducing AEDs ${ }^{\dagger}$} & \multicolumn{2}{|c|}{$\begin{array}{c}\text { Enzyme-inducing } \\
\text { AEDs+VPA }\end{array}$} & \multicolumn{2}{|c|}{$\begin{array}{c}\text { VPA+Non-enzyme- } \\
\text { inducing AEEs }\end{array}$} \\
\hline $\begin{array}{c}\text { LAMICTAL } \\
\text { average } \\
\text { daily dose (mg) }\end{array}$ & $\begin{array}{c}\text { Total } \\
\text { patient } \\
\text { number }\end{array}$ & $\begin{array}{c}\text { Percentage } \\
\text { of patients } \\
\text { withdrawn }\end{array}$ & $\begin{array}{c}\text { Total } \\
\text { patient } \\
\text { number }\end{array}$ & $\begin{array}{c}\text { Percentage } \\
\text { of patients } \\
\text { withdrawn }\end{array}$ & $\begin{array}{c}\text { Total } \\
\text { patient } \\
\text { number }\end{array}$ & $\begin{array}{c}\text { Percentage } \\
\text { of patients } \\
\text { withdrawn }\end{array}$ \\
\hline 12.5 & 9 & 0.0 & 10 & 0.0 & 51 & 7.8 \\
25 & 3 & 0.0 & 7 & 0.0 & 58 & 12.1 \\
50 & 182 & 1.1 & 111 & 0.9 & 35 & 5.7 \\
100 & 993 & 1.4 & 179 & 4.5 & 15 & 40.0 \\
$\geq 125$ & 601 & 2.8 & 11 & 18.2 & 0 & 0.0 \\
\hline
\end{tabular}

-Average daily dose in week 1

tEnzyme-inducing AEDs indude carbamazepine, phencbartital, phenyloin, and primidone.

¥Non-enzyme-inducing AEDs incude clonazepam, dobazam, ethosuoimide, methsuximide, vigabattin, and gabapentin.

Hypersensitivity reactions: Rash has also been reported as part of a hypersensitvity syndrome associated with a variable pattem of systemic symptoms including fever, lymphadenopathy, facial oedema and abnormalifies of the blood and liver. The syndrome shows a wide spectrum of clinical severity and may rarely lead to disseminated intravascular coagulation (DIC) and multiorgan failure. It is important to note that early manifestations of hypersensitivity (e.g., fever, lymphadenopathy) may be present even though rash is not evident. If such signs and symptoms are present, the patient should be evaluated immediately and LAMICTAL discontinued if an alternative aetiology cannot be established.

Prior to initiation of treatment with LAMICTAL, the patient should be instructed that a rash or other signs or symptoms of hypersensitivity (e.g., fever, lymphadenopathy) may herald a serious medical event and that the patient should report any such occurrence to a physician immediately.

\section{PRECAUTIONS}

Abrupt discontinuation of any antiepileptic drug (AED) in a responsive patient with eplepsy may provoke rebound seizures. In general, withdrawal of an AED should be gradual to minimize this risk. Unless safety concems (i.e., rash) require a more rapid withdrawal, the dose of LAMICTAL (lamotrigine) should be tapered over a period of at least two weeks (see DOSAGE AND ADMINISTRATION).

Occupational hazards

Patients with uncontrolled epilepsy should not drive or handle potentially dangerous machinery. During clinical trials, common adverse effects included dizziness, ataxia, drowsiness, diplopia, and blurred vision. Patients should be advised to refrain from activites requiring mental alertness or physical coordination until they are sure that LAMICTAL does not affect them adversely.

Skin-related events

In adult controlled studies of adjunctive lamotrigine therapy, the incidence of rash (usually maculopapular and/or erythematous) in patients receiving LAMICTAL was $10 \%$ compared with $5 \%$ in placebo patients. The rash usually 
occurred within the first six weeks of therapy and resolved during continued administration of LAMICTAL. LAMICTAL was discontinued because of rash in $1.1 \%$ of adult patients in controlled studies and $3.8 \%$ of all patients in all studies. The rate of rash-related withdrawal in clinical studies was higher with more rapid initial titration dosing and in patients receiving concomitant valproic acid (VPA), particularly in the absence of enzyme-inducing AEDs (see Tables 3 and 4; see also WARNINGS and DOSAGE AND ADMINISTRATION).

Increased incidence of rash-related withdrawal was seen when initial doses were higher and titration more rapid than recommended under DOSAGE AND ADMINISTRATION.

\section{Drug Interactions}

Antleplleptlc drugs (AEDs): Lamotrigine does not affect the plasma concentrations of concomitantly administered enzyme-inducing AEDs. Antiepileptic drugs that induce hepatic drug-metabolizing enzymes (phenytoin, carbamazepine, phenobarbital, primidone) increase the plasma clearance and reduce the elimination half-life of lamotrigine (se ACTION AND CLINICAL PHARMACQLOGY).

Valproic acid reduces the plasma clearance and prolongs the elimination half-life of lamotrigine (see ACTION AND CLINICAL PHABMACOLOGY). When LAMICTAL was administered to 18 healthy volunteers already receiving valproic acid, a modest decrease ( $25 \%$ on average) in the trough steady-state valproic acid plasma concentrations was observed over a 3-week period, followed by stabilization. However, the addition of LAMICTAL did not affect the plasma concentration of valproic acid in patients receiving enzyme-inducing AEDs in combination with valproic acid. See also PRECAUTIONS, Skin-related events.

The net effects of co-administration of LAMICTAL with phenytoin, carbamazepine or valproic acid are summarized in Table 5 .

Table 5 Summary of AED interactions with LAMICTAL

\begin{tabular}{|l|l|l|}
\hline AED & $\begin{array}{l}\text { AED plasma concentration } \\
\text { with adjunctive LAMICTAL* }\end{array}$ & $\begin{array}{l}\text { Lamotrigine plasma concentration } \\
\text { with adjunctive AEDs }\end{array}$ \\
\hline Phenytoin (PHT) & No significant effect & $\downarrow 50 \%$ \\
Carbamazepine (CBZ) & No significant effect & $\downarrow 40 \%$ \\
CBZ epoxide & Conficting data & $\uparrow 200 \%$ \\
Valproic acid (VPA) & Decreased & No significant effect \\
VPA + PHT and/or CBZ & Not evaluated & \\
\hline
\end{tabular}

"From adjunctive clinical trials and volunteer studies.

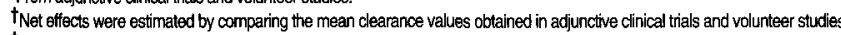

F Not administered, but an active metabolite of carbamazepine.

Oral contraceptives: In a study of 12 female volunteers, LAMICTAL did not affect plasma concentrations of ethinyloestradiol and levonorgestrel following administration of the oral contraceptive pill. However, as with the introduction of other chronic therapy in patients taking oral contraceptives, the patient should be asked to report any change in the menstrual bleeding pattem.

Drugs depressing cardiac conduction: (see Patients with special diseases and conditions and Cardlac conduction abnormallties).

Druglaboratory test interactions: LAMICTAL has not been associated with any assay interferences in clinical laboratory tests

\section{Use In pedlatrics}

Safety and efficacy in patients below the age of 16 years, other than those with Lennox-Gastaut syndrome, have not been established.

Use in the elderly

The safety and efficacy of LAMICTAL in elderly patients with epilepsy have not been systematically evaluated in clinical trials. Caution should thus be exercised in dose selection for an elderly patient, recognizing the more frequent hepatic, renal, and cardiac dystunctions and limited experience with LAMICTAL in this population.

\section{Ues in obsterncs}

Pregnancy: Studies in mice, rats and rabbits given lamotrigine orally or intravenously revealed no evidence of teratogenicity; however, matemal and secondary fetal toxicity were observed. Studies in rats and rabbits indicate that lamotrigine crosses the placenta; placental and fetal levels of lamotrigine were low and comparable to levels in matemal plasma. Because animal reproduction studies are not always predictive of human response, LAMICTAL should only be used during pregnancy if the benefits of therapy outweigh the risks associated with it.

Clinical trial data indicate that lamotrigine has no effect on blood folate concentrations in adults; however, its effects during human fetal development are unknown.

To facilitate monitoring fetal outcomes of pregnant women exposed to lamotrigine, physicians are encouraged to register patients, before fetal outcome (e.g., ultrasound, results of anmiocentesis, birth, etc.) is known, in the Antiepilpetic Drug Pregnancy Registry by calling $1800336-2176$ (toll free).

Labor and delivery: The effect of LAMICTAL on labor and delivery in humans is unknown.

Nursing mothers: LAMICTAL is excreted in human milk. Because of the potential for adverse reactions from LAMICTAL in nursing infants, breast-feeding while taking this medication is not recommended.

Patlents with speclal diseases and conditions

Clinical experience with LAMICTAL in patients with concomitant illness is limited. Caution is advised when using LAMICTAL in patients with diseases or conditions that could affect the metabolism or elimination of the drug.

Benal fallure: A study in individuals with chronic renal failure (not receiving other AEDs) indicated that the elimination half-life of unchanged lamotrigine is prolonged relative to individuals with normal renal function (see ACTION AND CLINICAL PHARMACOLOGY). Use of LAMICTAL in patients with severe renal impairment should proceed with caution.

Impalred IVer function: There is no experience with the use of LAMICTAL in patients with impaired liver function. Caution should be exercised in dose selection for patients with this condition.

Cardlac conduction abnormalthies: One placebo-controlled trial that compared electrocardiograms at baseline and during treatment demonstrated a mild prolongation of the P-R interval associated with LAMICTAL administration. The prolongation was statistically significant but clinically insignificant. Patients with significant cardiovascular disease or electrocardiographic abnormalities were, however, systematically excluded from clinical trials. Thus, LAMICTAL should be used with caution in patients with cardiac conduction abnormalities, and in patients taking concomitant medications which depress AV conduction.

Dependence liabillity

No evidence of abuse potential has been associated with LAMICTAL, nor is there evidence of psychological or physical dependence in humans.

Laboratory tests

The use of LAMICTAL does not require routine monitoring of any clinical laboratory parameters or plasma levels of concomitant AEDs.

\section{ADVERSE REACTIONS}

RARELY, SERIOUS SKIN RASHES, INCLUDING STEVENS-JOHNSON SYNDROME AND TOXIC EPIDERMAL NECROLYSIS (LYELL SYNDROME) HAVE BEEN REPORTED. ALTHOUGH THE MAJORITY RECOVER FOLLOWING DRUG WITHDRAWAL, SOME PATIENTS EXPERIENCE IRREVERSIBLE SCARRING AND THERE HAVE BEEN RARE CASES OF ASSOCIATED DEATH (see WARNINGS)

Adverse experiences in patients receiving LAMICTAL (lamotrigine) were generally mild, occurred within the first two weeks of therapy, and resolved without discontinuation of the drug

Commonly observed

The most commonly observed adverse experiences associated with the use of adjunctive therapy with LAMICTAL (incidence of at least $10 \%$ ) were dizziness, headache, diplopia, somnolence, ataxia, nausea, and asthenia.

Dizziness, diplopia, ataxia, and blurred vision were dose-related and occurred more commonly in patients receiving carbamazepine in combination with LAMICTAL than in patients receiving other enzyme-inducing AEDs with LAMICTAL. Reduction of the daily dose and/or alteration of the timing of doses of concomitant antiepileptic drugs and/or LAMICTAL may reduce or tilminate these symptoms. Clinical data suggest a higher incidence of rash in patients who are receiving concomitant valproic acid, or non-inducing AEDs (see WAANINGS; see also PRECAUTIONS, Skin-related events, Table 3).
Adverse events assoclated with discontinuation of treatment

Across all aduit add-on studies, the most common adverse experiences associated with discontinuation of LAMICTA were rash, dizziness, headache, ataxia, nausea, diplopia, somnolence, seizure exacerbation, asthenia, and blured vision. In controlled clinical trials, $6.9 \%$ of the 711 patients receiving LAMICTAL discontinued therapy due to an adverse experience, versus $2.9 \%$ of the 419 patients receiving placebo. Of 3501 patients and volunteers who received LAMICTAL in premarketing clinical studies, $358(10.2 \%)$ discontinued therapy due to an adverse experience. Serious adverse events assoclated with discontinuation of treatment

Discontinuation due to an adverse experience classified as serious occurred in $2.3 \%$ of adult patients and volunteer who received LAMICTAL in the premarketing studies. Rash accounted for almost half of the discontinuations due to serious adverse experiences. More rapid initial titration of LAMICTAL and concomitant use of valproic acid were associated with higher incidences of rash-related withdrawal in clinical studies (see WARNINGS; see also PRECAUTIONS, Skin-related events, Table 4).

Adult controlled add-on cllnical studles

Table 6 enumerates adverse experiences that occurred with an incidence of $2 \%$ or greater among refractory patients with epilepsy treated with LAMICTAL.

Table 6 Treatmentemergent adverse experience incidence in adult placebo-controlled clinical studies*

\begin{tabular}{|c|c|c|c|}
\hline $\begin{array}{l}\text { Body system } \\
\text { Adverse experience } t\end{array}$ & & $\begin{array}{l}\text { Percent of patlents } \\
\text { recelving LAMICTAL } \\
\text { (and other AEDs) } \\
\text { ( } n=711)\end{array}$ & $\begin{array}{l}\text { Percent of patients } \\
\text { recelving placebo } \\
\text { (and other AEDs) } \\
\quad(n=419)\end{array}$ \\
\hline BODY AS A WHOLE & $\begin{array}{l}\text { Headache } \\
\text { Accidental injury } \\
\text { Asthenia } \\
\text { Flu syndrome } \\
\text { Pain } \\
\text { Back pain } \\
\text { Fever } \\
\text { Abdominal pain } \\
\text { Infection } \\
\text { Neck pain } \\
\text { Malaise } \\
\text { Seizure exacerbation }\end{array}$ & $\begin{array}{r}29.1 \\
9.1 \\
8.6 \\
7.0 \\
6.2 \\
5.8 \\
5.5 \\
5.2 \\
4.4 \\
2.4 \\
2.3 \\
2.3\end{array}$ & $\begin{array}{r}19.1 \\
8.6 \\
8.8 \\
5.5 \\
2.9 \\
6.2 \\
3.6 \\
3.6 \\
4.1 \\
1.2 \\
1.9 \\
0.5\end{array}$ \\
\hline DIGESTIVE & $\begin{array}{l}\text { Nausea } \\
\text { Vomiting } \\
\text { Diarnea } \\
\text { Dyspepsia } \\
\text { Constipation } \\
\text { Tooth disorder }\end{array}$ & \begin{tabular}{r|}
18.6 \\
9.4 \\
6.3 \\
5.3 \\
4.1 \\
3.2
\end{tabular} & $\begin{array}{l}9.5 \\
4.3 \\
4.1 \\
2.1 \\
3.1 \\
1.7\end{array}$ \\
\hline MUSCULOSKELETAL & $\begin{array}{l}\text { Myalgia } \\
\text { Arthralgia }\end{array}$ & $\begin{array}{l}2.8 \\
2.0\end{array}$ & $\begin{array}{l}3.1 \\
0.2\end{array}$ \\
\hline NERYOUS & $\begin{array}{l}\text { Dizziness } \\
\text { Ataxia } \\
\text { Somnolence } \\
\text { Incoordination } \\
\text { Insomnia } \\
\text { Tremor } \\
\text { Depression } \\
\text { Anxiety } \\
\text { Convulsion } \\
\text { Irritability } \\
\text { Speech disorder } \\
\text { Memory decreased }\end{array}$ & $\begin{array}{r}38.4 \\
21.7 \\
14.2 \\
6.0 \\
5.6 \\
4.4 \\
4.2 \\
3.8 \\
3.2 \\
3.0 \\
2.5 \\
2.4\end{array}$ & $\begin{array}{r}13.4 \\
5.5 \\
6.9 \\
2.1 \\
1.9 \\
1.4 \\
2.6 \\
2.6 \\
1.2 \\
1.9 \\
0.2 \\
1.9\end{array}$ \\
\hline RESPIRATORY & $\begin{array}{l}\text { Rhinitis } \\
\text { Pharyngitis } \\
\text { Cough increased } \\
\text { Respiratory disorder }\end{array}$ & $\begin{array}{r}13.6 \\
9.8 \\
7.5 \\
5.3\end{array}$ & $\begin{array}{l}9.3 \\
8.8 \\
5.7 \\
5.5\end{array}$ \\
\hline SKIN AND APPENDAGES & $\begin{array}{l}\text { Rash } \\
\text { Prunitus }\end{array}$ & $\begin{array}{r}10.0 \\
3.1\end{array}$ & $\begin{array}{l}5.0 \\
1.7\end{array}$ \\
\hline SPECIAL SENSES & $\begin{array}{l}\text { Diplopia } \\
\text { Blured vision } \\
\text { Vision abnormality }\end{array}$ & $\begin{array}{r}27.6 \\
15.5 \\
3.4\end{array}$ & $\begin{array}{l}6.7 \\
4.5 \\
1.0\end{array}$ \\
\hline $\begin{array}{l}\text { UROGENITAL } \\
\text { (Female patients) }\end{array}$ & $\begin{array}{l}\text { Dysmenormea } \\
\text { Menstrual disorder } \\
\text { Vaginitis }\end{array}$ & $\begin{array}{c}(n=365) \\
6.6 \\
5.2 \\
4.1\end{array}$ & $\begin{array}{c}(\mathrm{n}=207) \\
6.3 \\
5.8 \\
0.5\end{array}$ \\
\hline
\end{tabular}

*Patients in these studies were receiving 1 to 3 concomitant enzyme-inducing antiepileptic drugs in addition to LAMICTAL or placebo. Patients may have reported multiple adverse experiences during the study or at discontinuation Thus, patients may be included in more than one category.

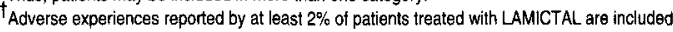

\section{Other events observed during clinlcal studies}

During clinical testing multiple doses of LAMICTAL were administered to 3501 patients and volunteers. The conditions and duration of exposure to LAMICTAL during these clinical studies varied greatly. Studies included monotherapy and pediatric trials. A substantial proportion of the exposure was gained in open, uncontrolled clinical studies. Adverse experiences associated with exposure to LAMICTAL were recorded by clinical investigators using terminology of their own choosing. Consequently, it is not possible to provide a meaninglul estimate of the proportion of individuals experiencing adverse events without first grouping similar types of adverse experiences into a smaller number of standardized event categories.

Since the reported adverse experiences occurred during treatment with LAMICTAL in combination with other antiepileptic drugs, they were not necessarily caused by LAMICTAL.

The following adverse events have been reported on one or more occasions by at least $1 \%$ of patients and volunteers exposed to LAMICTAL: anorexia, weight gain, amnesia, concentration disturbance, confusion, emotional lability, nervousness, nystagmus, paresthesia, thinking abnomality, and vertigo. (All types of events are included except those already listed in Table 6.)

\section{Adult monotherapy clinical studies}

Withdrawals due to adverse events were reported in $42(9.5 \%)$ of newly diagnosed patients treated with LAMICTAL monotherapy. The most common adverse experiences associated with discontinuation of LAMICTAL were rash $(6.1 \%)$, asthenia $(1.1 \%)$, headache $(1.1 \%)$, nausea $(0.7 \%)$, and vomiting $(0.7 \%)$. Ad|unctlve therapy in Lennox-Gastaut syndrome

In 169 adult and pediatric patients with Lennox-Gastaut syndrome, 3.8\% of patients on LAMICTAL and $7.8 \%$ of patients on placebo discontinued due to adverse experiences. The most commonly reported adverse experiences that led to discontinuation were rash for patients treated with LAMICTAL, and deterioration of seizure control for patients treated with placebo. Fever and infection occurred at least $10 \%$ more frequently in patients $\leq 12$ years of age than in patients $>12$ years of age on LAMICTAL. Rash occurred at least $10 \%$ more frequently in female patients than male patients on LAMICTAL. Table 7 lists adverse events that occurred in at least $1 \%$ of 79 adult and pediatric patients who received LAMICTAL up to $15 \mathrm{mg} / \mathrm{kg}$ per day or a maximum of $400 \mathrm{mg}$ per day.

Other events observed during clinical practice and from "compassionate plea" patients

In addition to the adverse experiences reported during clinical testing of LAMICTAL, the following adverse experiences have been reported in patients receiving LAMICTAL marketed in other countries and from worldwide "compassionate plea" patients. These adverse experiences have not been listed in Tabies 6 and 7 and data are insufficient to support an estimate of their incidence or to establish causation. The listing is alphabetized: apnea, enythema multiforme, esophagitis, hematemesis, hemolytic anemia, pancreatitis, pancytopenia and progressive immunosuppression. 
Table 7 Treatmentemergent adverse experlence incidence in placebo-controlled add-on trlal In adult and pedlatric patients with Lennox-Gastaut syndrome

\begin{tabular}{|c|c|c|c|}
\hline $\begin{array}{l}\text { Body system/ } \\
\text { Adverse experience }\end{array}$ & & $\begin{array}{c}\text { Percent of patients } \\
\text { recelving LAMICTAL } \\
(n=79)\end{array}$ & $\begin{array}{c}\text { Percent of patients } \\
\text { recelving placebo } \\
(\mathrm{n}=90)\end{array}$ \\
\hline BODY AS A WHOLE & $\begin{array}{l}\text { Infection } \\
\text { Accidental injury } \\
\text { Flu syndrome } \\
\text { Asthenia } \\
\text { Abdominal pain } \\
\text { Back pain } \\
\text { Edema of the face } \\
\text { Lab test abnormal } \\
\text { Pain }\end{array}$ & $\begin{array}{r}13 \\
9 \\
5 \\
3 \\
3 \\
1 \\
1 \\
1 \\
1\end{array}$ & $\begin{array}{l}8 \\
7 \\
0 \\
1 \\
0 \\
0 \\
0 \\
0 \\
0\end{array}$ \\
\hline CARDIOVASCULAR & Hemorthage & 3 & 0 \\
\hline DIGESTIVE & $\begin{array}{l}\text { Vomiting } \\
\text { Constipation } \\
\text { Diantea } \\
\text { Nausea } \\
\text { Anorexia } \\
\text { Stomatitis aphthosa } \\
\text { Tooth disorder }\end{array}$ & $\begin{array}{l}9 \\
5 \\
4 \\
4 \\
3 \\
1 \\
1\end{array}$ & $\begin{array}{l}7 \\
2 \\
2 \\
1 \\
1 \\
0 \\
0\end{array}$ \\
\hline ENDOCRINE & $\begin{array}{l}\text { Cushing's syndrome } \\
\text { Hypothyroidism }\end{array}$ & $\begin{array}{l}\dagger \\
1\end{array}$ & $\begin{array}{l}0 \\
0\end{array}$ \\
\hline HEMIC AND LYMPHATIC & $\begin{array}{l}\text { Lymphadenopathy } \\
\text { (enlarged cenvical nodes) }\end{array}$ & 1 & 0 \\
\hline NERVOUS SYSTEM & $\begin{array}{l}\text { Alaxia } \\
\text { Convulsions } \\
\text { Tremor } \\
\text { Agitation } \\
\text { Coordination } \\
\text { Dizziness } \\
\text { Emotional lability } \\
\text { Nervousness } \\
\text { Vertigo }\end{array}$ & $\begin{array}{l}4 \\
4 \\
3 \\
1 \\
1 \\
1 \\
1 \\
1 \\
1\end{array}$ & $\begin{array}{l}1 \\
1 \\
0 \\
0 \\
0 \\
0 \\
0 \\
0 \\
0\end{array}$ \\
\hline RESPIRATORY & $\begin{array}{l}\text { Pharyngitis } \\
\text { Bronchitis } \\
\text { Pneumonia } \\
\text { Dyspnea }\end{array}$ & $\begin{array}{r}14 \\
9 \\
3 \\
1\end{array}$ & $\begin{array}{r}10 \\
7 \\
0 \\
0\end{array}$ \\
\hline SKIN & $\begin{array}{l}\text { Rash } \\
\text { Eczema } \\
\text { Nail disorder }\end{array}$ & $\begin{array}{l}9 \\
4 \\
1\end{array}$ & $\begin{array}{l}7 \\
0 \\
0\end{array}$ \\
\hline SPECIAL SENSES & $\begin{array}{l}\text { Blepharitis } \\
\text { Conjunctivitis } \\
\text { Keratitis } \\
\text { Ear pain } \\
\text { Eye pain }\end{array}$ & $\begin{array}{l}1 \\
1 \\
1 \\
1 \\
1\end{array}$ & $\begin{array}{l}0 \\
0 \\
0 \\
0 \\
0\end{array}$ \\
\hline UROGENITAL & $\begin{array}{l}\text { Urinary tract infection } \\
\text { Balanitis } \\
\text { Penis disorder }\end{array}$ & $\begin{array}{l}3 \\
2 \\
2\end{array}$ & $\begin{array}{l}0 \\
0 \\
0\end{array}$ \\
\hline
\end{tabular}

The most frequently reported adverse reactions in children $\leq 12$ years of age in both treatment groups were pharyngitis, fever, and infection.

\section{SYMPTOMS AND TREATMENT OF OVERDOSAGE}

During the clinical development program, the highest known overdose of LAMICTAL (lamotrigine) occurred in 33-year old female who ingested between 4000 and $5000 \mathrm{mg}$ LAMICTAL that corresponded to a plasma level of $52 \mu \mathrm{g} / \mathrm{mL}$ four hours after the ingestion. The patient presented to the emergency room comatose and remained comatose for 8 to 12 hours, retumed to almost nomal over the next 24 hours, and completely recovered by the third day. Among patients $\leq 16$ years of age, the two highest known single doses of LAMICTAL have been $3000 \mathrm{mg}$ by a 14-year old female and approximately $1000 \mathrm{mg}$ by a 4-year old male. The 14-year old female was taking marketed LAMICTAL after the dose, she lost consciousness and was admitted to the hospital for supportive therapy, where she recovered fully (time to recovery not reported). The 4-year old male was drowsy and agitated when found, and his condition worsened to coma level II after hospitalization. He was given supportive therapy, and his condition improved rapidly with full recovery in 3 days.

There are no specific antidotes for LAMICTAL. Following a suspected overdose, hospitalization of the patient is advised. General supportive care is indicated, including frequent monitoring of vital signs and close observation of the patient. If indicated, emesis should be induced or gastric lavage should be performed. It is uncertain whether hemodialysis is an effective means of removing lamotrigine from the blood. In six renal fallure patients, about $20 \%$ o the amount of lamatrigine in the body was removed during 4 hours of hemodialysis. DOSAGE AND ADMINISTRATION

\section{General}

LAMICTAL (lamotrigine) is intended for oral administration and may be taken with or without lood. LAMICTAL should be added to the patient's current antiepileptic therapy.

Valproic acid more than doubles the elimination half-life of lamotrigine and reduces the plasma clearance by $50 \%$; conversely, hepatic enzyme-inducing drugs such as carbamazepine, phenytoin, phenobarbital, and primidone reduce the elimination half-life of lamotrigine by $50 \%$ and double the plasma clearance (see ACTION AND CLINICAL PHARMACOLOGY). These clinically important interactions require dosage schedules of LAMICTAL as summanized in Tables 8 through 11.

LAMICTAL does not alter plasma concentrations of concomitantly administered enzyme-inducing AEDs, and therefore, they do not usually require dose adjustment to maintain therapeutic plasma concentrations. For patients receiving LAMICTAL in combination with other AEDs, an evaluation of all AEDs in the regimen should be considered if a change in seizure control or an appearance or worsening of adverse experiences is observed. If there is a need to discontinue therapy with LAMICTAL, a step-wise reduction of dose over at least two weeks (approximately $50 \%$ per week) is recommended unless safety concems (i.e., rash) require a more rapid withdrawal (see WARNINGS and PRECAUTIONS).

The relationship of plasma concentration to clinical response has not been established for lamotrigine. Dosing of LAMICTAL should be based on therapeutic response. In controlled clinical studies, doses of LAMICTAL that were efficacious generally produced steady-state trough plasma lamotrigine concentrations of 1 to $4 \mu \mathrm{g} / \mathrm{mL}$ in patients receiving one or more concomitant AEDs. Doses of LAMICTAL producing this plasma concentration range were well tolerated. As with any antiepileptic drug, the oral dose of LAMICTAL should be adjusted to the needs of the individual patient, taking into consideration the concomitant AED therapy the patient is receiving.

Adults and children over 12 years of age

Do not exceed the recommended intial dose and subsequent dose escalations of LAMICTAL. More rapid initlal titration has been associated wlth an increased incidence of serious dermatological reactions (see WARNINGS). For patients taking AEDs whose pharmacokinetic interactions with LAMICTAL are currently unknown, follow the titration schedule for concomitant VPA and non-enzyme-inducing AEDs.

There have been no controlled studles to establlish the effectlveness or optimal dosing regimen of add-on LAMICTAL therapy In pattents recelving only non-enzyme--nducing AEDs or valprolc acid. However, avallable data trom open clinical trials indlcate that the addiflon of LAMICTAL under these conditions is associated with a higher Incidence of serlous rash or rash-related withdrawal, even at an initial titration dose of $12.5 \mathrm{mg}$ dally (see PRECAUTONS, SkIn-related events, Tables 3 and 4; see also WARNINGS). The potential medical benefits of the addition of LAMICTAL under these conditions must be weighed against the increased risk of serious rash. If use of LAMICTAL under these conditions is considered clinically indicated, titration should proceed with extreme caution, especially during the first six weeks of treatment.

\begin{tabular}{|l|l|}
\hline Weeks $1+2$ & $25 \mathrm{mg}$ once a day \\
\hline Weeks $3+4$ & $25 \mathrm{mg}$ twice a day \\
\hline Usual maintenance & $\begin{array}{l}\text { To achieve maintenance, doses may be increased by } \\
25-50 \mathrm{mg} \text { every } 1 \text { to } 2 \text { weeks. } \\
\text { Usual dose is between } 50-100 \mathrm{mg} \text { twice a day. }\end{array}$ \\
\hline
\end{tabular}

"Enzyme-inducing AEDs include carbamazepine, phenobatitial, phenytoin, and primidon

tColumn reflects dosage recommendations in the U.K. and is provided for information.

Usual dose is between
$50-100 \mathrm{mg}$ twice a day.

Table 9 LAMICTAL added to enzyme-inducing AEDs" (without VPA) in patients over 12 years of age

\begin{tabular}{|l|l|}
\hline Weeks $1+2$ & $50 \mathrm{mg}$ once a day \\
\hline Weeks $3+4$ & $50 \mathrm{mg}$ twice a day \\
\hline Usual maintenance & $\begin{array}{l}\text { To achieve maintenance, doses may be increased by } 100 \mathrm{mg} \text { every } 1 \text { to } 2 \text { weoks. } \\
\text { Usual dose is between } 150-250 \mathrm{mg} \text { twice a day. }\end{array}$ \\
\hline
\end{tabular}

"Enzyme-inducing AEDs include carbamazepine, phenobarbital, phenytoin, and primidone.

Withdrawal of concomitant AEDs in adults

Concomitant AEDs may be decreased over a 5 -week period, by approximately $20 \%$ of the original dose every woek However, a slower taper may be used if clinically indicated. During this period, the dose of LAMICTAL administered will be dependent upon the effect of the drug being withdrawn on the pharmacokinetics of lamotrigine, logether with the overall clinical response of the patient. The withdrawal of enzyme-inducing AEDs (i.e., phenytoin, phenobarbital, primidone, and carbamazepine) will result in an approximate doubling of the $t_{\text {t }}$ of lamotrigine. Under these conditions, it may be necessary to reduce the dose of LAMICTAL. In contrast, the withdrawal of enzyme inhibiting AEDs (i.e., valproic acid) will result in a decrease in the $t_{1}$ of lamotigine and may require an increase in the dose of LAMICTAL

Pediatrlc dosing

Do not exceed the recommended initial dose and subsequent dose escalations of LAMICTAL. More rapid initial tifration has been associated with an increased incldence of serious dermatological reactions (see WARNINGS). Safety and efficacy in pattents below the age of 16 years, other than those with Lennox-Gastaut syndrome, have not been establlshed.

Table 10 Pediatric dosing with LAMICTAL for patients receiving valproic acid with or without enzymeinducing AEDs*

\begin{tabular}{|c|c|c|c|c|}
\hline \multicolumn{2}{|c|}{ Weight range } & $\begin{array}{l}\text { Weeks } 1+2 \\
0.15 \mathrm{mg} / \mathrm{kg} \\
\text { once a day }\end{array}$ & $\begin{array}{l}\text { Weeks } 3+4 \\
0.3 \mathrm{mg} / \mathrm{kg} \\
\text { once a day }\end{array}$ & $\begin{array}{l}\text { Weeks } 5 \text { and onwards } \\
\text { to usual malntenance doset } \\
\text { To achieve maintenance, doses } \\
\text { may be increased by } 0.3 \text { mgkg } \\
\text { every } 1-2 \text { weeks, to a maximum } \\
\text { of } 200 \mathrm{mg} / \text { day. Usual dose is } \\
\text { between } 1-5 \text { mgkg once a day. } .\end{array}$ \\
\hline$<17 \mathrm{~kg}$ & $<37 \mathrm{lbs}$ & \multicolumn{3}{|c|}{$\begin{array}{l}\text { Do not take LAMICTAL because therapy cannot be initiated with currently available } \\
\text { tablet strengths. }\end{array}$} \\
\hline $17-33 \mathrm{~kg}$ & $37-73 \mathrm{bs}$ & $5 \mathrm{mg}$ every other day & $5 \mathrm{mg} /$ day & $\begin{array}{l}\text { Increase dose by no more } \\
\text { than } 5 \text { modday every } 1-2 \text { weeks. }\end{array}$ \\
\hline $34-49 \mathrm{~kg}$ & $75-108$ lbs & $5 \mathrm{mg} / \mathrm{day}$ & $10 \mathrm{mg} / \mathrm{day}$ & $\begin{array}{l}\text { Increase dose by no more } \\
\text { than } 10 \text { mgday every } 1-2 \text { woeks. }\end{array}$ \\
\hline $250 \mathrm{~kg} \S$ & $\geq 110$ bs & $5 \mathrm{mg} / \mathrm{day}$ & $15 \mathrm{mg} / \mathrm{day}$ & $\begin{array}{l}\text { Increase dose by no more } \\
\text { than } 15 \text { mgdday every } 1-2 \text { weeks. }\end{array}$ \\
\hline
\end{tabular}

"Enzyme-inducing AEDs indude carbamazepine, phenobarbital, phenytoin, and primidone.

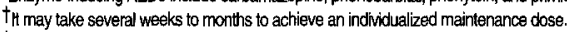

†Can be given as two divided doses.

\$insufficient data are available to be able to support the mykg dosing in patients weighing more than $50 \mathrm{~kg}$

Table 11 Pediatric dosing with LAMICTAL for patients receiving enzyme-1nducing AEDs*t,t without valproic acid

\begin{tabular}{|c|c|c|c|c|}
\hline \multicolumn{2}{|c|}{ Weight range } & $\begin{array}{l}\text { Weeks } 1+2 \\
0.3 \mathrm{mg} k \mathrm{~kg} \\
\text { twice a day }\end{array}$ & $\begin{array}{l}\text { Weeks } 3+4 \\
0.6 \mathrm{mg} / \mathrm{kg} \\
\text { twice a day }\end{array}$ & $\begin{array}{l}\text { Weeks } 5 \text { and onwards } \\
\text { to usual maintenance doses } \\
\text { To achieve maintenance, doses } \\
\text { may be increased by } 1.2 \mathrm{mgkg} \\
\text { every } 1-2 \text { weeks, to a maximum of } \\
400 \mathrm{mg} / \mathrm{day} \text {. Usual dose is between } \\
2.5-7.5 \mathrm{mgkg} \text { twice a day. }\end{array}$ \\
\hline $8 \mathrm{~kg}$ & $<20$ lbs & \multicolumn{3}{|c|}{$\begin{array}{l}\text { Do not take LAMICTAL because therapy cannot be initated with currently available } \\
\text { tablet strengths }\end{array}$} \\
\hline $9-12 \mathrm{~kg}$ & $20-26 \mathrm{lbs}$ & 5 mg/day & $10 \mathrm{mg} / \mathrm{day}$ & $\begin{array}{l}\text { Thcrease dose by no more } \\
\text { than } 10 \mathrm{mg} / \text { day every } 1-2 \text { weeks. }\end{array}$ \\
\hline $13-16 \mathrm{~kg}$ & $29-35 \mathrm{lbs}$ & $5 \mathrm{mg} / \mathrm{day}$ & $15 \mathrm{mg} / \mathrm{day}$ & $\begin{array}{l}\text { Increase dose by no more } \\
\text { than } 15 \text { mg/day every } 1-2 \text { weeks. }\end{array}$ \\
\hline $17-20 \mathrm{~kg}$ & $37-44$ lbs & $10 \mathrm{mg} / \mathrm{day}$ & $20 \mathrm{mg} / \mathrm{day}$ & $\begin{array}{l}\text { Increase dose by no more } \\
\text { than } 20 \text { mg/day every } 1-2 \text { weeks. }\end{array}$ \\
\hline $21-24 \mathrm{~kg}$ & $46-53 \mathrm{lbs}$ & 10 mgiday & $25 \mathrm{mg} /$ day & $\begin{array}{l}\text { Increase dose by no more } \\
\text { than } 25 \mathrm{mg} / \text { day every } 1-2 \text { weeks. }\end{array}$ \\
\hline $25-29 \mathrm{~kg}$ & $55-64$ lbs & $15 \mathrm{mg} / \mathrm{day}$ & $30 \mathrm{mg} / \mathrm{day}$ & $\begin{array}{l}\text { Increase dose by no more } \\
\text { than } 30 \text { mg/day every } 1-2 \text { weeks. }\end{array}$ \\
\hline $30-33 \mathrm{~kg}$ & $66-73165$ & 15 mgday & $35 \mathrm{mg}$ day & $\begin{array}{l}\text { Tncrease dose by no more } \\
\text { than } 35 \mathrm{mg} \text { day every } 1.2 \text { weeks. }\end{array}$ \\
\hline $34-37 \mathrm{~kg}$ & $75-81 \mathrm{lbs}$ & 20 mgday & $40 \mathrm{mg} / \mathrm{day}$ & $\begin{array}{l}\text { Increase dose by no more } \\
\text { than } 40 \mathrm{mg} \text { day every } 1-2 \text { weeks. }\end{array}$ \\
\hline $38-41 \mathrm{~kg}$ & $84-90$ lbs & $20 \mathrm{mg} / \mathrm{day}$ & $45 \mathrm{mg} / \mathrm{day}$ & $\begin{array}{l}\text { Increase dose by no more } \\
\text { than } 45 \text { mglday every } 1-2 \text { weeks. }\end{array}$ \\
\hline $42-45 \mathrm{~kg}$ & $92-99$ lbs & 25 mgiday & $50 \mathrm{mg} / \mathrm{day}$ & $\begin{array}{l}\text { Increase dose by no more } \\
\text { than } 50 \text { mgdday every } 1-2 \text { weeks. }\end{array}$ \\
\hline $46-49 \mathrm{~kg}$ & $101-108 \mathrm{lbS}$ & $25 \mathrm{mg} / \mathrm{day}$ & 55 mg/day & $\begin{array}{l}\text { Increase dose by no more } \\
\text { than } 55 \mathrm{mg} / \text { day every } 1-2 \text { weeks. }\end{array}$ \\
\hline $50-54 \mathrm{~kg}$ & $110-119 \mathrm{lbs}$ & $30 \mathrm{mg} / \mathrm{day}$ & 60 mg/day & $\begin{array}{l}\text { Increase dose by no more } \\
\text { than } 60 \mathrm{mg} / \text { day every } 1-2 \text { weeks. }\end{array}$ \\
\hline $55-58 \mathrm{~kg}$ & $121-128$ bs & $30 \mathrm{mg} / \mathrm{day}$ & 65 mgday & $\begin{array}{l}\text { Tricrease dose by no more } \\
\text { than } 65 \text { mg/day every } 1-2 \text { weeks. }\end{array}$ \\
\hline$\geq 59 \mathrm{~kg}$ & $\geq 130 \mathrm{lbs}$ & $35 \mathrm{mg} / \mathrm{day}$ & 70 mg/day & $\begin{array}{l}\text { Increase dose by no more } \\
\text { than } 70 \text { mgday every } 1-2 \text { weeks. }\end{array}$ \\
\hline
\end{tabular}

"Enzyme-inducing AEDs include carbamazepine, phenobarbital, phenytoin, and primidone.

tCan be given as two divided doses.

ҒTotal daily dose can be divided

$\$$ It may take several weeks to months to achieve an individualized maintenance dose.

IInsufficient data are available to be able to support the $\mathrm{mg} / \mathrm{kg}$ dosing in patients weighing more than $59 \mathrm{~kg}$.

The starting doses and dose escalations listed above are different than those used in clinical trials, however, the maintenance doses are the same as those used in clinical trials. Smaller starting doses and slower dose escalations than those used in clinical trials are recommended because of concerm that the risk of serious rash may be greater with higher initial doses and more rapid dose escalation. Consequently, it may take several weeks to months to 


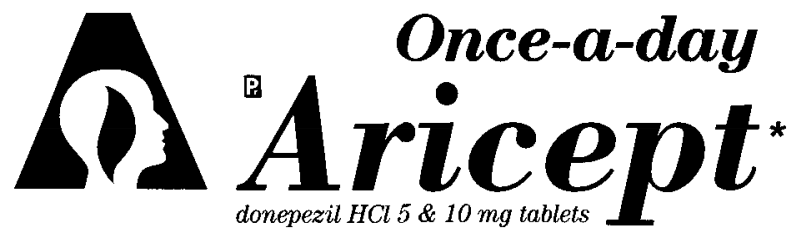

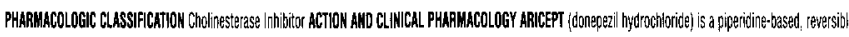

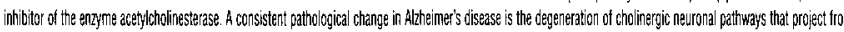

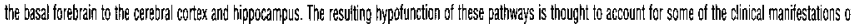

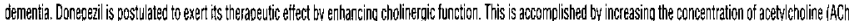

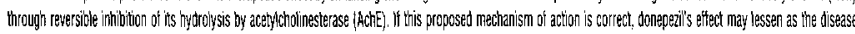

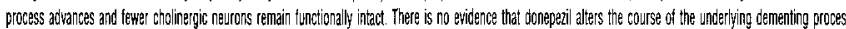

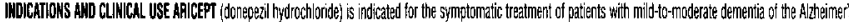

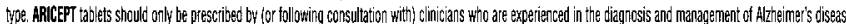

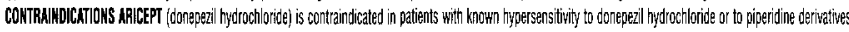

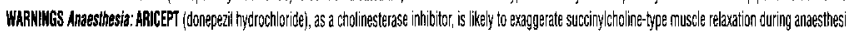

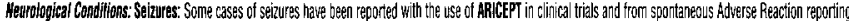

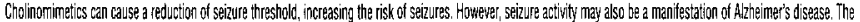

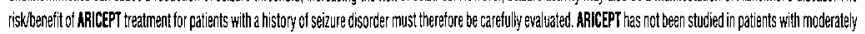

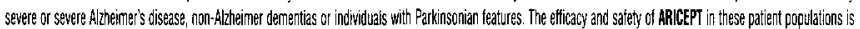

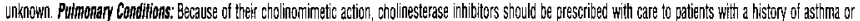

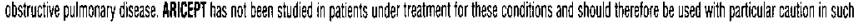

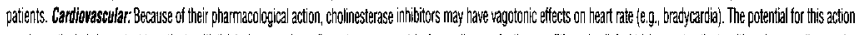

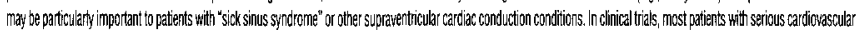

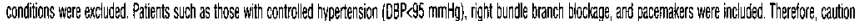

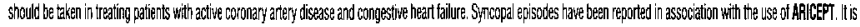

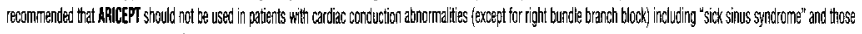

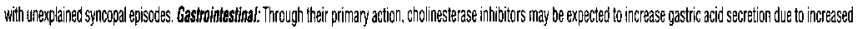

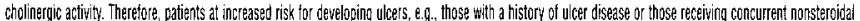

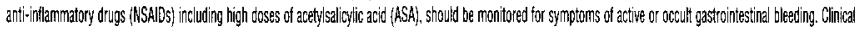

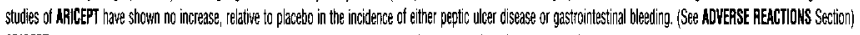

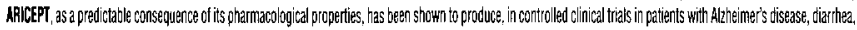

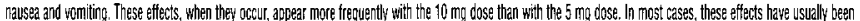

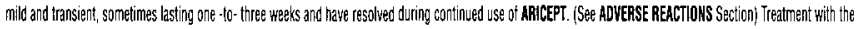

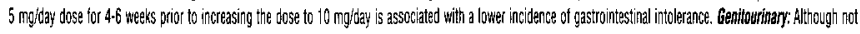

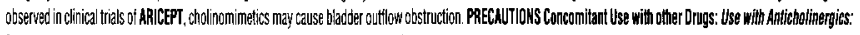

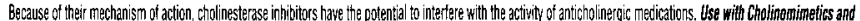

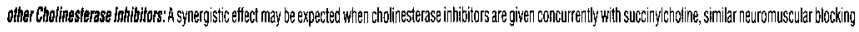

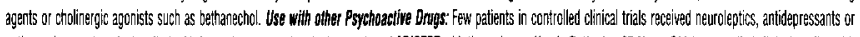

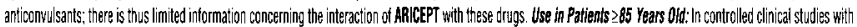

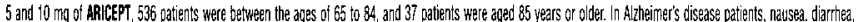

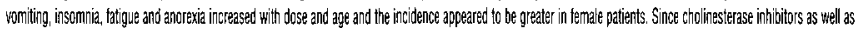

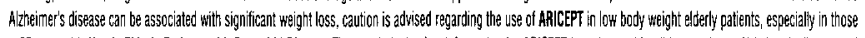

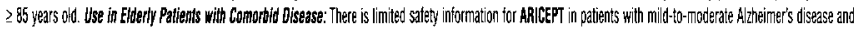

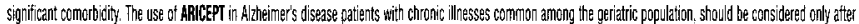

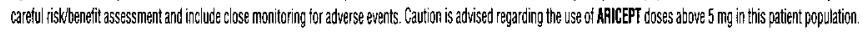

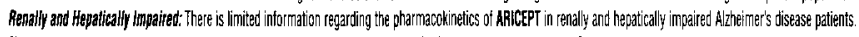

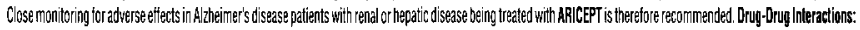

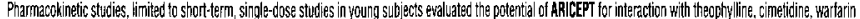

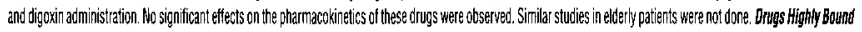

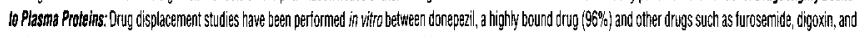

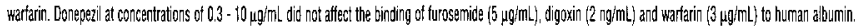

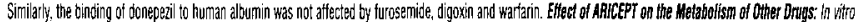

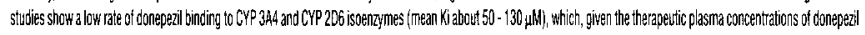

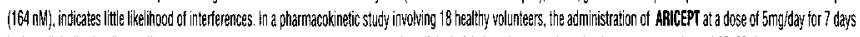

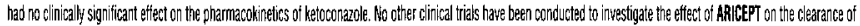

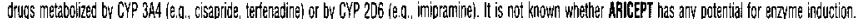

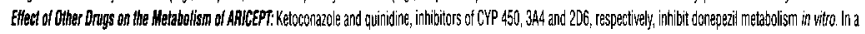

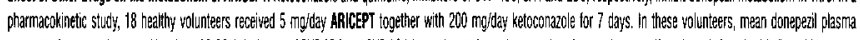

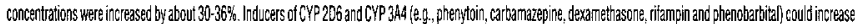

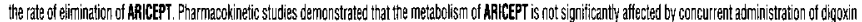

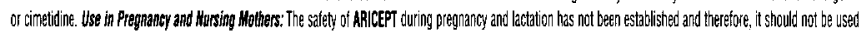

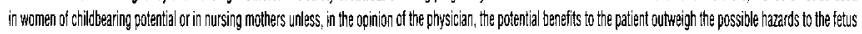

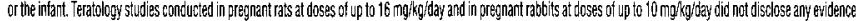

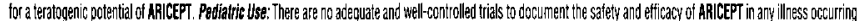

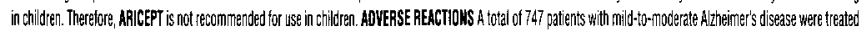

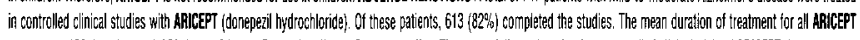

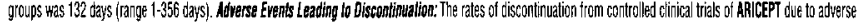

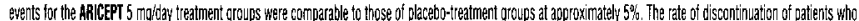

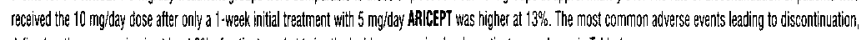

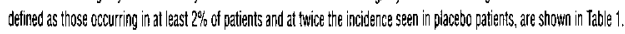

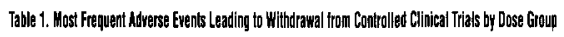

\begin{tabular}{|c|c|c|c|}
\hline Dose Group & Placelo & 5 mydtay AfICEPT & $10 \mathrm{mgj}$ jay A ARICEPI \\
\hline 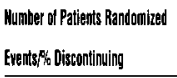 & 355 & 350 & 315 \\
\hline Nassea & $1 \%$ & $1 \%$ & $3 \%$ \\
\hline Diarritea & $0 \%$ & $\langle 1 \%$ & $3 \%$ \\
\hline Yomiting & $<1 \%$ & $<1 \%$ & $2 \%$ \\
\hline
\end{tabular}

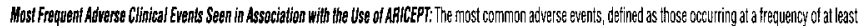

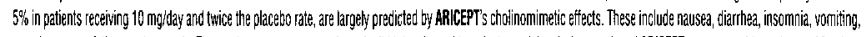

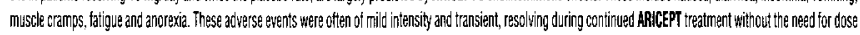

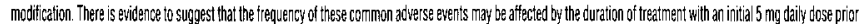

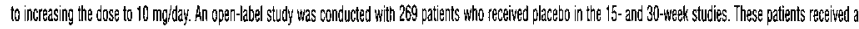

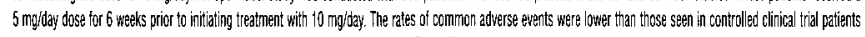

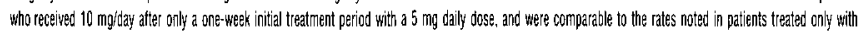

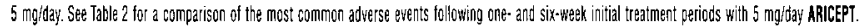

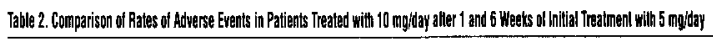

\begin{tabular}{|c|c|c|c|c|}
\hline \multirow[b]{2}{*}{ Adverse Everil } & \multicolumn{2}{|c|}{ Mo Initial Treatnent } & \multirow{2}{*}{ 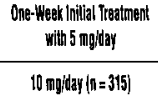 } & \multirow{2}{*}{ 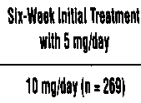 } \\
\hline & Placeto $\{n=315\}$ & 5 mogltay $(n=311)$ & & \\
\hline Naysea & $6 \%$ & $5 \%$ & $19 \%$ & $6 \%$ \\
\hline Diamea & $5 \%$ & $8 \%$ & $15 \%$ & $9 \%$ \\
\hline Insemnia & $6 \%$ & $6 \%$ & $14 \%$ & $6 \%$ \\
\hline Fotigue & $3 \%$ & $4 \%$ & $8 \%$ & $3 \%$ \\
\hline Vomiting & $3 \%$ & $3 \%$ & $8 \%$ & $5 \%$ \\
\hline Muscle Cramps & $2 \%$ & $6 \%$ & $x^{x i n}$ & $3 \%$ \\
\hline Amerexiz & $2 \%$ & $3 \%$ & $7 \%$ & $3 \%$ \\
\hline
\end{tabular}

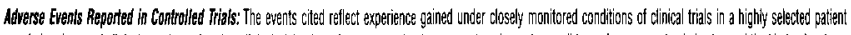

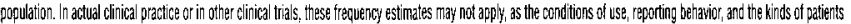

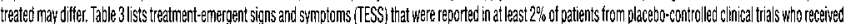

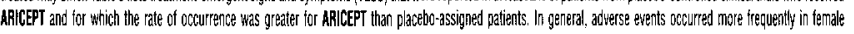

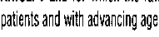

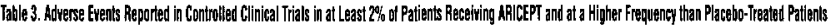

\begin{tabular}{|c|c|c|c|c|c|}
\hline $\begin{array}{l}\text { Body Systemi } \\
\text { Adverse Erents }\end{array}$ & $\begin{array}{l}\text { Placebo } \\
n=355\end{array}$ & $\begin{array}{l}\text { ARICEPT } \\
n=747\end{array}$ & 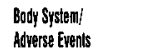 & $\begin{array}{l}\text { Placedo } \\
n=355\end{array}$ & $\begin{array}{l}\text { APICFP } \\
n=747\end{array}$ \\
\hline 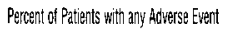 & 72 & 74 & Mebbolic and Mutrilinaral & & \\
\hline Boty as a thole & & & Weight Lecreass & 1 & 3 \\
\hline Hestache & 9 & 10 & Musscilostelatal System & & \\
\hline Pain, yarous kections & 8 & 9 & Muscle Cramps & 2 & 6 \\
\hline Acciden: & 6 & 7 & Aithilits & 1 & 2 \\
\hline Fotigule & 3 & 5 & Mervous System & & \\
\hline Cardiourssular Sysitem & & & Insomnia & 6 & 9 \\
\hline Synope & 1 & 2 & Diziness & 6 & 8 \\
\hline Digestive System & & & Depression & 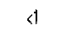 & 3 \\
\hline Nausez & 6 & 11 & Abnormal Drezans & 0 & 3 \\
\hline Dierrinea & 5 & 10 & Somomalence & 1 & 2 \\
\hline Honiting & 3 & 5 & Urogenital & & \\
\hline Anorexia & 2 & 4 & Frequent Urination & 1 & 2 \\
\hline
\end{tabular}

Henic and Lymphatic Systems

Ecchymposis

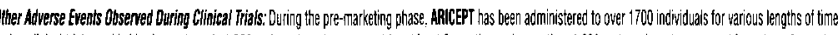

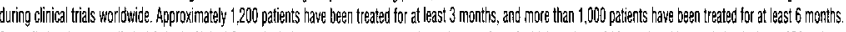

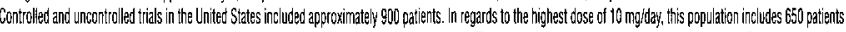

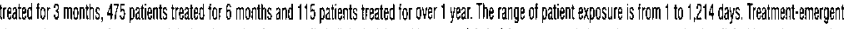

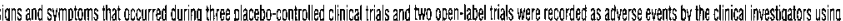

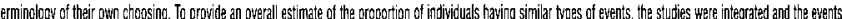

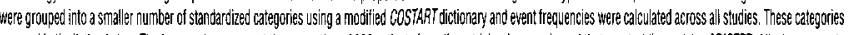

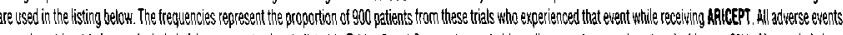

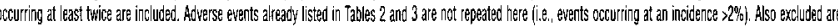

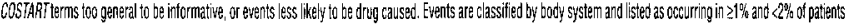

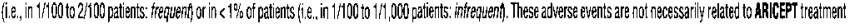

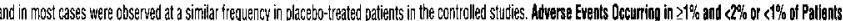

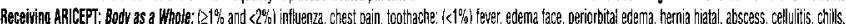

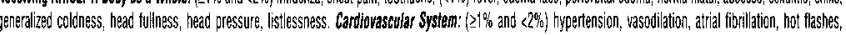

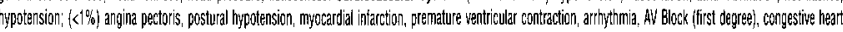

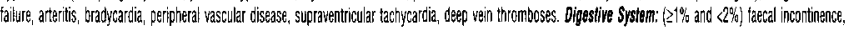

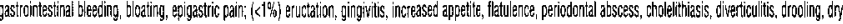

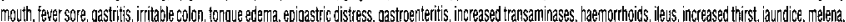

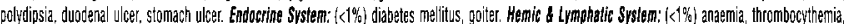

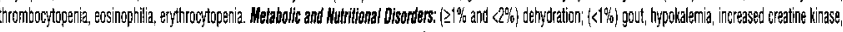

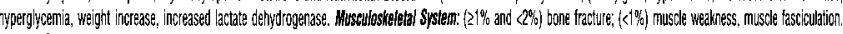

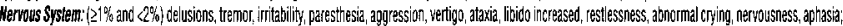

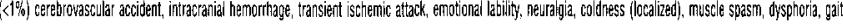

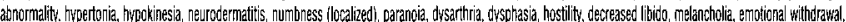

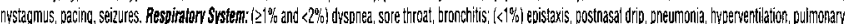

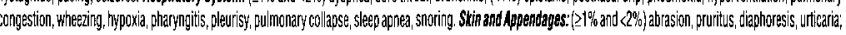

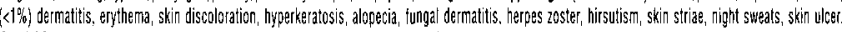

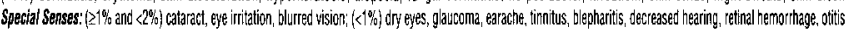

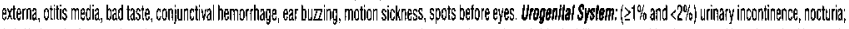

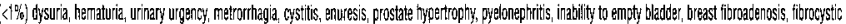

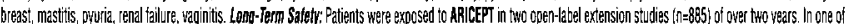

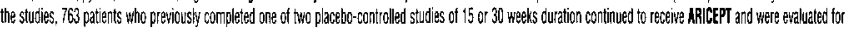

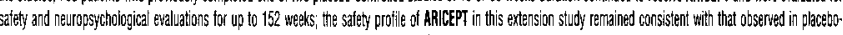

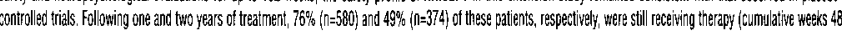

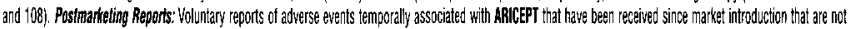

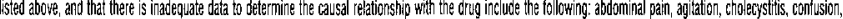

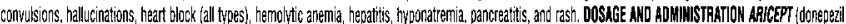

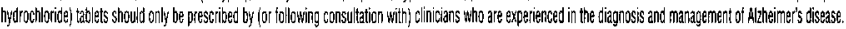

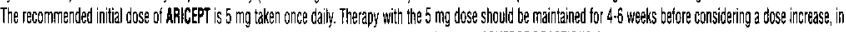

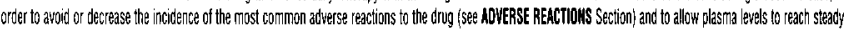

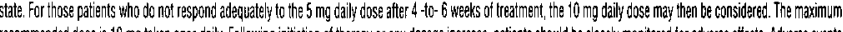

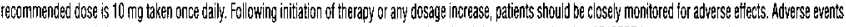

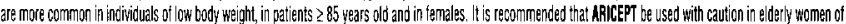

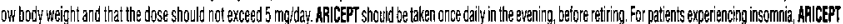

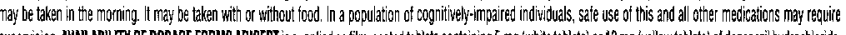

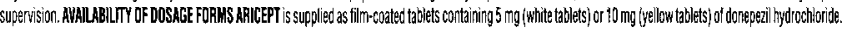

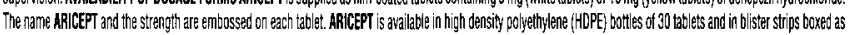

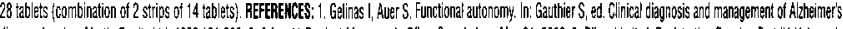

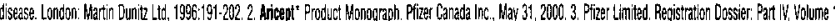

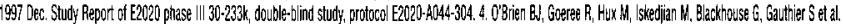

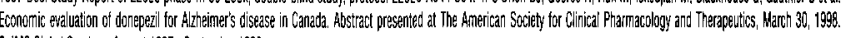

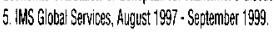

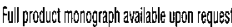

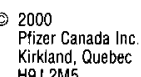




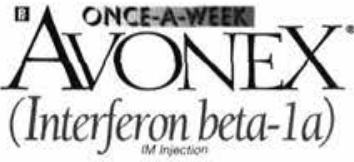

PRESCRIBING INFORMATION

THERAPEUTIC CUSSIFICATION

Immunomodulator

\section{ACTION AND CINICAL PHARMACOLOGY}

\section{Description}

AVONEX (Interteron beta-1a) is produced by recombinant DNA technology. Interferon beta-1a is a 166 amino acid glycoprotein with a predicted molecular weight of approximately 22,500 daltons. It is produced by mammalian cells (Chinese Hamster Ovary cells) into which the human interteron beta gene has been introduced. The amino acid sequence of AVONEX ${ }^{*}$ is identical to that of natural human interteron beta

Using the World Health Organization (WHO) natural interferon beta standard, Second International Standard for Interferon, Human Fibroblast (Gb-23-902-531), AVONEX" has a specific activity of approximately 200 million international units (IU) of antiviral activity per $\mathrm{mg} ; 30 \mathrm{mcg}$ of AVONEX" contains 6 million IU of antiviral activity.

\section{General}

Interterons are a tamily of naturally occurring proteins and glycoproteins that are produced by eukaryotic cells in response to viral infection and other biological inducers. Interferon beta, one member of this family, is produced by various cell types including fibroblasts and macrophages. Natural interteron beta and Interferon beta-1a are similarly glycosylated Glycosylation of other proteins is known to alfect their stability, activity biodistribution, and hall-lite in blood. Glycosylation also decteases aggregation of proteins. Protein aggregates are thought to be involved in the immunogenicity of recombinant proteins. Aggregated forms of interteron beta are known to have lower levels of specific activity than monomeric (non-aggregated) forms of interferon beta.

\section{Biologic Activities}

Interferons are cytokines that mediate antiviral, antiproliferative, and immunomodulatory activities in response to viral infection and other biological inducers. Three major interferons have been distinguished: alpha, beta, and gamma. Interferons alpha and beta form the Type I class of interferons and interferon gamma is a Type II interteron. These interferons have overlapping but clearly distinct biological activities. Interferon beta exerts its biological effects by binding to specific receptors on the surface of human cells. This binding initiates a complex cascade of intracellular events that lead to the expression of numerous interferoninduced gene products and markers. These include 2', 5'-0ligoadenylate synthetase, $B_{2}$-microglobulin, and neopterin. These products have been measured in the serum and cellular fractions of blood collected from patients treated with AVONEX

The specific interferon-induced proteins and mechanisms by which AVONEX exerts its effects in multiple sclerosis (MS) have not been fully defined. To understand the mechanism(s) of action of AVONEX" studies were conducted to determine the effect of IM injection of AVONEX on levels of the immunosuppressive cylokine interleukin 10 (IL-10) in serum and cerebrospinal fluid (CSF) of treated patients. IL-10, or cytokine synthesis inhibitory factor, is a potent immunosuppressor of a number of pro-inflammatory cytokines such as interferon gamma (IFN- $\gamma$ ), tumor necrosis factor alpha (TNF- $\propto$ ), interleukin 1 (IL-1), tumor necrosis factor beta (TNF- B), and interleukin 6 (IL-6), which are secreted by T lymphocyte helper-1 (Th') cells and macrophages. Elevated serum It-10 levels were seen after IM injection of AVONEX" trom 48 hours post-injection through at least 7 days. Similarly, in the Phase III study, IL-10 levels in CSF were significantly increased in patients treated with AVONEX ${ }^{\circ}$ compared to placebo. CSF IL-10 levels correlated with a tavourable clinical treatment response to AVONEX. Upregulation of IL-10 represents a possible mechanism of action of interferon beta in relapsing MS, IL-10 has been demonstrated to decrease relapses in acute and chronic relapsing experimental autoimmune encephalomyelitis (EAE), an animal model resembling MS. However, no relationship has been established between the absolute levels of IL-10 and the clinical outcome in MS.

\section{CUNICAL TRIALS: EFFECTS IN MULTIPLE SCLEROSIS}

The clinical effects of AVONEX" (Interferon beta-1a) in MS were studied in a randomized, multicentre, double-blind, placebo-controlled study in patients with relapsing (stable or progressive) MS. In this study. 301 patients received either 6 million IU (30 mog) of AVONEX ( $n=158)$ or placebo $(n=143)$ by IM injection once weekly. Patients were entered into the trial over a 2 $1 / 2$ year period, received injections for up to 2 years, and continued to be followed until study completion. By design, there was staggered enrollment into the study with termination at a fixed point, leading to variable lengths of follow-up. There were 144 patients treated with AVONEX for more than 1 year, 115 patients for more than 18 months. and 82 patients for 2 years.

All patients had a definite diagnosis of MS of at least 1 year duration and had at least 2 exacerbations in the 3 years prior to study entry (or 1 per yea if the duration of disease was less than 3 years). At entry, study participants were without exacerbation during the prior 2 months and had Kurtzke Expanded Disability Status Scale (EDSS) scores ranging from 1.0 to 3.5 . The mean EDSS score at baseline was 2.3 tor placebo-treated patients and 2.4 for AVONEX ${ }^{\circ}$-treated patients. Patients with chronic progressive multiple sclerosis were excluded from this study.

The primary outcome assessment was time to progression in disability. measured as an increase in the EDSS of at least 1.0 point that was sustained for at least 6 months. The requirement for a sustained 6 month change was chosen because this reflects permanent disability rather than a transient effect due to an exacerbation. Studies show that of the patients who progress and are confirmed after only 3 months, $18 \%$ revert back to their baseline EDSS, whereas after 6 months only $11 \%$ revert.

Secondary outcomes included exacerbation frequency and results of magnetic resonance imaging (MRI) scans of the brain including gadolinium (Gd)-enhanced lesion number and volume and T2-weighted (proton density) lesion volume. Additional secondary endpoints included upper and lower extremity function tests.

Time to onset of sustained progression in disability was significantly longer in patients treated with AVONEX $^{3}$ than in patients receiving placebo $(p=0.02)$. The Kaplan-Meier plots of these data are presented in Figure 1. The Kaplan-Meier estimate of the percentage of patients progressing by the end of 2 years was $34.9 \%$ for placebo-treated patients and $21.9 \%$ for AVONEX ${ }^{-}$-treated patients, indicating a slowing of the disease process This represents a significant reduction in the risk of disability progression in patients treated with AVONEX', compared to patients treated with placebo.

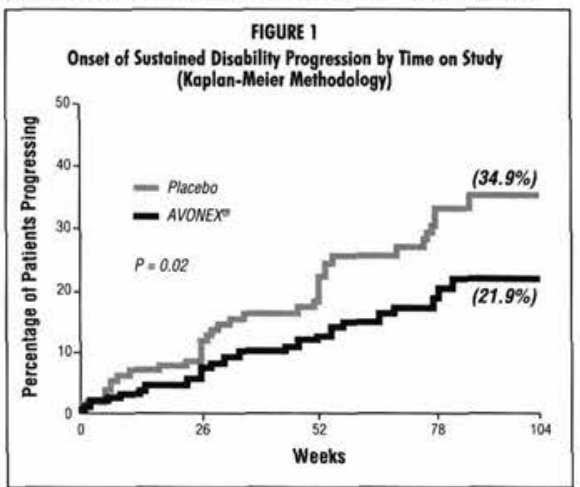

Note: Disability progression represents at least a 1.0 point increase in EDSS score sustained for at least 6 months. The value $p=0.02$ refers to the statistical difference between the overall distribution of the two curves, not to the difference in estimates at any given timepoint (e.g. $34.9 \%$ vs. $21.9 \%$ at Week 104.).

The distribution of confirmed EDSS change from study entry (baseline) to the end of the study is shown in Figure 2. There was a statistically signifcant difterence between treatment groups in confirmed change for patients with at least 2 scheduled visits ( 136 placebo-treated and 150 AVONEX treated patients; $p=0.006$; see Table 1). Contimed EDSS change was calculated as the difference between the EDSS score at study entry and 1 of the scores determined at the last 2 scheduled visits. Further analyses using more rigorous measures of progression of disability were performed. When the requirement for sustained EDSS change was increased from 6 months to 1 year, a significant benefit in favour of AVONEX recipients persisted $(p=0.002)$. When treatment failure was defined as 2.0 points or greater increase in EDSS sustained for 6 months, $18.3 \%$ of placebo-treated patients worsened compared to $6.1 \%$ of AVONEX -treated patients. Additionally, significantly fewer AVONEX recipients progressed to EDSS milestones of $4.0(14 \%$ vs. $5 \%, p=0.014)$ or $6.0(7 \%$ vs. $1 \%, p=0.028)$ )

The rate and frequency of exacerbations were determined as secondary outcomes (see Table 1). AVONEX treatment significantly decreased the frequency of exacerbations in patients who were enrolled in the study for at least 2 years, from 0.90 in the placebo-treated group to 0.61 in the AVONEX $x^{-}$-treated group ( $p=0.002$ ). This represents a $32 \%$ reduction. Additionally, placebo-treated patients were twice as likely to have 3 or more exacerbations during the study when compared to AVONEX ${ }^{\circ}$-treated patients ( $32 \%$ vs. $14 \%$ ).

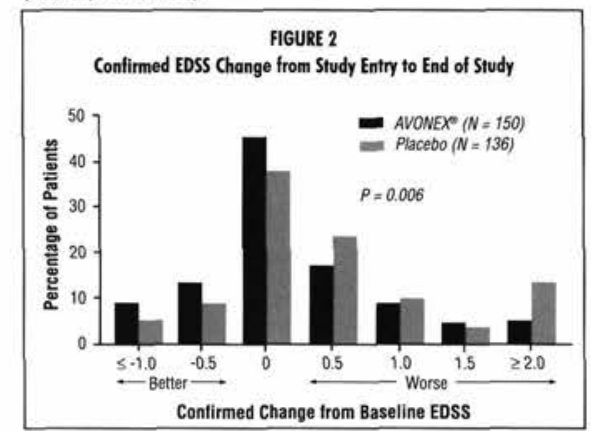

Gd-enhanced and T2-weighted (proton density) MRI scans of the brain were obtained in most patients at baseline and at the end of 1 and 2 years of treatment. Gd-enhancing lesions seen on brain MRI scans represent areas of breakdown of the blood brain barrier thought to be secondary to inflammation. Patients treated with AVONEX demonstrated significantly lower Gd-enhanced lesion number after 1 and 2 years of treatment $(p \leq 0.05$; see Table 1). The mean number of Gd-enhanced lesions for patients treated with AVONEX ${ }^{2}$ was 3.2 at baseline and 0.8 at Year 2, compared to 2.3 at baseline and 1.6 at Year 2 for the placebo-treated patients. The volume of Gd-enhanced lesions was also analyzed and showed similar treatment effects $(D \leq 0.03$ ). Percentage change in T2-weighted lesion volume from study entry to Year 1 was significantly lower in AVONEX'-treated than placebo-treated patients $(p=0.02)$. A significant difference in T2-weighted lesion volume change was not seen between study entry and Year 2. Treatment with AVONEX ${ }^{*}$ resulted in a significant decrease in the number of active (new and enlarging) T2 lesions over 2 years ( $p=0.002$ ). The exact relationship between MRI findings and the clinical status of patients is unknown.

Of the limb function tests, only 1 demonstrated a statistically significant difference between treatment groups (favoring AVONEX ${ }^{*}$ ).

Twenty-three of the 301 patients ( $8 \%$ ) discontinued treatment prematurely. Of these, 1 patient treated with placebo $(1 \%)$ and 6 patients treated with AVONEX ${ }^{5}(4 \%)$ discontinued treatment due to adverse events. Of these 23 patients, 13 remained on study and were evaluated for clinical endpoints. A summary of the effects of AVONEX ${ }^{*}$ on the primary and major secondary endpoints of this study is presented in Table 1

\section{Toble 1}

MANOR CUINICAL ENDPOINTS

\begin{tabular}{llll}
\hline Endpoint & Placebo AVONEX & P.Value \\
\hline
\end{tabular}

\section{PRIMARY ENDPOINT:}

Time to sustained progression

in disability (N: 143, 158)

- See Figure 1 -

0.02

Percentage of patients progressing

in disability at 2 years

(Kaplan-Meier estimate)

SECONDARY ENDPOINTS:

\section{DISABIUTYY}

Mean confirmed change in

EDSS from study entry to end

of study (N: 136,150$)^{4}$

\section{EXACERBATIONS FOR PATIENTS}

COMPLETING 2 YEARS:

Number of exacerbations ( $N: 87,85)$

$\begin{array}{lll}0 & 26 \% & 38 \% \\ 1 & 30 \% & 31 \% \\ 2 & 11 \% & 18 \% \\ 3 & 14 \% & 7 \% \\ \geq 4 & 18 \% & 7 \%\end{array}$

Percentage of patients

exacerbation-free ( $\mathrm{N}: 87,85)$

Annual exacerbation rate

(N: 87, 85)

$26 \% \quad 38 \%$

$0.10^{4}$

MRI

Number of Gd-enhanced lesions:

At study entry (N: 132, 141)

$\begin{array}{lcc}\text { Mean (Median) } & 2.3(1.0) & 3.2(1.0) \\ \text { Range } & 0-23 & 0-56 \\ \text { Mean (Median) } & 1.6(0) & 1.0(0) \\ \text { Range } & 0-22 & 0-28 \\ \text { ar } 2 \text { (N: } 82,83) & & \\ \text { Mean (Median) } & 1.6(0) & 0.8(0) \\ \text { Range } & 0-34 & 0-13\end{array}$

Range

$0.90-0.61-0.002^{5}$

Percentage change from study entry

to Year $1(\mathrm{~N}: 116,123)$

$$
\text { Median }
$$

$-13.1 \%$

Percentage change from study entry

to Year $2(\mathrm{~N}: 83,81)$

$$
\text { Median }
$$

Number of new and enlarging lesions

at Year 2 ( $N: 80,78$ )

Median

Note: $(\mathrm{N}:$. ) denotes the number of evaluable placebo and AVONEX (Interferon beta-1a) patients, respectively.

Patient data included in this analysis represent variable periods of time on study.

Analyzed by Mantel-Cox (logrank) test.

' Analyzed by Mann-Whitney rank-sum test.

- Analyzed by Cochran-Mantel-Haenszel test.

Analyzed by likelihood ratio test.

- Analyzed by Wilcoxon rank-sum test. 
INDICATIONS AND CLINICAL USE

AVONEX (interferon beta-1a) is indicated for the treatment of relapsing forms of multiple scierosis to slow the progression of disability, decrease the frequency of clinical exacerbations, and reduce the number and volume of active brain lesions identified on Magnetic Resonance imaging (MRI) scans. Safety and efficacy have not been evaluated in patients

with chronic progressive multiple sclerosis.

\section{CONTRAINDICATIONS}

AVONEX (Interferon beta-1a) is contraindicated in patients with a history of hypersensitivity to natural or recombinant interteron beta, human albumin, or any other component of the formulation.

\section{WARNINGS}

AVONEX (Interteron beta-1a) should be used with caution in patients with depression. Depression and suicide have been repotted to occur in patients receiving other interferon compounds. Depression and suicidal ideation are known to occur at an increased frequency in the MS population. A relationship between the occurrence of depression and/or suicidal ideation and the use of AVONEX has not been established. An equal incidence of depression was seen in the olacebo-treated and AVONEX -treated patients in the placebo-sentrolled relapsing MS study. Patients treated with AVONEX should be advised to report immediately any symptoms of depression and/or suicidal ideation to their prescribing physicians. If a patient develops depression, antidepressant therapy or cessation of AVONEX therapy should be considered.

\section{PRECAUTIONS}

\section{General}

Caution should be exercised when administering AVONEX (Interferon beta-1a) to patients with pre-existing seizure disorder. In the placebocontrolled study, 4 patients receiving AVONEX experienced seizures, while no seizures occurred in the placebo group. Of these 4 patients, 3 had no prior history of seizure. It is not known whether these events were related to the effects of MS alone, to AVONEX . or to a combination of both. For patients with no prior history of seizure who developed seizures during therapy with AVONEX an etiologic basis should be established and appropriate anti-convulsant therapy instituted prior to considering resumption of AVONEX treatment. The effect of AVONEX administration on the medicai management of patients with seizure disorder is unknown. Patients with cardiac disease, such as angina, congestive heart failure, or arrhythmia, should be closely monitored for worsening of their clinical condition during initiation of therapy with AVONEX. AVONEX does not have any known direct-acting cardiac toxicity; however, symptoms of th syndrome seen with AVONEX therapy may prove stresstul to patients with severe cardiac conditions.

\section{Laboratory Tests}

In addition to those laboratory tests normally required for monitoring patients with MS, complete blood cell counts and white blood cell differential, platejet counts, and blood chemistries, including liver and thyroid function tests, are recommended during AVONEX therapy. During the placebo-controlled study, complete blood cell counts and white blood cell differential, platelet counts, and blood chemistries were pertormed at least every 6 months. There were no significant difterences between the placebo and AVONEX groups in the incidence of thyroid abnorma ities, liver enzyme elevation, leukopenia, or thrombocytopenia (these are known to be dose-related laboratory abnormalities associated with the use of interferons). Patients with myelosuppression may require more intensive monitoring of complete blood cell counts, with differential and platelet counts.

\section{Drug Interactions}

No formal drug interaction studies have been conducted with AVONEX ${ }^{\text {D }}$ In the placebo-controlled study, corticosteroids or ACTH were administered for treatment of exacerbations in some patients concurrently receiving AVONEX ${ }^{*}$. In addition, some patients receiving AVONEX were also treated with anti-depressant therapy and/or oral contraceptive therapy. No unexpected adverse events were associated with these concomitant therapies.

Other interferons have been noted to reduce cytochrome P-450 oxidase-mediated drug metabolism. Formal hepalic drug metabolistrs studies with AVONEX in humans have not been conducted. Hepatic microsomes isolated from AVONEX -treated rhesus monkeys showed no influence of AVONEX ${ }^{\text {to }}$ on hepatic P-450 enzyme metabolism activity. As with all interferon products, proper monitoring of patients is required if AVONEX is given in combination with myelosuppressive agents.

\section{Use in Pregnancy}

If a woman becomes pregnant or plans to become pregnant while taking AVONEX' she should be informed of the potential hazards to the fetus, and it should be recommended that the woman discontinue therapy. The reproductive toxicity of AVONEX ${ }^{\text {ta }}$ has not been studied in animals or humans. In pregnant monkeys given interferon beta at 100 times the recommended weekly human dose (based upon a body surface area comparison), no teratogenic or other adverse effects on fetal development were observed. Abortilacient activity was evident following 3 to 5 doses at this level. No abortifacient effects were observed in monkeys treated at 2 times the recommended weekly human dose (based upon a body surface area comparison). Although no teratogenic effects were seen in these studies, it is not known if teratogenic effects would be observed in humans. There are no adequate and well-controlled studies with interferons in pregnant women.
Nursing Mothers

It is not known whether AVONEX is excreted in human milk. Because of the potential of serious adverse reactions in nursing infants, a decision should be made to either discontinue nursing or to discontinue AVONEX

\section{Pediatric Use}

Safety and effectiveness have not been established in pediatric patients below the age of 18 years.

\section{Information to Potients}

Patients should be informed of the most comrnon adverse events associated with AVONEX administration, including symptoms associated with flu syndrome (see Adverse Events and Information for the Palient) Symptorns of flu syndrome are most prominent at the initiation of therapy and decrease in frequency with continued treatment. In the placebocontrolled study, patients were instructed to take $650 \mathrm{mg}$ acełaminophen immediately prior to injection and for an additional 24 hours after each injection to modulate acute symptoms associated with AVONEX administration.

Patients should be cautioned to report depression or suicidal ideation (see Warnings)

When a physician determines that AVONEX ${ }^{*}$ can be used outside of the physician's office, persons who will be administering AVONEX should receive instruction in reconstitution and injection, including the review of the injection procedures (see Information for the Patient). If a patient is to self-administer, the physical ability of that patient to self-inject intramuscularly should be assessed. If home use is chosen, the first injection should be performed under the supervision of a qualified health care professional. A puncture-resistant container for disposal of needles and syringes should be used. Patients should be instructed in the technique and importance of proper syringe and needle disposal and be cautioned against reuse of these items.

\section{ADVERSE EVENIS}

The satety data describing the use of AVONEX (Interferon beta-1a) in MS patients are based on the placebo-controlled trial in which 158 patients randornized to AVONEX were treated tor up to 2 years (see Clinical Trials) The 5 most common adverse events associated (at $p<0.075$ ) with AVONEX treatment were flu-like symptoms (otherwise unspecified), muscle ache "ever, chills, and asthenia. The incidence of all 5 adverse events diminished with continued treatmen.

One patient in the placebo group attempted suicide; no AVONEX $X^{\text {-treated }}$ patients attempted suicide. The incidence of depression was equal in the 2 treatment groups. However, since depression and suicide have been reported with other interferon products, AVONEX should be used with caution in patients with depression (see Warnings)

in the placebo-controlled study, 4 patients receiving AVONEX experienced seizures, while no seizures occurred in the placebo group. Ot these 4 patients, 3 had no prior history of seizure. It is not known whether these events were related to the effects of MS alone, to AVONEX ${ }^{\text {, }}$ or to a combination of both (see Precautions).

Table 2 enumerates adverse events and selected laboratory abnormalities that occurred at an incidence of $2 \%$ or more among the 158 patients with relapsing MS treated with $30 \mathrm{mcg}$ of AVONEX ${ }^{\otimes}$ once weekly by IM injection. Reported adverse events have been classified using standard COSTART terms. Terms so general as to be uninformative or more common in the placebo-treated patients have been excluded.

AVONEX ${ }^{\text {}}$ has also been evaluated in 290 patients with illnesses other than MS. The majority of these patients were enrolled in studies to evaluate AVONEX treatment of chronic viral hepatitis $B$ and $C$, in which the doses studied ranged from $15 \mathrm{mcg}$ to $75 \mathrm{mcg}$, given subcutaneously (SC), 3 times a week, for up to 6 months. The incidence of common adverse events in these studies was generally seen at a trequency similar to that seen in the placebo-controlled MS study. In these non-MS studies, inflammation at the site of the SC injection was seen in $52 \%$ of treated patients. In contrast, injection site inflammation was seen in $3 \%$ of MS patients receiving AVONEX ${ }^{\infty}, 30 \mathrm{mcg}$ by IM injection. SC injections were also associated with the following local reactions: injection site necrosis, injection site atrophy. injection site ederna, and injection site hemorrhage. None of the above was observed in the MS patients participating in the placebo-controlled study.

\section{Table 2}

Adverse Events ond Selected Loboratory Abnoumolities in the Placebo-Controlled Study

\begin{tabular}{lcc}
\hline Adverse Event & Placebo & AVONEX \\
& $(N=143)$ & $(N=158)$ \\
\hline
\end{tabular}

\section{Body as a Whole}

Headach

$57 \% \quad 67 \%$

Flu-like symptoms (otherwise unspecified) ${ }^{*}$ Pain

Chills*

Infection
Adverse Events and Selected Laboratory Abnormallities in the Placebo-Controlled Study

\begin{tabular}{|c|c|c|}
\hline Adverse Event & $\begin{array}{l}\text { Placebo } \\
(\mathrm{N}=143)\end{array}$ & $\begin{array}{c}\text { AVONEX } \\
(\mathrm{N}=158)\end{array}$ \\
\hline Chest pain & $4 \%$ & $6 \%$ \\
\hline Injection site reaction & $1 \%$ & $4 \%$ \\
\hline Malaise & $3 \%$ & $4 \%$ \\
\hline Injection site inflammation & $0 \%$ & $3 \%$ \\
\hline Hypersensitivity reaction & $0 \%$ & $3 \%$ \\
\hline Ovarian cyst & $0 \%$ & $3 \%$ \\
\hline Ecchymosis injection site & $1 \%$ & $2 \%$ \\
\hline \multicolumn{3}{|l|}{ Cordiovoscular System } \\
\hline Syncope & $2 \%$ & $4 \%$ \\
\hline Vasodilation & $1 \%$ & $4 \%$ \\
\hline \multicolumn{3}{|l|}{ Digestive System } \\
\hline Nausea & $23 \%$ & $33 \%$ \\
\hline Diarchea & $10 \%$ & $16 \%$ \\
\hline Dyspepsia & $7 \%$ & $11 \%$ \\
\hline Anorexia & $6 \%$ & $7 \%$ \\
\hline \multicolumn{3}{|l|}{ Hemic and Lymphotic System } \\
\hline Anemia $^{*}$ & $3 \%$ & $8 \%$ \\
\hline Eosinophils $\geq 10 \%$ & $4 \%$ & $5 \%$ \\
\hline \multicolumn{3}{|l|}{ HCT $(\%) \leq 32$ (temales) } \\
\hline or $\leq 37$ (males) & $1 \%$ & $3 \%$ \\
\hline \multicolumn{3}{|c|}{ Metabolic and Mutrilionol Disorders } \\
\hline $\mathrm{SGOT} \geq 3 \times \mathrm{ULN}$ & $1 \%$ & $3 \%$ \\
\hline \multicolumn{3}{|l|}{ Musculoskelefal System } \\
\hline Muscle ache* & $15 \%$ & $34 \%$ \\
\hline Arthralgia & $5 \%$ & $9 \%$ \\
\hline \multicolumn{3}{|l|}{ Nervous System } \\
\hline Sleep difficult & $16 \%$ & $19 \%$ \\
\hline Dizziness & $13 \%$ & $15 \%$ \\
\hline Muscle spasm & $6 \%$ & $7 \%$ \\
\hline Suicidal tendency & $1 \%$ & $4 \%$ \\
\hline Seizure & $0 \%$ & $3 \%$ \\
\hline Speech disorder & $0 \%$ & $3 \%$ \\
\hline Ataxia & $0 \%$ & $2 \%$ \\
\hline \multicolumn{3}{|l|}{ Respiratory System } \\
\hline Upper respiratory tract infection & $28 \%$ & $31 \%$ \\
\hline Sinusitis & $17 \%$ & $18 \%$ \\
\hline Dyspnea & $3 \%$ & $6 \%$ \\
\hline \multicolumn{3}{|l|}{ Skin and Appendages } \\
\hline Urticaria & $2 \%$ & $5 \%$ \\
\hline Alopecia & $1 \%$ & $4 \%$ \\
\hline Nevus & $0 \%$ & $3 \%$ \\
\hline Herpes zoster & $2 \%$ & $3 \%$ \\
\hline Herpes simplex & $1 \%$ & $2 \%$ \\
\hline \multicolumn{3}{|l|}{ Special Senses } \\
\hline Otitis media & $5 \%$ & $6 \%$ \\
\hline Hearing decreased & $0 \%$ & $3 \%$ \\
\hline \multicolumn{3}{|l|}{ Urogenital } \\
\hline Vaginitis & $2 \%$ & $4 \%$ \\
\hline
\end{tabular}

Other events observed during premarket evaluation of AVONEX administered either SC or IM in all patient populations studied, are tisted in the paragraph that follows. Because most of the events were observed in open and uncontrolled studies, the role of AVONEX in their causation cannot be reliably determined. Body as a Whole: abscess, ascites, cellulitis, facial edema, hernia, injection site fibrosis, injection site hypersensitivity, lipoma, neoplasm, photosensitivity reaction, sepsis, sinus headache, toothache; Cardlovascular System: arrhythmia, arteritis, heart arrest, hemorrhage, hypotension, palpitation, pericarditis, peripheral ischemia peripheral vascular disorder, postural hypotension, pulmonary embolus, spider angioma, telangiectasia, vascular disorder; Digestive System: blood in stool, colitis, constipation, diverticulitis, dry mouth, gallbladde disorder, gastritis, gastrointestinal hemorrhage, gingivitis, gurn hemorrhage, hepatoma, hepatomegaly, increased appetite, intestinal perforation, intestinal obstruction, periodontal abscess, periodontitis, proctitis, thirst, tongue disorder, vomiting; Endocrine System: hypothyroidism; Hemic and Lymphatic System: coagulation time increased, ecchymosis, lymphadenopathy, petechia; Metabollc and Nutritional Dlsorders: abrormal healing, dehydration, hypoglycemia, hypomagnesemia, hypokalemia; Musculoskeletal System: arthritis, bone pain, myasthenia osteonecrosis, synovitis; Nervous System: abnormal gait, amnesia, anxiety, Bel'l's Palsy, clumsiness, depersonalization, drug dependence, facial paralysis, hyperesthesia, increased libido, neurosis, psychosis; Respiratory System: emphysema, hemoptysis, hiccup, hyperventiation, laryngitis, pharygeal edema, pneumonia; Skin and Appendages: basal 
cell carcinoma, blisters, cold clammy skin, contact dermatitis, erythema, furunculosis, genital pruritus, nevus, rash, seborrhea, skin ulcer, skin discolouration; Special Senses: abnormal vision, conjunctivitis, earache, eye pain, labyrinthitis, vitreous floaters: Urogenital: breast fibroadenosis, breast mass, dysuria, epididymitis, fibrocystic change of the breast, fibroids, gynecomastia, hematuria, kidney calculus, kidney pain, leukorrhea, menopause, nocturia, pelvic inflammatory disease, penis disorder, Peyronies Disease, polyuria, post menopausal hemorrhage, prostatic disorder, pyelonephritis, testis disorder, urethral pain, urinary urgency, urinary retention, urinary incontinence, vaginal hemorrhage

Serum Neutralizing Antibodies

MS patients treated with AVONEX may develop neutralizing antibodies specific to interferon beta. Analyses conducted on sera samples from 2 separate clinical studies of AVONEX ${ }^{8}$ suggest that the plateau for the incidence of neutralizing antibodies formation is reached at approximately 12 months of therapy. Data furthermore dernonstrate that at 12 months approximately $6 \%$ of patients treated with AVONEX develop neutralizing antibodles.

\section{SYMPTOMS AND TREATMENT OF OVERDOSAGE}

Overdosage is unilikely to occur with use of AVDNEX (Interferon beta-1a). In clinical studies, overdosage was not seen using Interferon beta-1a at a dose of $75 \mathrm{mcg}$ given SC 3 times per week.

\section{DOSAGE AND ADMINISTRATION}

The recommended dosage of $A V O N E X^{\star}$ (Interferon beta-1a) for the treatment of relapsing forms of multiple sclerosis is $30 \mathrm{mcg}$ injected intramuscularly once a week

AVONEX is intended for use under the guidance and supervision of a physician. Patients may self-inject only if their physician determines that it is appropriate and with medical follow-up, as necessary, after proper training in IM injection technique.

\section{PHARMACEUTICAL INFORMATION}

\section{Composilion:}

AVONE is supplied as a sterile white to oft-white lyophilized powder in a single-use vial containing $33 \mathrm{mcg}$ ( $6.6 \mathrm{million}$ IU) of Interferon beta- 1 a $16.5 \mathrm{mg}$ Albumin Human, USP, $6.4 \mathrm{mg}$ Sodium Chloride, USP, $6.3 \mathrm{mg}$ Dibasic Sodium Phosphate, USP, and $1.3 \mathrm{mg}$ Monobasic Sodium Phosphate. USP, and is preservative-free. Diluent is supplied in a single-use vial (Steriie Water for Injection, USP, preservative-free)

\section{Reconstitution:}

AVONEX is reconstituted by adding $1.1 \mathrm{~mL}(\mathrm{cc}$ ) of diluent (approximate $\mathrm{pH} 7.3$ ) to the single-use vial of lyophilized powder; $1.0 \mathrm{~mL}$ (cc) is withdrawn for administration.

\section{Siability and Storage:}

Vials of AVONEX must be stored in a $2-8^{\circ} \mathrm{C}\left(36-46^{\circ}\right)$ refrigerator. Should refrigeration be unavailable, AVONEX ${ }^{\circ}$ can be stored at up to $25^{\circ} \mathrm{C}\left(77^{\circ} \mathrm{F}\right)$ for a period of up to 30 days. DO NOT EXPOSE TO HIGH TEMPERATURES DO NOT FREEZE. Do not use beyond the expiration date stamped on the vial Following reconstitution, it is recommended the product be used as soon as possible but within 6 hours stored at $2-8^{\circ} \mathrm{C}\left(36-46^{\circ} \mathrm{F}\right)$ DO NOT FREFZE RECONSTITUTED AVONEX

\section{AVAILABIUTY OF DOSAGE FORHS}

AVONEX (Interteron beta-1a) is available as:

Package (Administration Pack) containing 4 Administration Dose Packs (each containing one vial of AVONEX⿻一丿 three alcohol wipes, one $3 \mathrm{cc}$ syringe, one Micro Pin ${ }^{\varpi}$, one needte, and one adhesive bandage).

REFERENCES

1 AVONEX $X^{\star}$ Product Monograph, April 6, 1998

2 Jacobs LD, Cookłair DL, Rudick RA, et al. Intramuscular interferon beta-1a tor disease progression in relapsing multipje sclerosis. Ann Neurol. 1996:39:285-294

3 Data on file, PRB \#8154-1, Biogen, Inc. November 20, 1997.

4 Data on file, Biogen, Inc.

5 Herndon RM, et al. Ongoing efficacy and safety analysis of interferon beta-1a (AVONEX ${ }^{\text {}}$ ) in patients with Multiple Sclerosis. 122 nd Annual Meeting ANA, San Diego, CA, 1997

\section{(1-888-456-2263

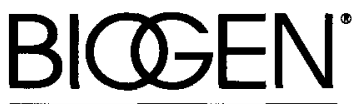

\section{CANADA}

www.biogencanada.com

3 Robert Speck Parkway, Suite 300, Mississauga, Ontario L4Z 2G5 (C) 1999 Biogen Canada, Inc. All rights reserved. achieve an indridualized maintenance dose

The smallest available strength of LAMICTAL Chewable/Dispersible Tablets is $5 \mathrm{mg}$, and only whole tablets should be administered (scoreline on the $5 \mathrm{mg}$ tablet is not intended for tablet spliting). Therefore, recommended doses have been determined based on the individual, or combination of, tablet strengths which most closely approximate, but do NOT exceed, the target dose calculated on the basis of patient weight. LAMICTAL should not be administered if the calculated daily dose is less than $2.5 \mathrm{mg}$ (e.g., patients weighing less than $17 \mathrm{~kg}[37 \mathrm{lbs}]$ and on concomitant VPA, $O$ patients weighing less than $9 \mathrm{~kg}$ [20 lbs] and on concomitant EIAEDs without VPA). If the initial calculated daly dose of LAMICTAL is $2.5105 \mathrm{mg}$, then $5 \mathrm{mg}$ of LAMICTAL should be taken on altemative days for the first 2 weeks.

For patients taking AEDs whose pharmacokinetic interactions with LAMICTAL are currently unknown, follow the titration schedule for concomitant VPA.

Elderly patients

There is little experience with the use of LAMICTAL in elderly patients. Caution should thus be exercised in dose selection for an elderly patient, recognizing the more frequent hepatic, renal and cardiac dystunctions.

Patients with Impaired renal function

The elimination half-life of lamotrigine is prolonged in patients with impaired renal function (see ACTION AND CLINICAL PHARMACOLOGY). Caution should be exercised in dose selection for patients with impaired renal function.

Patlents whth impaired hepatic function

There is no experience with the use of LAMICTAL in patients with impaired llver function. Because lamotriging is metabolized by the liver, caution should be exercised in dose selection for patients with this condition.

\section{PHARMACEUTICAL INFORMATION}

\section{Drug substance}

Brand name: LAMICTAL

Common name: Lamotrigine

Chemical name: 1,2,4-triazine-3,5-diamine, 6-(2,3-dichioropheny)-[USAN]

Chemical name: 6-(2,3-dichlorophenyl)-1,2,4-triazine-3,5-diamine [Chem. Abstr.]

Structural formula: [USAN]

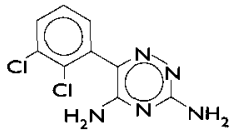

Molecular formula: $\mathrm{C}_{9} \mathrm{H}_{7} \mathrm{Cl}_{2} \mathrm{~N}_{5}$

Molecular weight: 256.0

Description: Lamotrigine is a white to pale cream powder. The $\mathrm{pK}$ at $25^{\circ} \mathrm{C}$ is 5.7 . It is practically insoluble in water $(0.017 \% \mathrm{~W} / \mathrm{N})$; slightly soluble in ethanol $(0.41 \% \mathrm{w} / \mathrm{V})$, chloroform $(0.11 \% \mathrm{w} / \mathrm{V})$ and 0 ctanol $(0.28 \% \mathrm{~W} / \mathrm{V})$

Compostion

LAMICTAL Tablets contain lamotrigine and the following non-medicinal ingredients: cellulose, lactose, magnesium stearate, povidone, sodium starch glycollate, and colouring agents:

- $25 \mathrm{mg}$ (white tablets) - None

- $100 \mathrm{mg}$ (peach tablets) - Sunset Yellow, FCF Lake

- $150 \mathrm{mg}$ (cream tablets) - Feric oxide, yellow

LAMICTAL Chewable/Dispersible Tablets $(5 \mathrm{mg})$ contain lamotrigine and the following non-medicinal ingredients: aluminum magnesium silicate, blackcumant flavour, calcium carbonate, hydroxypropylcellulose, magnesium stearate, povidone, saccharin sodium and sodium starch glycollate.

Administration of LAMICTAL Chewable/Dispersible Tablets

LAMICTAL Chewable/Dispersible Tablets may be swallowed whole, chewed, or dispersed in water or diluted fruit juice. The scoreline on the $5 \mathrm{mg}$ tablet is not intended for tablet spliting. If the tablets are chewed, consume a small amount of water or diluted fruit juice to aid in swallowing. To disperse the tablets, add the tablets to a small amount of liquid (1 teaspoon, or enough to cover the medication). Approximately 1 minute later, when the tablets are completely lispersed, swirl the solution and consume the entire quantity immediately. No attempt should be made to administer dispersed, swirl the solution and consume
partial quantities of the dispersed tablets.

partial quantities of the dispersed tablets.

Stability and storage recommendation

LAMICTAL Tablets should be stored at controlled room temperature $\left(15^{\circ} \mathrm{C}\right.$ to $\left.30^{\circ} \mathrm{C}\right)$ in a dry place and protected from light.

AVAILABIITY OF DOSAGE FORMS

LAMICTAL Tablets (scored, shield-shaped, engraved "LAMICTAL") are available in three different strengths in the following pack formats:

- $25 \mathrm{mg}$ tablets (white) in bottles of 100 ;

- $100 \mathrm{mg}$ tablets (peach) in bottles of 100

- $150 \mathrm{mg}$ tablets (cream) in bottles of 60

LAMICTAL Chewable/Dispersible Tablets (white, scored and biconvex, engraved "LAMICTAL") are available in the following pack format:

- $5 \mathrm{mg}$ (initiation dose only) in blisters of 28 .

Product Monograph available to healthcare professionals upon request.

References:

1. Motte J, Trevathan E, Arvidsson JFV, et al. Lamotrigine for generalized seizures associated with the Lennox-Gastaut syndrome. N Engl J Med 1997;337:1807-1812. 2. Product Monograph of PrLamicta| (lamotrigine), Glaxo Wellcome Inc. May 1999. 3. Mullens L, Gallagher J, and Manasco P. Improved neurological function accompanies effective control of the Lennox-Gastaut syndrome with Lamictab: results of a multinational, placebo-controlled trial. Epilepsia 1996;37(Suppl. 5):163.
GlaxoWellcome Glaxo Wellcome Inc.

Mississauga, Ontario, Canada L5N 6 L4 


\section{REQUIP}

ropinirole (as ropinirole hydrochloride)

Tablets: $0.25 \mathrm{mg}, 1.0 \mathrm{mg}, 2.0 \mathrm{mg}, 5.0 \mathrm{mg}$ THERAPEUTIC CLASSIFICATION

AntiParkinsonian Agent / Dopamine Agonist

INDICATIONS AND CLINICAL USE

REQUIP (ropinirole hydrochloride) is indicated in the treatment of the signs and symptoms of idiopathic Parkinson's disease. REQUIP can be used both as early therapy, without concomitant levodopa and as an adjunct to levodopa.

REQUIP (ropinirole hydrochloride) is contraindicated in patients with known hypersensitivity to ropinirole hydrochloride or the excipients of the drug product.

WARNINGS

Orthostatic Symptoms - Dopamine agonists appear to impair the systemic regulation of blood pressure with resulting orthostatic symptoms of dizziness or lightheadedness, with or without documented hypotension. These symptoms appear to occur especially during dose escalation. Therefore, patients treated with dopamine agonists should be carefully monitored for signs and symptoms of orthostatic hypotension, especially during dose escalation and should be informed of this risk. Hallucinations - In controlled trials. REOUIP (ropinirole hydrochloride) caused hallucination in $5.1 \%$ of patients during early therapy (1.4\% in the placebo group) and in (a) pection and severity that it led to discontinuation in $1.3 \%$ and $1.9 \%$ of patients during early and adjunct therapy, respectively. The incidence of hallucination was dose-dependent both in early and adjunct therapy studies.

\section{PRECAUTIONS}

Cardiovascular - Since REQUIP (ropinirole hydrochloride) has not been studied in patients with a history or evidence of significant cardiovascular disease including myocardial infarction, unstable angina, cardiac decompensation, cardiac arrtythmias, vaso-occlusive disease (including cerebral) or cardiomyopathy it should be used with caution in such patients. There is limited experience with REOUIP in patients treated with antihypertensive and antiarrhythmic agents. Consequently, in such patients, the dose of REQUIP should be titrated with caution. Neuroleptic Malignant Syndrome - A symptom complex resembling the neuroleptic malignant syndrome (characterized by elevated temperature, muscular rigidity, altered consciousness, and autonomic instability), with no other obvious etiology, has been reported in association with rapid dose at of changes in anti-Parkinsonian therapy. A a diabetic male patient with Parkinsons disease, who developed fever, muscle stiffness, and drowsiness 8 days after beginning REQUIP treatment. The patient also experienced acute bronchitis, which did not respond to antibiotic treatment. REQUIP was discontinued three days before the patient died. The reporting physician considered these events to be possibly related to REQUIP treatment. A single spontaneous report of severe muscle pain has been reported in a 66 year old male patient around his thigh. The reporting physician considered the event to be probably related to REQUIP treatment. Retinal Pathology in Rats - In a two year carcinogenicity study in albino Sprague-Dawley rats, retina atrophy was observed at incidences of $0 \%, 1.4 \%, 1.4 \%$ and $10 \%$ of ma rats and $0 \%, 4.4 \%, 2.9 \%$ and $12.9 \%$ of female rats dosed at $0,1.5,15$ and $50 \mathrm{mg} / \mathrm{kg} /$ day respectively. The incidence was significantly higher in both male and female animals dosed at $50 \mathrm{mg} / \mathrm{kg} /$ day. The $50 \mathrm{mg} / \mathrm{kg} / \mathrm{daj}$ dose represents a 2.8 fold greater exposure (AUC) and a 13.1 fold greater exposure $\left(C_{m}\right)$ to ropinirole in rats than the exposure would be in humans at the maximum recommended dose of $24 \mathrm{mg} / \mathrm{day}$. The

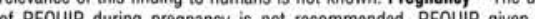
of REQUP during pregnancy is not recommended. REQUIP given 10 pregnant rats during organogenesis (gestation days 8 through 15) resulted in decreased fetal body weight at $60 \mathrm{mg} / \mathrm{kg} /$ day (approximately -4 times the AUC at the maximal human dose of $8 \mathrm{mg}$ ti.d), increased fetal death at $90 \mathrm{mg} / \mathrm{kg} / \mathrm{day}$ (approximately 5 times the AUC at the maximal human dose of $8 \mathrm{mg}$ ti.d) and digital malformations at $150 \mathrm{mg} / \mathrm{kg} / \mathrm{day}$ (approximately 8-9 times the AUC at the maximal human dose of $8 \mathrm{mg}$ ti.d). These effects occurred at maternally toxic doses. There was no indication of an effect on development of the conceptus a a maternally toxic dose of $20 \mathrm{mg} / \mathrm{kg} /$ day in the rabbit. In a perinata. postnatal study in rats, $10 \mathrm{mg} / \mathrm{kg} / \mathrm{day}$ of REQUIP (approximately $0.5-0.6$ times the AUC at the maximal human dose of $8 \mathrm{mg}$ ti.d) impaired growt and development of nursing offspring and altered neurologic development of female offspring. Nursing Mothers - Since REQUIP suppresses lactation, it should not be administered to mothers who wish to breast-feed infants. Studies in rats have shown that REQUIP and/or is metabolites cross the placenta and are excreted in breast milk. Consequently, the human fetus and/or neonate may be exposed to dopamine agonist activity. Use in Women receiving Estrogen Replacement Therapy - In female patients on long-term treatment with Replacement Therapy - In female patients on long-term treatment with conjugated estrogens, oral clearance was reduced and elimination halflife prolonged compared to patients not receiving estrogens (see therapy, REQUIP may be titrated in the recommended manner according to clinical response. However, if estrogen replacement therapy is stopped or introduced during treatment with REQUIP, adjustment of the REQUIP The net been established. Renal and Hepatic pediatric population Impairment - No dosage adjustment is needed in patients with mild to moderate renal impairment (creatinine clearance of 30 to 50 muminn). Because the use of REQUIP in patients with severe renal impairment or hepatic impairment has not been studied, administration of REQUIP Drugs: Neuroleptics and other centrally active dopamine antagonists may diminish the effectiveness of REQUIP. Therefore, concomitant use of these products is not recommended. Based on population pharmacokinetic assessment, no interaction was seen between REQUIP and tricyclic antidepressants or benzodiazepines. Anti-Parkinson Drugs:
Based on population pharmacokinetic assessment, there were no Parkinson's between REQUIP and drugs commonly used to treat Levodopa: The potential pharmacokinetic interaction of levodopa/carbidopa ( $100 \mathrm{mg} / 10 \mathrm{mg}$ bid.) and REQUIP ( $2 \mathrm{mg}$ t.i.d.) was assessed in levodopa naive (de novo) male and female patients with

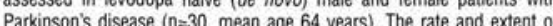
Parkinson's disease ( $n=30$, mean age 64 years). The rate and extent of
availability of REQUIP at steady state were essentially the same with or availability of REQUIP at steady state were essentially the same with or as well as its elimination half-life, were essentially the same in the presence and absence of REQUIP. Inhibitors of CYP1A2: Ciprofloxacin: The effect of ciprofloxacin ( $500 \mathrm{mg}$ b.i.d) on the pharmacokinetics of REQUIP (2 mg ti.d.) was studied in male and female patients with Parkinson's disease ( $n=12$, mean age 55 years). The extent of systemic availability of REQUIP was significantly increased when coadministered with ciprofloxacin (AUC increased by 1.84 fold). Thus, in patients already receiving CYP1A2 inhibitors such as ciprofloxacin, REQUIP therapy may receiving CYP1A2 inhibitors such as ciprofloxacin, REQUIP therapy may
be instituted in the recommended manner and the dose titrated according be instituted in the recommended manner and the dose titrated according to clinical response. However, if therapy with a drug known to be an inhibitor of CYP1A2 is stopped or introduced during treatment with CYP1A2: Theophylline: The effect of oral theophylline ( $300 \mathrm{mg}$ b.i.d.) on the pharmacokinetics of REQUIP (2 mg ti.d.) was studied in male and female patients with Parkinson's disease ( $n=12$, mean age 59 years). There was no marked change in the rate or extent of availability of REQUIP when coadministered with theophylline. Similarly, coadministration of REQUIP with intravenous theophylline $(5 \mathrm{mg} / \mathrm{kg})$ did not result in any marked change in the pharmacokinetics of theophylline It is therefore unlikely that substrates of CYP1A2 would significantly alter the pharmacokinetics of REQUIP, and vice-versa. Digoxin: The effect of REQUIP ( $2 \mathrm{mg}$ ti.d.) on the pharmacokinetics of digoxin $(0.125-0.25 \mathrm{mg}$ o.d.) was studied in male and female patients with Parkinson's disease $(n=10$, mean age 72 years). Coadministration at steady state with REQUIP resulted in a 10\% decrease in digoxin AUC although mean trough digoxin plasma concentrations were unaltered. However, the effect of highe recommended doses of REQUIP on the pharmacokinetics of digoxin is not known. Alcohol: No information is available on the potential for interaction between REQUIP and alcohol. As with other centrally active medications, patients should be cautioned against taking REQUIP with alcohol. Psycho-Motor Performance - As orthostatic symptoms of dizziness or lightheadedness as well as somnolence may occur during REQUIP therapy patients should be cautioned not to drive a motor vehicle or operate potentially hazardous machinery until they are reasonably certain that REQUIP therapy does not affect their ability to engage in such activities

\section{ADVERSE REACTIONS}

Adverse Reactions Associated with Discontinuation of Treatment - 0 1599 patients who received REQUIP (ropinirole hydrochloride) during the premarketing clinical trials, $17.1 \%$ in early-therapy studies and $17.3 \%$ in adjunct-therapy studies discontinued treatment due to adverse reactions. The events resulting in discontinuation of REQUIP in $1 \%$ or more of patients were as follows: Early therapy: nausea $(6.4 \%)$, dizziness $(3.8 \%)$, aggravated Parkinson's disease $(1.3 \%)$, hallucination $(1.3 \%)$, headache $(1.3 \%)$, somnolence $(1.3 \%)$ and vomiting $(1.3 \%)$. Adjunct therapy. dizziness $(2.9 \%)$, dyskinesia $(2.4 \%)$, confusion $(2.4 \%)$, vomiting $(2.4 \%)$ hallucination $(1.9 \%)$, nausea $(1.9 \%)$, anxiety $(1.9 \%)$, and increase sweating $(1.4 \%)$. Patients over 75 years of age $(n=130)$ showed slightly higher incidences of withdrawal due to hallucination, confusion and diziness than patients less than 75 years of age. Most Frequent Adverse Events - Adverse events occurring with an incidence of greater than, or equal to, $10 \%$ were as follows: Early therapy: nausea, dizziness somnolence, headache, peripheral edema vomiting, syncope, fatigue and viral infection. Adjunct therapy: dyskinesia, nausea, dizziness, somnolence and headache. Dopamine agonists, with an ergoline chemical structure have been associated with adverse experiences such as retroperitoneal fibrosis, erythromelalgia and pulmonary reactions. REQUIP has a novel, non-ergoline chemical structure and no reports of such events have been observed in clinical trials. Incidence of Adverse Events in Placebo Controlled Trials - The incidence of postura hypotension, an event commonly associated with initiation of dopamine agonist therapy, was not notably different from placebo in clinical trials. However decreases in systolic blood pressure to $<90 \mathrm{mmHg}$ have been observed in $13 \%$ ( 665 years), 16\% (65-75 years) and $7.6 \%$ ( $>75$ years) of patients treated with REQUIP. Table 1 lists adverse events that occurre at an incidence of $2 \%$ or more among REQUIP-treated patients who participated in placebo-controlled trials for up to one year. Patients were dosed in a range of $0.75 \mathrm{mg}$ to $24 \mathrm{mg} /$ day. Reported adverse events were classified using a standard World Health Organization (WHO)-based dictionary terminology. The prescriber should be aware that these figures can not be used to predict the incidence of adverse events in the course of usual medical practice where patient characteristics and other factors differ from those which prevailed in the clinical trials. Similarly, the cited frequencies can not be compared with figures obtained from other clinical frequencies can not be compared with figures obtained from other clinical
investigations involving different treatments, uses and investigators. The investigations involving different treatments, uses and investigators. The
cited figures, however, do provide the prescribing physician with some cited figures, however, do provide the prescribing physician with some
basis for estimating the relative contribution of drug and non-drug factors to the adverse events incidence rate in the population studied. The Adverse Reactions section has been condensed. See full Product Monograph for the complete information.

\section{DOSAGE AND ADMINISTRATION}

REQUIP (ropinirole hydrochloride) should be taken three times daily. While administration of REQUIP with meals may improve gastrointestin tolerance, REQUIP may be taken with or without food. The recommended starting dosage is $0.25 \mathrm{mg}$ three times daily. Based on individual patient response, dosage should then be titrated by weekly increments of 0.25 $\mathrm{mg}$ per dose as described in the table below. After week 4 , daily dosage may be increased by 0.5 to $1.0 \mathrm{mg}$ per dose on a weekly basis up to 24 $\mathrm{mg}$ per day. Doses greater than $24 \mathrm{mg} /$ day have not been tested in clinical trials. Smaller dose increments are recommended for patients who may be at risk for orthostatic symptoms. In clinical trials, initial benefits were observed with $3 \mathrm{mg} /$ day and higher doses.

\begin{tabular}{|l|c|c|c|c|}
\hline & \multicolumn{4}{|c|}{ Week } \\
\hline & 1 & 2 & 3 & 4 \\
\hline Unit Dose (mg) & 0.25 & 0.5 & 0.75 & 1.0 \\
\hline Total Daily Dose (mg) & 0.75 & 1.5 & 2.25 & 3.0 \\
\hline
\end{tabular}

TABLE and adjunct therapy studies

\begin{tabular}{|c|c|c|c|c|}
\hline & \multicolumn{2}{|c|}{ Eally Merapr } & \multicolumn{2}{|c|}{ Adjunet Therapy } \\
\hline & $\begin{array}{l}\text { REOUIP } \\
N=157 \\
\text { so octurence } \\
\end{array}$ & 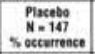 & \begin{tabular}{|c|} 
REQUiP \\
$N=208$ \\
Soctertence \\
\end{tabular} & $\begin{array}{c}\text { Placebo } \\
N=120 \\
x \text { octurtense }\end{array}$ \\
\hline $\begin{array}{l}\text { Autonomic Nervous System } \\
\text { Sweating Increased } \\
\text { Mouth Dry } \\
\text { Fushing }\end{array}$ & $\begin{array}{l}64 \\
51 \\
32 \\
\end{array}$ & $\begin{array}{l}4.1 \\
34 \\
0.7\end{array}$ & $\begin{array}{l}7.2 \\
5.3 \\
1.4\end{array}$ & $\begin{array}{l}17 \\
08 \\
0.8\end{array}$ \\
\hline 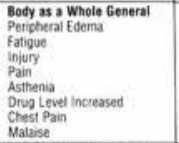 & $\begin{array}{l}134 \\
108 \\
76 \\
64 \\
45 \\
3.8 \\
32\end{array}$ & $\begin{array}{l}41 \\
41 \\
41 \\
11 \\
27 \\
20 \\
07\end{array}$ & $\begin{array}{l}3.9 \\
706 \\
53 \\
5.7 \\
67 \\
1.4\end{array}$ & $\begin{array}{l}25 \\
92 \\
33 \\
3.3 \\
3.8 \\
0.8\end{array}$ \\
\hline $\begin{array}{l}\text { Cardiovastular General } \\
\text { Syncope } \\
\text { Hypotension Postural } \\
\text { Hypertension } \\
\text { Hypotension }\end{array}$ & $\begin{array}{l}11.5 \\
64 \\
45 \\
19 \\
\end{array}$ & $\begin{array}{l}1.4 \\
4.8 \\
3.4 \\
0.0 \\
\end{array}$ & $\begin{array}{l}29 \\
34 \\
24\end{array}$ & $\begin{array}{l}17 \\
3.7 \\
3.8 \\
0.8\end{array}$ \\
\hline 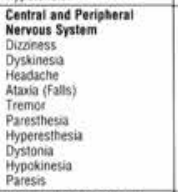 & $\begin{array}{l}40.1 \\
17.2 \\
7 \\
3.8 \\
3\end{array}$ & $\begin{array}{c}21.8 \\
170 \\
- \\
20 \\
20 \\
=\end{array}$ & $\begin{array}{l}260 \\
337 \\
168 \\
96 \\
63 \\
5.3 \\
43 \\
53 \\
2.3 \\
29\end{array}$ & $\begin{array}{l}15.8 \\
125 \\
11.7 \\
6.7 \\
25 \\
25 \\
4.2 \\
42 \\
40\end{array}$ \\
\hline 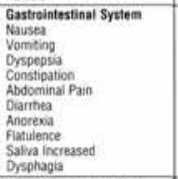 & $\begin{array}{l}59.9 \\
121 \\
96 \\
83 \\
64 \\
78 \\
38 \\
25 \\
13 \\
13\end{array}$ & $\begin{array}{l}21.8 \\
68 \\
48 \\
75 \\
27 \\
1.4 \\
14 \\
0.0\end{array}$ & $\begin{array}{l}298 \\
72 \\
58 \\
8.7 \\
48 \\
7 . \\
19 \\
24 \\
24\end{array}$ & $\begin{array}{l}183 \\
42 \\
53 \\
35 \\
75 \\
25 \\
0.8 \\
0.8 \\
0.8\end{array}$ \\
\hline $\begin{array}{l}\text { Heart Rate and Rinythm } \\
\text { Palpitation }\end{array}$ & 3.2 & 20 & 29 & 25 \\
\hline $\begin{array}{l}\text { Metabolice and Nutritional } \\
\text { Alikaine Phospluate Increased } \\
\text { Weight Decrease }\end{array}$ & 2.5 & 1.4 & $\begin{array}{l}10 \\
24 \\
\end{array}$ & $\begin{array}{l}0.0 \\
0.8\end{array}$ \\
\hline $\begin{array}{l}\text { Musculosiceletal System } \\
\text { Anthralous } \\
\text { Anthentis }\end{array}$ & 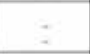 & 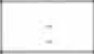 & $\begin{array}{l}67 \\
29\end{array}$ & $\begin{array}{l}50 \\
0.8\end{array}$ \\
\hline $\begin{array}{l}\text { Psychiatric } \\
\text { Somnolence } \\
\text { Anciefy } \\
\text { Coctusion } \\
\text { Hallucination } \\
\text { Nervousness } \\
\text { Yawning } \\
\text { Amnesia } \\
\text { Dreasing Abnormal }\end{array}$ & $\begin{array}{l}40.1 \\
51 \\
51 \\
32 \\
32\end{array}$ & $\begin{array}{l}6.1 \\
1.4 \\
1.4 \\
0.0 \\
1.4\end{array}$ & $\begin{array}{l}202 \\
63 \\
87 \\
10.1 \\
48 \\
4.8 \\
29 \\
\end{array}$ & $\begin{array}{l}8.3 \\
3.3 \\
1.7 \\
4.2 \\
25 \\
-0.8 \\
17 \\
17\end{array}$ \\
\hline $\begin{array}{l}\text { Red Blood Cell } \\
\text { Anemas }\end{array}$ & - & - & 24 & 0.0 \\
\hline $\begin{array}{l}\text { Reproductive Male } \\
\text { impotence }\end{array}$ & 25 & 1.4 & - & - \\
\hline 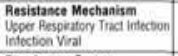 & 108 & 34 & $\begin{array}{l}87 \\
7.2\end{array}$ & $\begin{array}{l}83 \\
6.7\end{array}$ \\
\hline 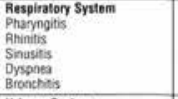 & $\begin{array}{l}64 \\
38 \\
38 \\
32 \\
25 \\
25\end{array}$ & $\begin{array}{l}41 \\
27 \\
27 \\
00 \\
1.4 \\
\end{array}$ & 29 & 5 \\
\hline $\begin{array}{l}\text { Urinary Snttem } \\
\text { Urinary Tract Iffection }\end{array}$ & 5.1 & 41 & 63 & 25 \\
\hline $\begin{array}{l}\text { Vassular Extracerdiac } \\
\text { Petipheral Ischemaic }\end{array}$ & 25 & 00 & - & - \\
\hline 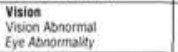 & $\begin{array}{l}5.7 \\
32 \\
\end{array}$ & $\begin{array}{l}34 \\
14 \\
\end{array}$ & $z$ & $=$ \\
\hline
\end{tabular}

When REQUIP is administered as adjunct therapy to levodopa, the dose of levodopa may be decreased gradually as tolerated once a therapeutic effect with REQUIP has been observed. REQUIP should be discontinued gradually over a 7-day period. The frequency of administration should be reduced from three times daily to twice daily for 4 days. For the remainin 3 days, the frequency should be reduced to once daily prior to complete withdrawal of REQUIP. Renal and Hepatic Impairment: In patients with mild to moderate renal impairment, REQUIP may be titrated in the recommended manner according to clinical response. Patients with severe renal impairment or on hemodialysis have not been studied and administration of REQUIP to such patients is not recommended. Patients with hepatic impairment have not been studied and administration of REQUIP to such patients is not recommended. Estrogen Replacement Therapy: In patients already receiving estrogen replacement therapy, REQUIP may be titrated in the recommended manner according to clinica response. However, if estrogen replacement therapy is stopped or starte during treatment with REQUIP, adjustment of the REQUIP dosage may be required.

REQUIP is supplied as a pentagonal film-coated Tiltab" tablet with beveled edges containing ropinirole (as ropinirole hydrochloride) as follows: $0.25 \mathrm{mg}$ - white imprinted with SB and $4890 ; 1.0 \mathrm{mg}$ - green imprinted with $\mathrm{SB}$ and $4892 ; 2.0 \mathrm{mg}$ - pale pink imprinted with $\mathrm{SB}$ and $4893: 50$ $\mathrm{mg}$ - blue tablets imprinted with SB and 4894. REQUIP is available in bottles in the pack size of 100 tablets. It is also available in $0.25 \mathrm{mg}$ as a single unit blister pack of 21 tablets.

Full Product Monograph available to practitioners upon request.

\section{REFERENCES}

1. Rascol 0 , et al. Ropinirole in the Treatment of Early Parkinson's Study. Mov Disord 1998:13:39-45.

4. Schrag AE, et al. The Safety of Ropinirole, a selective non-ergoline dopamine agonist in patients with Parkinson's disease. Clin Neuropharmacol 1998-21:169-175.

\section{S3 SmithKlıne Beecham}

- SmithKline Beecham Pharma,

a div. of SmithKline Beecham Inc., 1999
Oakville, Ontario L6H 5V2

PAAB

CCPP 


\section{$3^{\text {RD }}$ ANNUAL NEUROLOGY \\ RESIDENTS HEADACHE COURSE}

\section{HEADACHES IN CHILDREN, WOMEN AND THE ELDERLY PLUS NEUROBIOLOGY 2000}

\section{Saturday October 2I, 2000}

Introduction

MNI Greetings

Greeting from The Director

Headache at the MNI

Neurobiology of Headache $\mathbf{2 0 0 0}$

\section{Serotonin}

Pathophysiology of Headache

Post Junctional Receptors

Update on Spreading Depression

Pediatric Migraine

\section{Overview}

Case Presentation

Migraine in Women

Overview

Case Presentation

First Cased Based Session
A. Purdy
M. Aube
R. Murphy
B. Fiendel
Headache in the Elderly
Overview
Special Considerations
Trigeminal Neuralgia
Second Case Based Session

E. Hamel

P. Goadsby

D. Dodick

C. Jarvis

J. Dooley

D. MacGregor

W. Becker

R. Giammarco

All Faculty

\section{Case Based Sessions}

Two Break out sessions

Three Cases for two sessions

All clinical faculty noted and

\section{Sunday October 22, 2000}

J. Edmeads

P. Goadsby

D. Dodick

All Faculty

Special Considerations

Psychiatric Issues in Headache F. Sheftell

Atypical Facial Pain

M. Gawel

Faculty for Case Based Sessions

Drs. C. Roberge, G. Robinson and B. Anderson

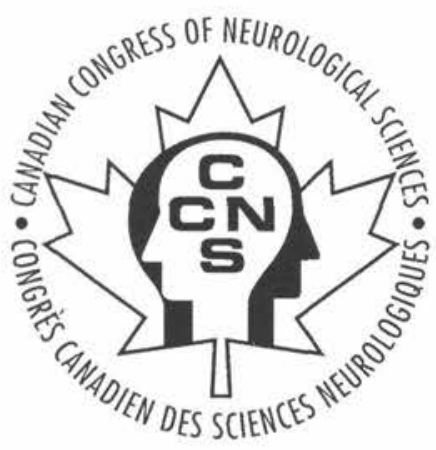

For more information please contact the Canadian Congress of Neurological Sciences Tel: (403) 229-9544; Fax: (403) 229-I66I; E-mail: brains@ccns.org 


\section{Canadian League Against Epilepsy- Glaxo Wellcome Epilepsy Fellowship}

This fellowship has been created to support research and clinical training in the field of epilepsy in Canada. The fellowship is valued at $\$ 45,000$ and will be awarded for a one year period. The award will be tenable as of July 1 st, 2001.

Candidates must have an $\mathrm{MD}$ or $\mathrm{PhD}$ degree. Preference will be given to those who have completed a specialty program approved by the Royal College of Physicians and Surgeons of Canada, but others are welcome to apply and will be considered. Applications must contain a research proposal relevant to epilepsy. The proposed research must be done in Canada.

Applications must be received by December 1, 2000.

Further details and instructions for applicants may be obtained from:

\section{CLAE-GW Fellowship}

Linda Ashford

Canadian Congress of Neurological Sciences

P.O. Box 4220, Stn. C.

Calgary AB Canada

T2T $5 \mathrm{~N} 1$

\section{Ligue Canadienne contre l'épilepsie Bourse de recherche dinique en épilepsie}

Cette bourse a été cré afin de soutenir la recherche clinique dans le domaine de épilepsie au Canada. D'une valeur de $45000 \$$, la bourse sera attribuée pour une période d'un an et prendra effet le ler juillet 2001.

Les candidats doivent être titulaire d'un diplôme de médecine ou d'un doctorat de 3ième cycle. Une préférence sera donnée à ceux qui sont inscrits à un programme de spécialité approuvé par le Collège royal des médecins et chirurgiens du Canada. Tous les autres canadidats seront les bienvenus et leurs demandes seront considérés. Les demandes doivent contenir un projet de recherche dans le domaine de l'épilepsie. La recherche proposé doit être entreprise au Canada.

La date limite de réception des demandes de bourse : le ler decembre 2000.

Pour obtenir plus de précisions, écrire à l'adresse suivante:

CLAE-GW Fellowship

Linda Ashford

Canadian Congress of Neurological Sciences

P.O. Box 4220, Stn. C.

Calgary AB Canada

T2T $5 \mathrm{~N} 1$

\section{Canadian Headache Society- Glaxo Wellcome Headache Fellowship}

This fellowship has been created to support research and clinical training in the field of headache in Canada. The fellowship is valued at $\$ 45,000$ and will be awarded for a one year period. The award will be tenable as of July $1 \mathrm{st}$, 2001.

Candidates must have an $\mathrm{MD}$ or $\mathrm{PhD}$ degree. Preference will be given to those who have completed a specialty program approved by the Royal College of Physicians and Surgeons of Canada, but others are welcome to apply and will be considered. Applications must contain a research proposal relevant to headache. The proposed research must be done in Canada.

Applications must be received by December 1, 2000 .

Further details and instructions for applicants may be obtained from:

Dr. WJ Becker

President, Canadian Headache Society

c/o Neurology

12th Floor, Foothills Hospital

1403 29th St. NW

Calgary AB Canada T2N 2T9

\section{Société canadienne des céphalées} Bourse de rechereche dinique en céphalée

Cette bourse a été cré afin de soutenir la recherche clinique dans le domaine de la céphalée au Canada. D'une valeur de $45000 \$$, la bourse sera attribuée pour une période d'un an et prendra effet le ler juillet 2001.

Les candidats doivent être titulaire d'un diplôme de médecine ou d'un doctorat de 3ième cycle. Une préférence sera donnée à ceux qui sont inscrits à un programme de spécialité approuvé par le Collège royal des médecins et chirurgiens du Canada. Tous les autres canadidats seront les bienvenus et leurs demandes seront considérés. Les demandes doivent contenir un projet de recherche dans le domaine de la céphalée. La recherche proposé doit être entreprise au Canada.

La date limite de réception des demandes de bourse : le ler decembre 2000.

Pour obtenir plus de précisions, écrire à l'adresse suivante:

Dr. WJ Becker

President, Canadian Headache Society

c/o Neurology

12th Floor, Foothills Hospital

140329 th St. NW

Calgary AB Canada T2N 2T9 


\section{ADVERTISEMENT FOR Pediatric Neurologist}

The Department of Pediatrics, College of Medicine, University of Saskatchewan, Saskatoon, Saskatchewan is seeking a pediatric neurologist in the Division of Pediatric Neurology. The Department of Pediatrics is located at Royal University Hospital and provides pediatric tertiary care for the province of Saskatchewan. Candidates should have interest and expertise in teaching undergraduate and postgraduate trainees, research, and clinical work. The successful candidate will be a member of a three person group and will share in a one in three call schedule. The Division supports an accredited and funded fellowship training program in child neurology.

Candidates must have completed training in the specialty of pediatric neurology and must hold FRCP(C) qualifications in Pediatrics or Neurology or equivalent.

The University of Saskatchewan is committed to employment equity. Members of designated groups (women, aboriginal people, people with disabilities and visible minorities are encouraged to self-identify on their applications).

Interested candidates should write to: Dr. Noel Lowry, Division of Pediatric Neurology, Department of Pediatrics, Royal University Hospital, Saskatoon, Saskatchewan S7N 0W8.

\section{Hôpital régional de Sudbury Regional Hospital Neurology Positions Sudbury, Ontario}

KING MEDICAL

THE CANADIAN ELECTRODE PLACE

- JARI - CHALGREN

- KENDALL - NUTAB

- KING MEDICAL

- MEDICOTEST

- BLUE SENSOR

- NEUROLINE

- MEDTRONIC - DANTEC

- 3M CANADA

- D.O. WEAVER

Biggest selection in Canada of disposable Electrodes

Tel (905) 833-3545

Fax (905) 833-3543

E-mail soren@kingmedical.com

King Medical Ltd.

145 Kingsworth Road

King City - Ontario L7B 1K1

The Hôpital régional de Sudbury Regional Hospital (HRSRH) is currently recruiting 2 full-time neurologists to redevelop the neurology component of our Neuroscience Program. They will work with our four-person Neurosurgical Service to provide neurology/neurosurgical care to the patient population served by the Sudbury Regional Hospital.

The HRSRH is one of the largest tertiary referral centres in the province and serves as the regional resource and referral centre for residents throughout Northeastern Ontario. It houses over 600 beds, 18 surgical operating rooms, 2,700 employees and a medical staff of 260 . The HRSRH is the result of restructuring of 3 local acute hospitals into one new entity on a single redeveloped site. When complete in 2002, the HRSRH will be approximately 873,000 square feet spread over a 34 -acre site. It will be built to the latest standard, equipped with state-of-the-art technology and operated with an annual budget of over $\$ 165$ million.

With a population of 164,000 , the Regional Municipality of Sudbury is a dynamic and diversified community nestled in the heart of Northeastern Ontario. Traditionally, a resource-based community, Sudbury has established itself as a major centre for financial and business services, tourism, medical services as well as research and education. Serving a market of over 600,000 people, the Regional Municipality of Sudbury is well known as the service hub for all Northeastern Ontario. Sudbury boasts a vibrant French-speaking community which consists of approximately $30 \%$ of the population. The Region of Sudbury is well recognized by many industries as a prosperous community with a vibrant economic future. The region's school system provides for complete educational streams in both English and French as well as several levels of immersion. Laurentian University, Collège Boreal and Cambrian College offer extensive full and part-time post secondary programs in both English and French. The City has a thriving cultural community, including the Sudbury Symphony, Sudbury Theatre Centre, Théatre du Nouvel Ontario and the Northern Lights Festival Boréal to name just a few. Surrounding conservation areas and nearby provincial parks provide many opportunities for outdoor recreational activity.

An extremely competitive package, which includes income guarantees, has been created for these positions. In addition, the HRSRH is considered to be underserviced in the specialty of Neurology and a tax-free incentive grant may be available.

Candidates must have obtained specialty qualifications by the Royal College of Physicians and Surgeons of Canada and be eligible for licensure in Ontario. Senior residents and fellows who will be eligible for specialist certification in the near future may be considered.

Interested individuals may contact

Dr. Wayne Lambert, Medical Director, Critical Care Program

Hôpital régional de Sudbury Regional Hospital

2nd Floor - Memorial Site, 865 Regent Street, South

Sudbury, Ontario P3E 3V9

Telephone: (705) 671-1000, Ext. 297 Fax: (705) 671-5358 E-mail: wnlambert@hrsrh.on.ca 


\section{Surrey Memorial Hospital NEUROLOGIST}

The Department of Medicine at Surrey Memorial Hospital has an immediate opening for a Neurologist.

The successful candidate will have an FRCP(C) with certification in Neurology and evidence of strong clinical and interpersonal skills. This is an exceptional opportunity to join a thriving clinical practice of 6 Neurologists servicing a major community hospital in Surrey. The successful applicant will be expected to hold additional privileges at a regional neuroscience referral centre and several smaller community hospitals in the health region. Independent practice with shared office setting, appointment scheduling, bookkeeping and billing are already in place for immediate start-up. There is local access to $C T, M R I, E E G, E M G$, Neurosurgery and Neuroradiology. The successful candidate will be expected to share in the dedicated Neurology on-call rota. Candidates must be certified by the Royal College of Physician and Surgeons of Canada.

Surrey Memorial Hospital is a community and regional hospital with 440 acule care beds, serving a catchment area of approximately 500,000 people. The hospital currently provides a full range of noninvasive Neurology services.

The City of Surrey is located approximately $30 \mathrm{~km}$. south of Vancouver and is one of the fastest growing communities in the country. The community offers excellent living, educational, entertainment and recreational facilities in a beautiful West Coast setting.

If you are interested in this exciting practice opportunity, please send your letter of interest and curriculum vitae to:

K. Michael Kangalee

Director, Medical Services

Surrey Memorial Hospital

13750 - 96th Avenue

Surrey, B.C. V3V $1 Z 2$

Tel: (604) 585-5530

Fax: (604) 588-3320

Deadline for receipt of applications is 2000 September 15
DEPARTMENT OF CLINICAL NEUROSCIENCES

\section{NEUROLOGISTS}

The Department of Clinical Neurosciences of the University of Calgary and the Calgary Regional Health Authority invite applications for two positions in clinical neurology. The positions will be based at one of two 500-bed general hospitals and will include shared responsibility for the neurology consultation service. Remuneration will be fee-forservice. A hospital office, out-patient facilities and access to EEG and EMG laboratories will be available. Appointees are expected also to participate at least one day per week in one of the academic programs of the Department such as headache, movement disorders, etc. Expertise in EEG is desirable for one position. Appointees are expected to contribute actively to graduate and undergraduate teaching.

Applicants must hold a FRCPC in neurology. Highly qualified candidates are sought and preference will be given to those who have demonstrated academic ability in teaching and research and who bring needed skills to the Department.

Applications with a copy of the curriculum vitae and names of three references should be sent by September 15, 2000 to:

Dr. Thomas E. Feasby, Head

Department of Clinical Neurosciences

Foothills Hospital

1403-29th Street N.W.

Calgary, Alberta, T2N 2T9

\section{ADVERTISERS INDEX}

AstraZeneca

Zomig - A-26, A-27, A-29

Berlex

Betaseron - A-6, A-7, A-18, A-19,

A-32, A- 33, A- 34

Biogen

Avonex - A-12, A-13, A-50, A-51, A-52

Draxis Health

Zanaflex - A-3, A-40, A-41, A-45

Glaxo Wellcome

Amerge - IBC, A-30, A-31

Lamictal - A-4, A-5, A-14, A-15, A-46, A-47, A-48, A-52

Janssen-Ortho

Topamax - A-8, A-9, A-20, A-21, A-36, A-37

Novartis

Exelon - OBC, A-42, A-43, A-44, A-45

Parke Davis

Neurontin - A-11, A-17, A-23, A-35

Pfizer

Aricept - A-28, A-49

SmithKline

Requip - IFC, A-53

Classified Ads - A-54, A-55, A-56, A-57, A-58 


\section{Have a Nice Triptan}

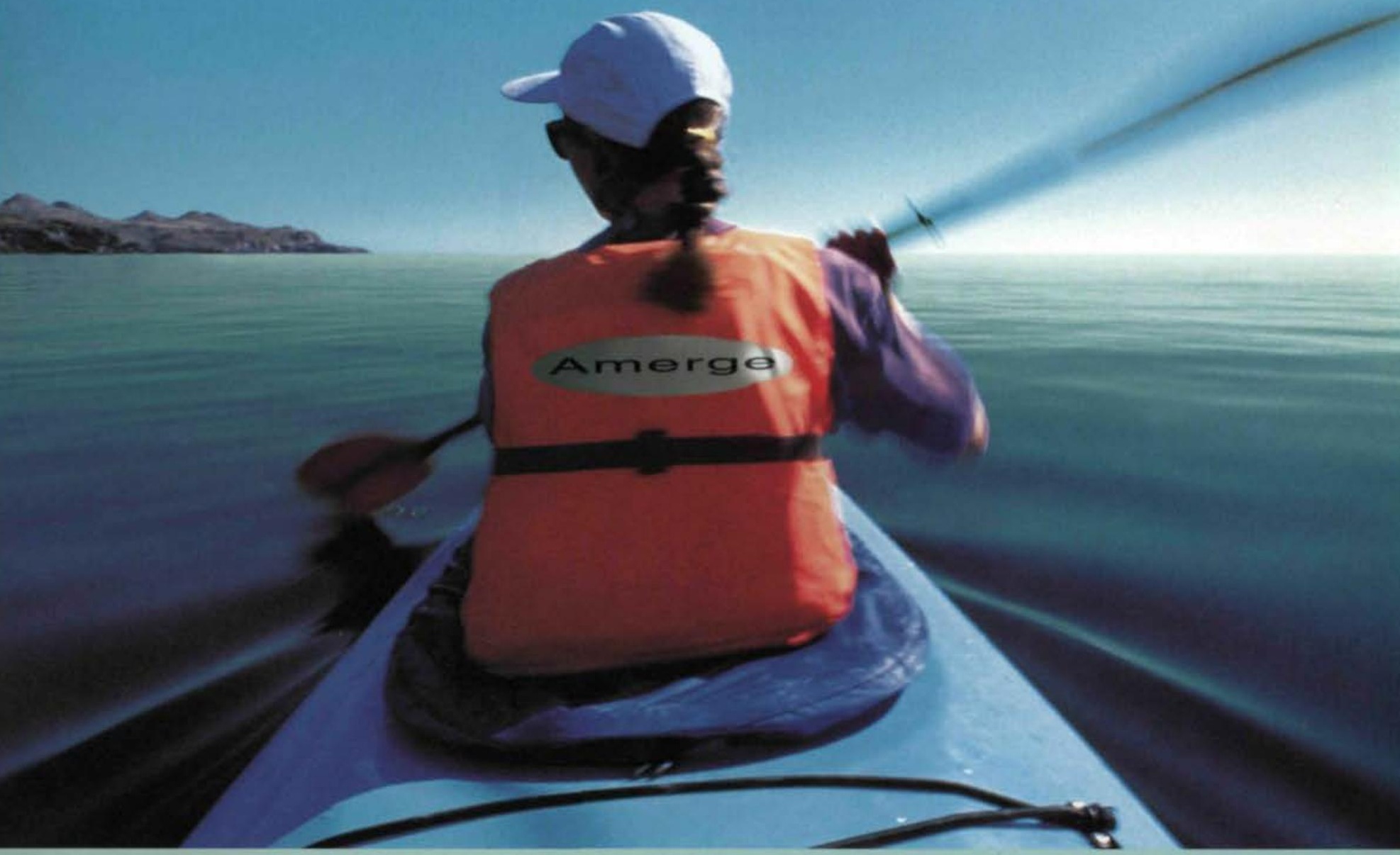

\section{Migraine relief with tolerability similar to placebo}

As shown in controlled clinical trials, AMERGE is a highly tolerable triptan with an incidence of adverse events similar to placebo. ${ }^{1-3 t}$ AMERGE provided significant migraine relief maintained over 24 hours. ${ }^{1,2}$ A recent study demonstrated that $93 \%$ of attacks per patient did not require a second dose for recurrences. ${ }^{45}$

t In controlled clinical trials, the incidence of adverse events was similar to placebo ( $31 \%$ for AMERGE $2.5 \mathrm{mg}$ vs. $32 \%$ for placebo ${ }^{2}$ ) 7 Headache relief-reduction of moderate or severe pain to mild or no pain. AMERGE. $2.5 \mathrm{mg} n=586$ : p<0.001 vs. placebo $60 \mathrm{~min}$ post-dose to $4 \mathrm{hrs} ; \mathrm{p}<0.05 \mathrm{vs}$. placebo at $4,8,12,24 \mathrm{hrs}$.

The median percentage does not represent recurrence rate. Headache recurrence equals a retum of moderate or severe pain in 4 to 24 hours post-dose following initial relief

AMERGE (naratriptan hydrochloride) is a selective 5.HT, receptor agonist indicated for the acute treatment of migraine attacks

with or without aura. AMERGE is not indicated for prophylactic therapy of migraine, or for the management of hemiplegic, basilar \&

with or without aura. AMERGE is not indicated for prophylactic therapy of migraine, or for the management of hemiplegic, basilar $\&$
ophthalmoplegic migraine. Safety and efficacy have not been established for cluster headache which is present in an older, predominantly ophthaimoplegic migraine. Safety and efficacy have not been established for cluster headache which is present in an older, predominantly
male population. AMERGE is contraindicated in patients with history, symptoms, or signs of ischemic cardiac, cerebrovascular, or peripheral male population. AMERGE is contraindicated in patients with history, symptoms, or signs of ischemic cardiac, cerebrovascular, or periph
vascular syndromes, valvular hear disease or cardiac arrhythmias. In addition, patients with other significant underlying cardiovascular vascular syndromes, valvular heart disease or cardiac arrhythmias. In addition, patients with other significant underlying card
diseases should not receive AMERGE AMERGE is also contraindicated in patients with uncontrolled or severe hypertension.

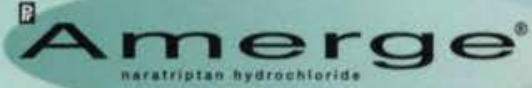

Making tolerability a part of migraine relief.

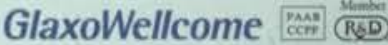




\section{Exelon can make a difference in patients with Alzheimer Disease}

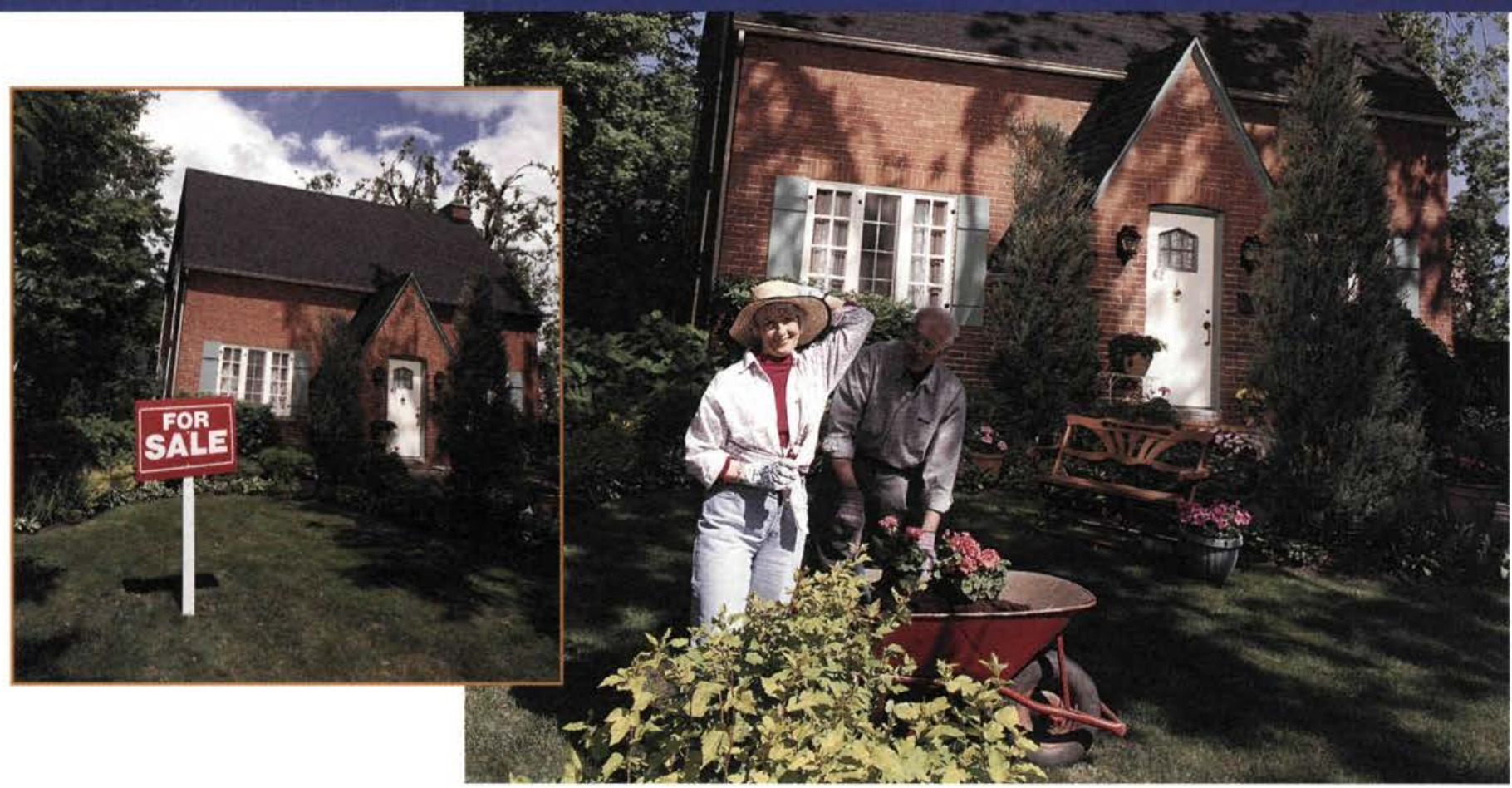

The only dual-acting cholinesterase inhibitor ${ }^{\dagger}$

EXELON can help enhance cholinergic activity in the brain by inhibiting acetylcholinesterase. In addition, EXELON also inhibits butyrylcholinesterase.

\section{Proven efficacy ${ }^{H}$ in 3 key domains - the ABCs of Alzheimer Disease}

Activities of Daily Living were maintained or improved with a mean difference of more than 3 points vs. placebo on the PDS $(p<0.05){ }^{.4}$

Behaviour and other parameters of global functioning assessed on the CIBIC-Plus were significantly improved vs. placebo $(p<0.05)^{2.5}$

Cognitive function was maintained or enhanced by a mean difference of almost 5 points vs. placebo on the ADAS-Cog $(p<0.001)^{3.9}$

\footnotetext{
$\dagger$ Comparative clinical significance has not been established

It Based on EXELON dosages of 6-12 mg/day

$\ddagger$ Double-blind, randomized, placebo-controlled, international multicentre dinical trial; $n=725$. PDS=Progressive Deterioration Scale.

$\S$ pooled results from three prospective, randomized, double-blind, placebo-controlled, international multicentre clinical trials; $n=2126$. CIBIC.Plus=-Clinician Interview-Based Impression of Change Scale.

Il Prospective, randomized, double-blind, placebo-controlled, cinical trial; $n=699$. ADAS-Cog=Alzheimer Disease Assessment Scale, Cognitive Subscale
}

Product Monograph available upon request.

\section{Individualized Dosing}

Dosing can be individualized to help optimize the therapeutic response. The suggested starting dose is $1.5 \mathrm{mg}$ b.i.d. ( $3 \mathrm{mg} /$ day), with the daily dose increased in $3 \mathrm{mg}$ increments every 4 weeks." Usual maintenance therapy is administered as $3-6 \mathrm{mg}$ b.i.d. (6-12 $\mathrm{mg} /$ day) with morning and evening meals.

\section{Now, EXELON can help many of your patients with Alzheimer Disease look forward to staying at home a while longer.}

EXELON (rivastigmine as the hydrogen tartrate salt) is indicated for the symptomatic treatment of mild to moderate dementia of the Alzheimer type

The most common side effects associated with EXELON therapy are generally mild and of short duration, occur mainly in the titration phase, and usually subside with continued treatment. During maintenance therapy, the most common side effects at doses of $6-12 \mathrm{mg} /$ day were nausea (15\%), vomiting (14\%) and dizziness (10\%).

\# Dose increases can be considered after a minimum of two weeks, as tolerated. Dose increases above $6 \mathrm{mg} /$ day should proceed cautiously. The maximum dose should not exceed $6 \mathrm{mg}$ b.i.d. For elderly patients ( $>85$ years old) with low body weight (especially females) or serious comorbid diseases, it is recommended to start treatment with less frequent dosing ( $1.5 \mathrm{mg}$ once a day) and to escalate dosage at a slower rate.

EXELON has not been studied in controlled clinical trials for longer than 6 months. There is no evidence that rivastigmine alters the course of the underlying dementing process.

1. Rösler M, Anand R, Cicin-Sain A, et al. BMJ 1999;318:633-40.

2. Schneider LS, Anand R, Farlow MR. Intl I Ger Psychopharm 1998;Suppl(1):S1-S34.

3. Corey-Bloom J, Anand R, Veach J. Intl I Ger Psychopharm 1998:1:55-65.

4. Exelon Product Monograph, April 13, 2000, Novartis Pharmaceuticals Canada Inc

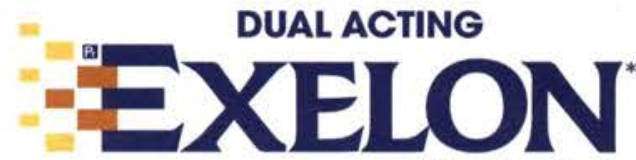

(rivastigmine)

For brief prescribing information see pages $A-42, A-43, A-44, A-45$ 